\title{
Ambientes Atmosféricos Intraurbanos na Cidade de São Paulo e Possíveis Correlações com Doenças dos Aparelhos: Respiratório e Circulatório
}

\section{EDELCI NUNES DA SILVA}

Tese apresentada ao Programa de Pós-Graduação em Saúde Pública da Faculdade de Saúde Pública da Universidade de São Paulo para obtenção do título de DOUTOR em Saúde Pública.

Área de Concentração: Saúde Ambiental

Orientadora: Profa. Titular Helena Ribeiro

São Paulo 


\section{AGRADECIMENTOS}

Todos que realizam um trabalho de pesquisa sabem que esse caminho é árduo e não é feito sozinho. Várias pessoas tornaram esse percurso mais leve e possível de ser realizado. Considero-me uma pessoa de muita sorte por ter encontrado pessoas tão especiais na minha trajetória.

À Profa. Helena Ribeiro, minha orientadora, que, com sua sabedoria e serenidade ensina e permite que você caminhe com suas próprias escolhas.

Aos professores do Departamento de Saúde Ambiental, em especial, a Profa. Adelaide Nardocci com quem pude dividir algumas angústias e cujos comentários contribuíram para acender algumas luzes.

Aos funcionários da faculdade de Saúde Pública pela atenção e apoio, tenho muito a agradecer à Viviane, Renilda, Vânia e aos funcionários do departamento de Saúde Ambiental.

À Profa. Roseli de Deus Lopes, diretora da Estação Ciência e ao Prof. Mikia Muramastu Vice- Diretor da Estação que permitiram que eu pudesse concluir a jornada.

À Profa. Paula Santana - por ter me acolhido em seu Gabinete, no além mar, na realização do estágio sanduiche.

Às geógrafas portuguesas Claudia Costa, Adriana Loureiro do Gabinete de Investigação de Geografia da Saúde da Universidade de Coimbra pela acolhida, companhia, atenção, carinho.

Ao Prof. Luis B. Lecha Estela, pelos muitos e-mails trocados, discussões sobre o biometeorologia.

Ao Engo. Sergio Salum e Prof. Mario Festa do Instituto Astronômico e Geofísico da Universidade de São Paulo pela cessão dos dados e material de apoio utilizado neste trabalho.

Ao colega Dr. Frederico Funari pelo apoio, pela resolução de dúvidas e pelas horas de conversa, as quais tornaram o caminhar mais divertido.

Ao Roberto Tadeu pela cessão dos dados meteorológicos do Aeroporto de Congonhas e atenção dispensada em vários momentos.

Ao técnico Nazário do Centro de Gerenciamento de Emergências de São Paulo pelo interesse e apoio dado na fase inicial da pesquisa.

Aos meus colegas e companheiros da Estação Ciência: Carmen Ruiz, Marco Antonio, Job Carvalho, Cléo Batista, Marcos M., Dirce, Cecília, Manoel que me apoiaram e ficaram na torcida. 
Às alunas Cíntia Menezes, Michele Kanashiro Kuda e Profa. Elisete Aubin e Profa. Gisela e à Silvia T. do Centro de Estatística Aplicada do IME/USP pelo apoio e modelagem dos dados.

Ao Marcus Estanislau pelas valiosas aulas de bioestatística e de regressão logística.

Aos meus amigos da pós-graduação: Maria Aparecida Oliveira, Fábio Lopes com que pude dividir os medos, aflições, alegrias, descobertas, surpresas, dúvidas surgidas nesse percurso.

Aos meus amigos de plantão: José Ricardo, Eustáquio de Sene, Núria Hanglei, Luis Fernando, Kátia Kalil, Eloísa D’lore , Mariano e Cris, Ivan Andresso e Dalva, Wilson e Luiza., Reinaldo Teles, Sueli Castro, Roberto Caner, Alfredo Queiroz, Dulce Maria, Reinaldo Pereira, Chris Meyer em muitos momentos amenizaram o caminhar.

Às mães de plantão: Giovana Rodrigues, Edite Kanashiro, D. Olinda Rodrigues, Elisa por suprir a atenção e carinho que não pude oferecer aos meus filhos, durante as minhas ausências.

Às duas grandes amigas: Magali Franco Bueno e Maria Elisa Marcondes Helene pelas palavras, pelos chás e vitaminas de ânimo e incentivo.

Aos meus amigos portugueses: Carol e Leo (brasileiro aportuguesado) e D. Maria Alice cujo carinho, sopinhas, chazinhos e acolhida tornaram o frio mais suportável.

E finalmente, tenho muito a agradecer a minha família, sem a qual nada disso teria o menor sentido. Minhas irmãs: Edelma e Edelmara. Meus filhos: Pedro e Cora e meu companheiro Walter Saiani.

À minha mãe Eleney que muito me ensinou a importância do conhecimento.

Esta pesquisa foi parcialmente financiada pela Coordenação de Aperfeiçoamento Pessoal de Nível Superior - CAPES e Fundação de Amparo à Pesquisa do Estado de São Paulo - FAPESP. 
, o clima de São Paulo é um dos mais agradáveis do mundo. A situação da região, localizada somente uma milha e meia do trópico de Capricórnio e sua elevação de 1.200 pés acima do nível do mar proporcionam as vantagens do clima dos trópicos, sem os exageros do calor (SIGAUD 2009 escrito em 1844). 


\section{RESUMO}

Objetivo: A pesquisa teve como objetivo verificar como as condições atmosféricas intraurbanas atuam no agravamento dos problemas respiratórios, em crianças menores de cinco anos, e, circulatórias e respiratórias, em adultos com mais de sessenta anos, no setor Sul/Sudeste, da cidade de São Paulo, a partir da associação com as variáveis atmosféricas e o índice bioclimático PET (Physiological Equivalent Temperature). Métodos: Analisou-se 12.269 casos de internação por doenças respiratórias em crianças; 24.318 por doenças do aparelho circulatório e 8.894 do aparelho respiratório em idosos. Os dados foram agrupados segundo perfil socioambiental. Nas estações meteorológicas do IAG/USP e do aeroporto de Congonhas foram obtidas variáveis e obteve-se o índice de qualidade do ar na CETESB/CONGONHAS. Foram utilizados: análise estatística descritiva; modelo linear generalizado com distribuição binomial negativa (GLM); e modelo de regressão. Resultados: Houve associação estatística entre as variáveis atmosféricas ambientais e as internações hospitalares, porém de forma diferenciada e específica. O GLM apontou aumento nas internações hospitalares com a elevação em $1^{\circ} \mathrm{C}$ de amplitude térmica $(0,6 \%)$ índice de poluição $(0,2 \%)$ e com diminuição na temperatura média $(0,9 \%)$. A regressão apontou aumento de internações com a diminuição das temperaturas médias e mínimas e o índice PET indicou que o calor é protetor. A chance de ocorrência de internações foi $12 \%$ maior com a diminuição de $1^{\circ} \mathrm{C}$ no índice PET e com aumento $1^{\circ} \mathrm{C}$ na temperatura máxima, no grupo de pior perfil socioambiental. Doenças Respiratórias em Idosos: O GLM indicou aumento das internações hospitalares com a elevação em $1^{\circ} \mathrm{C}$ na amplitude térmica $(2,1 \%)$ e poluição $(0,2 \%)$ e diminuição em $1^{\circ} \mathrm{C}$ do PET $(1 \%)$. A regressão aponta maior risco com o aumento da amplitude térmica. Dias com maior taxa de internação foi 3,4\% maior nos distritos com perfil socioambiental intermediário, com o decréscimo de $1^{\circ} \mathrm{C}$ na temperatura mínima. Crianças: O GLM apontou aumento das internações hospitalares com o aumento em $1^{\circ} \mathrm{C}$ da temperatura média $(3,7 \%)$, da amplitude térmica $(2,7 \%)$ e da poluição $(0,2 \%)$ e diminuição em $1^{\circ} \mathrm{C}$ do índice PET (1\%). A regressão apontou risco nas faixas intermediárias de temperatura média, de menor temperatura mínima e de maior amplitude térmica. A faixa de conforto térmico mostrou que nas faixas de pouco calor $\left(>31^{\circ} \mathrm{C}\right)$ e frio $\left(<12^{\circ} \mathrm{C}\right)$ há proteção e maior risco na faixa de pouco frio $\left(<18^{\circ} \mathrm{C}\right)$. Houve associação estatística significante nos grupos de diferente perfil socioambiental, de forma homogênea. Conclusões: Houve associação entre a morbidade e as variáveis climáticas e o índice de conforto de forma diferenciada nos grupos etários e de doenças. O desconforto para frio e a alta amplitude térmica consistiram em fatores mais agravantes para o desencadeamento das doenças. Os resultados corroboram parcialmente a hipótese de que os distritos com piores condições socioambientais apresentam maior impacto negativos à saúde. Os dados confirmam a proposição no que se refere ao grupo de adultos com mais de sessenta anos, mas não apresentaram diferenças significativas para o grupo de crianças com doenças respiratórias e menores de cinco anos.

Palavras-chave: clima intraurbano, saúde urbana, doenças respiratórias, doenças circulatórias. 


\section{SUMMARY}

Objective: The research aimed to verify how the local climatic conditions can intensify the respiratory disease in children under five years, and circulatory and respiratory in adults sixty years and older. The sector south/southeast of São Paulo city from the association with the atmospheric variables and bioclimatic index PET (Physiological Equivalent Temperature). Methods: 12.269 cases respiratory diseases in children, 24318 circulatory diseases and 8.894 respiratory tract in elderly people were selected. Admissions data were grouped according to socio-environmental profile. Meteorological variables were obtained at IAG/USP and Congonhas' airport stations. Air quality data were obtained in Cetesb station. Statistical and numerical modeling tools were used. Statistical correlation between atmospheric variables and hospital admissions was observed, but in different ways. Results: Circulatory (>60 years old): GLM showed increase in hospital admissions with elevation in $1^{\circ} \mathrm{C}$ temperature range $(0.6 \%)$ index of pollution $(0.2 \%)$ and decrease in average temperature $(0.9 \%)$. The occurrence of hospitalizations was $12 \%$ higher with the decrease $1{ }^{\circ} \mathrm{C}$ in PET and increase in $1^{\circ} \mathrm{C}$ maximum temperature, to lower socioenvironmental profile. Respiratory Diseases (>60): GLM indicated increased hospitalizations with the increase in $1^{\circ} \mathrm{C}$ in a temperature range $(2.1 \%)$ and pollution $(0.2 \%)$ and decreased $1{ }^{\circ} \mathrm{C}$ PET $(1 \%)$. Higher admissions days $(3.4 \%)$ occurred in districts with middle socio-environmental profile with decrease $1^{\circ} \mathrm{C}$ minimum temperature. Children: GLM showed an increase in hospital admissions with an increase in average temperature $1{ }^{\circ} \mathrm{C}(3.7 \%)$, the temperature range $(2.7 \%)$ and pollution $(0.2 \%)$ and a decrease $1{ }^{\circ} \mathrm{C}$ of PET (1\%). Groups of different socioenvironmental was significantly associated with thermal comfort index and temperatures range. Conclusions: There were association between morbidity and climatic variables and comfort index in the age groups and diseases. The results partially support the hypothesis that the districts with the worst social and environmental conditions have a higher negative impact on health. The data confirm the proposition with regard to the group of adults over sixty years, but no significant differences for the group of children with respiratory diseases and under-fives.

Key words: urban bioclimate, urban health, respiratory diseases, circulatory diseases. 


\section{LISTA DE FIGURAS}

Figura 1 - Localização da área de estudo no município de São Paulo, SP, Brasil. ... 24

Figura 2 - Escala do Clima Urbano, adaptada da WMO 2008................................ 31

Figura 3 - Localização das Estações Meteorológicas IAG/USP e CONGONHAS, no setor Sul/Sudeste, município de São Paulo, SP, Brasil............................. 33

Figura 4 - Perfil socioambiental dos distritos, no setor Sul/Sudeste, Município de São Paulo, SP, Brasil........................................................................... 41

Figura 5 - Perfil Socioambiental dos distritos agrupados, no setor Sul/Sudeste, Município de São Paulo, SP, Brasil........................................................ 43

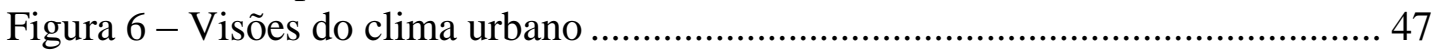

Figura 7 - Troca de calor entre ambiente e o homem - balanço energético ............. 53

Figura 8 - Principais vias de circulação e distribuição das áreas de favelas no Setor Sul/Sudeste, Município de São Paulo, SP. ............................................. 81

Figura 9 - Concentração das áreas de favelas, em relação ao tamanho (perímetro), no Setor Sul/Sudeste, Município de São Paulo, SP....................................... 82

Figura 10 - Índice de Desenvolvimento Humano (IDH) no Setor Sul/Sudeste, Município de São Paulo, SP, Brasil no ano de 2000 ............................... 83

Figura 11 - Proporção da população estudada em relação ao Município de São Paulo e em relação à área de estudo - Setor Sul/Sudeste para o ano de 2005.... 85

Figura 12 - Distribuição da proporção da população (\%) estimada de crianças de menores de cinco anos, por distrito, no setor Sul/Sudeste, Município de São Paulo, SP, no ano de 2005.

Figura 13 - Distribuição da proporção da população (\%) estimada de pessoas de sessenta e mais anos, por distrito, no setor Sul/Sudeste, Município de São Paulo, SP, no ano de 2005.

Figura 14 - Média mensal da temperatura do ar na EM-IAG/USP, no período de 2003 a 2007, São Paulo, SP.................................................................... 98

Figura 15 - Média mensal da temperatura máxima do ar na EM-IAG/USP, no período de 2003 a 2007, São Paulo, SP................................................ 99

Figura 16 - Média mensal da temperatura do ar mínima na EM-IAG/USP, no período de 2003 a 2007, São Paulo, SP. 100

Figura 17 - Média mensal da umidade relativa do ar na EM-IAG/USP, no período de 2003 a 2007, São Paulo, SP. 101

Figura 18 - Média mensal da velocidade do vento na EM-IAG/USP, no período de 2003 a 2007, São Paulo, SP. 102

Figura 19 - Média mensal da radiação solar (W/m2) na EM-IAG/USP, no período de 2003 a 2007, São Paulo, SP. 103

Figura 20 - Média mensal da temperatura média do ar na EM-CONGONHAS, no período de 2003 a 2007, São Paulo, SP.

Figura 21 - Média mensal da temperatura máxima do ar na EM-CONGONHAS, no período de 2003 a 2007, São Paulo, SP.

Figura 22 - Média mensal da temperatura mínima do ar na EM-CONGONHAS, no período de 2003 a 2007, São Paulo, SP............................................... 114

Figura 23 - Média mensal da umidade relativa do ar na EM-CONGONHAS, no período de 2003 a 2007, São Paulo, SP................................................... 115

Figura 24 - Média mensal da velocidade do vento na EM-CONGONHAS, no período de 2003 a 2007, São Paulo, SP................................................. 116 
Figura 25 - Ritmo mensal da temperatura média na EM-IAG/USP, São Paulo, SP,

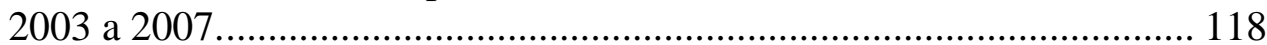

Figura 26 - Ritmo mensal da temperatura média na EM-CONGONHAS, São Paulo,

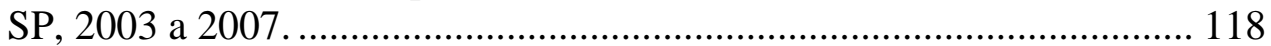

Figura 27 - Ritmo mensal da temperatura mínima na EM-IAG/USP, São Paulo, SP,

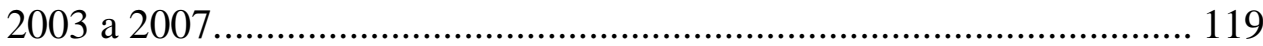

Figura 28 - Ritmo mensal da temperatura mínima na EM-CONGONHAS, São

Paulo, SP, 2003 a 2007..................................................................... 120

Figura 29 - Ritmo mensal da amplitude térmica na EM-IAG/USP, São Paulo, SP,

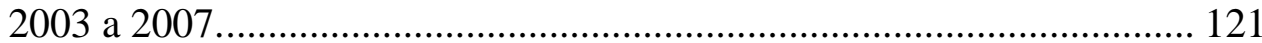

Figura 30 - Ritmo mensal da amplitude térmica na EM-CONGONHAS, São Paulo,

SP, 2003 a 2007............................................................................. 121

Figura 31 - Ritmo mensal do PET na EM-IAG, São Paulo, SP, 2003 a 2007........ 122

Figura 32 - Ritmo mensal do PET na EM-CONGONHAS São Paulo, SP, 2003 a

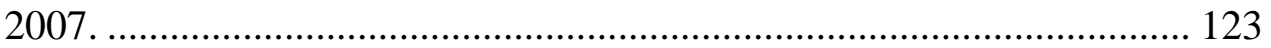

Figura 33 - Freqüência das diferenças entre as temperaturas máximas na EM-

IAG/USP e EM-Congonhas............................................................ 125

Figura 34 - Freqüência das diferenças entre as temperaturas mínimas nas EM-

IAG/USP e EM-Congonhas............................................................ 126

Figura 35 - Frequiência das diferenças entre as temperaturas médias nas EM-

IAG/USP e EM-Congonhas............................................................. 126

Figura 36 - Freqüência das diferenças entre Umidade Relativa do ar nas EM-

IAG/USP e EM-Congonhas................................................................. 127

Figura 37 - Freqüência da velocidade media diária do vento medido na EM-

IAG/USP 127

Figura 38 - Frequiência da velocidade media diária do vento medido na EM-

CONGONHAS. ......................................................................... 128

Figura 39 - Ritmo diário do conforto térmico (PET) na EM-IAG/USP e na EM-

CONGONHAS, no período de 01 de janeiro a 31 de dezembro 2003.... 130

Figura 40 - Ritmo diário do conforto térmico (PET) na EM-IAG/USP e na EM-

CONGONHAS, no período de 01 de janeiro a 31 de dezembro 2004... 130

Figura 41 - Ritmo diário do conforto térmico (PET) na EM-IAG/USP e na EM-

CONGONHAS, no período de 01 de janeiro a 31 de dezembro 2005.... 131

Figura 42 - Ritmo diário do conforto térmico (PET) na EM-IAG/USP e na EM-

CONGONHAS, no período de 01 de janeiro a 31 de dezembro 2006.... 131

Figura 43 - Ritmo diário do conforto térmico (PET) na EM-IAG/USP e na EM-

CONGONHAS, no período de 01 de janeiro a 31 de dezembro 2007 .... 132

Figura 44 - Frequencia das diferenças entre os valores do índice PET da EM-

IAG/USP e EM-CONGONHAS, no período de 2003 a 2007, São Paulo, SP.... 139

Figura 45 - Proporção (\%) dos poluentes relacionados a composição do índice de qualidade do ar, na Estação de Congonhas, São Paulo, SP. 2003 a 2007141

Figura 46 - Proporção (\%) do índice de qualidade do ar medido na Estação de Congonhas, São Paulo, SP, 2003 a 2007. 141

Figura 47 - Série temporal das internações hospitalares por doenças do aparelho circulatório em pessoas de sessenta e mais anos, no setor Sul/Sudeste, SP, 2003 a 2007. 143 
Figura 48 - Série temporal das internações hospitalares por doenças do aparelho respiratório em pessoas de sessenta e mais anos, no setor Sul/Sudeste, SP, 2003 a 2007. 144

Figura 49 - Série temporal das internações hospitalares por doenças do aparelho respiratório em crianças de menores de cinco anos, no setor Sul/Sudeste, SP, 2003 a 2007. 144

Figura 50 - Ritmo mensal das internações hospitalares por doenças do aparelho circulatório em pessoas de sessenta e mais anos, no setor Sul/Sudeste, SP, 2003 a 2007. 145

Figura 51 - Ritmo mensal das internações hospitalares por doenças do aparelho respiratório em pessoas de sessenta e mais anos, no setor Sul/Sudeste, SP, 2003 a 2007. 146

Figura 52 - Ritmo mensal das internações hospitalares por doenças do aparelho respiratório em crianças de menores de cinco anos, no setor Sul/Sudeste, SP, 2003 a 2007. 147

Figura 53 - Incidência de mensal de internação hospitalar por doenças do aparelho circulatório em pessoas com sessenta e mais anos, temperatura máxima e mínima absoluta e temperatura média mensal na EM-IAG/USP, no período de 2003 a 2007, Setor Sul/Sudeste, São Paulo, SP.

Figura 54 - Incidência de mensal de internação hospitalar por doenças do aparelho circulatório em pessoas com 60 e mais anos, temperaturas médias da máxima e mínima e temperatura média mensal na EM-CONGONHAS, no período de 2003 a 2007, Setor Sul/Sudeste, São Paulo, SP. 153

Figura 55 - Incidência de mensal de internação hospitalar por doenças do aparelho respiratório em pessoas com 60 e mais anos, temperatura máxima e mínima absoluta e temperatura média mensal na EM-IAG/USP, no período de 2003 a 2007, setor Sul/Sudeste, São Paulo, SP. 160

Figura 56 - Incidência de mensal de internação hospitalar por doenças do aparelho respiratório em pessoas com 60 e mais anos, temperaturas médias das máximas e das mínimas e temperatura média mensal na EM-IAG/USP, no período de 2003 a 2007, setor Sul/Sudeste, São Paulo, SP. 161

Figura 57 - Incidência de mensal de internação hospitalar por doenças do aparelho respiratório em crianças de menores de cinco anos, temperaturas médias das máximas e das mínimas e temperatura média mensal na EM-IAG/USP, no período de 2003 a 2007, setor Sul/Sudeste, São Paulo, SP. 165 


\section{LISTA DE PRANCHAS}

Prancha 1 - Ritmo diário das temperaturas do ar, umidade relativa média do ar, vento e radiação solar, na EM-IAG/USP, de 1 de janeiro a 31 de dezembro de 2003.

Prancha 2 - Ritmo diário das temperaturas do ar, umidade relativa média do ar, vento e radiação solar, na EM-IAG/USP, de 1 de janeiro a 31 de dezembro de 2004.

Prancha 3 - Ritmo diário das temperaturas do ar, umidade relativa média do ar, vento e radiação solar, na EM-IAG/USP, de 1 de janeiro a 31 de dezembro de 2005.

Prancha 4 - Ritmo diário das temperaturas do ar, umidade relativa média do ar, vento e radiação solar, na EM-IAG/USP, de 1 de janeiro a 31 de dezembro de 2006.

Prancha 5 - Ritmo diário das temperaturas do ar, umidade relativa média do ar, vento e radiação solar, na EM-IAG/USP, de 1 de janeiro a 31 de dezembro de 2007.

Prancha 6 - Ritmo diário das temperaturas do ar, umidade relativa média do ar e velocidade do vento, na EM-CONGONHAS, de 1 de janeiro a 31 de dezembro de 2003 ............................................................................. 106

Prancha 7 - Ritmo diário das temperaturas do ar, umidade relativa média do ar e velocidade do vento, na EM-CONGONHAS de 1 de janeiro a 31 de dezembro de 2004.

Prancha 8 - Ritmo diário das temperaturas do ar, umidade relativa média do ar e velocidade do vento, na EM-CONGONHAS de 1 de janeiro a 31 de dezembro de 2005............................................................................ 108

Prancha 9 - Ritmo diário das temperaturas do ar, umidade relativa média do ar e velocidade do vento, na EM-CONGONHAS, de 1 de janeiro a 31 de dezembro de 2006.

Prancha 10 - Ritmo diário das temperaturas do ar, umidade relativa média do ar e velocidade do vento, na EM-CONGONHAS, de 1 de janeiro a 31 de dezembro de 2007.

Prancha 11 - Frequiência das faixas de conforto térmico (PET) na EM-IAG/USP, no

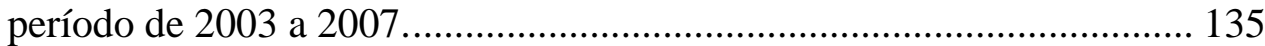

Prancha 12 - Frequiência das faixas de conforto térmico (PET) na EMCONGONHAS no período de 2003 a 2007. ............................................ 137

Prancha 13 - Mapas da incidência das internações por doenças do aparelho circulatório em adultos de sessenta e mais anos, no setor Sul/Sudeste, município de São Paulo, 2003 a 2007.

Prancha 14 - Mapas da incidência das internações por doenças do aparelho respiratório em adultos de sessenta e mais anos, no setor Sul/Sudeste, município de São Paulo, 2003 a 2007. 150

Prancha 15 - Mapas da incidência das internações por doenças do aparelho respiratório em crianças menores de cinco anos, no setor Sul/Sudeste, município de São Paulo, 2003 a 2007. 


\section{LISTA DE TABELAS}

Tabela 1 - Total de internações hospitalares por ano, segundo local de residência, no município de São Paulo, Brasil - 2003 a 2007.

Tabela 2 - Total de internações hospitalares, segundo doenças do Capítulo 9 e Capítulo 10 da CID, no município de São Paulo, Brasil - 2003 a 2007. ... 27

Tabela 3 - Escala de interpretação para o índice de conforto PET calibrada para a cidade de São Paulo em ambientes externos.

Tabela $4 \mathrm{a}$ - Propriedades da superfície e da atmosfera urbanas em comparação à

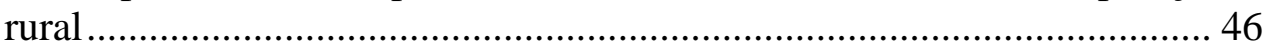

Tabela 4b - Efeitos do clima nas áreas urbanas .................................................... 46

Tabela 5 - Estatística descritiva dos dados meteorológicos da EM-IAG/USP, no

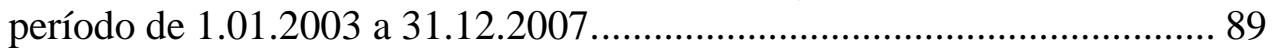

Tabela 6 - Estatística descritiva dos dados meteorológicos da EM-CONGONHAS, no período de 1.01.2003 a 31.12.2007....................................................... 104

Tabela 7 - Teste de correlação entre as variáveis medidas no EM-IAG/USP e EMCONGONHAS.

Tabela 8 - Teste de médias pareadas para as variáveis medidas na EM-IAG/USP e EM-CONGONHAS no período de 01 de janeiro de 2003 a 31 de dezembro de 2007.

Tabela 9 - Quantidade e porcentagem de dias, segundo faixa de sensação térmica, na EM-IAG/USP e na EM-CONGONHAS, no período de 2003 a 2007.... 138

Tabela 10 - Resultados do modelo final ajustado para o número de internações por doenças circulatórias em pessoas de sessenta e mais anos, no setor Sul/Sudeste, São Paulo, SP, no período de 2003 a 2007. 155

Tabela 11 - Risco Relativo; Intervalo de Confiança; valor p para o índice de conforto térmico (PET) e internações por doenças circulatórias em pessoas de sessenta e mais anos no setor Sul/Sudeste, São Paulo, SP, por faixa de exposição, controladas pela poluição do ar, 2003 a 2007....................... 156

Tabela 12 - Risco Relativo; Intervalo de Confiança; valor $p$ para a temperatura mínima e internações por doenças circulatórias em pessoas de sessenta e mais anos no setor Sul/Sudeste, São Paulo, SP, por faixa de exposição, controladas pela poluição do ar, 2003 a 2007 157

Tabela 13 - Risco Relativo; Intervalo de Confiança; valor $p$ para a temperatura máxima e internações por doenças circulatórias em pessoas de sessenta e mais anos no setor Sul/Sudeste, São Paulo, SP, por faixa de exposição, controladas pela poluição do ar, 2003 a 2007. 158

Tabela 15 - Resultados do modelo final ajustado para o número de internações por doenças respiratórias em pessoas de sessenta e mais anos, no setor Sul/Sudeste, São Paulo, SP, no período de 2003 a 2007. 162

Tabela 16 - Risco Relativo; Intervalo de Confiança; valor $p$ para a amplitude térmica e internações por doenças respiratórias em pessoas de sessenta e mais anos no setor Sul/Sudeste, São Paulo, SP, por faixa de exposição, controladas pela poluição do ar, 2003 a 2007. 163

Tabela 17 - Resultados do modelo final ajustado para o número de internações por doenças respiratórias em crianças menores de cinco anos, no setor Sul/Sudeste, São Paulo, SP, no período de 2003 a 2007. 167 
Tabela 18 - Risco Relativo; Intervalo de Confiança; valor $p$ para o índice de conforto (PET) e internações por doenças respiratórias em crianças de menores de cinco anos e mais anos no setor Sul/Sudeste, São Paulo, SP, por faixa de exposição, controladas pela poluição do ar, 2003 a 2007. 168

Tabela 19 - Risco Relativo; Intervalo de Confiança; valor $p$ para a temperatura mínima e internações por doenças respiratórias em crianças de menores de cinco anos e mais anos no setor Sul/Sudeste, São Paulo, SP, por faixa de exposição, controladas pela poluição do ar, 2003 a 2007. 169

Tabela 20 - Risco Relativo; Intervalo de Confiança; valor $p$ para a temperatura média e internações por doenças respiratórias em crianças de menores de cinco anos e mais anos no setor Sul/Sudeste, São Paulo, SP, por faixa de exposição, controladas pela poluição do ar, 2003 a 2007. 170

Tabela 21 - Risco Relativo; Intervalo de Confiança; valor p para a amplitude térmica e internações por doenças respiratórias em crianças de menores de cinco anos e mais anos no setor Sul/Sudeste, São Paulo, SP, por faixa de exposição, controladas pela poluição do ar, 2003 a 2007. 171

Tabela 22 - Resultados do modelo ajustado para as variáveis atmosféricas da EMCONGONHAS e internações por doenças circulatórias em adultos maiores de sessenta anos, controladas pela poluição do ar, segundo o perfil socioambiental dos distritos, no setor Sul/Sudeste, São Paulo, SP, 2003 a 2007.

Tabela 23 - Resultados do modelo ajustado para as variáveis atmosféricas da EMIAG/USP e internações por doenças circulatórias em adultos maiores de sessenta anos, controladas pela poluição do ar, segundo o perfil socioambiental dos distritos, no setor Sul/Sudeste, São Paulo, SP, 2003 a 2007. 174

Tabela 24 - Resultados do modelo ajustado para as variáveis atmosféricas da EMCONGONHAS e internações por doenças respiratórias em adultos maiores de sessenta anos, controladas pela poluição do ar, segundo o perfil socioambiental dos distritos, no setor Sul/Sudeste, São Paulo, SP, 2003 a 2007. 175

Tabela 25 - Resultados do modelo ajustado para as variáveis atmosféricas da EMIAG/USP e internações por doenças respiratórias em adultos maiores de sessenta anos, controladas pela poluição do ar, segundo o perfil socioambiental dos distritos, no setor Sul/Sudeste, São Paulo, SP, 2003 a 2007. 176

Tabela 26 - Resultados do modelo ajustado para as variáveis atmosféricas da EMCONGONHAS e internações por doenças respiratórias em crianças menores de cinco anos, controladas pela poluição do ar, segundo o perfil socioambiental dos distritos, no setor Sul/Sudeste, São Paulo, SP, 2003 a 2007. 177

Tabela 27 - Resultados do modelo ajustado para as variáveis atmosféricas da EMIAG/USP e internações por doenças respiratórias em crianças menores de cinco anos, controladas pela poluição do ar, segundo o perfil socioambiental dos distritos, no setor Sul/Sudeste, São Paulo, SP, 2003 a 2007 178 


\section{LISTA DE ABREVIATURAS}

AIH - Autorização de Internação Hospitalar

ATA - Anticiclone Tropical Atlântico

CET - Temperatura Efetiva Corrigida

CETESB - Companhia Ambiental do Estado de São Paulo

CID - Código Internacional de Doenças

CVD - Doenças cardiovasculares

DATASUS - Departamento de Informática do Sistema Único de Saúde

EM-CONGONHAS - Estação Meteorológica do Aeroporto de Congonhas

EM-IAG/USP - Estação Meteorológica do Instituto Astronômico e Geofísico da

Universidade de São Paulo

ET - Temperatura Efetiva

IDH - Índice de Desenvolvimento Humano

IRA - Infecções Respiratórias Agudas

GLM - Modelo Linear Generalizado

MTA - Massa Tropical Atlântica

MTC - Massa Tropical Continental

NE - Nordeste

OMM - Organização Meteorológica Mundial

PEFI - Parque Estadual das Fontes do Ipiranga

PET - Pysiological Equivalent Temperature

S - Sul

SIH-SUS - Sistema de Informações Hospitalares do Sistema Único de Saúde

SSW - Sul Sudoeste

SUS - Sistema Único de Saúde

TABWIN - Tabulador de Informações de Saúde para Ambiente Windows

UBL - Urban Boundary Layer

UCL - Urban Canopy Layer

$\mathrm{W}$ - Oeste

WMO - World Meteorological Organization 


\section{ÍNDICE}

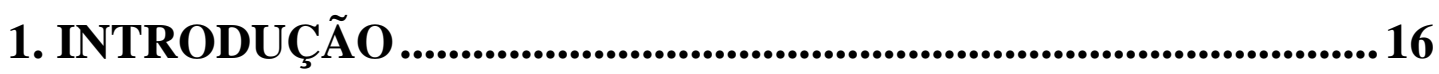

2. PROCEDIMENTOS METODOLÓGICOS ....................................21

2.1 Pesquisa bibliográfica e documental .................................................................................21

2.2 Seleção da amostra................................................................................................................................22

2.3 Dados Climáticos e Bioclimáticos ........................................................................................29

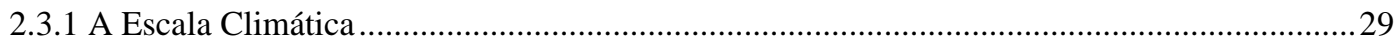

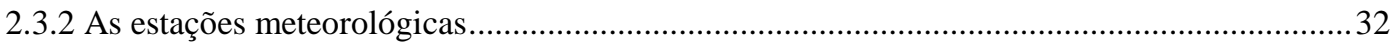

2.3.3 Cálculo do índice PET (Physiological Equivalent Temperature) .............................................34

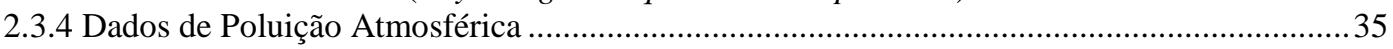

2.4 Análises dos dados ................................................................................................................................36

2.4.1 Aspectos climáticos e bioclimáticos do Setor Sul/Sudeste ......................................................36

2.4.2 Análise das internações hospitalares no setor Sul/Sudeste........................................................36

2.4.3 Associação entre as variáveis meteorológicas e as internações hospitalares.............................37

3. AMBIENTE ATMOSFÉRICO............................................................... 44

3.10 clima urbano.............................................................................................................................................44

3.2 Biometeorologia e Bioclimatologia Urbana ..........................................................................48

3.3 Relações do clima com a saúde humana .................................................................................................51

3.4 Estudos sobre clima e saúde.....................................................................................................................56

4. ÁREA DE ESTUDO .............................................................................

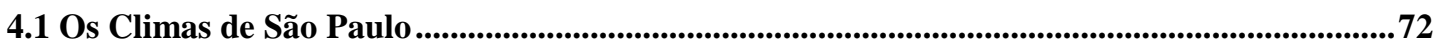

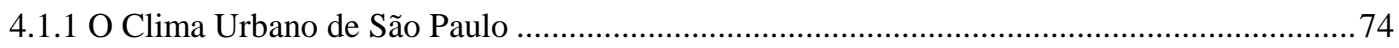

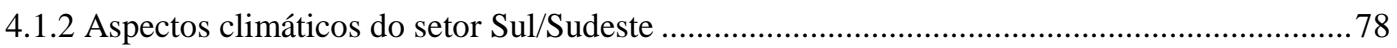

4.2 Aspectos da ocupação do setor Sul/Sudeste ........................................................................80

4.3 População da área de estudo ..........................................................................................................................84

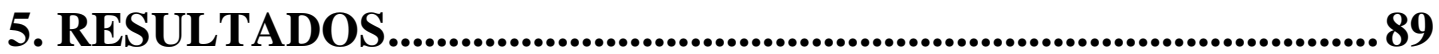

5.1. Características Climáticas do Setor Sul/Sudeste ..............................................................89

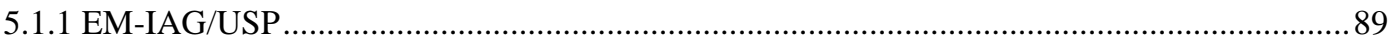

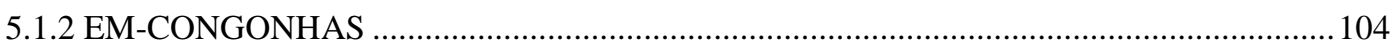

5.1.3 Séries Temporais do ambiente termal na EM-IAG/USP e EM-CONGONHAS .................. 117

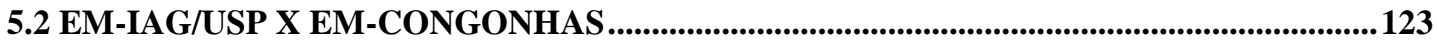

5.3 Características bioclimáticas do Setor Sul/Sudeste....................................................................128 
5.5 As Internações hospitalares no setor Sul/Sudeste ................................................................142

5.5.1 Séries temporais das internações hospitalares no setor Sul/Sudeste. ...................................... 142

5.5.2 Análises espaciais das internações hospitalares no setor Sul/Sudeste ................................ 147

5.6 A relação clima e saúde no setor Sul/Sudeste .................................................................152

5.6.1 Doenças circulatórias em pessoas de sessenta e mais anos ................................................ 152

5.6.2 Doenças respiratórias em adultos com mais de 60 anos.................................................... 159

5.6.3 Doenças respiratórias crianças de menores de 5 anos ........................................................ 164

5.7 A relação clima e saúde por perfil socioambiental no setor Sul/Sudeste...................................171

5.7.1 Doenças circulatórias em pessoas de sessenta e mais anos .............................................. 172

5.7.2 Doenças respiratórias em pessoas de sessenta e mais anos ............................................... 174

5.7.1 Doenças respiratórias em crianças menores de cinco anos ............................................... 176

6. DISCUSSÃO DOS RESULTADOS ............................................ 179

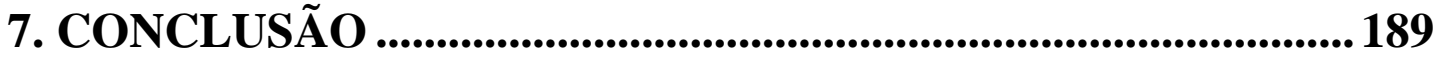

8. REFERÊNCIAS ................................................................................. 192

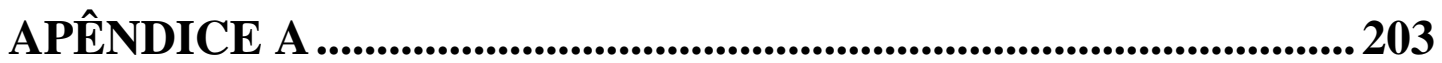

APÊNDICE B ............................................................................................ 205

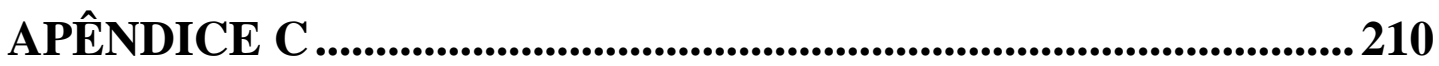

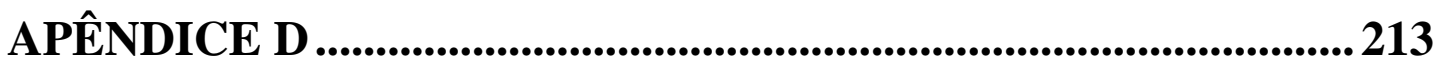




\section{INTRODUÇÃO}

A sociedade brasileira, impulsionada pelo processo de industrialização ${ }^{1}$, passou por um ritmo acelerado de urbanização, sobretudo após a década de 1950, levando à intensificação dos processos migratórios, dos fluxos de bens e mercadorias e dos investimentos seletivos, acarretando no crescimento das metrópoles (SANTOS e SILVEIRA 2001, ALMEIDA 2001).

A cidade de São Paulo, com aproximadamente 11 milhões de habitantes (FUNDAÇÃO SEADE 2009) e uma área de $1.509 \mathrm{~km}^{2}$, incorporou as novas demandas do modelo econômico global - globalização - e obteve seu status de metrópole global, ou seja, tornou-se o centro de comando, negócios e fluxos de informações que concentram atividades de serviços e informação e, portanto, um importante pólo econômico no país e no mundo ${ }^{2}$.

Até a década de 1970, a organização do espaço da cidade de São Paulo baseou-se no padrão centro-periferia, ou seja, as áreas centrais dotadas de infraestrutura urbana foram destinadas à população de alta renda, enquanto as áreas periféricas distantes do centro e carentes de infra-estrutura foram ocupadas pelas camadas mais pobres da população.

Nas décadas seguintes, as transformações impulsionadas pela globalização provocaram a modificação do padrão centro-periferia. As novas necessidades do mercado e do capital levaram à incorporação e investimentos em novas áreas e à desvalorização daquelas já consolidadas. Por exemplo, o deslocamento de investimentos econômicos para regiões distantes do centro histórico — como a região da Avenida Paulista e, mais recentemente, a Avenida Luis Carlos Berrini dinamizou e valorizou essas áreas. A região do centro histórico, "esvaziada" dos investimentos, passou a ser ocupada pela população mais pobre, concentrada em cortiços, bem como moradores de rua. Por outro lado, a especulação imobiliária, que

\footnotetext{
${ }^{1} \mathrm{O}$ termo industrialização tem significado amplo, como processo social complexo, que tanto inclui a formação de um mercado nacional, quanto os esforços de equipamento do território para torná-lo integrado, como a expansão do consumo em formas diversas, o que impulsiona a vida de relações e ativa o próprio processo de urbanização (SANTOS 1996, p. 27).

${ }^{2}$ Conforme Santos e Silveira, o papel metropolitano de São Paulo é definido por esta ser uma "capital relacional" e não mais uma capital industrial. Ou seja, a metrópole paulistana é "o centro que promove a coleta das informações, as armazena, classifica, manipula e utiliza a serviço dos atores hegemônicos da economia, da sociedade, da cultura e da política. Por enquanto, é São Paulo que absorve e concentra esse papel no poder decisório.” (SANTOS e SILVEIRA 2001, p. 210).
} 
elevou o preço das áreas recém incorporadas, provocou o deslocamento de uma parcela da população de classe média para bairros periféricos, em condomínios fechados - verticais e horizontais — de médio e alto padrões. Esse modelo caracterizou-se pelo aprofundamento do processo de segregação e polarização da vida social.

"A lógica de ocupação do espaço urbano que de modo geral favorece os grandes grupos econômicos e parcelas da população, somada à distribuição seletiva das infraestruturas e dos equipamentos urbanos, induz ao crescimento das periferias urbanas, à melhor expressão da segregação socioespacial a que são submetidas partes das cidades e a grande maioria de seus habitantes. A seletividade dos investimentos privados e, principalmente, dos investimentos públicos é a matriz da desigual valorização das cidades" (ALMEIDA 2001, p. 399).

A cidade tem, portanto, nos seus interstícios, um mosaico complexo de espaços ricos e pobres, altamente segregados. Há presença de bairros nobres, convivendo lado a lado com favelas, espaços verticalizados e consolidados com cortiços e moradores sem-teto. As favelas crescem na periferia, mas também estão presentes nos setores ricos, recém incorporados pelo capital (ALMEIDA 2001; SANTOS e SILVEIRA 2001; TASCHNER e BOGUS 2001).

O crescimento populacional do município de São Paulo, porém, tem diminuído nas últimas décadas. A taxa de crescimento anual foi de $1,1 \%$ na década de 1980-1991, de 0,9\% ao ano na década passada (entre 1991 e 2000) e as projeções para essa última década apontam um crescimento ainda menor de $0,6 \%$ ao ano (FUNDAÇÃO SEADE 2009).

Há, também, uma tendência de modificação do perfil populacional. A população da cidade está envelhecendo. O percentual da população com 60 anos e mais aumentou, entre 1970 e 1991, de 6,08\% para 8,08\% (TASCHNER e BOGUS 2001, p. 35) e, em 2006, representava 10,6\% da população total (FUNDAÇÃO SEADE 2007). Na periferia, o percentual também vem aumentando. Nas décadas anteriores a 1991 era de 3\%; em 1991, de 4,60\% e, em 1996, 4,99\% da população tinha 60 e mais anos (TASCHNER e BOGUS 2001, p. 35).

Essa dinâmica espacial e populacional se, por um lado, cria uma cidade heterogênea, por outro lado, concentra em algumas áreas "nobres", dotadas de serviços e infra-estrutura, a população mais rica da cidade e, em áreas periféricas, a 
população de baixa renda, com todo tipo de carência — de moradia, de emprego, de serviços, de infra-estrutura básica, como abastecimento de água e coleta de esgotos, de saúde, de educação e de cultura e lazer —, aprofundando os problemas sociais e mantendo a população na espiral da pobreza, como ressalta SANTOS (1996, p. 10).

“[...] o fato de que a população não tem acesso aos empregos necessários, nem aos bens e serviços essenciais, fomenta a expansão da crise urbana. Algumas atividades continuam a crescer, ao passo que a população se empobrece e observa a degradação de suas condições de existência. [...] A cidade em si, como relação social e como materialidade, torna-se criadora de pobreza, tanto pelo modelo socioeconômico de que é o suporte como por sua estrutura física, que faz dos habitantes das periferias (e dos cortiços) pessoas ainda mais pobres. A pobreza não é apenas o fato do modelo socioeconômico vigente, mas, também, do modelo espacial."

Considera-se que uma das dimensões da degradação das condições de existência são as condições ambientais a que estão submetidas parcelas da população da cidade, revelando mais uma dimensão da pobreza urbana.

“[...] as cidades não são homogêneas entre si, nem em seus espaços intra-urbanos. Sobretudo nos países em desenvolvimento, este período de grande crescimento da população urbana, provocou, também, o crescimento das disparidades sociais e ambientais urbanas, assim como as desigualdades em saúde" (RIBEIRO 2006, p.279).

RIBEIRO (2006) e SANTOS (2003) ressaltam, porém, que a urbanização em si não é um mal. Os autores argumentam que, do ponto de vista da saúde, a urbanização trouxe muitos benefícios tanto no nível individual quanto no coletivo. De modo geral, houve queda nas taxas de mortalidade e de mortalidade infantil tardia e aumento na expectativa de vida, em função dos vários benefícios trazidos pelos equipamentos urbanos, como o acesso à água potável, saneamento básico e energia, bem como pelos programas de vacinação, acesso aos serviços médicos, educação e informação, entre outros.

A modernização levou, portanto, a uma mudança no perfil da morbimortalidade, tanto da população urbana, quanto da população rural, aproximando as características de ambas. Portanto, nas cidades, o surgimento e o agravamento das patologias estão muito ligados ao modo de vida e às desigualdades sociais e ambientais (RIBEIRO 2006). No meio urbano paulistano, ressalta RIBEIRO (2006) 
"as patologias mais relevantes estão relacionadas às faixas etárias, ao ambiente social e aos impactos ambientais das diversas poluições” (p. 292).

A apreensão dos impactos do ambiente na saúde deve, portanto, considerar esse complexo processo de transformações - espaciais, populacionais, sociais e ambientais - ocorrido nas áreas urbanas, e, mais especificamente, nas cidades dos países em desenvolvimento.

Estudos sobre a atuação da atmosfera sobre a saúde humana têm mostrado que os efeitos da poluição do ar constituem um grave problema ambiental e de saúde pública da metrópole, desde o final da década de 1960 (RIBEIRO e CARDOSO 2003, p. 2013).

Do ponto de vista climático, a organização do espaço urbano, em São Paulo, criou, ao mesmo tempo, ambientes confortáveis, como áreas verdes e ruas arborizadas, e desconfortáveis: áreas muito poluídas, bastante adensadas e sem arborização. Dessa forma, a apreensão dos fenômenos climáticos, nas escalas local e micro, é essencial para o entendimento sobre a repercussão na saúde dos diferentes grupos sociais ou segmentos de grupos (crianças, idosos etc.), residentes em ambientes agravantes ou amenizadores dos atributos climáticos.

Partiu-se, então, da premissa de que as variações de ambiente atmosférico e de conforto térmico — assim como outras variáveis ambientais e também socioeconômicas - estão associadas com a ocorrência de doenças, tanto na escala urbana, quanto na escala intraurbana ${ }^{3}$. Assim, as condições climáticas das áreas intraurbanas são diferenciadas e geram ambientes mais ou menos confortáveis. $\mathrm{O}$ desconforto térmico se constitui em um fator de risco importante para a ocorrência das doenças respiratórias e circulatórias, sobretudo para os grupos vulneráveis.

Para esta pesquisa foram elaboradas duas hipóteses: a primeira é de que, na escala intraurbana, as condições atmosféricas podem ser fatores ambientais importantes no desencadeamento das doenças respiratórias e circulatórias.

\footnotetext{
${ }^{3}$ A questão das escalas será discutida no item 2.3.1 deste trabalho.
} 
A segunda hipótese diz respeito aos padrões de ocupação, os quais geram ambientes mais ou menos confortáveis, se constituindo também em fatores impactantes sobre a saúde das pessoas. Assim, sob a mesma condição atmosférica, o impacto negativo sobre a saúde é maior na população residente em áreas com piores condições socioambientais, ainda que considerando uma população com padrão econômico semelhante ${ }^{4}$.

A pesquisa teve como objetivo verificar como as condições atmosféricas intraurbanas atuam no agravamento dos problemas respiratórios em crianças menores de cinco anos e circulatórias e respiratórias em adultos com mais de sessenta anos, no setor Sul/Sudeste da cidade de São Paulo.

Os objetivos específicos consistiram em verificar o agravamento de problemas circulatórios e respiratórios na população estudada a partir das características do ambiente atmosférico em escala local, testando as variáveis atmosféricas e o índice bioclimático PET (Physiological Equivalent Temperature) por faixas de exposição e por meio do estudo dos distritos agrupados segundo perfil socioambiental.

Buscando comparar dados atmosféricos em áreas com situações diferentes de ocupação do solo urbano, optou-se por dirigir a pesquisa à porção Sul da cidade, onde há duas estações meteorológicas com base de dados regulares e bastante confiáveis, cujos entornos apresentam características distintas em relação, principalmente, ao adensamento e à porcentagem de áreas verdes: o Aeroporto de Congonhas e a Estação Meteorológica do Instituto Astronômico e Geofísico da Universidade de São Paulo.

A estação meteorológica de Congonhas está localizada no aeroporto, em uma área intensamente urbanizada e a estação meteorológica do Instituto Astronômico e Geofísico da Universidade de São Paulo localiza-se dentro de um parque - o Parque Estadual das Fontes do Ipiranga —, sendo rodeada por uma mata arbórea densa. Considera-se que as estações captem, respectivamente, as características de ambientes mais e menos urbanizados.

\footnotetext{
${ }^{4} \mathrm{O}$ projeto de pesquisa foi elaborado considerando que os dados de morbidade seriam adquiridos no SUS - Sistema Único de Saúde, portanto, se referem à população mais pobre.
} 
Foi definido um recorte espacial do entorno das estações meteorológicas que abrangeu 14 distritos, cujas características representam uma amostra do mosaico diversificado de ocupação do espaço urbano da cidade de São Paulo.

O estudo feito a partir deste recorte espacial privilegia uma escala de análise intraurbana, que, do ponto de vista do clima urbano, é considerada a escala local. É importante ressaltar que o foco da análise não está nem na cidade como um todo, meso-escala -, nem se atém aos recortes espaciais da micro-escala, que corresponderiam aos quarteirões ou edifícios.

Dessa forma, este estudo caracterizou os aspectos climáticos da área de estudo - o setor Sul/Sudeste da cidade de São Paulo —, descreveu o perfil da morbidade por doenças respiratórias em crianças e respiratórias e circulatórias em adultos com mais de sessenta anos e verificou as condições sob as quais o ambiente térmico é mais nocivo. Também comparou os impactos do ambiente atmosférico em três grupos de distritos com diferentes perfis socioambientais.

\section{PROCEDIMENTOS METODOLÓGICOS}

A pesquisa contou com as seguintes etapas: a) pesquisa bibliográfica e documental; b) caracterização da morbidade por doenças respiratórias em crianças menores de cinco anos e adultos com mais de sessenta anos e doenças circulatórias em adultos com mais de sessenta anos; c) caracterização dos aspectos climáticos e bioclimáticos, em escala local, a partir dos dados de duas estações meteorológicas a do Departamento de Ciências Atmosféricas do Instituto Astronômico e Geofísico da Universidade de São Paulo (EM-IAG/USP) e do Aeroporto de Congonhas (EMCONGONHAS); d) verificação da associação entre o ambiente atmosférico e a morbidade no setor Sul/Sudeste por faixas de exposição; e) agrupamento dos distritos segundo perfil socioambiental e análise da relação entre estes grupos e o ambiente atmosférico e a morbidade no setor Sul/Sudeste por distritos.

\subsection{Pesquisa bibliográfica e documental}

A pesquisa bibliográfica abarcou estudos nacionais e internacionais relacionados à investigação sobre a relação entre clima e saúde produzidos em 
diferentes centros de pesquisa. Além dessa temática, abrangeu estudos nas áreas de clima urbano, bioclimatologia e bioclimatologia urbana, clima urbano de São Paulo, índices de conforto e suas aplicações.

A pesquisa documental consistiu na pesquisa de dados de morbidade, populacionais, informações ambientais e socioeconômicas e bases cartográficas para a elaboração deste trabalho. Foram consultados órgãos de pesquisa que disponibilizam informações sobre a cidade de São Paulo na rede mundial de computadores. Os seguintes órgãos foram consultados: o Departamento de Informática do SUS (DATASUS), a Fundação Sistema Estadual de Análise de Dados (SEADE), as Secretarias Municipais de Planejamento e do Verde e Meio Ambiente de São Paulo, o Instituto Brasileiro de Geografia e Estatística e o Centro de Estudos da Metrópole.

\subsection{Seleção da amostra}

Os dados de morbidade foram obtidos a partir das internações em hospitais públicos de pessoas residentes em 14 distritos do município de São Paulo: Cidade Ademar, Cidade Dutra Campo Belo Campo Grande Cursino Socorro Itaim Bibi Jabaquara Moema Pedreira, Sacomã, Santo Amaro, Saúde e Vila Mariana, os quais doravante recebem a denominação de setor Sul/Sudeste (Figura 1).

A população estudada é a de crianças menores de cinco anos, para as internações por doenças respiratórias e o grupo etário de sessenta e mais anos para doenças do aparelho circulatório e respiratórias. Trata-se de grupos com maior vulnerabilidade aos impactos negativos do ambiente atmosférico.

Os dados secundários de morbidade referente às internações hospitalares registradas nas AIHs - Autorizações de Internações Hospitalares ${ }^{5}$ - foram obtidos no Sistema de Informações Hospitalares do Sistema Único de Saúde (SIH/SUS), disponíveis no sítio do DATASUS, selecionados por código de endereçamento postal (CEP).

\footnotetext{
${ }^{5}$ Arquivos referentes às AIHs pagas. Esses dados referem-se às informações contidas nos arquivos rdpsp.dbc para o município de São Paulo. Disponível em: ftp://msbbs.datasus.gov.br/Arquivos_Publicos/Estado_SP/00_index.htm. Acesso em: fevereiro de 2009.
} 
O SIH-SUS ${ }^{6}$ é um banco de dados administrativo cujo objetivo é viabilizar o pagamento dos serviços prestados pelo SUS e que contém informações sobre as internações hospitalares. Trata-se de informações relevantes, que permitem avaliar o perfil epidemiológico de uma determinada população. Cabe ressaltar que a amostra selecionada refere-se somente àqueles pacientes que utilizam o Sistema Único de Saúde (SUS).

\footnotetext{
6 As Autorizações de Internação Hospitalar - AIH - correspondem a mais de 1.300.000 internações/mês. Fonte: http://w3.datasus.gov.br/DATASUS acesso em 14.03.2009. Acesso em: fevereiro de 2009.
} 


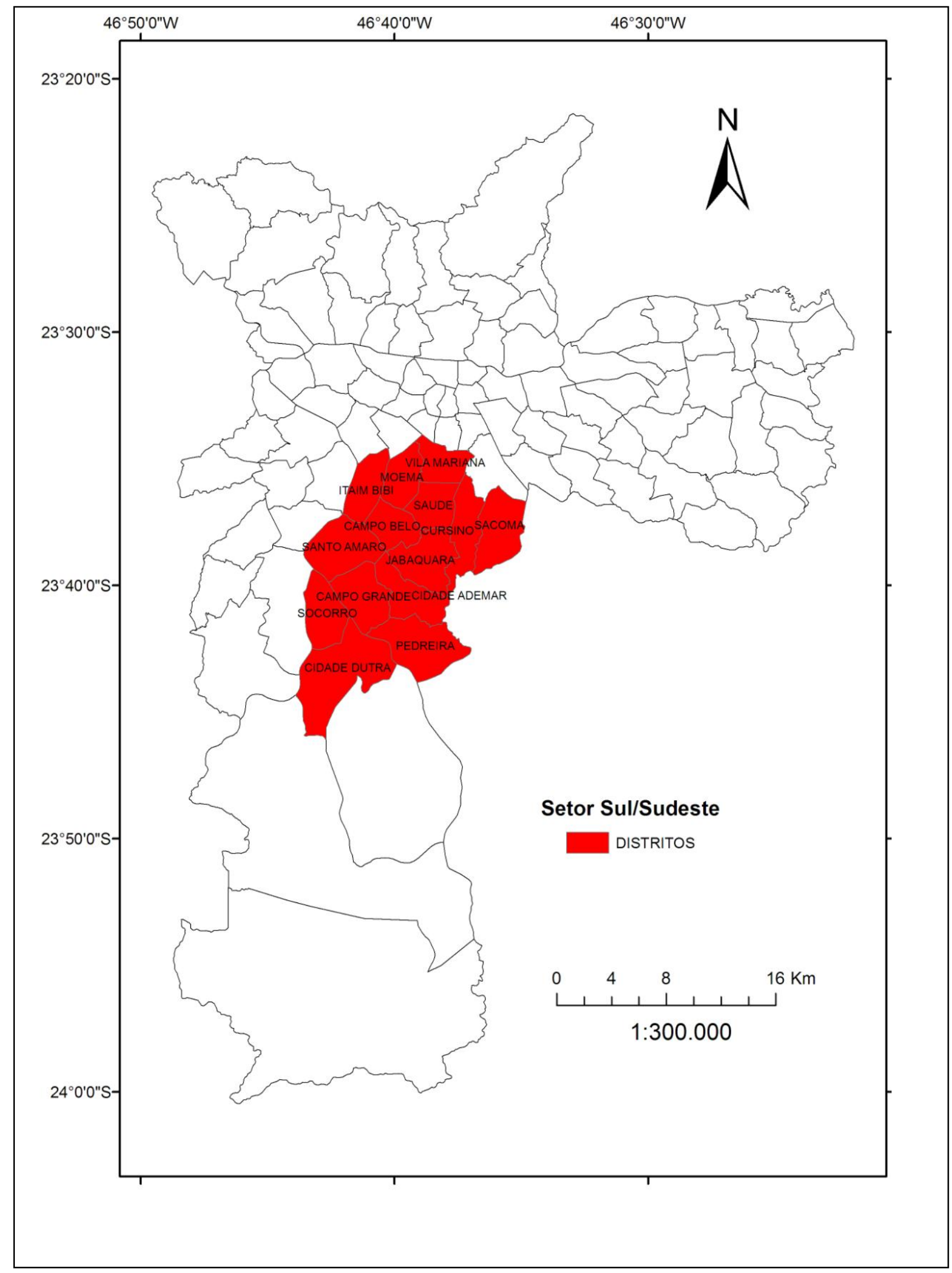

Figura 1 - Localização da área de estudo no município de São Paulo, SP, Brasil. 
Estudo realizado para traçar o perfil sociodemográfico da população usuária do SUS apontou que os utilizadores do sistema concentram-se nas camadas mais pobres da população e com maiores necessidades de saúde, com predomínio de pretos e pardos, baixa escolaridade e sem posse de plano de saúde privado (RIBEIRO et al. 2006, p. 1020).

Alguns autores avaliaram a confiabilidade das informações hospitalares e constataram algumas limitações: com relação aos diagnósticos; aos sub-registros principalmente dos diagnósticos secundários - ou sobre-registros; ao uso da internação como unidade de análise do sistema ao invés do indivíduo; à ausência de dados acerca das condições sociais e econômicas; à definição a respeito da inclusão ou exclusão dos serviços de assistência hospitalar no SIH/SUS mediante o estabelecimento de normas e a mudança periódica de portarias e de política de reembolso (BITTENCOURT et. al 2006; VERAS e MARTINS 1994).

A despeito dessas limitações, os autores consideram que a qualidade das informações disponíveis no banco de dados das AIHs é superior à que geralmente lhe é atribuída e apresentou avanços com relação a registros de diagnósticos (BITTENCOURT et al. 2006; VERAS e MARTINS 1994).

Durante o processo de tratamento dos dados das AIHs, alguns problemas foram detectados: a duplicação da informação, principalmente no que se refere às internações de longa duração; o grande intervalo de tempo entre as ocorrências e a inserção das informações no banco de dados — uma internação ocorrida em maio de 2003, por exemplo, pode aparecer no banco somente em dezembro de 2006 —; a ausência de registro do CEP ou a informação sobre o CEP do indivíduo nem sempre corresponder ao de sua residência, podendo constar o CEP do hospital em que ele foi internado.

Os problemas relacionados ao CEP e à falta de dados sobre a projeção populacional na escala do setor censitário impediram seu uso como unidade de agregação dos dados. Dessa forma, foi utilizado o nível do distrito como escala espacial.

A partir do conjunto de dados do Estado de São Paulo foram selecionadas as informações relativas à cidade de São Paulo — código do município 355030 — e, posteriormente, os dados referentes às doenças, classificadas pela Classificação 
Internacional de Doenças - CID 10, Capítulos 9 e 10, que tratam, respectivamente, das "Doenças do Aparelho Respiratório" e das "Doenças do Aparelho Circulatório" _, nos ano entre 2003 e 2007.

A Tabela 1 apresenta a quantidade de casos referentes às AIHs pagas no período de 2003 a 2007. Esses dados referem-se às informações contidas nos arquivos rdpsp.dbc para o município de São Paulo.

Tabela 1 - Total de internações hospitalares por ano, segundo local de residência, no município de São Paulo, Brasil - 2003 a 2007.

\begin{tabular}{l|lllll}
\hline & Total & Cap. 9 & \% & Cap. 10 & \% \\
\hline 2003 & 536.234 & 53.779 & 10,02 & 53.560 & 9,98 \\
2004 & 544.213 & 56.150 & 10,31 & 53.726 & 9,87 \\
2005 & 566.245 & 57.934 & 10,21 & 54.007 & 9,53 \\
2006 & 571.083 & 59.393 & 10,40 & 55.401 & 9,70 \\
2007 & 602.837 & 62.997 & 10,45 & 59.229 & 9,82 \\
& & & & & \\
\hline TOTAL & 2.820 .612 & 290.253 & 10,29 & 275.923 & 9,78 \\
\hline
\end{tabular}

Fonte: Datasus. http://msbbs.datasus.gov.br.

As internações por doenças do aparelho circulatório (Capítulo 9) correspondem a aproximadamente $10 \%$ do total das internações no período e as internações por doenças do aparelho respiratório representam em torno de $9 \%$.

Como foi dito anteriormente, o banco de dados das AIHs tem finalidade administrativa. Assim, uma internação ocorrida em um determinado ano pode ser processada no ano seguinte à internação ou nos anos subseqüentes. Por exemplo, no banco de dados de 2004 há informações sobre internações ocorridas em 2003, 2002, 2001, 2000 e assim por diante, ou seja, as informações referem-se ao ano em que os procedimentos com a internação foram pagos e não ao ano em que ela ocorreu.

Dessa forma, para obter o conjunto das informações de internação ocorridas em um determinado ano, reuniram-se todas as tabelas em um só banco de dados 
(2003 a 2008) ${ }^{7}$. A partir daí os dados foram selecionados pelo campo data de internação (DT_INTER). O próximo passo foi selecionar, a partir do diagnóstico principal (DIAG_PRI), as internações referentes às doenças referenciadas na CID 10 no Capítulo 9 - Doenças do Aparelho Circulatório (I00 - I99) e no Capítulo 10 Doenças Respiratórias (J00-J32; J40-J47; J80-J99) ${ }^{8}$.

O georreferenciamento dos dados foi feito a partir do Código de Endereçamento Postal (CEP) de residência do paciente, utilizando o programa Arcgis versão 9.2. Foi utilizada base de ruas com projeção SAD69. Os endereços cujos CEPs não foram localizados foram excluídos da análise.

Além dessa perda, foram descartadas as informações relativas às internações duplicadas, sendo considerado somente um dos eventos informado ${ }^{9}$. Concluído esse procedimento, obteve-se novo total de internações para o município de São Paulo, mostrado na Tabela 2.

Tabela 2 - Total de internações hospitalares, segundo doenças do Capítulo 9 e Capítulo 10 da CID, no município de São Paulo, Brasil - 2003 a 2007.

\begin{tabular}{l|llll}
\hline & Cap. 9 & \% & Cap. 10 & \% \\
\hline 2003 a 2007 & 283.323 & 10,0 & 242.826 & 8,6 \\
\hline
\end{tabular}

Fonte: DATASUS 2009. http://msbbs.datasus.gov.br.

A Tabela 3 mostra o total de internações hospitalares no período de 2003 a 2007, após a inclusão dos dados remanescentes do banco de dados de 2008 e a exclusão dos casos cujos CEPs não foram encontrados e dos dados duplicados. Os casos referentes a doenças do aparelho circulatório corresponderam a $10,0 \%$ e as doenças do aparelho respiratório 8,6\% em relação ao total de internações ocorridas no município.

Apesar de ser possível a desagregação até o nível do setor censitário, isso não foi realizado devido à falta de informação sobre a projeção populacional neste nível.

\footnotetext{
${ }^{7} \mathrm{O}$ ano de 2008 foi incluído, pois contém dados referentes a internações de 2007, 2006, 2005 e outros anos anteriores.

${ }^{8}$ Foram considerados somente os grupos da doença que possivelmente são afetados pelo ambiente atmosférico. Os códigos referentes à exposição a agentes externos às dos grupos J60 a J70, bem como causas não relacionáveis às condições climáticas - grupos J33 a J39 - não foram considerados.

9 Para maiores detalhes sobre procedimento de emissão das AIHs e duplicação dos dados ver PORTELA et al. (1997).
} 
Dessa forma, adotou-se o recorte espacial do distrito como menor nível de agregação dos dados. Sendo assim, o próximo passo foi separar as internações por faixa etária para o município de São Paulo e para o setor Sul/Sudeste, consistindo este último o universo da amostra considerada neste estudo (Tabela 3 ).

Tabela 3 - Total de internações hospitalares por ano, segundo doenças do Capítulo 9 e Capítulo 10 da CID e faixas etárias, no município de São Paulo e no Setor Sul/Sudeste, SP, Brasil - 2003 a 2007.

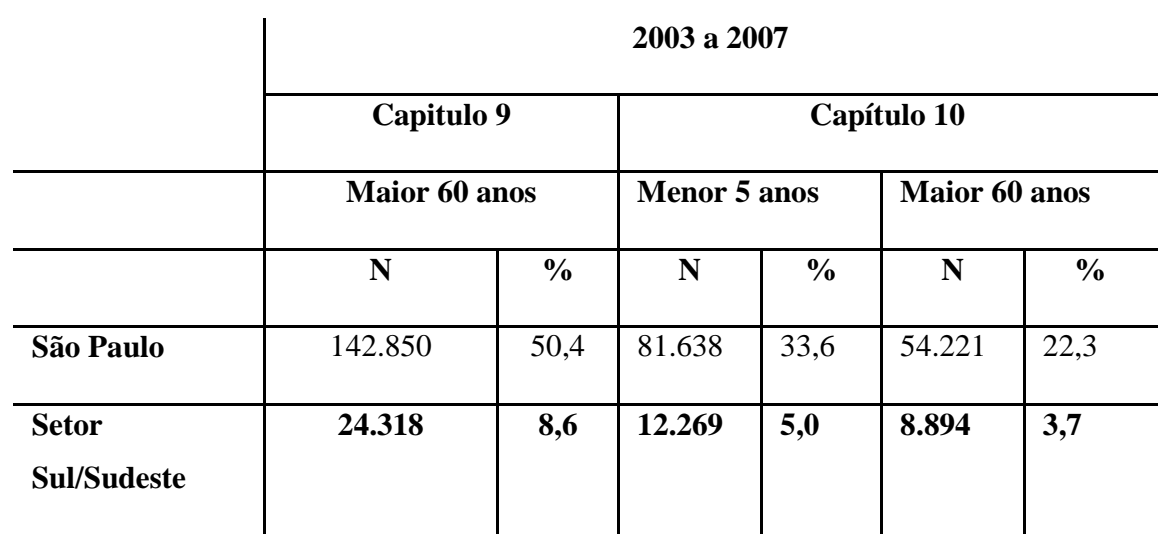

Fonte: DATASUS 2009. http://msbbs.datasus.gov.br.

Os casos de internação por doenças do aparelho circulatório - Capítulo 9 de pessoas maiores de sessenta anos corresponderam a 50,4\% das internações do município de São Paulo no período de 2003 a 2007 e 8,6\% das internações no setor Sul/Sudeste. No mesmo período, as internações por doenças do aparelho respiratório de crianças menores de cinco anos corresponderam a 33,6\% do total das internações no município e as internações pela mesma causa de pessoas acima de sessenta anos representaram $22,3 \%$. No setor Sul/Sudeste a proporção das em relação ao total das internações no município de São Paulo foi de 5,0\% e 3,7\% nas respectivas faixas etárias.

Portanto, o total de internações no setor Sul/Sudeste foi de 45.481 casos. Destes, 53\% (24.318) correspondem às internações por doenças circulatórias, $27 \%$ (12.269) às internações por doenças respiratórias em crianças de menores de cinco anos e $20 \%$ (8.894) às internações por doenças respiratórias em pessoas acima de sessenta anos. 


\subsection{Dados Climáticos e Bioclimáticos}

Neste item discute-se a escala climática escolhida para tratar da associação entre as condições atmosféricas e a ocorrência de doenças dos aparelhos circulatório e respiratório. Entende-se que a definição precisa da escala e sua articulação com escalas superiores (de maior abrangência espacial) e inferiores é fundamental nos estudos climáticos.

São, a seguir, caracterizadas as estações meteorológicas que originaram os dados utilizados nesta pesquisa, bem como descritas as características do uso do solo nos entornos de ambas as estações.

Os últimos subitens são dedicados à descrição das variáveis analisadas no estudo e ao comentário sobre a relevância de cada um deles para a abordagem aqui desenvolvida.

\subsubsection{A Escala Climática}

A definição da escala climática e a articulação com os níveis superiores e inferiores da atmosfera urbana são elementos importantes a serem considerados na observação e análise dos climas urbanos. Pesquisadores da área de climatologia geográfica reconhecem que a definição de escala em climatologia não é simples e há muita confusão entre os investigadores que se dedicam a esta temática (ANDRADE 2005; MONTEIRO 1976).

Nessa pesquisa optou-se por utilizar a definição de escala proposta pela WMO - Organização Meteorológica Mundial —, pois permite a comparação com estudos internacionais. Considerando-se a nomenclatura sugerida por esta organização, assume-se que neste trabalho foram verificadas as características dos atributos climáticos na escala local.

A escala local, segundo a Organização Meteorológica Mundial (WMO), compreende a área de abrangência das estações meteorológicas padrão. Nas áreas urbanas, representam a característica média do clima da vizinhança com tipos similares de desenvolvimento urbano (cobertura da superfície, tamanho e espaçamento dos edifícios, tipo de atividade predominante) que estão sendo captados. A área de abrangência varia de um a vários quilômetros. 
A escala local, neste estudo, está representada pelas duas estações meteorológicas situadas na área de abrangência do setor Sul/Sudeste. O Aeroporto de Congonhas caracteriza os aspectos da atmosfera mais impactada pelas alterações do entorno mais intensamente urbanizado e a EM-IAG/USP em uma área mais bem preservada, representando as características da atmosfera menos impactada pela ocupação urbana. intraurbana.

Nos estudos climáticos, a cada escala horizontal — referente à área de abrangência da superfície terrestre - corresponde uma escala vertical, que diz respeito à camada da atmosfera na qual é considerada a dinâmica dos atributos climáticos envolvidos. Nos estudos desta natureza, assim como em qualquer estudo que considere a dimensão espacial dos fenômenos, é importante que esteja clara a dinâmica dos fenômenos na escala adotada, sem perder de vista a articulação com as escalas maiores e menores.

Neste estudo optou-se por estudar os efeitos das condições atmosféricas sobre a saúde em uma escala local, de maior detalhe que a escala da cidade, mas sem chegar ao nível de detalhamento que propiciam os estudos em escala microclimática.

A cidade de São Paulo, considerada em sua totalidade, é representada pela escala superior chamada de Mesoescala, abrangendo a influência de toda a cidade sobre o tempo e clima. A abrangência espacial é de dezenas de quilômetros de extensão e a escala vertical é a Urban Boundary Layer - UCL, ou seja, a camada limite da atmosfera que envolve a cidade. (Figura 2). Para a caracterização do clima urbano, nesta escala, é necessária uma rede de observação de superfície e a articulação com as condições sinópticas.

Numa escala inferior encontra-se a escala Microclimática. Nessa escala, a caracterização do microclima relaciona-se a estruturas individuais, como prédios, árvores, rodovias, ruas, pátios e jardins. A abrangência espacial estende-se de pouco mais de um a centenas de metros. A camada atmosférica que a envolve é a Urban Canopy Layer - UCL, que compreende a camada de ar que vai da superfície até o topo dos edifícios. Caracteriza-se pela complexidade, principalmente derivada da natureza da cobertura da superfície (WMO 2008, OKE 1999). 
Para a finalidade deste estudo, porém, não foram consideradas exclusivamente as condições atmosféricas, mas igualmente alguns fatores socioambientais que intervém nas condições de saúde. Com o propósito de distinguir a escala climática local que considera apenas os fatores atmosféricos, do recorte adotado para a análise aqui empreendida, adotou-se a nomeação "escala intraurbana".

A Figura 2 mostra os diferentes níveis de organização (escalas vertical e horizontal) do clima urbano, segundo OKE (OKE 1999, WMO 2008).

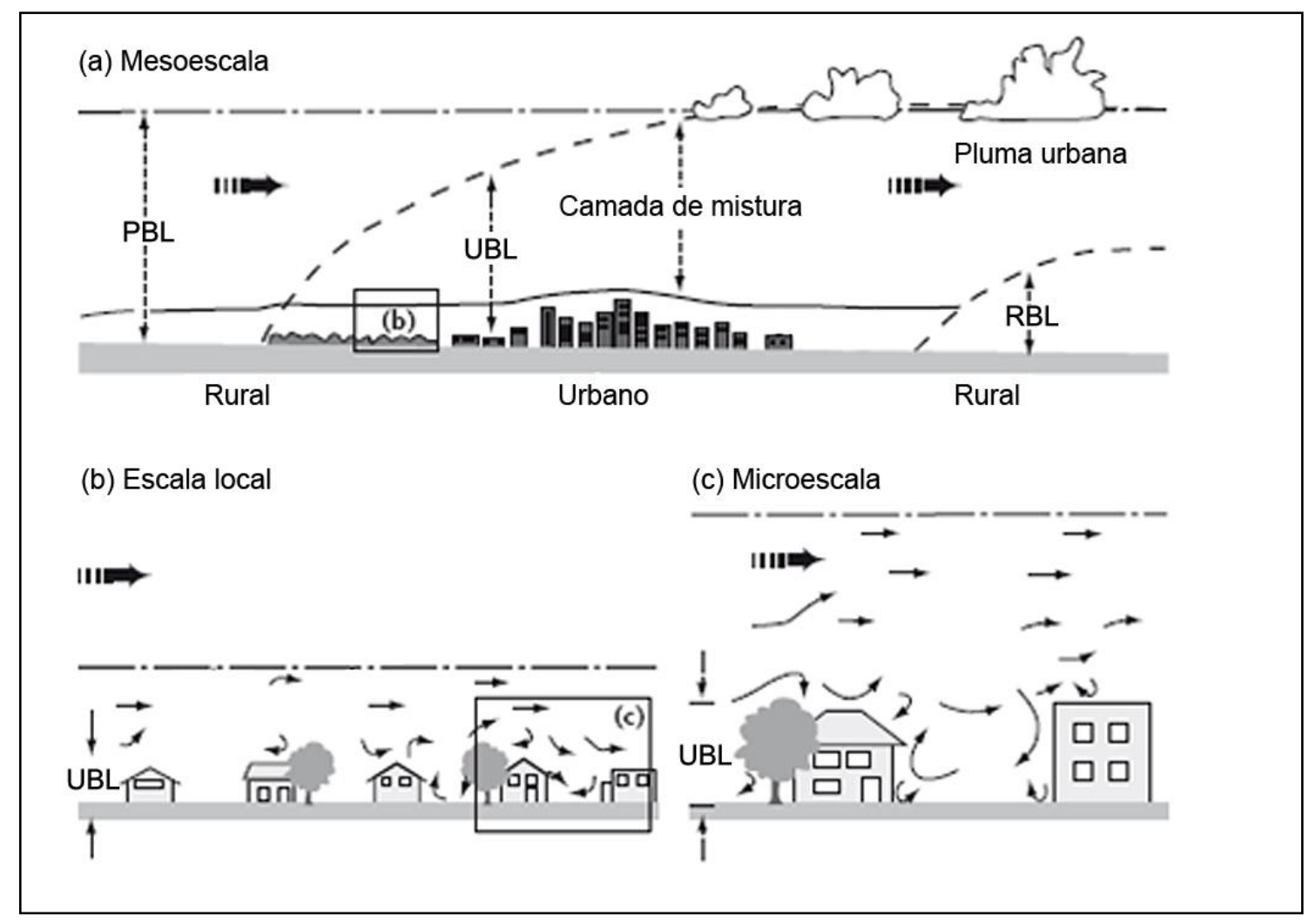

Figura 2 - Escala do Clima Urbano, adaptada da WMO 2008. 


\subsubsection{As estações meteorológicas}

O presente estudo investigou o ambiente atmosférico intraurbano a partir dos dados de duas estações meteorológicas: a EM-IAG/USP e a EM-CONGONHAS. As estações meteorológicas situam-se na porção sudeste da cidade de São Paulo, a primeira em uma área densamente arborizada - o Parque Estadual das Fontes do Ipiranga (PEFI) — e a segunda em uma região intensamente urbanizada (Figura 3).

a) EM-IAG/USP

A estação meteorológica EM-IAG/USP situa-se no Parque Estadual das Fontes do Ipiranga (PEFI) à latitude $23^{\circ} 39^{\prime} \mathrm{S}$ e longitude $46^{\circ} 37^{\prime} \mathrm{W}$, ao Sul do distrito do Cursino, bairro da Água Funda. Dista $11 \mathrm{~km}$ do centro, na zona sul do município de São Paulo, em uma altitude de 799,2 m, Está registrada na Organização Meteorológica Mundial sob o número 83.004.

b) EM-CONGONHAS

O Aeroporto Internacional de Congonhas está situado na área urbana do município de São Paulo, na latitude de 23 37’32”S e na longitude de $46^{\circ} 39^{\prime} 21^{\prime \prime} \mathrm{W}$. Localizado na porção SSW do distrito de Campo Belo, bairro do Jabaquara, está distante $10 \mathrm{~km}$ ao sul da Praça da Sé (marco zero). Trata-se de um local intensamente ocupado por edificações horizontais e verticais, vias de intenso tráfego terrestre como as Avenidas dos Bandeirantes e Washington Luis - além do tráfego aéreo.

\subsubsection{Variáveis Meteorológicas}

Foram utilizados dados diários de temperaturas média, mínima e máxima do ar $\left({ }^{\circ} \mathrm{C}\right)$, umidade relativa média do ar $(\%)$ e velocidade média do vento $(\mathrm{m} / \mathrm{s})$, obtidos das estações meteorológicas do IAG/USP e do Aeroporto de Congonhas - EMCONGONHAS. Os dados de Radiação Solar Global (MJ/dia) foram obtidos na EMIAG/USP. 


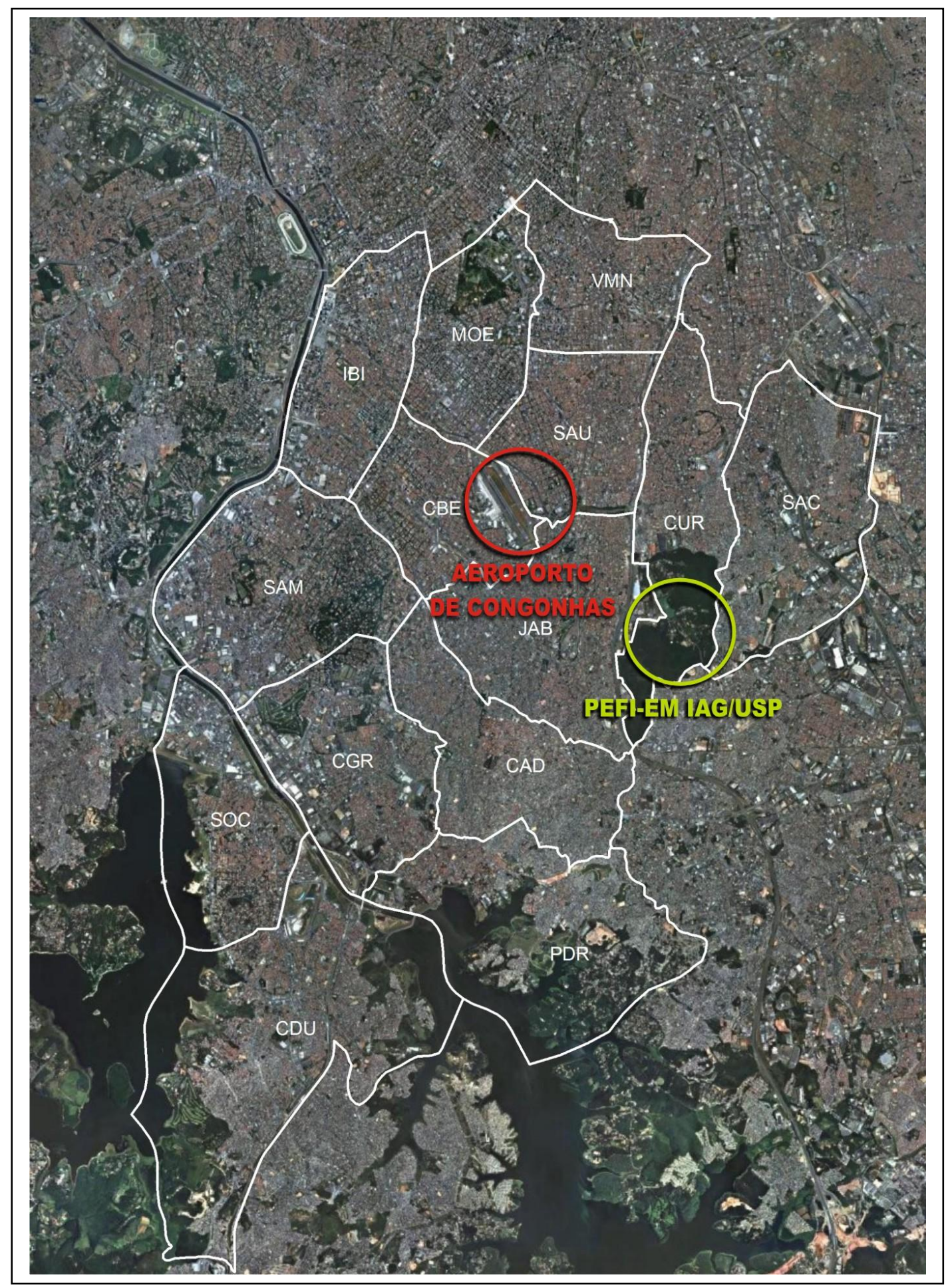

Figura 3 - Localização das Estações Meteorológicas IAG/USP e CONGONHAS, no setor Sul/Sudeste, município de São Paulo, SP, Brasil.

Fonte: Imagem Google Earth. 


\subsubsection{Cálculo do índice PET (Physiological Equivalent Temperature)}

O índice PET (Physiological Equivalent Temperature) foi desenvolvido por JENDRITZKY (publicado pela primeira vez em inglês em 1981), baseado nos trabalhos de Fanger e adaptado para situações externas (JENDRITZKY et al. 2001).

HÖPPE (1999, p. 263) define o índice PET de um determinado ambiente (interno ou externo) como a temperatura equivalente à temperatura do ar de um ambiente interno padrão (sem vento e sem radiação), em que o balanço de calor do corpo humano é mantido, com temperaturas do centro e da pele do corpo iguais às do ambiente de referência. Para o ambiente de referência são considerados: a taxa de metabolismo de trabalho $80 \mathrm{~W}$ e o isolamento térmico de 0,9 clo para vestimenta; a temperatura média radiante igual à temperatura do ar; velocidade do vento igual a 0,1 $\mathrm{m} / \mathrm{s}$; e pressão do vapor de $12 \mathrm{hPa}$, que equivale a $\mathrm{UR}=50 \%$.

O índice de conforto PET, neste trabalho, foi calculado utilizando o software Rayman versão 2.0, disponível gratuitamente no endereço http://www.mif.unifreiburg.de/rayman. Os parâmetros utilizados para o cálculo do índice PET foram: temperatura média do ar $\left({ }^{\circ} \mathrm{C}\right)$, umidade relativa média $(\%)$, velocidade média do vento $(\mathrm{m} / \mathrm{s})$ - obtido nas Estações Meteorológicas do IAG/USP e Aeroporto de Congonhas. Os dados de radiação global só estavam disponíveis na EM-IAG/USP; dessa forma, os valores do índice PET foram calculados com os valores de radiação global do IAG/USP para as duas localidades. Além dos parâmetros meteorológicos foram fornecidos dados de latitude, longitude e altitude da localização de cada uma das estações meteorológicas e o fuso horário da cidade de São Paulo.

As variáveis foram organizadas em uma única planilha, em uma seqüência estabelecida pelo software. O modelo rodado calculou os índices Predicted Mean Vote (PMV), Physiologically Equivalent Temperature (PET) e Standart Effective Temperature (SET), além de outras variáveis, como temperatura média radiante (tmr).

O índice de conforto PET foi calibrado para ser utilizado como parâmetro em áreas externas na cidade de São Paulo por MONTEIRO (2008, p. 187), que encontrou boa correlação $(0,84)$ entre esse indicador e as repostas dos entrevistados em sua pesquisa. O autor modificou a faixa de interpretação para avaliação da 
sensação térmica em espaços abertos mais abrangentes. A escala de interpretação constitui-se em um índice de temperatura equivalente à sensação térmica do indivíduo, conforme pode ser observado na Tabela 3.

Tabela 3 - Escala de interpretação para o índice de conforto PET calibrada para a cidade de São Paulo em ambientes externos.

\begin{tabular}{l|l|l}
\hline PET & $\begin{array}{l}\text { Sensação } \\
\text { Térmica }\end{array}$ & Estresse Fisiológico \\
\hline$<4^{\circ} \mathrm{C}$ & Muito Frio & Forte estresse de frio \\
\hline$<12^{\circ} \mathrm{C}$ & Frio & Moderado estresse de frio \\
\hline$<18^{\circ} \mathrm{C}$ & Pouco Frio & Leve estresse de frio \\
\hline $18^{\circ} \mathrm{C}-26^{\circ} \mathrm{C}$ & Confortável & Sem estresse térmico \\
\hline$>26^{\circ} \mathrm{C}$ & Pouco calor & Leve estresse de calor \\
\hline$>31^{\circ} \mathrm{C}$ & Calor & Moderado estresse de calor \\
\hline$>43^{\circ} \mathrm{C}$ & Muito calor & Forte estresse de calor \\
\hline
\end{tabular}

Fonte: MONTEIRO (2008, p. 180)

\subsubsection{Dados de Poluição Atmosférica}

Com o objetivo de incluir dados de poluição como parâmetro de controle, foram selecionados os índices de poluição atmosférica medidos na Estação de Monitoramento da Qualidade do Ar da Companhia Ambiental do Estado de São Paulo - CETESB, cujos equipamentos estão instalados a 3,5 m de altura. Situada no Bairro Aeroporto, zona Sul do município de São Paulo, à latitude 23³6'29”S e longitude 46³9'37' W, em uma altitude de $760 \mathrm{~m}$, a estação distancia-se aproximadamente 400 metros do Aeroporto de Congonhas (CETESB 2004).

O índice de qualidade do ar é um indicador qualitativo e é calculado a partir dos parâmetros de poluição e meteorológicos para cada poluente medido nas estações de monitoramento. $\mathrm{O}$ indicador divulgado refere-se ao pior indicador do dia no respectivo ponto de medição (CETESB 2009, p. 14). Assim, o índice de qualidade do ar de um determinado dia pode referir-se ao poluente $\mathrm{CO}$ e ao $\mathrm{MP}_{10}$ no dia seguinte. Os dados utilizados referem-se, então, aos indicadores qualitativos, como "bom", "regular" e "inadequado" sem, contudo especificar o poluente.

Segundo os padrões estabelecidos, considera-se que, quando a qualidade do ar é boa, praticamente não há risco à saúde. Quando a qualidade do ar é regular, sintomas como tosse seca e cansaço podem surgir entre os grupos sensíveis (crianças, 
idosos e pessoas com doenças respiratórias e cardíacas), e problemas de saúde mais sérios tem a probabilidade de ocorrer entre o grupo de risco e se estender a toda a população quando a qualidade do ar é inadequada a péssima (CETESB 2009).

\subsection{Análises dos dados}

A análise dos dados foi elaborada seguindo as seguintes etapas: a) características das variáveis meteorológicas das duas estações e do índice PET e a comparação entre as informações obtidas em ambas as estações; b) perfil temporal e espacial das internações hospitalares no setor Sul/Sudeste; c) associação entre as variáveis meteorológicas e as internações hospitalares.

\subsubsection{Aspectos climáticos e bioclimáticos do Setor Sul/Sudeste}

As variáveis meteorológicas e o índice de conforto foram organizados em planilha eletrônica Microsoft Office Excel 2003. A fim de caracterizar o aspecto do clima local e o comportamento das variáveis atmosféricas medidas nas duas estações meteorológicas e as influências dos seus entornos imediatos, foram feitos cálculos estatísticos descritivos; associação entre as variáveis (correlação de Pearson); elaboração de gráficos; e cálculo das diferenças entre as variáveis medidas nas duas estações meteorológicas. Foram utilizados o software Microsoft Office Excel 2003 para elaboração dos gráficos e tabelas, o software SPSS, versão 16, para elaboração dos modelos estatísticos de regressão e o software ArchGIS, versão 9.2, para a elaboração dos mapas.

\subsubsection{Análise das internações hospitalares no setor Sul/Sudeste}

A fim de analisar o perfil das internações hospitalares no setor Sul/Sudeste da cidade de São Paulo, do ponto de vista temporal e espacial, foram construídos gráficos e mapas temáticos, descritos a seguir:

- Gráficos de série temporal e suavização, utilizando média móvel de 30 dias $^{10}$;

- Gráfico boxplot ${ }^{11}$ do ritmo semanal e mensal de internação;

\footnotetext{
${ }^{10}$ A média móvel é construída considerando-se a média do dia mais os últimos 29 dias.

${ }^{11} \mathrm{O}$ boxplot (diagrama de caixa) é um gráfico que descreve simultaneamente várias características importantes de um conjunto de dados, tais como centro, dispersão, desvio e identificação das observações que estão longe do centro dos dados. Essas observações são chamadas de outliers (ESTANISLAU e SEGRI s/d).
} 
- Gráfico de incidência das internações mensais, por ano, padronizada por idade, por 10.000 habitantes, onde:

- Tx Inc. $=\quad \mathrm{n}^{\mathrm{o}}$ de internações/mês no distrito x 10.000 hab.

população da faixa etária no distrito

- Mapas temáticos da incidência anual, padronizados por idade, por 10.000 habitantes:

Tx Inc. $=\quad \mathrm{n}^{\mathrm{o}}$ de internações/ano no distrito x 10.000 hab.

população da faixa etária no distrito

\subsubsection{Associação entre as variáveis meteorológicas e as internações hospitalares}

Esta fase foi realizada seguindo diferentes etapas, em que se buscou verificar a associação entre o conjunto de internações hospitalares ocorridas nos 14 distritos selecionados para cada grupo de doenças — denominado setor Sul/Sudeste —, as variáveis meteorológicas e o índice de conforto térmico PET.

As seguintes análises foram realizadas:

1) Análise inferencial, utilizando Modelo Linear Generalizado com Distribuição Binomial Negativa (GLM), realizada pela equipe de estatísticos do Centro de Estatística Aplicada do Instituto de Matemática e Estatística da USP (MENEZES et al. 2009).

2) Análise de Regressão Logística por faixa de exposição das variáveis meteorológicas, controladas pelo indicador de qualidade do ar.

3) Análise de Regressão Logística por grupo de doenças e perfil socioambiental dos distritos do setor Sul/Sudeste. 
2.4.3.1 Análise inferencial GLM com distribuição binomial negativa

A análise inferencial foi realizada pela equipe de consultoria do Centro de Estatística Aplicada do Instituto de Matemática e Estatística da USP, sendo que detalhes do procedimento dessa análise podem ser consultados no relatório de Análise Estatística, sob código RAE-CEA09P18 (MENEZES et al. 2009). No entanto, a seguir são descritas as principais características desta etapa da análise.

A partir do conjunto de dados selecionados para este estudo, foi definido o Modelo Linear Generalizado com Distribuição Binomial Negativa (GLM) como melhor modelo para testar a existência de correlação entre as variáveis meteorológicas e o índice PET e as internações hospitalares. O modelo GLM com ajuste da distribuição binomial negativa foi escolhido, pois é considerado mais adequado para tratar variável discreta e porque no conjunto dos dados havia um número de dias com zeros, ou seja, nenhuma internação.

Nestas análises, decidiu-se utilizar os dados referentes à EM-CONGONHAS, por melhor representar as características do clima urbano. As variáveis explicativas utilizadas no modelo foram:

- Temperatura média do ar $\left({ }^{\circ} \mathrm{C}\right)$;

- Temperatura mínima do ar $\left({ }^{\circ} \mathrm{C}\right)$;

- Amplitude térmica $\left({ }^{\circ} \mathrm{C}\right)$;

- Índice de Conforto Térmico $\left({ }^{\circ} \mathrm{C}\right)$;

- Índice de Poluição do Ar (variável qualitativa).

As variáveis "ano" e "dias da semana", foram incluídas no modelo como controle. Sendo ambas variáveis qualitativas, o risco relativo estimado é construído em relação a um nível de referência. Para a variável "ano", considerou-se como referência o ano de 2003 e, para dia da semana, o domingo foi estabelecido como parâmetro.

Uma estrutura de defasagem (lag) de um e dois dias foi determinada. No Apêndice B estão os gráficos de ajuste do modelo.

\subsubsection{Análise de regressão logística por faixa de exposição}

As análises com o modelo GLM mostraram que as variáveis meteorológicas e de sensação térmica são capazes de explicar as internações hospitalares, no entanto, 
não foram capazes de responder às seguintes questões: Quais são os limites térmicos e as faixas de conforto mais agravantes para internações hospitalares por doenças respiratórias e circulatórias? Quais são as características desta associação quando considerados os dados da EM-CONGONHAS e da EM-IAG/USP?

Para responder essas questões foram elaboradas análises de regressão logística, utilizando o seguinte procedimento:

- Organizou-se o banco de dados com as informações diárias das internações, por grupo de pacientes;

- Calculou-se a incidência diária padronizada das internações hospitalares com base na projeção da população anual, por faixa etária, para os anos de 2003 a 2007 ;

$\mathrm{n}^{\mathrm{o}}$ de internações/dia x 10.000 habitantes

população da faixa etária do setor Sul/Sudeste por ano

- Calculou-se a mediana da incidência das internações. Foram estabelecidos como dias não doentes os valores abaixo da mediana e os valores acima da mediana como dias doentes, transformando a informação em variável dicotômica;

- A seleção das variáveis climáticas foi feita a partir do resultado do cálculo de regressão logística para cada variável, a fim de testar a significância estatística de cada uma delas. As associações cujo $p$ valor foi igual ou menor a 0,05 (ou 5\%) foram consideradas na construção dos modelos por faixa de exposição (Apêndice D).

- As faixas de exposição das variáveis meteorológicas foram estabelecidas a partir da técnica de quartis, ou seja, os dados foram separados em os valores abaixo de $25 \%$; entre 25 e $50 \%$, entre $50 \%$ e $75 \%$, acima de $75 \%$ da distribuição do conjunto de dados da EM-CONGONHAS. Para o índice de conforto foi utilizada a faixa de exposição determinada para a cidade de São Paulo, conforme Tabela 3. 
- A variável "poluente" foi categorizada em boa e ruim. A categoria ruim abrangeu os dias de qualidade do ar regular e inadequado. Foram feitos os cálculos de regressão logística com a variável qualidade do ar como controle.

2.4.3.3 Análise de regressão logística, segundo perfil socioambiental dos distritos do setor Sul/Sudeste.

Nesta fase, a análise de regressão buscou avaliar o impacto das variáveis atmosféricas na morbidade da população residente em áreas com diferentes padrões de ocupação, no setor Sul/Sudeste. Para isso, utilizou-se como referência o perfil socioambiental traçado pela Secretaria do Verde e Meio Ambiente para os distritos da cidade de São Paulo (SVMA 2004).

O Atlas Ambiental do Município de São Paulo estabeleceu o perfil socioambiental do município de São Paulo a partir da correlação entre os perfis ambiental $^{12}$ e socioeconômico ${ }^{13}$ dos distritos do município. Os 96 distritos foram reunidos em oito grupos (I a VIII) que expressam sua qualidade socioambiental. Os distritos referentes aos grupos I e II possuem a melhor situação e os grupos VII e VIII representam a pior situação. Nos demais distritos as condições socioambientais variam de média a ruim (SVMA 2004, p. 232-235). A Figura 4 mostra o mapa do perfil socioambiental dos distritos do setor estudado.

\footnotetext{
${ }^{12}$ Os indicadores ambientais foram construídos com base nos dados de vegetação e clima urbano.

${ }^{13}$ O perfil socioeconômico refere-se ao um índice que relacionou nove indicadores: densidade bruta; taxa de crescimento populacional; mediana da idade; renda média familiar; escolaridade média, segundo anos de estudo da população de quatro anos ou mais; taxa de mortalidade infantil; quota residencial $\left(\mathrm{m}^{2} / \mathrm{hab}\right)$ e porcentagem de população favelada; e taxa de mortalidade por causas externas (SVMA 2004, p. 222-230).
} 

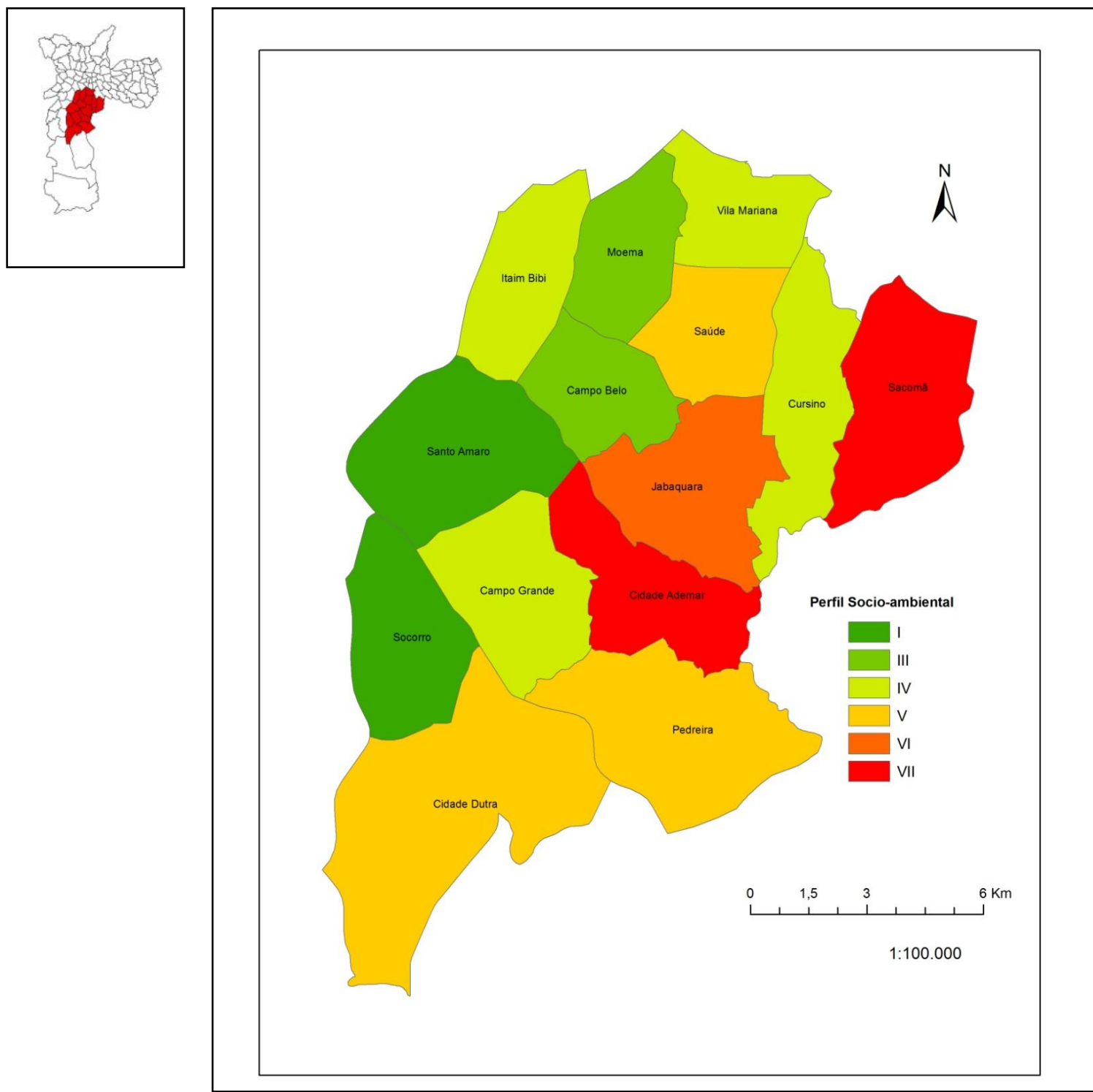

Figura 4 - Perfil socioambiental dos distritos, no setor Sul/Sudeste, Município de São Paulo, SP, Brasil.

Fonte: SVMA 2004 
Os distritos foram reagrupados a fim de obter uma amostra maior de dados de internação. Dessa forma, os distritos GI e GIII foram agrupados e denominados MELHOR, os distritos dos grupos GIV e GV foram designados de INTERMEDIÁRIO e os distritos dos grupos GVI e GVII foram categorizados como de PIOR condição socioambiental (Figura 5).

- A construção dos modelos seguiu as mesmas etapas elaboradas do item anterior, A seleção das variáveis climáticas que compuseram o modelo foi feita a partir do resultado do cálculo de regressão logística para cada variável individualmente. As associações cujo $p$ valor foi igual ou menor a 0,05 (ou $5 \%$ ) foram consideradas na construção dos modelos, por grupo de distrito (Apêndice D). 

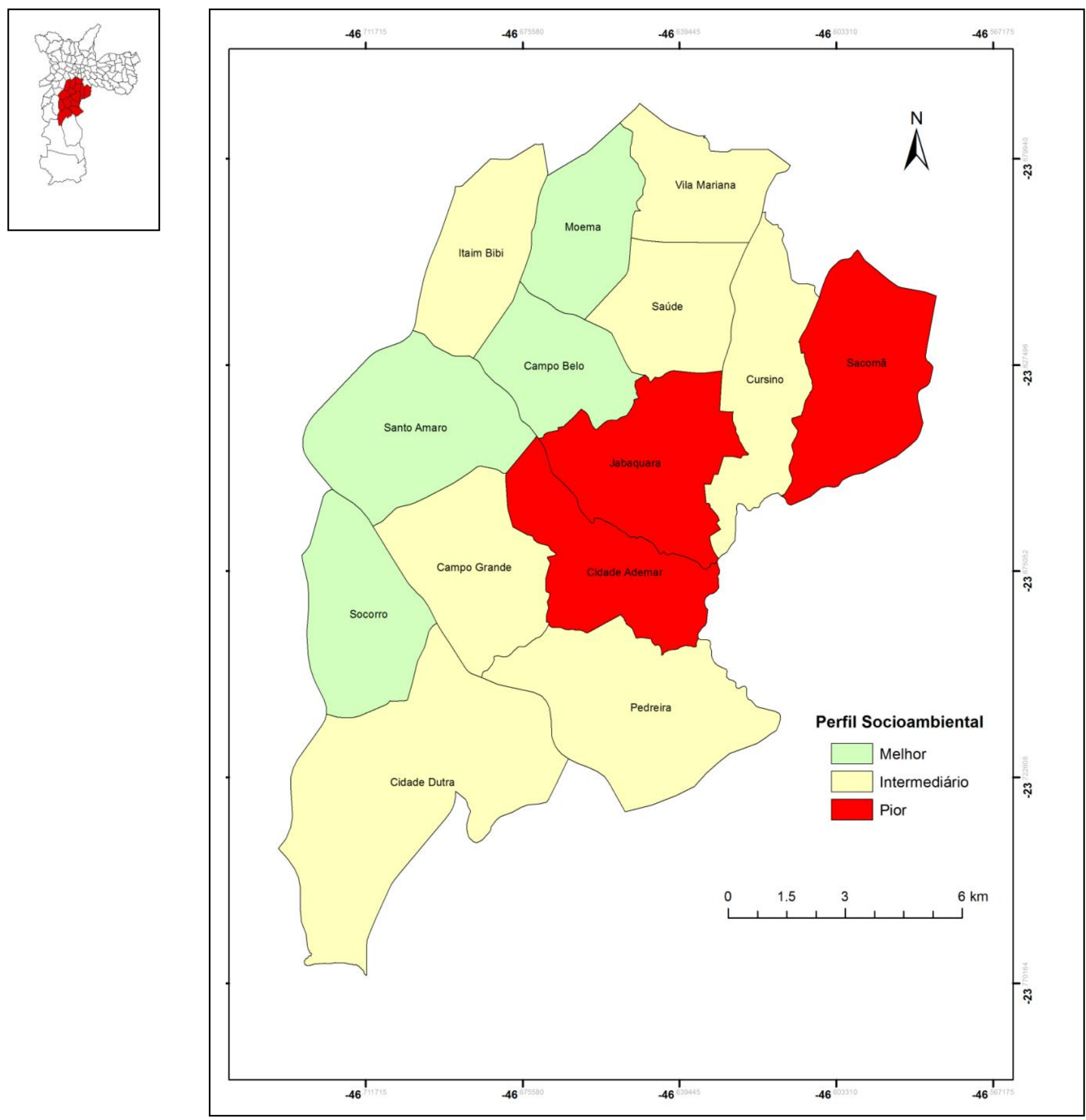

Figura 5 - Perfil Socioambiental dos distritos agrupados, no setor Sul/Sudeste, Município de São Paulo, SP, Brasil.

Fonte: SVMA 2004 


\section{AMBIENTE ATMOSFÉRICO}

Este capítulo expõe os conceitos que fundamentaram o desenvolvimento desta pesquisa. Inicia-se com a abordagem dos primeiros estudos sobre o clima urbano e a compreensão atual deste conceito. A seguir, distingue os conceitos de tempo e clima e mostra as diferentes concepções da Climatologia, da Biometeorologia e da Bioclimatologia Urbana acerca destes conceitos. A relação entre o clima e a saúde humana é abordada neste capítulo, com ênfase no conforto térmico, discutindo alguns dos indicadores desenvolvidos para avaliá-lo. Finalmente discutem-se os efeitos do clima sobre a saúde e bem-estar humanos a partir de uma revisão bibliográfica na literatura internacional e brasileira, com atenção particular às análises empreendidas no estado e na cidade de São Paulo.

\subsection{O clima urbano}

A produção do espaço urbano alterou significativamente as características climáticas locais, como amplamente descrito na literatura. É fato que, nas cidades, convive-se com o que se denominou clima urbano ${ }^{14}$.

A observação das alterações da atmosfera urbana e suas repercussões negativas no ambiente remontam ao século XIX, com o trabalho de Howard, em 1833, sobre o clima de Londres. Primeiro estudo dedicado ao clima das cidades, menciona as diferenças de temperatura entre o campo e a área urbanizada e descreve o problema das névoas urbanas (city fog) e as repercussões adversas à saúde (citado por LANDSBERG 1956).

Na segunda metade do século XX, os estudos relacionados à compreensão das alterações climáticas em áreas urbanas ganharam impulso, especialmente nos países do Hemisfério Norte. Em “O Clima das Cidades”, Landsberg discorre sobre os fatores que causam a modificação do clima nas cidades. $\mathrm{O}$ autor considera a poluição como a maior aberração atmosférica em relação às condições naturais trazidas pela urbanização (LANDSBERG 1956, p.586).

\footnotetext{
${ }^{14}$ Clima urbano é um sistema que abrange o clima de um dado espaço terrestre e sua urbanização (MONTEIRO 1976).
} 
OKE (1981) considera que a ilha de calor $^{15}$ é o exemplo mais claro de modificação não intencional do clima em áreas urbanas e que pode trazer conseqüências nocivas, tanto biológicas, como econômicas e meteorológicas.

A Tabela 4a apresenta as características típicas do clima urbano em relação às propriedades da superfície e da atmosfera e a Tabela $4 \mathrm{~b}$ mostra as modificações nas variáveis meteorológicas em áreas urbanas e sua magnitude, segundo OKE (1997).

A modificação da superfície da área onde se assenta a cidade tem implicações no balanço de energia, no balanço hidrológico e na ventilação da área urbana. Por sua vez, pode levar a alterações nos atributos climáticos, como a temperatura, a umidade, a formação de neblina e a precipitação (Tabela 4b).

OKE (1981) e LANDSBERG (1956) apontam, portanto, que as alterações climáticas no meio urbano geralmente trazem consequiências mais danosas do que benéficas para o homem e comprometem, de forma significativa, a qualidade do ambiente urbano.

\footnotetext{
${ }^{15}$ A ilha de calor urbana corresponde a uma área na qual a temperatura da superfície é mais elevada que nas áreas circunvizinhas.
} 
Tabela 4a - Propriedades da superfície e da atmosfera urbanas em comparação à rural

\begin{tabular}{lllll}
\hline Propriedade & Mudança & & \multicolumn{2}{c}{ Magnitude } \\
\hline Rugosidade linear & Maior & Rural: 0.01-0.5 $\mathrm{m}$ & Urbano 1.5-2.5m & Suburbano 0.6-1.0m \\
Albedo & Menor & Rural: 0.12-0.20 & Urbano 0.14 & Suburbano 0.15 \\
Emissividade & Maior? & Rural 0.92-0.98 & Urbano 0.94-0.96 & \\
Entrada térmica & Maior & Rural 600-2000 & Urbano 1200-2100 & Suburbano 800-1700 J m-2 ${ }^{-1 / 2} \mathrm{~K}^{-1}$ \\
Calor Antropogênico & Maior & Rural ausente & Urbano 50-100 Wm $\mathrm{Wm}^{-2}$ & Suburbano 15-50 Wm \\
Nuvens & Maior & Rural 2-5 x 10 & Urbano 103-104 cm & \\
\hline Fonte: OKE 1997, p. 275. & & &
\end{tabular}

Tabela 4b - Efeitos do clima nas áreas urbanas

\begin{tabular}{lll}
\hline Variável & Mudança & Magnitude da mudança ou comentário \\
\hline Turbulência & Maior & $10-50 \%$ \\
Velocidade do Vento & Diminui & $5-30 \%$ para $10 \mathrm{~m}$ com fluxo forte \\
& Aumenta & No fluxo fraco com ilha de calor \\
Direção do Vento & Alterado & $1-10^{\circ}$ \\
Tornados & Menos & \\
Radiação UV & Muito Menos & $25-90 \%$ \\
Radiação Solar & Menos & $1-25 \%$ \\
Entrada & Maior & $5-40 \%$ \\
infravermelho & de & \\
Visibilidade & Reduzida & \\
Evaporação & Menos & Aproximadamente $50 \%$ \\
Convecção & Maior & Aproximadamente $50 \%$ \\
Estoque de calor & Maior & Aproximadamente $200 \%$ \\
Temperatura do Ar & Mais Quente & $1-3^{\circ}$ a cada 100 anos; $1-3^{\circ}$ C média anual e mais de $12^{\circ}$ C a média \\
& & horária \\
Umidade & Mais seco & No verão durante o dia \\
& Mais úmido & No verão à noite, em todo o inverno \\
Nuvem & Mais neblina & Na direção do vento da cidade \\
& Mais nuvens & Especialmente a sotavento da cidade \\
Fog & Mais $\quad$ ou & Depende da quantidade de aerossol e do entorno \\
Precipitação & menos & \\
Neve & Menos & Algumas se convertem em chuva \\
Precipitação Total & Mais? & Mais a sotavento do que na cidade \\
Tempestades & Mais & \\
& &
\end{tabular}

Fonte: OKE 1997 p. 275. 
Para TAESLER (1986), o estudo do clima urbano pode ser considerado de dois pontos de vista: o da climatologia, cujo principal interesse é estudar o impacto da área urbana na atmosfera; e o do planejamento urbano e de projeto de edificações (building design), cujo interesse maior está na direção oposta, ou seja, estudar os impactos da atmosfera urbana nos aspectos funcionais, econômicos e de segurança do ambiente edificado na saúde e bem-estar de seus ocupantes (TAESLER 1986, p.201 citado por MONTEIRO 1990, p. 100).

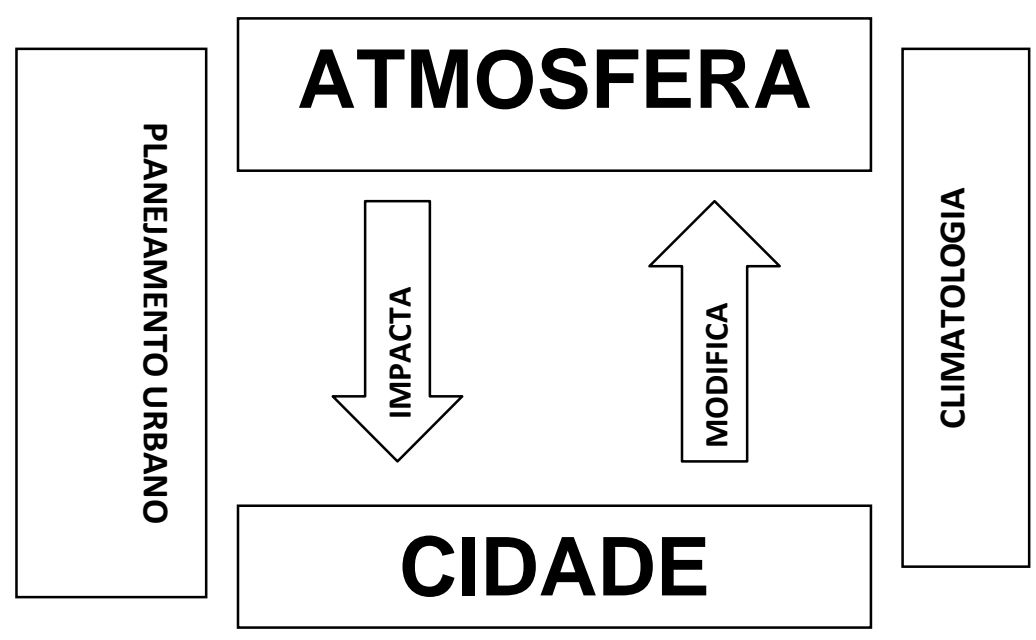

Figura 6 - Visões do clima urbano Fonte: Elaborado a partir de Taesler (1986, p. 201), citado por MONTEIRO (1990, p. 100).

Há necessidade de compreender como as alterações feitas pelo homem nas cidades modificaram as características climáticas locais. A busca desse entendimento se constitui no campo de interesse da climatologia urbana. O planejamento urbano, a climatologia aplicada e a bioclimatologia urbana têm como objetivo compreender como essas alterações interferem na qualidade do ambiente urbano e, consequentemente, na saúde e bem-estar dos citadinos. Essa compreensão deve levar, portanto, a intervenções que possam criar ambientes mais saudáveis.

O comitê de especialistas em biometeorologia da Sociedade Meteorológica Alemã definiu o clima urbano ideal como aquele que é espacialmente e temporalmente uma variável do estado da atmosfera dentro das estruturas urbanas, contendo o menor conteúdo de poluentes produzido pelo homem quanto possível. Além disso, a grande variedade espacial dos microclimas urbanos deve oferecer à população proteção às condições extremas (MAYER 1993, p.957). 
MAYER (1993) pondera, contudo, que "clima urbano ideal" de fato não existe, mas cabe à climatologia urbana aplicada indicar formas para aproximação a esta situação ideal e as medidas de planejamento a serem tomadas a fim de minimizar o estresse climático para os seres humanos, tendo como objetivo final a obtenção de um clima urbano tolerável.

\subsection{Biometeorologia e Bioclimatologia Urbana}

$\mathrm{O}$ ambiente atmosférico dos seres humanos refere-se ao tempo e ao clima. $\mathrm{O}$ estudo das interações e reações entre organismos vivos e o ambiente atmosférico desenvolve-se no campo da biometeorologia e/ou bioclimatologia.

Os conceitos de tempo e clima são diferentes, mas frequentemente são usados como sinônimos ou de forma inadequada. Tempo atmosférico refere-se à condição física e complexa da atmosfera atual em um período de algumas horas e até semanas. Já o conceito de clima refere-se ao aspecto de longo prazo (JENDRITZKY 1993, p. 734; LECHA 2009; MONTEIRO 1991, 2001).

SORRE (1984, p. 32) definiu o clima de um determinado local, como a série dos estados da atmosfera, em sua sucessão habitual. Esse conceito introduziu a noção de ritmo climático que, no Brasil, propiciou uma nova abordagem analítica dos estudos climáticos (MONTEIRO 1971, 1991). Segundo JENDRITZKY (1993, p. 734), o clima é parte inerente do ambiente, ou seja, é parte da base da existência da vida, sendo sua conservação e desenvolvimento uma importante responsabilidade pública. O clima envolve todas as condições meteorológicas e processos durante um período relativamente longo, mas um período limitado. $\mathrm{O}$ sistema clima refere-se à combinação dos mecanismos de retroalimentação não-linear de diferentes intensidades e com variação no tempo, bem como ao comportamento da atmosferahidrosfera-criosfera-superfície-biosfera. Os elementos considerados no clima são os mesmos daqueles considerados no tempo, variando da macro à micro escala.

O estudo da atmosfera e seu funcionamento é conduzido por alguns campos disciplinares, como a Física, a Meteorologia, a Climatologia, enquanto em outras áreas, como a Agronomia e a Arquitetura, por exemplo, o interesse concentra-se na aplicação desse conhecimento. 
Segundo alguns autores, a Meteorologia é parte da Física e ocupa-se em estudar a atmosfera como um todo. Produz informação básica sobre o comportamento atmosférico, através de normas e processos internacionalizados de sistematização e padronização, tendo uma aplicação prática, como a previsão do tempo, por exemplo. Dessa forma, a meteorologia ocupa-se da compreensão do tempo atmosférico, ou seja, com a caracterização da atmosfera em toda sua extensão (MONTEIRO 1991; LECHA 2009).

Segundo os autores acima citados é importante ter claro essa diferenciação conceitual, pois as análises meteorológica e climática diferem do ponto de vista metodológico, muito embora em alguns momentos sejam complementares.

A Climatologia é uma área de estudo da Geografia e o estudo dos climas consiste em um dos vários tópicos de seu objeto de estudo. A construção do conhecimento climatológico apóia-se na informação produzida pela observação meteorológica, mas centraliza sua preocupação naquela camada mais complexa e turbulenta da atmosfera - a troposfera inferior (MONTEIRO 1991, p. 17).

A biometeorologia e a bioclimatologia consistem num ramo do conhecimento da meteorologia e da climatologia e, portanto, têm enfoques diferentes. A Sociedade Internacional de Biometeorologia, reunida em Paris, em 1956, definiu Biometeorologia como o estudo direto e indireto das inter-relações entre o ambiente geofísico e geoquímico da atmosfera e os organismos vivos — plantas, animais e o homem. A Biometeorologia Humana, por sua vez, estuda a influência do clima e do tempo no homem (Sociedade Internacional de Biometeorologia - Paris 1956 citado por TROMP 1963).

Para HÖPPE (1993), a biometeorologia humana é a ciência da influência do ambiente atmosférico no homem; caracteriza-se pela interdisciplinaridade, de modo que necessita da colaboração de outros campos do conhecimento, tais como a biologia e a medicina.

JENDRITZKY (1993, p. 733) considera que a informação meteorológica tem características próprias e só se torna um parâmetro biometeorológico se este tiver relevância biológica: “Apesar dos efeitos das condições atmosféricas na saúde, bemestar e desempenho humano é necessário transformar a informação primária e torná- 
la biologicamente relevante." Para o autor, a Biometeorologia humana é parte da meteorologia ambiental. Ela cobre uma série de questões ambientalmente relevantes aplicadas à ciência médica.

Alguns autores ressaltam a importância da avaliação biometeorológica e bioclimática em áreas urbanas de climas tropicais. A condução de pesquisas em biometeorologia urbana ${ }^{16}$ tem sido apontada como importante área de estudo para entender as relações entre clima e saúde nas cidades, sobretudo naquelas de clima tropical, a fim de compreender tanto os processos que podem desencadear doenças como aqueles que criam ambientes saudáveis (JAUREGUI 1993; TROMP 1963; LACAZ 1972; WEIHE 1984).

A bioclimatologia humana aplicada às cidades relaciona-se com aspectos do clima urbano e sua influência no conforto e desconforto e na saúde humanos. Os efeitos do espaço urbano nos componentes do clima, tais como temperatura, umidade, radiação e vento - elementos importantes para a manutenção do balanço de calor do corpo humano - têm sido bem documentados em todo o mundo. Desse modo, considera-se que, atualmente, há uma base de conhecimento para a aplicação da avaliação biometeorológica e/ou bioclimatológica nas áreas urbanas.

Como foi referido anteriormente, nas investigações que relacionam saúde e atmosfera tem havido maior enfoque nos efeitos da poluição atmosférica. Atualmente, é amplamente reconhecido que a presença de poluentes na atmosfera apresenta efeitos deletérios à saúde. Assim, em muitos países, têm-se realizado esforços para diminuir a poluição do ar e estabelecer padrões mínimos para exposição humana a esse tipo de poluição.

Entretanto, a incorporação da avaliação bioclimática ou biometeorológica na análise dos climas urbanos pode estender o campo de pesquisas em clima e saúde, contribuindo para ampliar o conhecimento a respeito também dos efeitos danosos do ambiente termal à saúde.

\footnotetext{
16 A biometeorologia urbana é um dos ramos da biometeorologia cujo objetivo é estudar a influência dos microclimas das habitações e das cidades na saúde humana, bem como o efeito das construções e do planejamento das cidades nestes microclimas.
} 


\subsection{Relações do clima com a saúde humana}

Atmosfera é parte do ambiente no qual o organismo humano está mergulhado, numa interação complexa e em permanente estado de confrontação, para manter o balanço das suas funções vitais, ou seja, o equilíbrio entre a produção e a perda de calor. As reações do organismo podem ser compreendidas como uma resposta às mudanças dos estados químico e físico da atmosfera (JENDRITZKY 1993, 1995).

O homem é um animal homeotérmico, isto é, é capaz de manter a temperatura corporal interna constante independentemente das variações de temperatura do meio externo. Para manter o calor interno do corpo entre $36,5^{\circ} \mathrm{C}$ e $37,5^{\circ} \mathrm{C}$, os seres humanos desenvolveram um sistema chamado termorregulação, o qual representa um aspecto importante da adaptabilidade da espécie (MORAN 1994, p. 121, FROTA e SCHIFFER 2001).

O sistema de termorregulação mantém o equilíbrio térmico do corpo pela produção de calor como um subproduto dos processos metabólicos (termogênese) ou pela perda de calor para o ambiente (termólise). O calor pode ser recebido ou liberado por condução, convecção, radiação ou evaporação (MORAN 1994, p. 121; FROTA e SCHIFFER 2001), conforme ilustrado na Figura 7.

Dessa forma, quando o calor do ambiente excede a taxa de dissipação do corpo — a sensação produzida é de calor —, o sistema termorregulador trabalha para que ocorra perda de calor (termólise); nesse caso, é acionado o sistema de resfriamento do corpo, como por exemplo, o suor. Caso a taxa de dissipação exceda o calor do ambiente - sensação de frio - , o sistema termorregulador trabalha para que haja manutenção do calor interno do organismo (termogênese) e, então, é acionado o sistema de produção de calor, como por exemplo, o calafrio. Em ambas as situações, a sensação é de desconforto (MORAN 1994; FROTA e SCHIFFER 2001, p. 20).

O conceito de conforto térmico é complexo e subjetivo. Segundo AUCILIEMS (1997, p. 162) o conforto térmico é o estado mental obtido: 1) fisiologicamente, quando os mecanismos termorregulatórios são minimamente 
ativados e 2) psicologicamente, quando a percepção é de satisfação com o ambiente térmico.

Há quase um século, as pesquisas relacionadas ao conforto humano vêm desenvolvendo indicadores que medem as condições do campo térmico em relação ao homem. Vários índices de conforto térmico foram desenvolvidos, considerando principalmente temperatura, umidade e vento: a temperatura efetiva (ET), a temperatura efetiva corrigida (CET) e o Wind Chill são os índices de conforto melhor conhecidos (AUCILIEMS 1997).

Sendo assim, os índices de conforto são usados para avaliar a relação de troca de calor entre o campo térmico e o homem. Segundo MONTEIRO (2008, p. 142) há dois tipos de modelos de índices: os de conforto térmico, que verificam a sensação térmica, e os modelos de estresse térmico, que verificam o esforço fisiológico. 


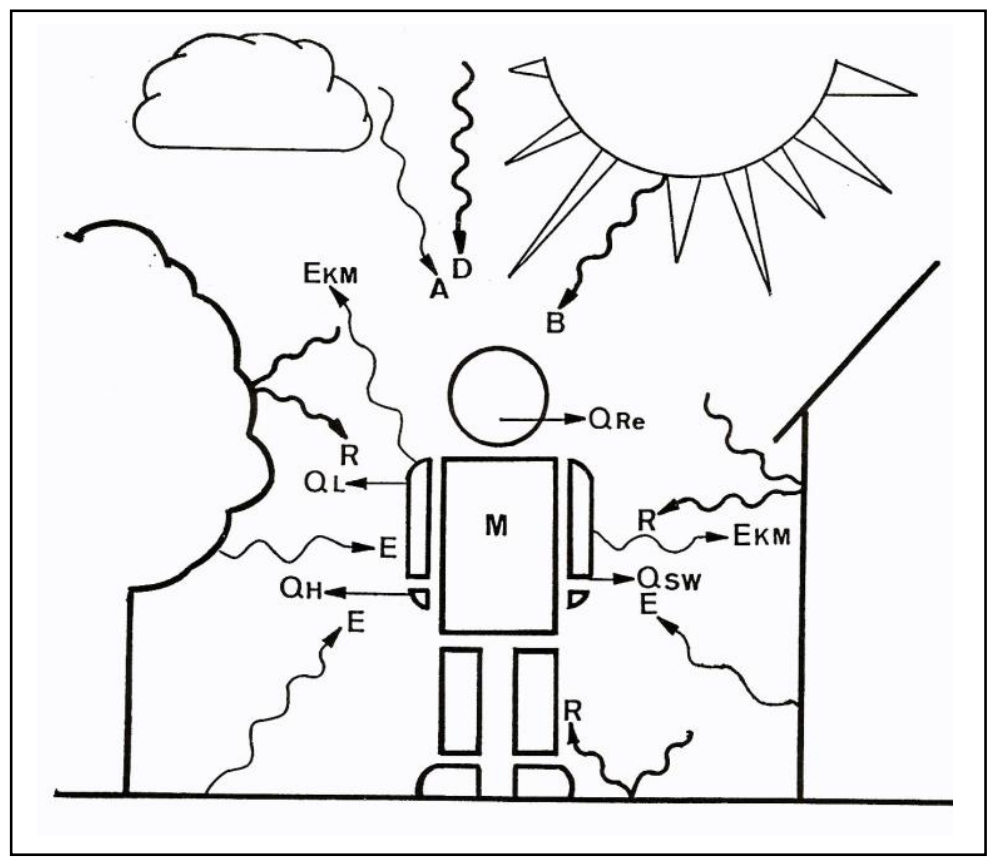

\section{Legenda:}

\begin{tabular}{c|l}
$\mathbf{M}-$ Taxa Metabólica & $\mathbf{I}$ - radiação solar direta \\
\hline $\mathbf{Q}_{\mathbf{H}}-$ Fluxo de calor sensível & $\mathbf{D}$ - radiação solar difusa \\
\hline $\mathbf{Q}_{\mathbf{S w}}$ - Fluxo de calor latente & $\mathbf{R}$ - radiação solar refletiva \\
\hline $\begin{array}{c}\mathbf{Q}_{\mathbf{L}}-\text { Fluxo de calor latente } \\
\text { pela difusão de vapor d'água }\end{array}$ & $\mathbf{A}$ - radiação refletiva pela a atmosfera \\
\hline $\begin{array}{c}\mathbf{Q}_{\mathbf{R e}}-\text { Fluxo da respiração } \\
\text { (sensível e latente) }\end{array}$ & $\mathbf{E}$ - emissão do entorno \\
\hline & $\begin{array}{c}\mathbf{E}_{\mathbf{K M}}-\text { radiação infravermelha emitida pela } \\
\text { superfície do corpo humano }\end{array}$
\end{tabular}

Figura 7 - Troca de calor entre ambiente e o homem - balanço energético Fonte: Jendritzky 1995. 
Embora exista uma grande quantidade de índices atualmente disponíveis, a maior parte deles foi desenvolvida para ambientes interiores e para climas temperados. FROTA e SCHIFFER (2001) consideram que alguns poucos têm aplicação no Brasil. As autoras relacionam os seguintes índices como os que apresentam melhores resultados ao serem aplicados para os climas brasileiros: a Carta Bioclimática de Olgyay; o Índice de Temperatura Efetiva de Yaglou e Houghthen - ou Índice de Temperatura Efetiva Corrigida de Vernon e Warner -; o Índice de Conforto Equatorial, também conhecido como Índice de Singapura de Webb; e o Diagrama Bioclimático de Givoni.

O Índice de Temperatura Efetiva (TE), um dos mais utilizados em estudos de bioclima em países tropicais, é considerado um índice de conforto térmico. Foi desenvolvido a partir das respostas subjetivas de conforto diante da variação das condições de temperatura do ar (ou de temperatura radiante), umidade e velocidade do vento; trata-se, portanto, de um índice subjetivo (MONTEIRO, 2008; FROTA e SCHIFFER 2001). Segundo MONTEIRO e ALUCCI (2007), os estudos realizados ao longo do século $\mathrm{XX}$ demonstram que os índices empíricos apresentam respostas significativas, mas apenas às situações específicas em que foram determinados.

Nos últimos anos, entretanto, tem havido um esforço dos pesquisadores em aprimorar os modelos e construir índices considerando as complexas condições do ambiente atmosférico e o balanço energético do organismo humano. Esses indicadores são construídos a partir de modelos analíticos e consideram um padrão de ambiente e característica humana (MONTEIRO e ALUCCI 2007).

Os índices de conforto complexos são indicadores que refletem a interação entre o homem e o seu ambiente termal e são calculados a partir dos seguintes parâmetros: a) do ambiente atmosférico, tais como temperatura do ar, umidade, velocidade do vento e radiação solar (temperatura térmica radiante); e b) individuais, os quais dependem do tipo de atividade, da vestimenta, do sexo, da idade etc. Em geral, os índices são elaborados a partir de amostras populacionais adaptadas a um determinado tipo de clima.

A bibliografia aponta a preocupação dos pesquisadores em aplicar esses índices em ambientes externos, especialmente nas áreas urbanas, a fim de avaliar as 
condições bioclimáticas com objetivos diversos como: no planejamento urbano, no turismo, na avaliação do clima e saúde etc. Os autores apontam a necessidade do caráter universal de um índice, ou seja, que possa ser aplicado em qualquer tipo climático e para todo tipo de pessoa (MATZARAKIS e MAYER 2000; JENDRITZKY et al., 2001).

MONTEIRO (2008) considera que a tendência atual nas pesquisas sobre conforto térmico é de se estabelecer um índice universal e realizar calibrações particulares que considerem os processos de adaptação e aclimatação dos habitantes nas regiões com diferentes tipos climáticos. Nesta perspectiva, o autor desenvolveu uma pesquisa, na cidade de São Paulo, e realizou a calibração de vários índices de conforto para serem usados em ambientes externos. O autor avaliou 72 situações ambientais na escala microclimática e entrevistou 1750 pessoas, encontrando boa correlação entre as respostas de sensação térmica e o índice PET $(0,84)$ e recomenda a utilização de uma faixa de interpretação de sensação térmica para os moradores da cidade de São Paulo MONTEIRO (2008).

Em outra linha de abordagem, o processo de adaptação do homem ao clima é considerado. Neste enfoque, encontra-se o estudo de LECHA (1998), que desenvolveu uma classificação biometeorológica com o objetivo de avaliar os efeitos à saúde em Cuba. $\mathrm{O}$ autor parte do princípio de que a população está adaptada a determinada condição climática e estabelece, a partir de um amplo estudo das variáveis meteorológicas, parâmetros para 18 tipos de tempo possíveis para aquele país, conjugando principalmente temperatura, umidade, nebulosidade e vento. $\mathrm{O}$ autor considera que os tratamentos estatísticos e índices desenvolvidos nos países de clima temperado não são adequados para a avaliação biometeorológica do clima tropical úmido cubano.

Do ponto de vista da saúde, a relevância da avaliação do ambiente térmico em áreas urbanas está na forte relação entre a termorregulação e a regulação circulatória e o ambiente atmosférico, ou seja, condições estressantes levam à sobrecarga no sistema termorregulador e ao comprometimento da saúde das pessoas, podendo, até mesmo, levá-las à morte. 
Há, portanto, a necessidade de compreender o impacto do ambiente atmosférico sobre as condições de saúde e bem-estar das pessoas, sobretudo em áreas urbanas, pois, segundo AUCILIEMS (1997, p.167), atribuir a morbidade e a mortalidade a um parâmetro específico pode ser errôneo e o fenômeno necessita ser tratado como parte da interação do complexo biológico-ambiente.

\subsection{Estudos sobre clima e saúde}

Em vários países, principalmente no Hemisfério Norte, estudos vêm sendo conduzidos a fim de compreender a influência da atmosfera/clima no desencadeamento, no aumento e no surgimento de doenças e vetores de doenças. Geralmente, são utilizados como indicadores as taxas de morbidade e mortalidade e a ênfase é dada a segmentos populacionais considerados mais vulneráveis, como crianças e idosos. Há grande variedade no uso de desenhos epidemiológicos estudos ecológicos, longitudinais, casos-controle, coorte - e métodos estatísticos correlação linear, modelos linear generalizados, regressão logística, entre outros.

Alguns estudos que analisaram doenças específicas, como as doenças respiratórias e cardiovasculares, mostraram que as pessoas são afetadas com o aumento ou diminuição das temperaturas. Em geral, as pesquisas utilizam a temperatura do ar e um índice de conforto térmico como parâmetros ambientais de exposição. Os trabalhos mais recentes têm utilizado índices complexos e têm encontrado associação entre esses indicadores complexos e dados de mortalidade e morbidade.

Alguns desses estudos apontam para uma forte correlação entre os eventos climáticos e as doenças; outros indicam conexões mais fracas entre ambos. A taxa de urbanização está fortemente associada ao excesso de mortes. O cálculo do excesso de mortalidade é apontado como um indicador mais importante do que o número absoluto de óbitos para explicar a associação entre a ocorrência destes e os parâmetros climáticos.

RUDEL et al. (2007) estudaram a relação entre os fatores meteorológicos e biometeorológicos e a mortalidade por doenças cardiovasculares em Viena, no verão (maio a setembro), no período de 1996 a 2005. As variáveis ambientais temperatura mínima diária (Tamin) e o índice PET (Temperatura Fisiológica Equivalente) foram 
usadas, respectivamente, como parâmetros meteorológico e biometeorológico de exposição. Foram selecionados os dias em que a taxa de mortalidade esteve entre $37 \%$ e $48 \%$ acima da média anual. A análise dos dados de mortalidade e as temperaturas limite de Tamin $>18^{\circ} \mathrm{C}$ e PET $>35^{\circ} \mathrm{C}$ mostraram claramente que os dias com PET $>35^{\circ} \mathrm{C}$ corresponderam, também, aos maiores valores de mortalidade. Durante o verão de 2003 , a soma dos dias com PET $>35^{\circ} \mathrm{C}$, bem como as taxas de mortalidade foram muito mais altos do que nos outros anos da série estudada. . Quando considerado a Tamin $>18^{\circ} \mathrm{C}$, pôde-se observar a mesma correlação. Os autores concluem que há um claro quadro de mortalidade relacionada ao calor e às condições selecionadas, ou seja, a PET para as tardes e a Tamin para as condições noturnas. Os autores ressaltam que se trata de estudo preliminar e que outros parâmetros - como as condições de poluição — deverão ser incluídos nas análises para verificar a mortalidade por todas as causas e não somente as cardiovasculares.

O’NEILL et al. (2005) estudaram como a poluição do ar e as epidemias respiratórias associam-se com as temperaturas extremas e a mortalidade diária na cidade do México e em Monterrey. Nesse estudo, os autores utilizaram como parâmetros a temperatura aparente, os $\mathrm{PM}_{10}$ e o $\mathrm{O}_{3}$. Foi avaliado o impacto da poluição do ar e das epidemias respiratórias na ocorrência das mortes e como estas associavam-se às temperaturas extremas. Foi observado excesso significativo de mortalidade nos dias de calor e de frio, nas duas cidades. Esta associação persistiu quando se controlaram os efeitos da poluição do ar, epidemias respiratórias e sazonalidade.

Os resultados das pesquisas que avaliam o impacto das variáveis atmosféricas sobre a mortalidade por todas as causas encontraram associação entre o aumento da mortalidade e as condições extremas de calor e frio. LASCHEWSKI e JENDRITZKY (2002) avaliaram as condições de exposição da população a partir de valores médios do parâmetro biometeorológico Temperatura Percebida (PT) e sua relação com a mortalidade, no Sudoeste da Alemanha, em 30 anos (1968-1997). Os resultados indicaram que a saúde da população no Sudoeste da Alemanha é sensível às condições térmicas ambientais. A mortalidade foi mais baixa durante as condições de conforto. Durante períodos com persistente estresse de frio, bem como de calor, as condições extremas influenciam a mortalidade. Sob condições moderadas, as 
mudanças nas características do tempo foram mais significativas, ou seja, o período de transição dos dias frios para os dias quentes resultaram em efeitos adversos à saúde, enquanto mudanças para dias frios foram protetoras, indicando maior adaptação da população ao frio.

Nesse trabalho é mostrado que a estação de transição do inverno para o verão resultou em elevação dos índices de mortalidade, quando comparada com o outono, nas mesmas condições. Os autores levantam a hipótese que a maior mortalidade na passagem para o verão tanto está relacionada à intensa atividade de adaptação no sistema regulatório quanto pode ser um indicador da relação indoor-outdoor, uma vez que as pessoas são mais expostas às condições externas no verão (LASCHEWSKI e JENDRITZKY 2002).

MARQUES (2007, p. 71) utilizou o índice PET para avaliar a mortalidade diária no distrito de Lisboa e concluiu que a relação do índice PET com a mortalidade diária é mais forte do que com a temperatura do ar. Considera que os índices de conforto - ao se basearem na ação combinada de diferentes variáveis atmosféricas -, explicam melhor a atuação sobre o organismo humano. Esta combinação afeta não só o conforto humano, mas também a saúde e, neste caso, em particular, a mortalidade diária no distrito de Lisboa durante o inverno.

DIAZ et al.. (2005) estudaram o efeito da temperatura extrema na mortalidade de idosos acima de 65 anos em Madrid, no período entre 1986 e 1997. Nesse trabalho, considerou-se a temperatura igual ou menor que $6^{\circ} \mathrm{C}$, em dias excepcionalmente frios (UCD). O efeito de UCD foi claro e a média do intervalo entre UCD e a ocorrência das mortes foi de oito dias. No entanto, a os valores de temperatura máxima do ar foram mais fortemente correlacionada com a mortalidade do que a temperatura mínima. A associação entre temperatura máxima e mortalidade mostrou dois picos de intervalo: entre quatro e cinco dias para causas respiratórias e entre sete e 14 dias para causas circulatórias. Os autores consideraram que o impacto associado às temperaturas extremas no inverno é muito diferente daquele relacionado às temperaturas extremas de verão.

Dados meteorológicos coletados em aeroportos foram utilizados na Itália (Roma, Turim e Milão) e na Austrália (Sydney). Os autores de ambos os estudos 
referem-se à relevância do uso de dados provenientes de aeroportos por sua alta confiabilidade, pelo seu padrão internacional e pela possibilidade de comparação tanto com outras localidades como com áreas urbanizadas e não urbanizadas ${ }^{17}$.

$\mathrm{Na}$ Itália, DONATO et al. (2008) avaliaram o impacto das variáveis meteorológicas na mortalidade por todas as causas para a população adulta maior de 35 anos, no período de 1997 a 2003, a partir de dados meteorológicos de aeroportos. Foram estudadas as cidades de Milão, Roma e Turim. Nas cidades de Roma e Turim, os aeroportos localizam-se, respectivamente, a 20 e $15 \mathrm{~km}$ dos centros das cidades; em Milão, o aeroporto dista $7 \mathrm{~km}$ da área central. $\mathrm{O}$ indicador de estresse térmico Temperatura Média Aparente (MAT) foi utilizado como parâmetro de exposição. O estudo mostrou que a temperatura média aparente (MAT) no aeroporto e no centro da cidade teve uma relação heterogênea com a mortalidade. A temperatura aparente para o aeroporto em Milão teve relação mais forte com a mortalidade do que a do centro da cidade. Quando considerada uma única exposição, observou-se efeito heterogêneo do aeroporto e do centro da cidade na mortalidade nas três cidades. Em Roma e Turim, a distribuição da MAT e o aumento da percentagem na mortalidade, em ambas as exposições, foram as mesmas para todas as condições consideradas.

VANECKOWA et al. (2008) estudaram o impacto dos parâmetros atmosféricos: temperaturas máximas e mínimas do ar, umidade relativa e pressão atmosférica diárias, na mortalidade diária por todas as causas, doenças circulatórias e respiratórias, no período 1993-2004, com dados obtidos na Estação Meteorológica do Aeroporto de Sydney, Austrália. Os poluentes $\mathrm{PM}_{10}$ e $\mathrm{O}_{3}$ foram incluídos na análise a fim de controlar o possível fator de confusão. O estudo mostrou que altas temperaturas resultam em aumento estatisticamente significante na mortalidade em Sydney, quando causas de morte previamente associadas com a temperatura cardiovasculares e respiratórias - foram consideradas. A população idosa foi a mais vulnerável, corroborando estudos anteriores em Sydney. O risco de morrer foi comparável com aquele encontrado em algumas cidades no sul dos Estados Unidos, mas, em geral, menor do que outros estudos em climas temperados ou em países de clima subtropical. Os autores apontam a faixa $23-24^{\circ} \mathrm{C}$ como aquela em que ocorreu

\footnotetext{
${ }^{17}$ No caso das cidades de Turim e Roma os aeroportos localizam-se em áreas distantes da cidade, em uma área não-urbanizada.
} 
a mais baixa mortalidade. $\mathrm{O}$ efeito da temperatura foi mais alto do que o da poluição atmosférica, mas ambos os poluentes $\mathrm{O}_{3}$ e $\mathrm{PM}_{10}$ são associados ao excesso de mortes, durante os seis meses mais quentes, em Sydney. Os autores consideram que, em Sydney, o material particulado permanece um importante assunto de saúde durante os meses mais quentes devido à incidência de incêndios florestais. A relação entre o $\mathrm{O}_{3}$ e a temperatura e a mortalidade foi considerada complexa e não pode ser explicada adequadamente no estudo. Outros poluentes atmosféricos, bem como suas interações com a temperatura e entre eles, podem também desempenhar um papel importante. Ainda que os idosos tenham sido apontados como grupo de alto risco, este não foi significativamente mais alto do que para todas as idades combinadas.

No Canadá, SMOYER et al. (2000) avaliaram a relação entre o estresse de calor e a mortalidade, em cinco cidades do Sudeste de Ontário, entre 1980 e 1996, para idosos acima de 64 anos. Nesse estudo, também foi considerada a temperatura aparente. Calculou-se o número de dias e o número de horas por dia em que a temperatura aparente ficou acima de $32^{\circ} \mathrm{C}$ para avaliar a aproximação e a duração dos episódios de estresse térmico. Os autores incluíram indicadores socioeconômicos, demográficos e habitacionais para identificar aspectos de adaptação e vulnerabilidade. A mortalidade entre os idosos foi significantemente mais alta nos dias de estresse de calor do que em dias de não-estresse, em todas as cidades, exceto em Windsor. As maiores correlações ocorreram em Toronto, London e Hamilton. As cidades com maior ocorrência de mortalidade, relacionadas ao calor, foram aquelas com taxas de urbanização relativamente mais elevadas e com alto custo de vida.

NASTOS e MATZARAKIS (2006) analisaram, em Atenas, a contribuição dos parâmetros meteorológicos na variabilidade total das infecções respiratórias (RI), no ano de 2002, a partir de consultas diárias. Utilizaram parâmetros meteorológicos diários medidos no Observatório Nacional de Atenas, como: temperaturas média, máxima e mínima, amplitude térmica, umidade e vento, considerando mudanças entre um dia e outro, bem como quatro parâmetros biometeorológicos: temperatura média radiante, PMV, PET e SET.. Os resultados evidenciaram a associação entre as condições atmosféricas e o número de consultas por infecções respiratórias. O intervalo entre o evento baixa temperatura e o pico de consultas foi de 
aproximadamente duas semanas e, em relação ao evento vento forte, de três dias. O parâmetro biometeorológico PMV foi fortemente relacionado com as consultas. Os autores consideram que os índices térmicos e a temperatura média radiante podem ser indicadores relevantes para a relação entre tempo e infecções respiratórias. Apontam, ainda, a necessidade de se avaliar modelos, em escala local e sazonalmente.

ALCOFORADO (1991) estudou a variação temporal do número de crises de dispnéia e a variabilidade do tempo atmosférico, no período entre 1988 e 1989, em Lisboa. Foi encontrada forte correlação entre o número de urgências e a temperatura dos três dias anteriores àquele em que o paciente recorreu aos Serviços Hospitalares. A diminuição da temperatura provocou o aumento das entradas. As correlações semanais ou de grupos de três dias foram mais fortes do que as correlações estabelecidas em nível diário. O estudo sazonal mostrou correlação forte (e negativa) entre a temperatura (sobretudo a mínima) e o número de casos urgentes tratados no Hospital, durante o outono, o inverno e a primavera. No entanto, no verão, as relações não foram evidentes. A correlação com as precipitações não foi significativa. A avaliação em relação à condição sinóptica mostrou frequências relativas mais elevadas a duas situações sinópticas completamente diferentes: tanto durante a ocorrência de situações anticiclônicas estáveis, com ventos fracos continentais, como durante situações perturbadas de Norte. Na primavera e no verão surgiu, freqüentemente, agudização dos problemas respiratórios durante situações de fluxo perturbado de Norte, embora o número de pacientes tenha sido relativamente elevado em certas situações anticiclônicas. A correlação com o estado do tempo mostrou que o aumento das crises de asma é proporcionalmente mais elevado nos episódios de ventos fracos de Leste e Nordeste, ventos fortes de Norte e também em dias de nebulosidade forte, associada aos ventos de quadrante Este. No entanto, a relação mais forte diz respeito à amplitude térmica diurna, diretamente proporcional ao número de casos de crises de asma. Os dias de bom tempo, com temperaturas elevadas de dia e muito baixas de noite (a que correspondem grandes amplitudes térmicas diurnas), ocorrem em situações anticiclônicas estáveis, em que existem condições para a acumulação de alérgenos junto ao solo, sua inalação por indivíduos sensíveis e, conseqüentemente, desencadeamento de crises de asma. 
$\mathrm{O}$ autor ressalta que melhor atenção tem sido dada, principalmente, à avaliação dos impactos das temperaturas extremas na saúde humana, impulsionados pela necessidade de melhor compreender os efeitos da possível mudança climática global, condição cada vez mais aceita em vários meios, desde o acadêmico-científico até o governamental.

Aqueles que focam as ondas de calor e as ondas de frio mostram que estas se constituem em grave problema para saúde da população, principalmente para aquelas pertencentes aos grupos de risco, ou seja, tanto os extremos de calor, quanto os extremos de frio relacionam-se com aumento da mortalidade e da morbidade, entre crianças e idosos, por exemplo.

Um exemplo recente refere-se à onda de calor, em 2003, que ocorreu no continente europeu. As temperaturas máximas atingiram valores iguais ou maiores a $40^{\circ} \mathrm{C}$. Recordes históricos dos parâmetros meteorológicos foram quebrados em alguns países, como na França, por exemplo, porém a duração do evento não teve precedente na Europa. Segundo DIAZ et al. (2006), apesar de o recorde de temperatura máxima $-50^{\circ} \mathrm{C}$ ocorrido em Sevilha, em 1881 - não ter sido atingido, o que mais marcou esse evento, na Espanha, foi a freqüência sem precedente da ocorrência de temperaturas máximas acima de $40^{\circ} \mathrm{C}$. Como consequência, houve aumento da mortalidade e da morbidade e as autoridades de órgãos de saúde atribuíram cerca de 30.000 mortes excedentes ao verão de 2003 em toda a Europa. Dessas, 50\% ocorreram na França (DIAZ et al. 2006, WHO 2004).

Uma revisão bibliográfica a fim de avaliar as informações epidemiológicas disponíveis sobre os estudos do impacto do calor sobre a saúde humana, conduzida por BASU E SAMET (2002), apontou que a temperatura ambiente é o parâmetro de exposição mais utilizado nesses estudos, bem como índices de exposição baseados na temperatura e umidade. Os resultados destas pesquisas apontam que a mortalidade aumenta durante as ondas de calor, sugerindo que as pessoas com doenças cardiovasculares e respiratórias têm um risco maior de morte associado à exposição ao calor; há alto risco para muitos grupos populacionais, incluindo idosos, crianças e pessoas de baixo status socioeconômico; outros fatores de risco específico incluem a falta de aparelhos de ar condicionado, a carência de meios de transporte, o uso de 
tranqüilizantes, a presença de doenças mentais e o fato de viver sozinho ou nos andares mais altos de prédios altos. Há estrutura de defasagem de 0-3 dias em que há o máximo de mortes, na sequiência das ondas de calor, indicando que a mortalidade relacionada ao calor é um evento agudo e requer intervenção imediata.

O EUROWINTER GROUP (1997) realizou estudo sobre o aumento da mortalidade sob baixas temperaturas (abaixo de $18^{\circ} \mathrm{C}$ ), em pessoas acima de 50 anos, entre 1992 e 1998, em oito regiões da Europa. O objetivo foi avaliar o impacto da diminuição das temperaturas no aumento da mortalidade por todas as causas, cardiovasculares, cerebrovasculares e respiratórias; medir a extensão da proteção pessoal contra o estresse de frio interno e externo para uma temperatura externa padrão; e relacionar as variáveis de proteção contra o frio. Os resultados mostraram que as taxas de mortalidade para todas as causas e de doenças respiratórias foram maiores com a queda na temperatura e que as medidas de proteção contra um dado grau de frio foram menores nas regiões com invernos medianos (menos frios). $\mathrm{O}$ mesmo é, em geral, verdadeiro para a mortalidade doença isquêmica do coração (IHD) e doenças cardiovasculares (CVD). Houve associação direta entre os índices de mortalidade e medidas de proteção contra o frio.

O estudo aponta que o excesso de mortalidade pode ser reduzido substancialmente pela melhora na proteção ao frio - particularmente em países com invernos mais quentes, onde a necessidade de evitar o frio é menos óbvia e nos quais as medidas tomadas contra o frio são menos efetivas. O estudo também recomenda melhorar a atenção da exposição das pessoas aos ambientes externos, uma vez que tais providências podem diminuir o impacto sobre a mortalidade, principalmente em países de climas mais quentes, onde as ações são falhas.

Em Cuba, utilizando a classificação biometeorológica, LECHA (1998) encontrou relação significativa entre incidência de doenças cardiovasculares e neurológicas e a ocorrência de estresse de calor, enquanto que a presença de dias frios e muito frios foi fortemente relacionada com o aumento de asma em adultos e crianças.

A questão da escala é um fator que chama a atenção nestes trabalhos. $\mathrm{Na}$ maioria dos trabalhos a cidade é considerada como um todo, pois, em geral, tanto os 
dados ambientais como os populacionais são mais disponíveis e acessíveis nessa escala. Há, portanto, carência de trabalhos em escalas de maior detalhe (setor censitário, bairros e domicílios etc.), o que pode ser explicado pela dificuldade de obtenção ou desagregação dos dados, pela falta de pessoal treinado e pelo maior período de tempo necessário para levantamento e organização dos dados, fatores que têm como consequiência um aumento de custo da pesquisa.

Assim, há forte preocupação, nesses países, em compreender os fatores associados aos agravos à saúde — derivados do ambiente térmico e outros fatores, como a poluição, por exemplo —, identificar os grupos vulneráveis e criar sistemas de alertas, de procedimentos de conduta e de atendimento emergencial para a população (WHO 2004, BASU e SAMET 2002, EUROWINTER 1997).

No Brasil, estudos vêm sendo conduzidos em vários centros de pesquisa e universidades, a fim de compreender os efeitos do clima sobre a saúde e bem-estar humanos, abrangendo equipes de pesquisadores de diferentes formações, destacandose, entre elas, a medicina, a epidemiologia, a meteorologia e a geografia.

Apesar de os estudos que relacionam temperatura e saúde — ou variáveis meteorológicas e saúde - não serem recentes, eles têm ganhado maior destaque nas últimas décadas, principalmente pela necessidade de melhor compreender os efeitos das alterações ambientais urbanas na saúde da população dos países tropicais e as possíveis vulnerabilidades frente às mudanças climáticas globais.

Diferentemente dos resultados encontrados nos países com clima temperado, as pesquisas conduzidas para identificar o impacto das temperaturas extremas no aumento da mortalidade, na cidade de São Paulo, mostraram resultados contraditórios. As investigações apontam ora o calor, ora o frio, como o fator mais fortemente associado às causas de mortes (cardiovascular e respiratória), enquanto outras sequer apontaram o calor como fator relevante. A faixa de 20 a $23^{\circ} \mathrm{C}$ é indicada como temperatura limite acima da qual há excesso de mortes (MCMICHAEL et al. 2008; BELL et al. 2008; GONÇALVES et al. 2005 e 2007; RIBEIRO SOBRAL 2005; GOUVEIA et al. 2003).

O fator de exposição utilizado, em geral, é a temperatura máxima do ar e o índice de conforto utilizado é a Temperatura Efetiva (TE), que considera as variáveis 
temperatura e umidade. Os parâmetros de poluição são incluídos nos modelos, com o objetivo de comparação entre estes e as variáveis meteorológicas. Alguns estudos relacionam os eventos de mortalidade ou morbidade com as condições sinópticas predominantes.

RIBEIRO SOBRAL (2005) estudou o impacto da ilha de calor urbana na mortalidade por doenças respiratórias e cardiovasculares em idosos e verificou maior risco de morte nas áreas onde a intensidade da ilha de calor é mais alta, mas o menor número de mortes ocorreu no verão e não foi observado excesso de mortalidade em dias com temperaturas acima de $35^{\circ} \mathrm{C}$. A autora considera que as diferenças diárias, como amplitude térmica ou oscilações entre um dia e outro podem estar relacionadas ao excesso de mortes e afirma que "há indicações de que o excesso de mortes está de certa forma relacionado a anomalias térmicas, nas diversas estações do ano, de forma diferenciada" (RIBEIRO SOBRAL 2005, p. 135).

GONÇALVES et al. (2007) buscaram avaliar como as variáveis ambientais - as variáveis meteorológicas, o índice de conforto Temperatura Efetiva (TE) e os poluentes $\mathrm{SO}_{2}, \mathrm{CO}, \mathrm{NO}_{2}$ e $\mathrm{PM}_{10}$ e $\mathrm{O}_{3}$ - afetam a variabilidade das doenças cardiovasculares (CVD) em São Paulo. Foi feita análise da série temporal de 1996 a 2000, para população maior de 65 anos. Os resultados mostraram claramente a variação sazonal nas taxas de mortalidade por CVD, as quais foram mais altas no inverno. $\mathrm{O}$ estudo apontou o tempo frio como condição de maior estresse, em que ocorreram mais mortes em São Paulo em relação ao tempo quente. O maior número de mortes ocorreu quando a temperatura efetiva foi menor do que $22^{\circ} \mathrm{C}$ e um pequeno acréscimo na mortalidade foi verificado quando a temperatura efetiva (TE) ultrapassou $30^{\circ} \mathrm{C}$. O estudo concluiu que o risco de morte por CVD devido ao frio é prevalecente. Uma estrutura de defasagem de três dias foi encontrada. Os poluentes apresentaram carga positiva em relação às mortes por $\mathrm{CVD}$, exceto o $\mathrm{O}_{3}$, embora menos significante estatisticamente.

GONÇALVES et al. (2005) examinaram o papel do tempo e dos poluentes atmosféricos no aumento da morbidade respiratória, durante os verões de 1992/1993 e 1993/1994, em São Paulo. Foram utilizados dados diários de admissão respiratória de crianças menores de 13 anos em 80 hospitais públicos. As variáveis de poluição 
utilizadas foram $\mathrm{PM}_{10}, \mathrm{SO}_{2}$, e $\mathrm{O}_{3}$ e as meteorológicas foram temperatura média, densidade do vapor de água e radiação solar. Foi aplicada média móvel de 3 dias para as variáveis meteorológicas e para os poluentes. $\mathrm{O}$ aumento da morbidade respiratória, em associação com o decréscimo da densidade de vapor de água e temperatura, indicou a influência dos fatores atmosféricos para a morbidade infantil. Os resultados mostraram que, durante um verão com pequenos contrastes na temperatura e pressão do vapor, a relação entre morbidade respiratória e poluição do ar — principalmente $\mathrm{O}_{3}$ — é mais observada (1992/1993). No entanto, sob condições de contraste sinóptico, uma forte relação entre variáveis atmosféricas - temperatura do ar e pressão do vapor - e morbidade respiratória pode ocorrer e o papel dos poluentes é minimizado ou não é claro. A investigação sugere a existência de uma relação complexa e possivelmente não linear, que pode variar de um verão para o outro.

Um estudo recente conduzido por MCMICHAEL et al.(2008), em 12 cidades com médio e baixo nível de desenvolvimento econômico ao redor do mundo, abrangendo países da Ásia, América, Europa e África - o "ISOTHURM project" —, avaliou os impactos dos extremos de temperatura na mortalidade. Os autores argumentam sobre a necessidade de dimensionar a vulnerabilidade da população residente nestes locais às possíveis mudanças climáticas globais e de estender as pesquisas para melhorar a compreensão do papel da adaptação das populações. Os autores ressaltam que as populações podem se tornar menos sensíveis aos efeitos do calor devido ao desenvolvimento econômico, mas que o rápido crescimento sem planejamento pode ter efeitos adversos no saneamento, na poluição do ar e nas condições de moradia e acrescentar maior vulnerabilidade no futuro. Melhorar a qualidade da moradia, ampliar o acesso à tecnologia, compreender os aspectos da topografia local e do desenho urbano, bem como os fatores comportamentais, são aspectos apontados para melhorar a capacidade adaptativa nos climas atuais e futuros. A pesquisa referida acima envolveu pesquisadores de vários países e descreveu a mortalidade por todas as causas (exceto causas externas), relacionada ao frio e ao calor. Mostrou que, tanto nas duas cidades brasileiras estudadas - São Paulo e Salvador —, como nas demais cidades, há associações positivas entre mortalidade e temperatura. Todas as cidades com temperaturas mínimas baixas e alta 
amplitude térmica apresentaram larga flutuação sazonal na mortalidade, com as mais altas taxas de morte ocorrendo em períodos relativamente frios, exceto para Delhi, onde ocorreu logo após o final das monções. Os dados sugerem que o calor contribuiu para a mortalidade por doenças cardiovasculares na maioria das cidades, e indicaram que nas cidades européias as mortes também se relacionaram ao frio. A mortalidade por doença respiratória aumentou com o calor em Bucareste, Sofia, Salvador e São Paulo, e, com o frio, no México, São Paulo, Santiago e Cape Town. Foi avaliado o limite de temperatura em que há aumento da mortalidade; em São Paulo, o limite encontrado foi de $21^{\circ} \mathrm{C}-23^{\circ} \mathrm{C}$, com aumento na mortalidade acima do limiar de calor $\left(23^{\circ} \mathrm{C}\right)$. Para o frio, o impacto na mortalidade parece acumular por longo tempo e não houve evidência clara de mortalidade em curto prazo. Foi observado que o padrão de mortalidade relacionada à temperatura é influenciado por fatores climáticos e não-climáticos (MCMICHEL et al. 2008).

BELL et al. (2008) examinaram a vulnerabilidade da mortalidade relacionada ao calor em três cidades da América Latina: São Paulo, no Brasil, Santiago, no Chile e Cidade do México, no México, de 1998 a 2002. Foi aplicado desenho epidemiológico de caso-controle para estimar a exposição-resposta não-linear das cidades específicas e a relação entre o tempo meteorológico e o risco de mortalidade total, cardiovascular e respiratória. Foi investigada a estrutura de defasagem da exposição e a suscetibilidade da mortalidade pelo sexo, idade e nível educacional. Os parâmetros meteorológicos utilizados foram a Temperatura Equivalente (Temperatura e Umidade) e os poluentes PM10 e O3. Altas temperaturas foram associadas com o risco de mortalidade nas cidades da América Latina estudadas, porém com natureza de associação diferente entre as cidades. Os resultados apontaram o alto risco de mortalidade relacionada ao calor para o grupo etário de 65 e mais anos, apesar de a vulnerabilidade por sexo e educação ser diferente entre as cidades. Em todas elas mais mortes foram atribuídas às causas cardiovasculares e respiratórias. O limite de temperatura aparente média acima da qual ocorreram mais mortes foi de $17,6^{\circ} \mathrm{C}$ e $20,9^{\circ} \mathrm{C}$ para Santiago, $25,0^{\circ} \mathrm{C}$ e $28,0^{\circ} \mathrm{C}$ para São Paulo e $16,3^{\circ} \mathrm{C}$ e $18,3^{\circ} \mathrm{C}$ para a cidade do México.

Os autores consideram que a compreensão da natureza da vulnerabilidade da população com respeito a temperaturas extremas é de essencial importância dado o 
potencial das mudanças climáticas para aumento das temperaturas e freqüência das ondas de calor. Pesquisas relacionadas à mortalidade relacionada ao calor requerem não somente a função exposição-resposta da temperatura e mortalidade, mas informações sobre as distinções dessas associações em diferentes áreas da cidade, como a susceptibilidade difere na população dentro da comunidade e como tais fatores (distribuição da idade, por exemplo) pode mudar com o tempo. Estudos futuros da relação entre temperatura e saúde, incluindo variação na vulnerabilidade, nas diferentes regiões, podem contribuir para o esforço de direcionar a compreensão dos efeitos do calor na saúde humana como conseqüência das mudanças climáticas.

GOUVEIA et al. (2003) realizaram um estudo relacionando as diferenças socioeconômicas, mortalidade e temperatura na cidade de São Paulo. A pesquisa considerou dados diários de mortes por diferentes causas (exceto mortes violentas), dados diários de temperatura no período 1991-1994. Foi observado aumento na mortalidade quando houve elevação de temperatura acima e queda abaixo do limite de $20^{\circ} \mathrm{C}$. Os grupos mais afetados foram os das crianças e dos idosos. O estudo não encontrou diferenças significantes nos estratos sociais, mas os autores consideraram que os resultados podem ter sido obscurecidos pelo fato de a pesquisa ter considerado os distritos e que estes são grandes e heterogêneos.

Buscando avaliar o impacto do ambiente térmico e as condições de moradia, na cidade de São Paulo, CARDOSO (2007) e NEDEL (2008) avaliaram o ambiente térmico interno das residências e a incidência de doenças respiratórias em crianças. CARDOSO (2007) conduziu dois estudos epidemiológicos (caso-controle e coorte) que associaram o micro-clima do ambiente interno das residências e as doenças respiratórias. Ambos os estudos mostraram que a amplitude térmica e a umidade do ambiente interno relacionam-se à maior incidência das doenças respiratórias. Para cada $1^{\circ} \mathrm{C}$ de aumento na amplitude térmica interna diária foi associado um aumento de cerca de $6 \%$, no primeiro estudo, e de $9 \%$, no segundo, na incidência de doenças respiratórias do trato inferior em crianças pequenas. Essas condições foram encontradas em residências de construções precárias, evidenciando que estas não protegem os habitantes dos efeitos climáticos externos. 
NEDEL (2008) avaliou o conforto térmico no interior das residências e as relações existentes entre variáveis meteorológicas, os tipos construtivos e os problemas respiratórios em crianças recém nascidas, na cidade de São Paulo, no período de janeiro de 2003 a julho de 2006, utilizando o índice de conforto Temperatura Efetiva (TE). O autor aponta que tanto o aspecto construtivo quanto a localização geográfica (microclima) têm um papel importante com relação ao aparecimento de chiado nas crianças. As crianças que moram em residências com estruturas construtivas deficientes apresentam maiores problemas de chiado. $\mathrm{O}$ estudo também aponta o elevado grau de umidade interna como fator prejudicial à saúde infantil. Ao avaliar as condições externas, mostra que o aparecimento do problema pode ocorrer no mesmo dia em que a temperatura externa cai ou em média de dois dias, quando a residência tem melhor isolamento térmico. A poluição externa também mostrou ser um fator importante, pois dois episódios de chiado ocorreram quando somente havia altas concentrações dos poluentes atmosféricos sobre São Paulo. Houve concordância dos dados de temperatura e conforto térmico interno e externo.

Em outras cidades do Brasil os estudos mostraram impacto na saúde da população decorrente de diferentes condições atmosféricas.

PITTON E DOMINGOS (2004) estudaram as relações entre crises hipertensivas e tipos de tempo segundo interpretação da circulação atmosférica regional a partir de imagens de satélite e cartas sinóticas nos residentes urbanos de Santa Gertrudes, SP, entre 1999 e 2001. Foram investigados dados de morbidade de hipertensos obtidos no Centro de Saúde de Santa Gertrudes. Os dados climatológicos locais utilizados foram: pressão atmosférica, umidade relativa, temperatura do ar e precipitação durante o período. As autoras concluíram que os dias com maior número de crises hipertensivas estiveram relacionados às chuvas isoladas ou aos longos períodos de seca, às maiores amplitudes térmicas ou às mudanças bruscas do tempo atmosférico e aos dias secos, ou seja, com baixos valores de umidade relativa.

BOTELHO et al. (2003) estudaram a influência das variáveis meteorológicas nos períodos climáticos (seco ou chuvoso) e as hospitalizações de crianças menores de 5 anos com problemas respiratórios. O estudo avaliou os prontuários do Pronto 
Socorro de Cuiabá (PSMC), Mato Grosso, Brasil, no período de janeiro a dezembro de 1999. As variáveis meteorológicas foram médias mensais de temperaturas média, máximas e mínimas, umidade relativa e focos de calor. Foram considerados os períodos seco (maio-outubro) e chuvoso (novembro-abril). A análise estatística dos dados foi feita com testes do qui-quadrado, ANOVA e Krustal-Wallis. A taxa de hospitalização por infecção respiratória aguda (IRA) encontrada, neste estudo, foi cerca de três a quatro vezes superior aos outros resultados apontados na literatura. Os resultados analisados permitiram concluir que a prevalência das infecções respiratórias agudas em crianças menores de cinco anos atendidas no PSMC é alta e está associada ao período seco do ano, à baixa umidade relativa do ar. CASTRO (2000) utilizou a abordagem rítmica para a associação das patologias do aparelho respiratório e os tipos de tempo no inverno em Rio Claro, SP, Brasil. Foram usadas as variáveis meteorológicas e de poluição do ar e dados de morbidade, dos invernos de 1995 a 1997. A análise dos dados foi feita a partir de estatística descritiva, elaboração de gráficos e cartas. O estudo mostra que houve correlação entre temperaturas médias mensais e óbitos por infecções respiratórias agudas (IRA), em Rio Claro. Observou-se que, em temperaturas abaixo de $20-21^{\circ} \mathrm{C}$, há maior número de mortes. A estabilidade causada pelas massas de ar polar tropicalizada e tropical tropicalizada e tropical atlântica exacerbou a morbidade e também a mortalidade por afecções respiratórias. $\mathrm{O}$ autor ressalta que a análise rítmica permitiu a representação conjunta dos elementos do clima: a variação e a representação diária dos parâmetros meteorológicos e de circulação atmosférica; a interação com o espaço urbanizado (topografia, uso do solo, distribuição espacial das indústrias e tráfego de veículos); a distribuição espacial das doenças respiratórias; e a análise têmporo-espacial, relacionando os estados atmosféricos com a incidência de morbidade.

SOUZA (2007) estudou a associação entre as variáveis meteorológicas e internações na área urbana de Presidente Prudente, no período de 2000 a 2005. A autora utilizou a metodologia rítmica na análise dos dados meteorológicos e associação com as internações hospitalares das doenças respiratórias. A análise dos dados mensais mostrou correlações entre as internações hospitalares (AIHs) e dados meteorológicos. A autora ressalta que períodos de estiagem prolongada, oscilações e quedas de temperatura e umidade relativa — na maioria das vezes, abaixo de $60 \%$ - 
estiveram presentes nos momentos em que houve aumento do número de casos de internação por agravos respiratórios. Ocorreu diminuição de casos nos períodos em que os sistemas frontais e sua instabilidade atmosférica, com o aumento dos ventos e das pancadas de chuvas, por isso, a autora considera que esses sistemas são "purificadores" do ar instalado no ambiente urbano.

BARROS (2006) estudou a ocorrência de doenças respiratórias e os tipos de tempo, utilizando a metodologia rítmica, na cidade de Brasília-DF. A autora aponta que o aumento nos atendimentos em prontos-socorros por doenças respiratórias ocorre quando há diminuição da umidade e da temperatura, bem como pelo aumento na amplitude térmica, condições típicas durante o outono e o inverno, quando há ocorrência de tipos de tempo seco.

Em modelo de estudo epidemiológico de coorte, GONZÁLES et al. (2008) avaliaram a relação entre o mês de nascimento e dois grupos de desfechos: hospitalizações por doenças respiratórias no período pré-escolar e diagnóstico de asma na vida adulta, em indivíduos pertencentes a uma coorte na cidade de Pelotas, RS, Brasil (1982-2005). Foram avaliadas 5.914 crianças nascidas nos três hospitais da região urbana em 1982, correspondendo a 99,2\% de todos os nascimentos acontecidos no município. Os dados de temperatura média diária foram obtidos nos registros do Centro de Pesquisas e Previsões Meteorologicas da UFPel. Nos seis primeiros meses de vida a maior associação foi com a temperatura média. Como variáveis dependentes, foram consideradas as hospitalizações por doenças respiratórias no período pré-escolar e diagnóstico de asma na vida adulta. Os autores destacam três resultados principais: houve maior frequiência de hospitalizações por pneumonia nos dois primeiros anos de vida e de hospitalizações por asma/ "bronquite" aos quatro anos entre as crianças que nasceram entre abril-junho (meses anteriores ao inverno). Em ambos os casos, o risco foi maior também entre crianças que viveram os seus seis primeiros meses de vida sob temperaturas ambientais mais frias. Esses estudos mostram a diversidade de metodologias e técnicas utilizadas na investigação de clima e saúde em diferentes regiões do país. Os estudos avaliados nesta revisão concentram-se em áreas urbanas, ou seja, cidades de grande, médio e pequeno porte. Os dados utilizados são de mortes por todas as causas ou causas específicas relacionadas aos possíveis impactos da atmosfera, como doenças 
respiratórias e circulatórias. Alguns estudos usam dados de mortalidade por todas as causas. Os dados de morbidade são provenientes das Autorizações de Internação Hospitalar (AIHs), registros de entrada em hospitais etc. As faixas etárias avaliadas correspondem àquelas pertencentes aos grupos de risco — crianças e adultos com 60 e mais anos. Desenhos de estudos de coorte e caso-controle são utilizados nas análises do impacto do clima sobre a saúde, sendo conduzidos por equipes multidisciplinares, em que há acompanhamento da condição de saúde do indivíduo participante da pesquisa.

Estudos conduzidos por geógrafos em diferentes instituições utilizam a metodologia de ritmo (tipos de tempo) desenvolvida por MONTEIRO (1971), que avalia as condições diárias das variáveis meteorológicas associadas à condição sinóptica, num esforço de considerar as condições atmosféricas de conjunto e os possíveis efeitos à saúde (CASTRO 2000; PINTON e DOMINGOS 2004; BARROS 2006; SOUZA 2007).

Os resultados apontam associação com os eventos de agravos à saúde e as variáveis atmosféricas. Mostram, porém, que a relação é complexa. O estudo de RIBEIRO SOBRAL (2005) não encontrou relação entre o calor e o excesso de mortes nas áreas estudadas, indicando que o maior número de mortes pode estar relacionado com a oscilação da temperatura (amplitude térmica). As pesquisas apontam para a maior vulnerabilidade das populações pobres aos impactos atmosféricos negativos - frio ou calor - e confirmam maior risco entre a população de idosos e crianças. Os estudos indoor realizados por CARDOSO (2007) e NEDEL (2008) indicam que as habitações precárias não protegem contra as condições adversas do ambiente externo, levando à maior incidência de casos por doenças respiratórias em crianças.

\section{4. ÁREA DE ESTUDO}

\subsection{Os Climas de São Paulo}

Cortada pelo ao trópico de Capricórnio e situada, aproximadamente, na faixa entre $23^{\circ} 20^{\prime}$ e $24^{\circ} 00^{\prime}$ de latitude S e $46^{\circ} 20^{\prime}$ e $46^{\circ} 50^{\prime}$ de longitude W, a cidade de São Paulo encontra-se numa zona climática de transição: entre os climas subtropicais e os climas tropicais, cuja principal característica é a alternância entre duas estações: uma 
quente e úmida — primavera-verão — e outra fria e relativamente mais seca outono-inverno (TARIFA E ARMANI 2001, p. 35).

Na maior parte do tempo a região está sob o domínio da Massa Tropical Atlântica (MTA). Essa massa forma-se sobre o oceano Atlântico e produz os ventos que adentram na porção leste do continente sul americano que transpõem as colinas e relativamente baixo - altitudes de 800 e 1000 metros, no rebordo cristalino, em direção ao litoral, atingem a cidade de São Paulo. As incursões da massa polar (extratropical) alternam-se com o domínio das massas tropicais (marítima e continental). O confronto dessas massas de ar produz as frentes, caracterizando tempo instável e causando pluviosidade, principalmente na primavera-verão. Ao norte do município, a Serra da Cantareira se constitui em uma barreira para esses ventos úmidos provenientes do oceano. Nesta porção da cidade, o efeito orográfico é responsável pelos altos índices pluviométricos e a altitude, pelas baixas temperaturas.

As incursões da massa polar (extratropical) alternam-se com o domínio das massas tropicais (marítima e continental). O confronto dessas massas de ar produz as frentes, caracterizando tempo instável e causando pluviosidade, principalmente na primavera-verão. Ao norte do município, a Serra da Cantareira se constitui em uma barreira para esses ventos úmidos provenientes do oceano. Nesta porção da cidade, o efeito orográfico é responsável pelos altos índices pluviométricos e a altitude, pelas baixas temperaturas.

A atuação do sistema Anticiclone Tropical Atlântico (ATA) produz tempo estável, com céu claro, e é responsável pelos períodos secos. No inverno, com o resfriamento da superfície, o centro da alta pressão tende a se deslocar para o continente. Com isso, a atmosfera torna-se estável e, nesse período, ocorre maior número de dias com inversão térmica de subsidência, agravando as condições de poluição na cidade.

A atuação da Massa Tropical Continental (MTC) é menos frequente, mas igualmente importante, na caracterização climática da cidade. Sua atuação produz os ventos de oeste e noroeste muito secos e quentes e, frequentemente, precedem as invasões da frente polar. 
As temperaturas médias são moderadas na cidade de São Paulo, porém com grandes oscilações térmicas diárias durante todas as estações do ano, caracterizando um comportamento térmico mais continental do que oceânico. As maiores temperaturas ocorrem no mês de fevereiro, sendo este o mês mais quente do ano. As menores temperaturas ocorrem em julho, correspondendo ao mês mais frio.

Os controles de macro-escala, como a latitude e a circulação secundária, associados às feições do relevo e à proximidade do oceano definem, de forma geral, os atributos climáticos da cidade. Contudo, o intenso processo de urbanização alterou as condições naturais do sítio urbano e, hoje, é praticamente impossível caracterizar o clima da bacia paulistana sem considerar os efeitos da ocupação e das atividades humanas.

\subsubsection{O Clima Urbano de São Paulo}

No Brasil, os estudos sobre o clima das cidades ganharam importância a partir da década de 1970, principalmente devido aos problemas ambientais que se avolumavam nas grandes cidades, decorrentes do processo acelerado de urbanização. Os estudos empreendidos, desde então, têm acumulado conhecimento sobre o funcionamento da atmosfera urbana e buscam compreender as especificidades dos climas tropicais, principalmente nas metrópoles.

LOMBARDO (1985) mostrou a ocorrência da ilha de calor na cidade de São Paulo e identificou que a maiores temperaturas ocorrem nas áreas onde há maior concentração de área construída, havendo uma atenuação das temperaturas nas regiões da cidade onde há maior concentração de áreas verdes e reservatórios de água. A autora aponta diferenças de até $10^{\circ} \mathrm{C}$ entre os ambientes mais quentes e mais frios em condições sinópticas específicas.

Alguns estudos, analisando as variáveis medidas em estações meteorológicas, na cidade de São Paulo, têm mostrado aumento das temperaturas decorrentes do processo de urbanização, bem como diferenças das variáveis medidas em relação aos diferentes padrões do uso do solo na cidade (CABRAL 1998; TARIFA e ARMANI 2001; RIBEIRO e AZEVEDO 2003; PEREIRA FILHO et al. 2007; XAVIER e PEREIRA FILHO 2007). 
CABRAL (1998) estudou dados de temperatura de 7 estações meteorológicas na cidade de São Paulo, no período de 1961 a 1997 análise mostrou tendência de aquecimento para série temporal das temperaturas médias, mínimas e máximas, principalmente nas estações meteorológicas em que há dados mais recentes. $\mathrm{O}$ autor considera que o estudo mostra, de maneira consistente, a influência da urbanização da cidade de São Paulo na evolução da temperatura do ar. Sugere que o aumento de temperatura tem relação direta com o crescimento da população e da expansão da mancha urbana, particularmente em termos de suas médias de mínimas, na maior parte dos casos com taxas de aquecimento bastante expressivas para serem explicadas por fatores de escala regional ou global.

RIBEIRO e AZEVEDO (2003) analisaram dados de 6 estações meteorológicas em áreas com padrões de uso do solo diferentes: áreas verdes como o Parque do Ibirapuera, o Parque Estadual das Fontes do Ipiranga (PEFI) e o Campus da Universidade de São Paulo (USP-Oeste) - e áreas urbanizadas, como o Parque D. Pedro I. As análises horárias dos dados mostraram a complexidade das diferenças de temperatura entre as estações e os autores consideram que não é possível estabelecer uma relação direta entre padrão de uso do solo e aumento ou diminuição de temperatura. Contudo, de modo geral, o estudo indicou amenização das temperaturas nas áreas verdes e maior aquecimento nas áreas urbanizadas.

Um estudo realizado por PEREIRA FILHO et al. (2007) com os dados da estação meteorológica do IAG/USP de 1936 a 2005 apontou mudanças significativas no ciclo anual das variáveis ao longo das últimas sete décadas. Houve diminuição da umidade relativa do ar; uma marcante mudança sazonal na pressão mínima diária, ocorrida na década de 1970, com mínimas relativas no período de inverno e máximas relativas na primavera e verão; queda na insolação diária média no mesmo período; aumento significativo da precipitação média diária mensal, principalmente no período chuvoso.

Com relação à temperatura, o referido estudo apontou que o aumento, no período de 1961 a 1991, foi maior do que $1,0^{\circ} \mathrm{C}$, ou seja, acima da estimativa global, que é de $0,5^{\circ} \mathrm{C}$. Os autores ponderam que "somado ao aumento global da temperatura, houve um aumento local da temperatura (mais significativo), que 
contribuiu para as mudanças climáticas observadas na RMSP” (PEREIRA FILHO et al. 2007, p. 111). Os autores observaram a identificação de ciclos curtos para a temperatura média do ar e consideram que há fatores de mudanças associadas a sistemas transientes globais - como El Niño/Oscilação Sul (ENOS) - e outros associados com mudanças locais de origem antrópica.

A distribuição de chuvas urbanas e a intensificação do problema das enchentes em São Paulo têm sido associadas à influência da ilha de calor e das atividades humanas - como a produção de calor antropogênico. Estudos que enfocam os eventos extremos de chuvas, em São Paulo, têm mostrado que estas se concentram sobre as áreas urbanas (AZEVEDO 2002, ALVES FILHO e RIBEIRO 2006; PEREIRA FILHO et al.2007).

PEREIRA FILHO et al. (2007, p.109) mostram que, na composição da distribuição de chuva acumulada de 18 eventos de enchente relacionados com a ilha de calor e brisa marítima, houve um núcleo de precipitação de até $650 \mathrm{~mm}$ sobre a RMSP e da ordem de $300 \mathrm{~mm}$ na periferia.

Além da concentração das chuvas em áreas urbanizadas, os estudos indicam que as atividades humanas influenciam no processo de intensificação das chuvas, uma vez que os episódios tendem a ocorrer nos dias úteis, com maior concentração de casos nos primeiros dias úteis da semana (ALVES FILHO e RIBEIRO 2006; AZEVEDO 2002).

PEREIRA FILHO et al. (2007, p. 111) identificaram que as anomalias de vento, que eram de sudoeste até a década de 1970, mudaram para nordeste. Sugere-se que essa mudança esteja relacionada com circulações térmicas induzidas pela ilha de calor. Até esta mesma década as anomalias de vento traziam ar relativamente seco e frio, passando a transportar, ar relativamente quente e úmido posteriormente.

A observação da entrada do vento de NE é ressaltada em AZEVEDO (2002) e RIBEIRO e AZEVEDO (2003):

O fato é que uma larga faixa na zona lesta da Região Metropolitana de São Paulo é persistentemente varrida por uma brisa do leste em direção à região central, na maior parte dos dias, durante o período da manhã. Também é freqüente que este fluxo assuma, gradativamente, antes da região central, a direção NE ou mesmo NNE [...] e certamente beneficia-se desse fluxo de ar mais fresco e úmido (RIBEIRO e AZEVEDO 2003, p. 31). 
A observação de campo nos permite inferir que no período de inversão da brisa oceanocontinente, há um fluxo sensível do Vale em direção à Zona Leste da área urbana, sobretudo no final da manhã e/ou início da tarde. Nesta porção da metrópole resulta na entrada de vento de NE [...] do ar que derrama do Vale em direção à Bacia de São Paulo (ou talvez seja "sugado" para a Bacia de São Paulo quando ocorre intensificação da brisa urbana nos dias centrais da semana) (AZEVEDO 2002, p.63).

XAVIER e PEREIRA FILHO (2007) analisaram as medições e observações da EM-IAG/USP, no período de 1936 a 2005 utilizando técnicas estatísticas. As variáveis analisadas foram: temperatura do ar (média, máxima e mínima), umidade relativa do ar, precipitação, vento (velocidade e direção) e insolação. De modo geral, as análises mostraram tendência de aumento das temperaturas médias, mínimas e máximas nas últimas décadas, diminuição da umidade relativa e aumento de chuvas intensas e diminuição das chuvas menos intensas. Com relação à insolação, não foram detectadas tendências nítidas de diminuição ou aumento dos índices diários e mensais no período estudado e, com relação ao vento, as análises foram inconclusivas.

Os resultados das pesquisas apresentadas acima permitem afirmar que as alterações nos elementos do clima apontadas por LANDSBERG (1956) e OKE $(1981)^{18}$ a partir de estudos realizados nas cidades de climas temperados são identificadas também nas cidades de clima tropical, como São Paulo.

As análises dos dados da estação do EM-IAG/USP apontam mudanças dos componentes climáticos, principalmente a partir da década de 1970, período da expansão econômica do país (milagre econômico) e do processo de aceleração da urbanização, mormente nos centros hegemônicos, como o centro-sul do país e a cidade de São Paulo.

Contudo, Ary França, em 1946, ao estudar o clima da bacia paulistana, já apontava o aumento das temperaturas da área urbanizada em relação a áreas não urbanizadas, indicando a influência da cidade na conformação dos atributos climático. No conjunto, pode-se observar que a área mais densamente construída é $1^{\circ} \mathrm{C}$ a $1,5^{\circ} \mathrm{C}$ mais quente do que os espaços suburbanos ou rurais" (FRANÇA 1946, p. 82).

\footnotetext{
${ }^{18}$ Estes estudos estão descritos com maior detalhe item 3.1 As alterações nos elementos do clima estão descritas nas Tabelas 4a e 4b.
} 
Considera-se que as modificações no clima ocorridas a partir da década de 1970 tenham se pronunciado com a expansão da metrópole paulista. A cidade, porém, não é homogênea. Diferenças na configuração geoecológica - morfologia, disposição dos corpos hídricos etc. —, assim como as diferenças no uso e ocupação do solo, intensificam ou amenizam as características do clima urbano em escala local. Estudos sobre clima urbano em diferentes escalas, conduzidos na cidade de São Paulo, têm mostrado diferenciações quando consideradas as escalas local e microclimática (TARIFA e ARMANI 2001; SILVA e RIBEIRO, 2006).

Em pesquisa realizada na favela Paraisópolis, situada na região sudoeste da cidade de São Paulo e próxima a áreas com excelentes condições ambientais e atmosféricas, verificou-se que o ambiente de favela aguça os extremos de temperatura, tanto em relação às temperaturas mais elevadas, quanto em relação às mais baixas (SILVA e RIBEIRO 2006).

Considerando tipos de ocupação, relevo, dados climatológicos e resposta térmica da superfície a partir de imagem de satélite, TARIFA e ARMANI (2001b) elaboraram um mapeamento detalhado dos climas da cidade de São Paulo, mostrando que há microclimas diferenciados quando considerada a escala intraurbana. Na mesma publicação é possível conhecer algumas pesquisas realizadas no Laboratório de Climatologia da Universidade de São Paulo, sobre diferentes aspectos e escalas de abordagem sobre o clima urbano de São Paulo, bem como a classificação dos climas urbanos proposta por estes autores (TARIFA e ARMANI 2001b).

\subsubsection{Aspectos climáticos do setor Sul/Sudeste}

O setor Sul/Sudeste do município de São Paulo compreende um mosaico microclimático que, segundo a classificação dos climas urbanos elaborada por TARIFA e ARMANI (2001b), é caracterizado por: a) Unidade Climática Urbana Central e b) Unidades Climáticas Urbanas de Periferia.

Os autores classificaram o clima desse setor como: Clima Tropical de Altitude do Planalto Paulistano/ colinas intermediárias/ morros baixos, terraços e patamares; e altas colinas/ colinas, patamares e rampas do Pinheiros. Esta subunidade, segundo os autores, caracteriza-se por temperatura média anual que 
varia de $19,6^{\circ} \mathrm{C}$ a $19,3^{\circ} \mathrm{C}$; média anual das máximas entre de $25,2^{\circ} \mathrm{C}$ a $24,9^{\circ} \mathrm{C}$ e média anual das mínimas de $15,8^{\circ} \mathrm{C}$ a $15,5^{\circ} \mathrm{C}$. Os totais pluviométricos anuais oscilam entre $1250 \mathrm{~mm}$ e $1580 \mathrm{~mm}$.

As áreas de maior densidade de construção, as vias de circulação de maior fluxo e tráfego de veículos e aviões - como a área compreendida pelo Aeroporto de Congonhas - , bem como as áreas industriais, individualizam-se e apresentam valores térmicos de superfície entre $30^{\circ} \mathrm{C}$ e $32^{\circ} \mathrm{C}$, nos meses de transição estacional - setembro e abril.

A área residencial, com predominância de casas e com pequena porcentagem de áreas verdes, corresponde à Unidade Climática Intermediária entre os bairros verdes e aqueles completamente áridos, apresentam a uma variação entre $29^{\circ} \mathrm{C}$ e $32^{\circ} \mathrm{C}$, dependendo de cada condição específica da superfície, ligada principalmente à densidade e altura das áreas verdes (arborização de ruas e quintais).

A área onde se encontra localizado o Parque do Estado individualiza-se pela formação florestal, que reduz a temperatura da superfície para um mínimo de até $23^{\circ} \mathrm{C}$ no outono (abril) e $25^{\circ} \mathrm{C}$ (setembro).

Nos bairros verdes - aqueles com casas baixas e alto índice de cobertura vegetal constituída por parques, jardins e praças —, a temperatura da superfície oscila entre $27^{\circ} \mathrm{C}$ e $29^{\circ} \mathrm{C}$ (setembro) ou de 27 a $30^{\circ} \mathrm{C}$ (abril).

Ao sul do Parque do Estado, abrangendo os distritos de Cidade Ademar, Campo Grande, Capela do Socorro, Pedreira e Cidade Dutra, a urbanização contínua avança para o Sul, entre as represas Guarapiranga e Billings. De acordo com a intensidade e densidade das edificações, bem como a maior ou menor porcentagem de áreas verdes, ocorrem variações no campo térmico, havendo queda nas temperaturas em manchas isoladas para valores de até $27^{\circ} \mathrm{C}$, tanto em setembro como em abril.

Os distritos de Capela do Socorro, Cidade Dutra e parte de Pedreira apresentam um padrão muito variado de ocupação; em alguns trechos próximos da Represa Guarapiranga e Billings se alternam padrões de uso do solo de nível médio com maior presença de cobertura vegetal. Os bairros muito próximos às represas 
devem sofrer uma freqüência maior de nevoeiros e névoas úmidas noturnas e matinais (TARIFA e ARMANI 2001b, p. 67-68).

\subsection{Aspectos da ocupação do setor Sul/Sudeste}

A região é cortada por importantes vias e de tráfego intenso, como a Avenida das Nações Unidas (Marginal do Rio Pinheiros), a Avenida dos Bandeirantes e a Rodovia dos Imigrantes, que faz a ligação com o litoral de São Paulo, entre outras. A Figura 8 mostra o mapa com as vias principais que cortam a região estudada, bem como a distribuição das áreas de favela no setor.

A Figura 9 mostra o mapa de distribuição das favelas agrupadas por tamanho. Dos quatorze distritos selecionados, todos apresentam áreas com moradia em favelas, sendo o distrito de Moema a única exceção. É possível verificar a maior concentração, em quantidade, em número e em tamanho, de áreas de favelas nos distritos do Jabaquara, Cidade Ademar, Cidade Dutra, Pedreira e Sacomã.

O IDH para os distritos do setor Sul/Sudeste está representado na Figura 10. Os distritos do Ibirapuera e Moema apresentam os melhores indicadores de desenvolvimento humano - altos índices —; por outro lado, os distritos de Cidade Ademar, Cidade Dutra e Pedreira apresentam os piores indicadores — índices baixos de desenvolvimento humano. Os distritos restantes apresentam nível médio de desenvolvimento. 

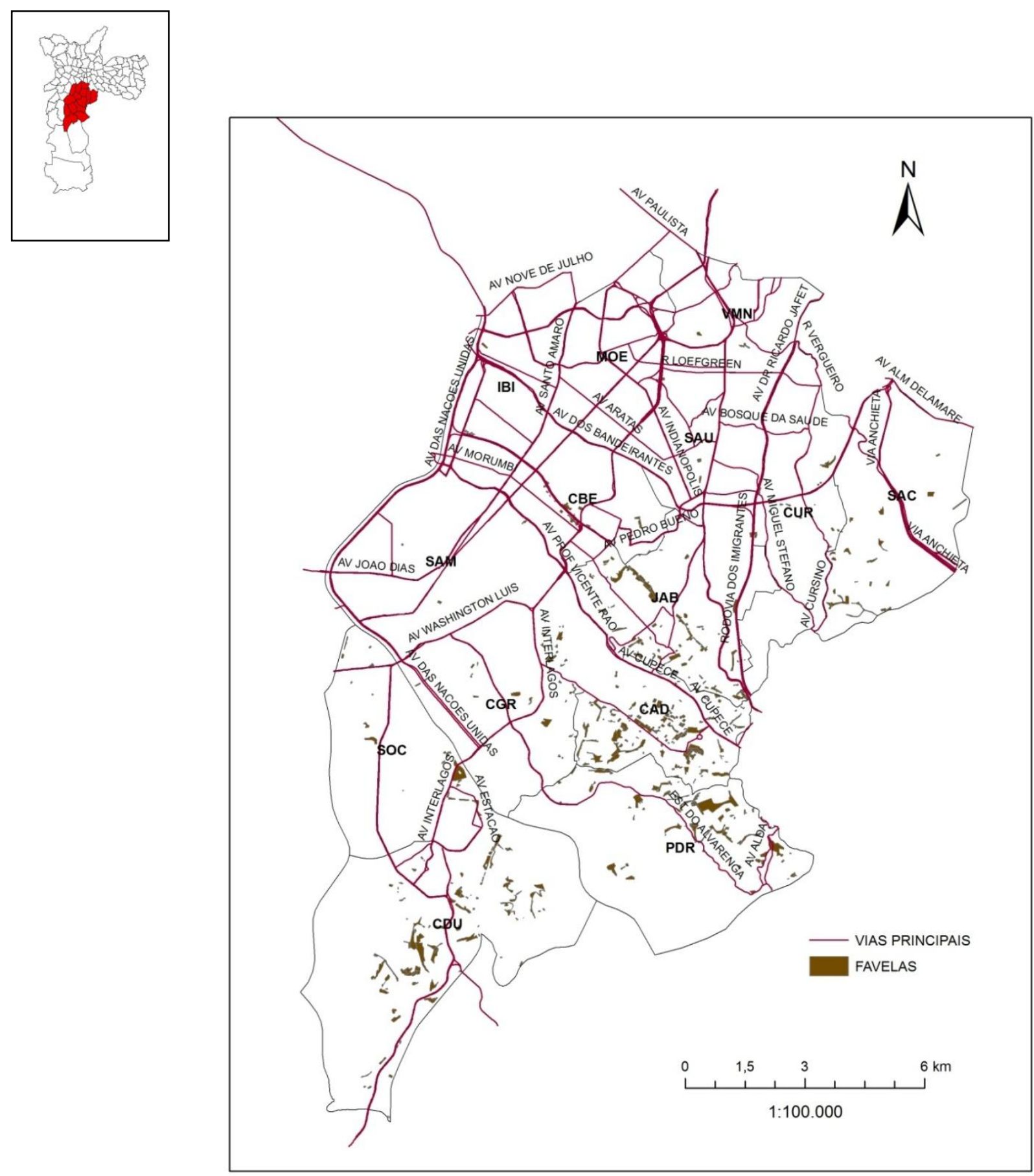

Figura 8 - Principais vias de circulação e distribuição das áreas de favelas no Setor Sul/Sudeste, Município de São Paulo, SP.

Fonte: Base Cartográfica Digital das Favelas do Município de São Paulo. PMSP/CEM 2003. 

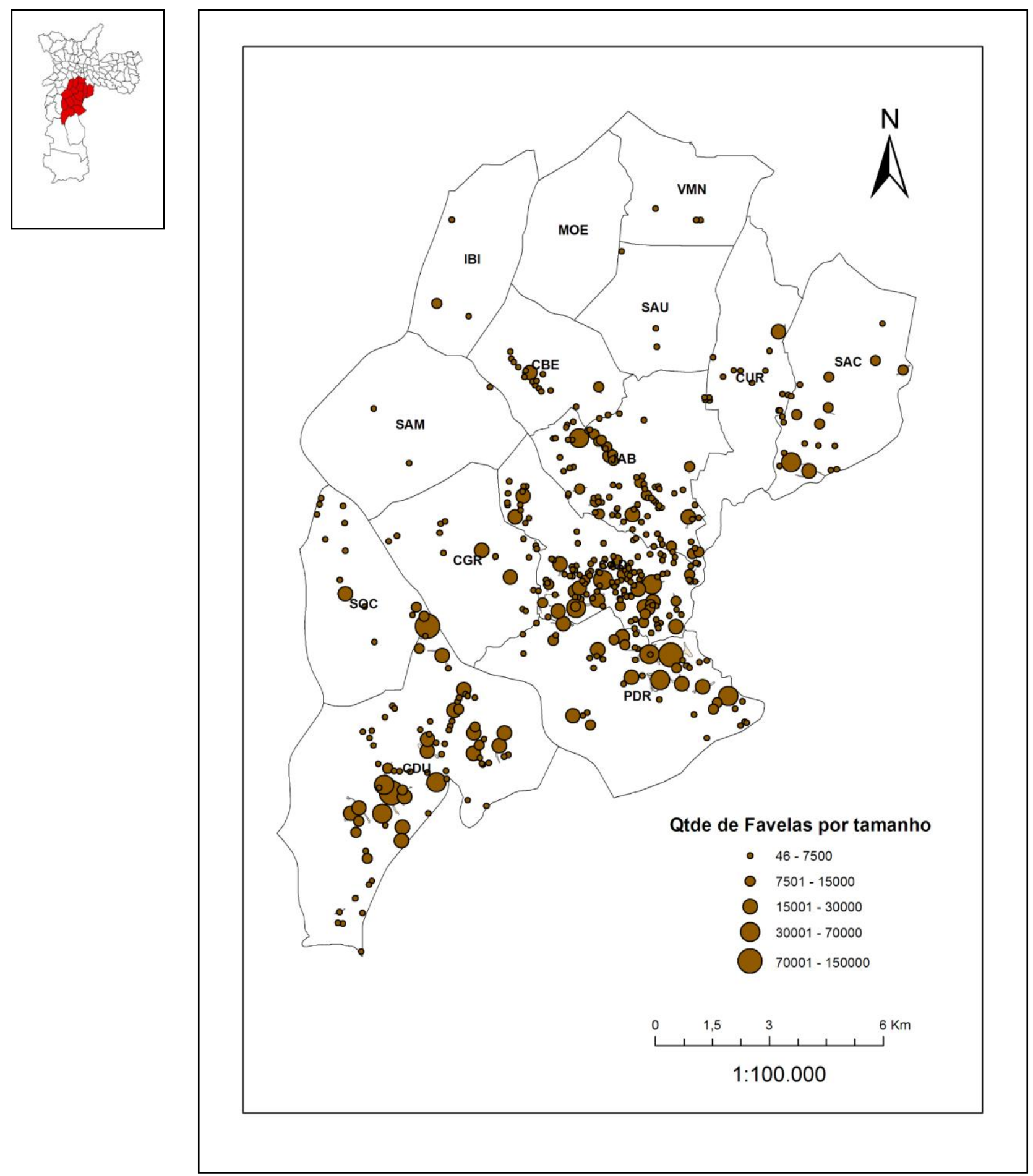

Figura 9 - Concentração das áreas de favelas, em relação ao tamanho (perímetro), no Setor Sul/Sudeste, Município de São Paulo, SP.

Fonte: Base Cartográfica Digital das Favelas do Município de São Paulo. PMSP/CEM 2003. 

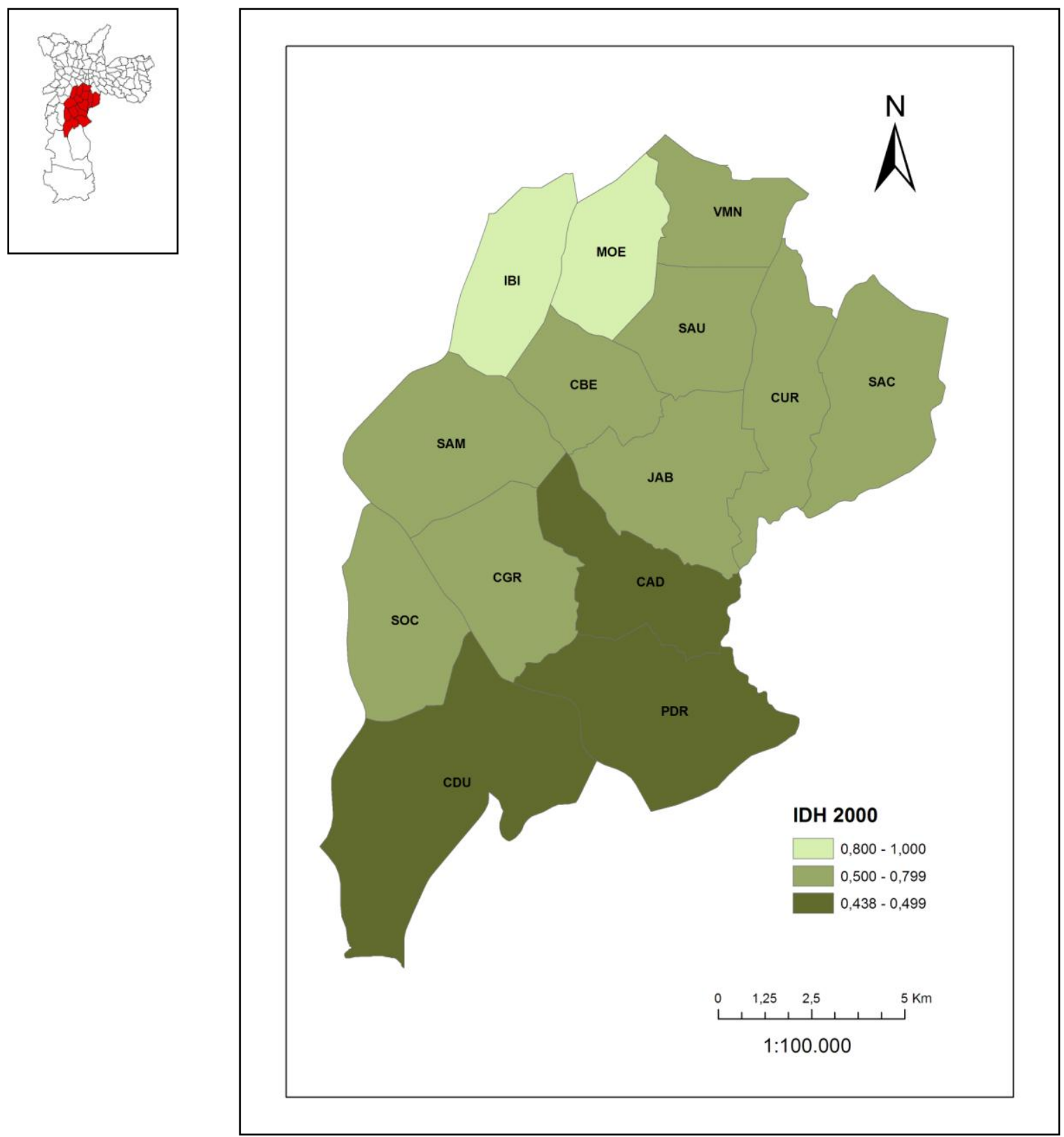

Figura 10 - Índice de Desenvolvimento Humano (IDH) no Setor Sul/Sudeste, Município de São Paulo, SP, Brasil no ano de 2000.

Fonte: www2.uol.com.br/aprendiz/n_noticias/.../id150802.doc 
O padrão de distribuição dos indicadores de desenvolvimento humano e socioambientais confirma o padrão de ocupação urbana da cidade de São Paulo, que, como vimos no Capitulo 1, privilegiou as áreas mais centrais, onde se concentra a população de mais alta renda, em detrimento das áreas periféricas, distantes do centro, em que há maior concentração da população de menor renda.

Os distritos de Cidade Ademar, Cidade Dutra e Pedreira apresentam os piores indicadores de IDH e socioambientais, bem como concentram maior número de favela (Figuras 8 a 10).

\subsection{População da área de estudo}

A população total do município de São Paulo e do setor Sul/Sudeste, estimada para o ano de $2005^{19}$, bem como a proporção dos grupos etários estudados - crianças menores de cinco anos e adultos com mais de sessenta anos —, está representada na Figura 11.

O total de população do setor Sul/Sudeste corresponde a aproximadamente $16 \%$ do total da população do município de São Paulo. O grupo etário de crianças menores de cinco anos residentes no setor Sul/Sudeste corresponde a 8,7\% do total da população de crianças menores de cinco anos residentes no município de São Paulo e o grupo etário de sessenta e mais anos a 10,2\% do total da população dessa faixa etária em relação à população total do município.

Em relação à população total residente no setor Sul/Sudeste, aproximadamente $15 \%$ são crianças menores de cinco anos e $20 \%$ correspondem à faixa etária de sessenta e mais anos.

19 A representação gráfica apresentada aqui se refere ao ano de 2005 (meio do período), considerando que os dados dos anos anteriores e posteriores são muito próximos aos desse ano. A apresentação dos dados de todo o período encontra-se no Apêndice A. 


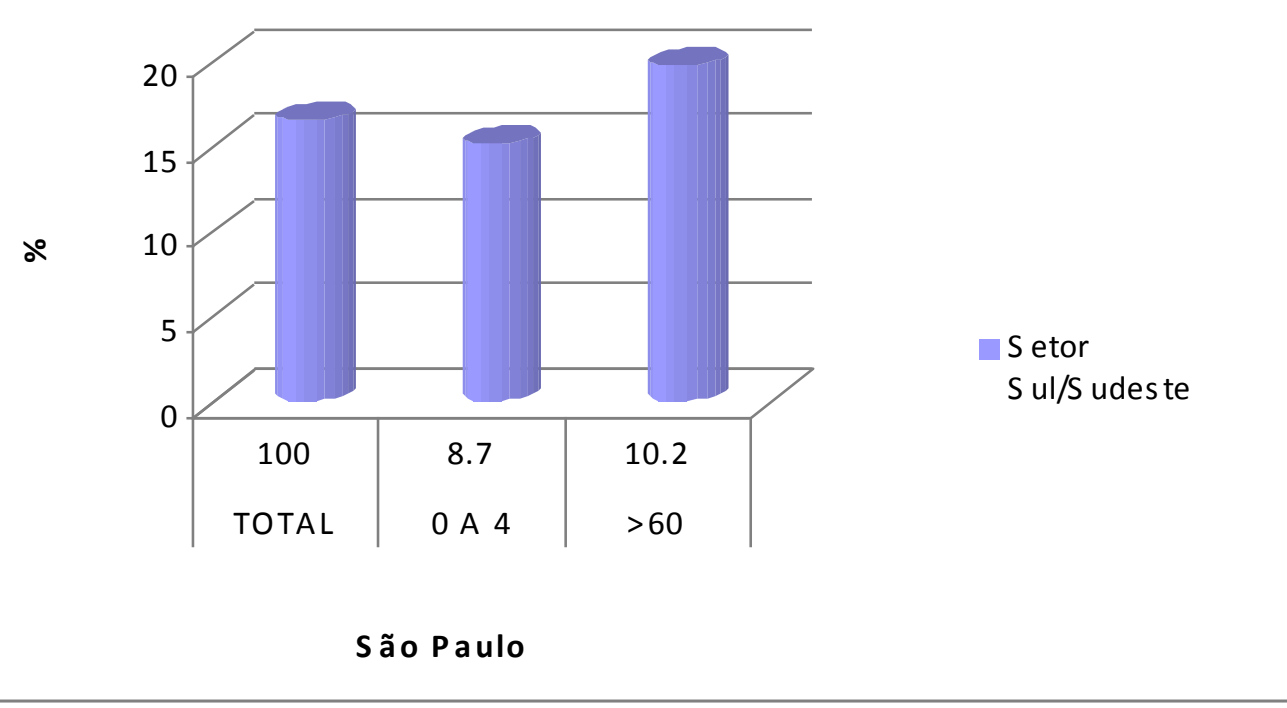

Figura 11 - Proporção da população estudada em relação ao Município de São Paulo e em relação à área de estudo - Setor Sul/Sudeste para o ano de 2005.

Fonte: Fundação SEADE 2009.

A proporção da população (\%), por distrito, de crianças residentes em relação ao total da população do setor Sul/Sudeste está representada no mapa da Figura 12. A distribuição mostra que os distritos mais centrais apresentam menores taxas de população infantil (menos de 5\%), enquanto os distritos do Sacomã, Jabaquara e Cidade Dutra apresentam taxas de até $15 \%$ da população constituída por crianças menores de cinco anos. O distrito de Cidade Ademar apresenta a maior proporção de crianças menores de cinco anos, taxa acima de $15 \%$ do total da população do setor.

A Figura 13 mostra que a população de mais de sessenta anos está concentrada nos distritos de Vila Mariana, Sacomã e Jabaquara - mais de $10 \%$ da população do setor - enquanto os distritos de Socorro e Pedreira contêm menos de $5 \%$ da população com mais de sessenta anos. Nos distritos restantes, até $10 \%$ da população tem de mais de sessenta anos.

Trata-se, portanto, de uma região muito diversificada em relação ao padrão de ocupação. Nesse setor podem ser encontradas áreas residenciais nobres, como os bairros arborizados com edificações baixas e também bairros verticalizados, áreas industriais mais antigas, como aquelas da região de Santo Amaro e Interlagos e áreas bastante adensadas com forte verticalização, como o eixo da Avenida Luis Carlos 
Berrini. Há, igualmente, amplos espaços verdes preservados - como a região do Parque Estadual das Fontes do Ipiranga (PEFI), onde se localizam o Parque Zoológico, Botânico e a EM-IAG/USP — e áreas de ocupação mais precária, como as favelas e os bairros de ocupação mais recente nas bordas das represas Guarapiranga e Billings. Esse mosaico confere aos distritos perfis socioeconômicos e ambientais diferenciados em relação às características da população. 

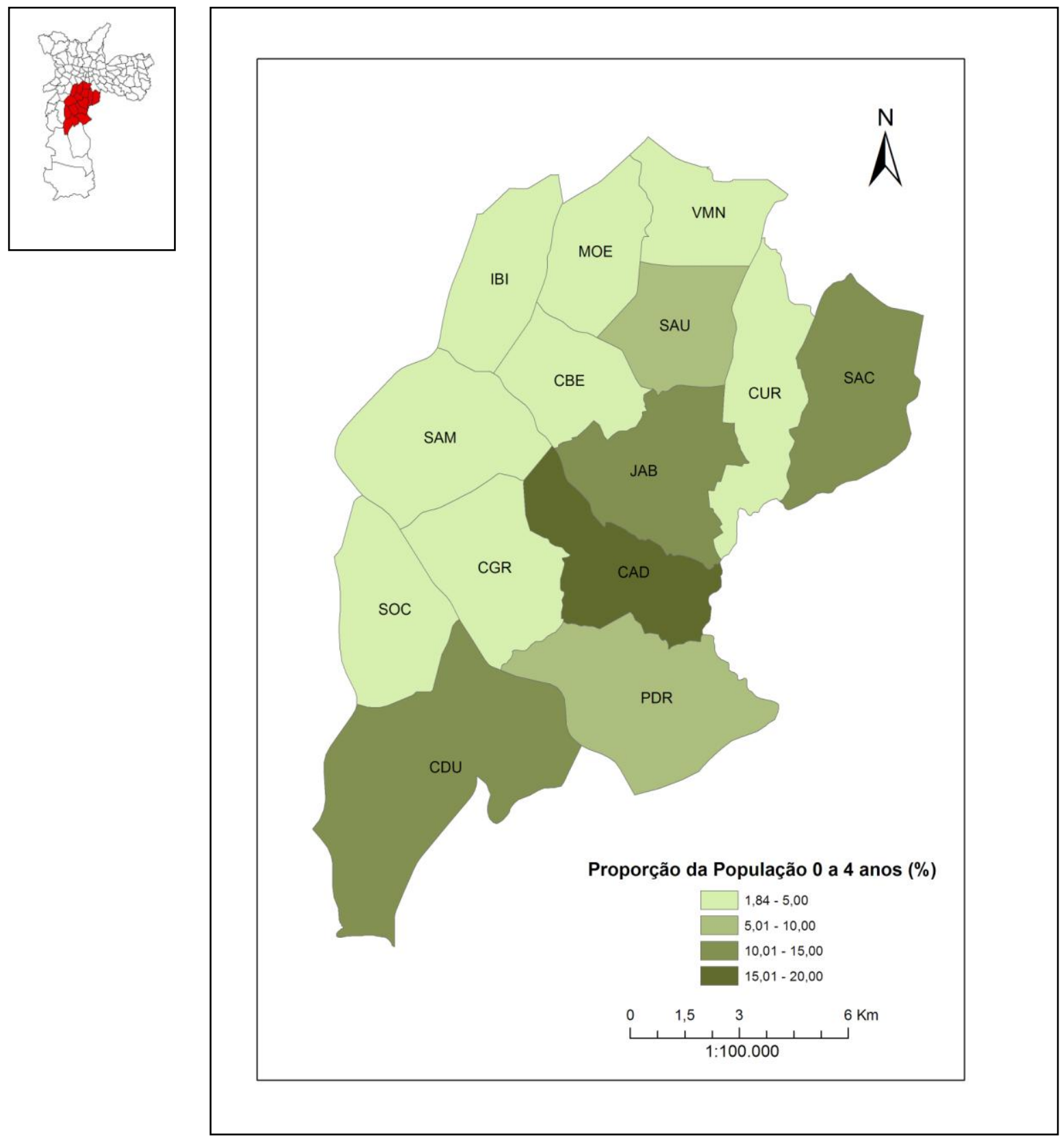

Figura 12 - Distribuição da proporção da população (\%) estimada de crianças de menores de cinco anos, por distrito, no setor Sul/Sudeste, Município de São Paulo, SP, no ano de 2005.

Fonte: Fundação SEADE 2009. 

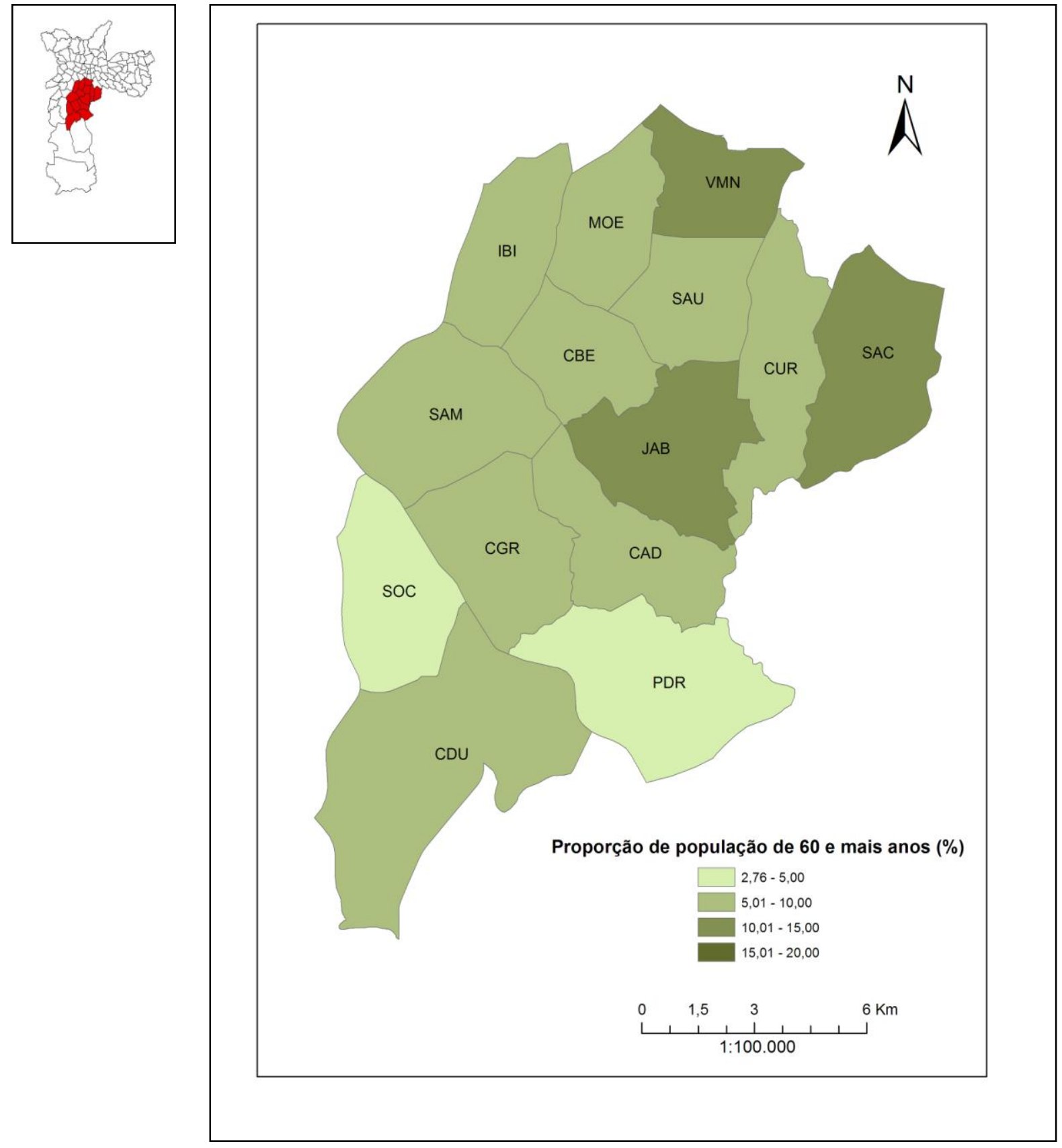

Figura 13 - Distribuição da proporção da população (\%) estimada de pessoas de sessenta e mais anos, por distrito, no setor Sul/Sudeste, Município de São Paulo, SP, no ano de 2005. Fonte: Fundação SEADE 


\section{RESULTADOS}

A seguir apresentam-se os resultados das análises descritivas das variáveis meteorológicas observadas no setor Sul/Sudeste, no período de 2003 a 2007.

\subsection{Características Climáticas do Setor Sul/Sudeste}

\subsubsection{EM-IAG/USP}

A análise estatística descritiva para os cinco anos de observação das variáveis medidas na EM-IAG/USP está expressa na Tabela 5. Foram 1826 dias de observação, sendo que, desses, somente em um dia não houve registro (29/02/2004).

A média da temperatura média diária do ar foi de $19,3^{\circ} \mathrm{C}$. A menor temperatura média do ar foi de $8,4^{\circ} \mathrm{C}$ e, a maior, $27,6^{\circ} \mathrm{C}$. A média das temperaturas máxima do ar foi de $25,3^{\circ} \mathrm{C}$, sendo que o maior valor medido foi de $35,1^{\circ} \mathrm{C}$ e o menor valor, de $11,4^{\circ} \mathrm{C}$. A temperatura mínima do ar teve média de $15,1^{\circ} \mathrm{C}$ e, o maior valor absoluto foi de $21,6^{\circ} \mathrm{C}$ e $3,3^{\circ} \mathrm{C}$ o menor valor absoluto. $\mathrm{O}$ valor médio de umidade relativa do ar foi de $79,9 \%$. O valor máximo absoluto de $96,4 \%$ e o valor mínimo de $44,4 \%$.

Tabela 5 - Estatística descritiva dos dados meteorológicos da EM-IAG/USP, no período de 1.01.2003 a 31.12.2007.

\begin{tabular}{|c|c|c|c|c|c|c|c|c|}
\hline & & Ta $(\mathrm{oC})$ & TaMax (oC) & TaMin $(0 \mathrm{C})$ & RH (\%) & $\mathbf{V}(\mathbf{m} / \mathbf{s})$ & $\begin{array}{c}\text { Rad, } \\
\text { Global } \\
\text { (W/m2) } \\
\end{array}$ & PET $\left({ }^{\circ} \mathrm{C}\right)$ \\
\hline \multicolumn{2}{|l|}{ Média } & 19,4 & 25,3 & 15,1 & 79,9 & 1,7 & 181,9 & 19,4 \\
\hline \multicolumn{2}{|l|}{ Mediana } & 19,5 & 25,7 & 15,4 & 80,9 & 1,6 & 180,1 & 19,3 \\
\hline \multicolumn{2}{|l|}{ Moda } & 20,5 & 26,2 & 15,2 & 92,2 & 1,4 & 86,8 & 19,1 \\
\hline \multicolumn{2}{|c|}{ Desvio Padrão } & 3,3 & 4,5 & 3,4 & 8,4 & 0,5 & 70,9 & 5,2 \\
\hline \multicolumn{2}{|c|}{ Mínimo } & 8,4 & 11,4 & 3,3 & 44,4 & 0,3 & 22,3 & 4,1 \\
\hline \multicolumn{2}{|l|}{ Maximo } & 27,6 & 35,1 & 21,6 & 96,4 & 4,8 & 395,6 & 32,2 \\
\hline \multirow[t]{3}{*}{ Percentil } & 25 & 17,1 & 22,3 & 12,8 & 75,0 & 1,3 & 134,0 & 15,9 \\
\hline & 50 & 19,5 & 25,7 & 15,4 & 80,9 & 1,7 & 180,1 & 19,3 \\
\hline & 75 & 21,9 & 28,6 & 17,8 & 85,5 & 2,0 & 230,5 & 23,3 \\
\hline
\end{tabular}

Fonte: Estação Meteorológica IAG/USP n=1825

O valor médio da velocidade do vento foi de $1,72 \mathrm{~m} / \mathrm{s}$, com máximo de 4,85 $\mathrm{m} / \mathrm{s}$ e mínimo de $0,29 \mathrm{~m} / \mathrm{s}$. A média dos valores de radiação solar global foi de 181,9 $\mathrm{W} / \mathrm{m}^{2}$, o valor máximo de $395,63 \mathrm{~W} / \mathrm{m}^{2}$ e mínimo de $22,3 \mathrm{~W} / \mathrm{m}^{2}$. 
O índice de conforto PET calculado com os dados dessa Estação Meteorológica apresentou média de $19,4^{\circ} \mathrm{C}$, mínima de $4,1^{\circ} \mathrm{C}$ e máxima de $32,2^{\circ} \mathrm{C}$.

As Pranchas 1 a 5 mostram gráficos do ritmo diário das temperaturas do ar, umidade relativa do ar, velocidade do vento e radiação solar na estação meteorológica EM-IAG/USP, no período de 2003 a 2007. A marcha das temperaturas não diverge muito entre os anos, apresentando forte oscilação interdiária, sobretudo no período de primavera-verão. As temperaturas médias do ar oscilaram em torno de $10^{\circ} \mathrm{C}$ e $25^{\circ} \mathrm{C}$, em todo o período (2003-2007), sendo que as maiores médias ocorrem no período da primavera-verão e, as menores médias, no período do inverno. As temperaturas máximas do ar oscilaram em torno de $15^{\circ} \mathrm{C}$ e $35^{\circ} \mathrm{C}$ e as temperaturas mínimas do ar entre $5^{\circ} \mathrm{C}$ e $20^{\circ} \mathrm{C}$.

Os valores de umidade relativa média do ar são altos e concentraram-se em torno de $60 \%$ a $90 \%$ no período, sendo que alguns dias do ano apresentam os valores de umidade abaixo de $60 \%$, correspondendo aos meses de julho, agosto, setembro outubro e novembro em todos os anos estudados. Observa-se, em 2007, um dia de umidade relativa média baixa (menor de 50\%) em setembro.

A velocidade média do vento diário oscila entre $1,0 \mathrm{~m} / \mathrm{s}$ e $2,0 \mathrm{~m} / \mathrm{s}$ na maior parte do ano, com tendência a aumento no final do período - novembro/dezembro. Os anos de 2003 e de 2007 apresentaram um dia, em novembro, com ventos médios acima de $4,0 \mathrm{~m} / \mathrm{s}$.

Os valores médios diários de radiação solar global oscilaram entre $50 \mathrm{~W} / \mathrm{m}^{2}$ e $400 \mathrm{~W} / \mathrm{m}^{2}$ o ano todo, com valores máximos atingindo o período de primavera/verão e mínimo no inverno, acompanhando o ciclo astronômico da posição do sol. A nebulosidade também interfere na entrada da radiação solar, impedindo parte dessa radiação de chegar à superfície terrestre. Nota-se a grande variabilidade dos valores de radiação, principalmente no período de primavera-verão, provavelmente devido à nebulosidade. 
Prancha 1 - Ritmo diário das temperaturas do ar, umidade relativa média do ar, vento e radiação solar, na EM-IAG/USP, de 1 de janeiro a 31 de dezembro de 2003.

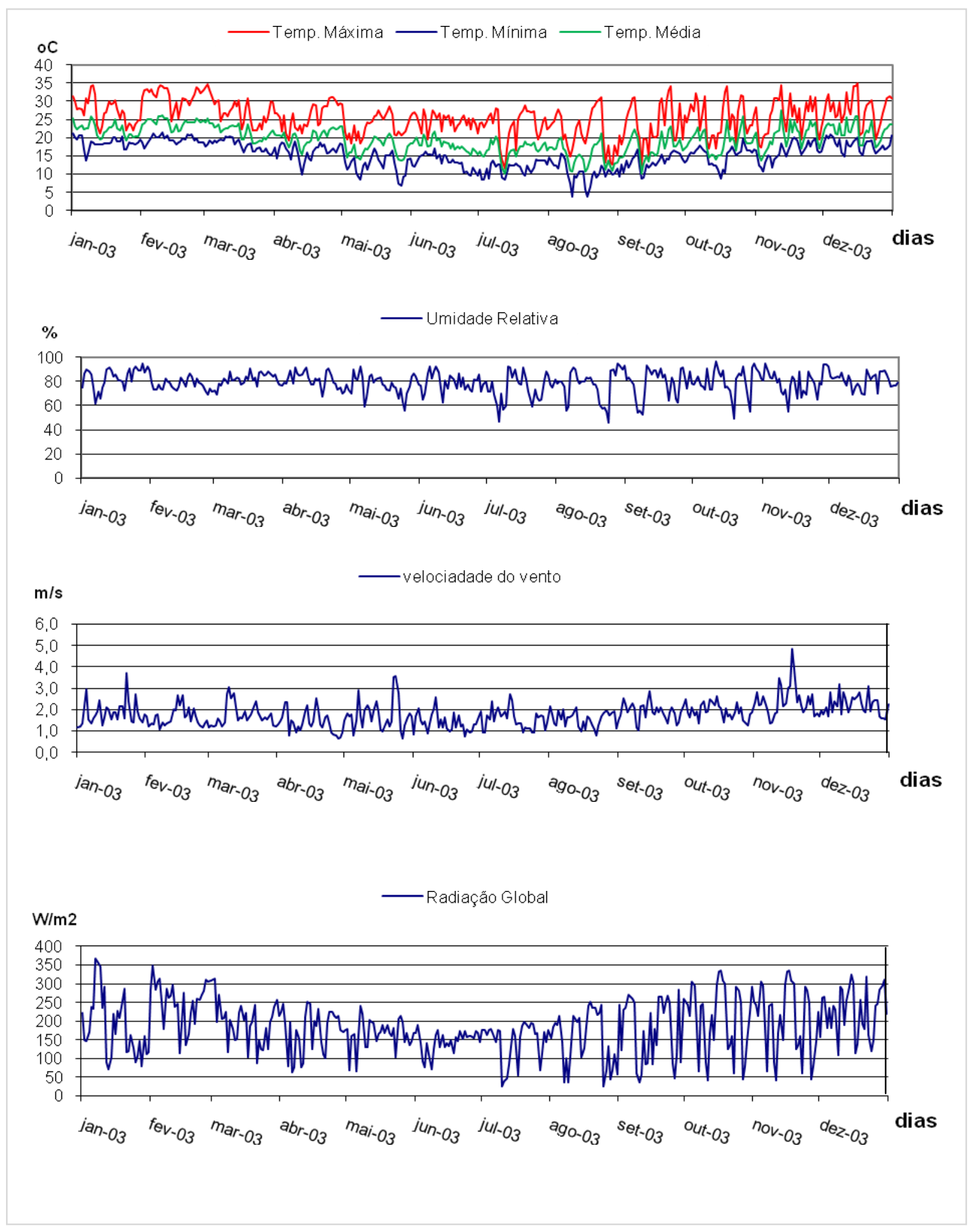

Fonte: EM-IAG/USP. 
Prancha 2 - Ritmo diário das temperaturas do ar, umidade relativa média do ar, vento e radiação solar, na EM-IAG/USP, de 1 de janeiro a 31 de dezembro de 2004.

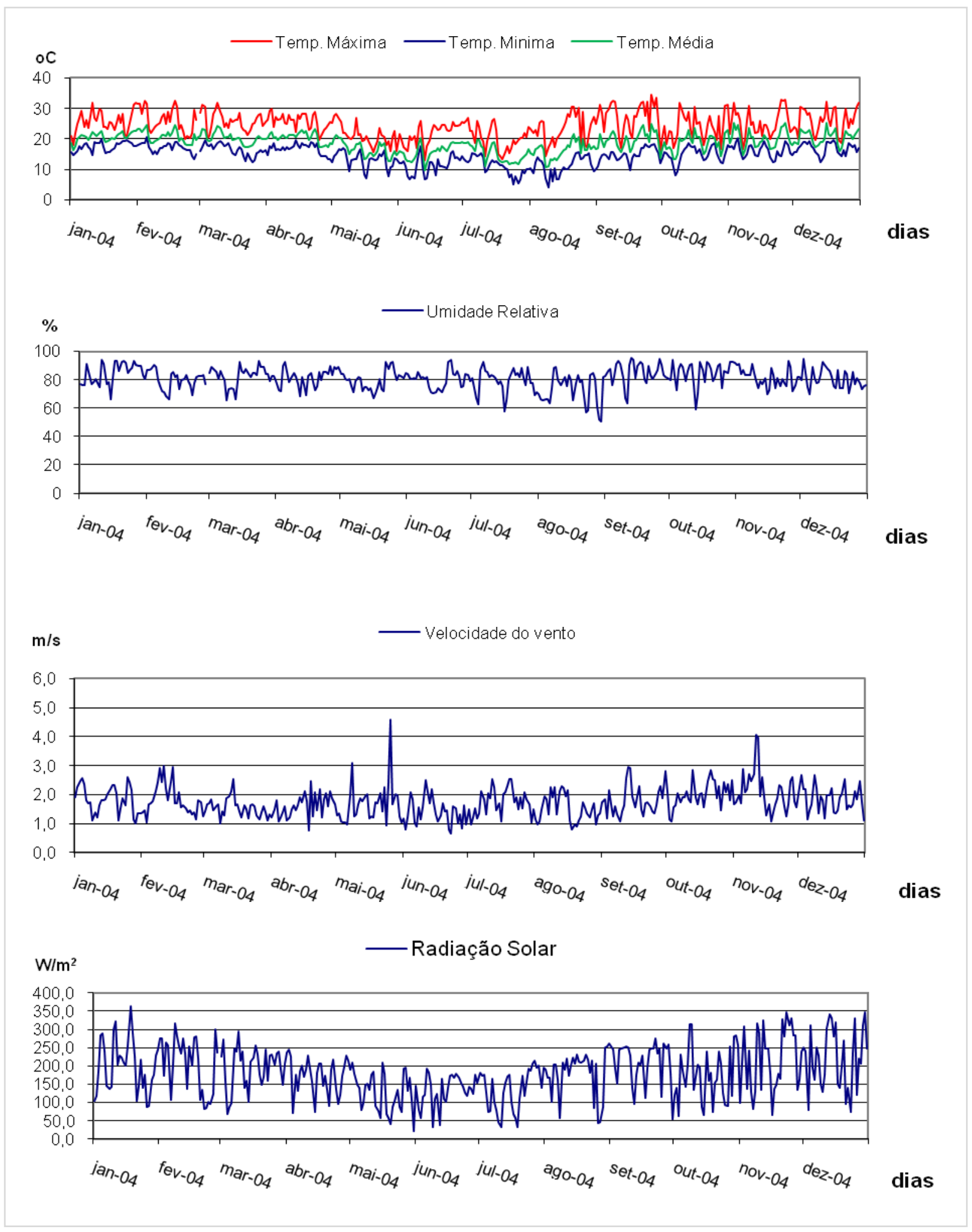

Fonte: EM-IAG/USP 
Prancha 3 - Ritmo diário das temperaturas do ar, umidade relativa média do ar, vento e radiação solar, na EM-IAG/USP, de 1 de janeiro a 31 de dezembro de 2005.
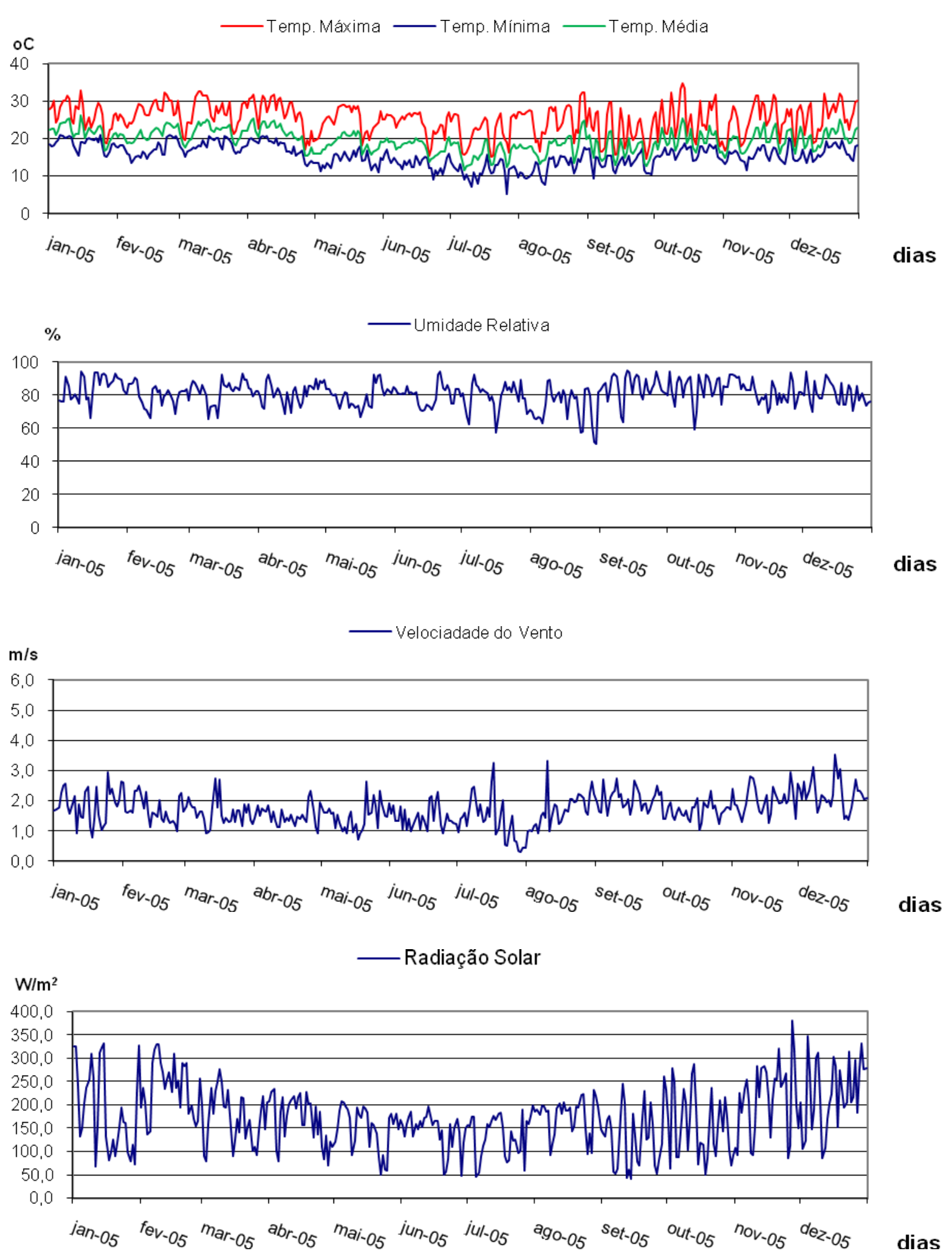

dias

Fonte: EM-IAG/USP 
Prancha 4 - Ritmo diário das temperaturas do ar, umidade relativa média do ar, vento e radiação solar, na EM-IAG/USP, de 1 de janeiro a 31 de dezembro de 2006.

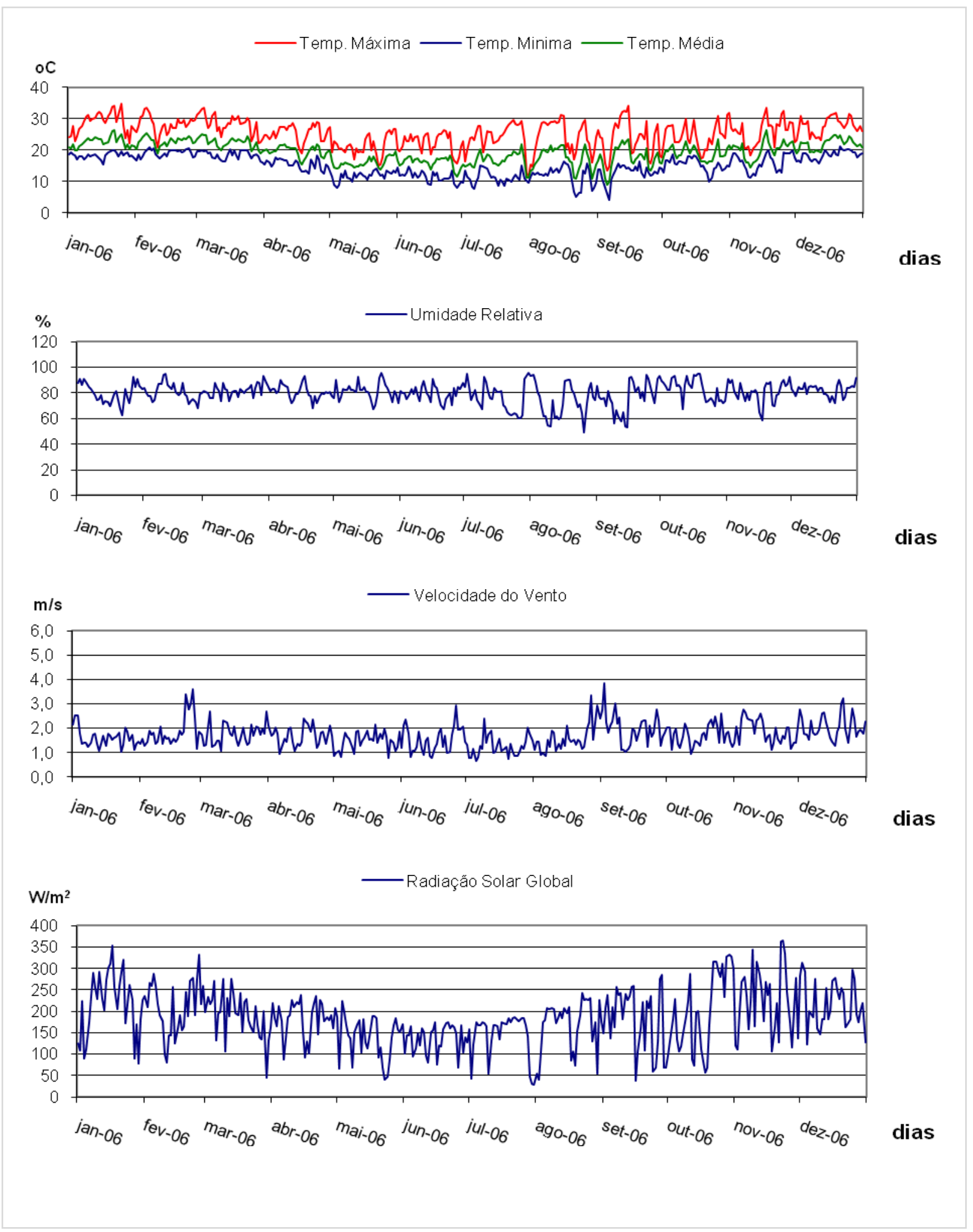

Fonte: EM-IAG/USP 
Prancha 5 - Ritmo diário das temperaturas do ar, umidade relativa média do ar, vento e radiação solar, na EM-IAG/USP, de 1 de janeiro a 31 de dezembro de 2007.

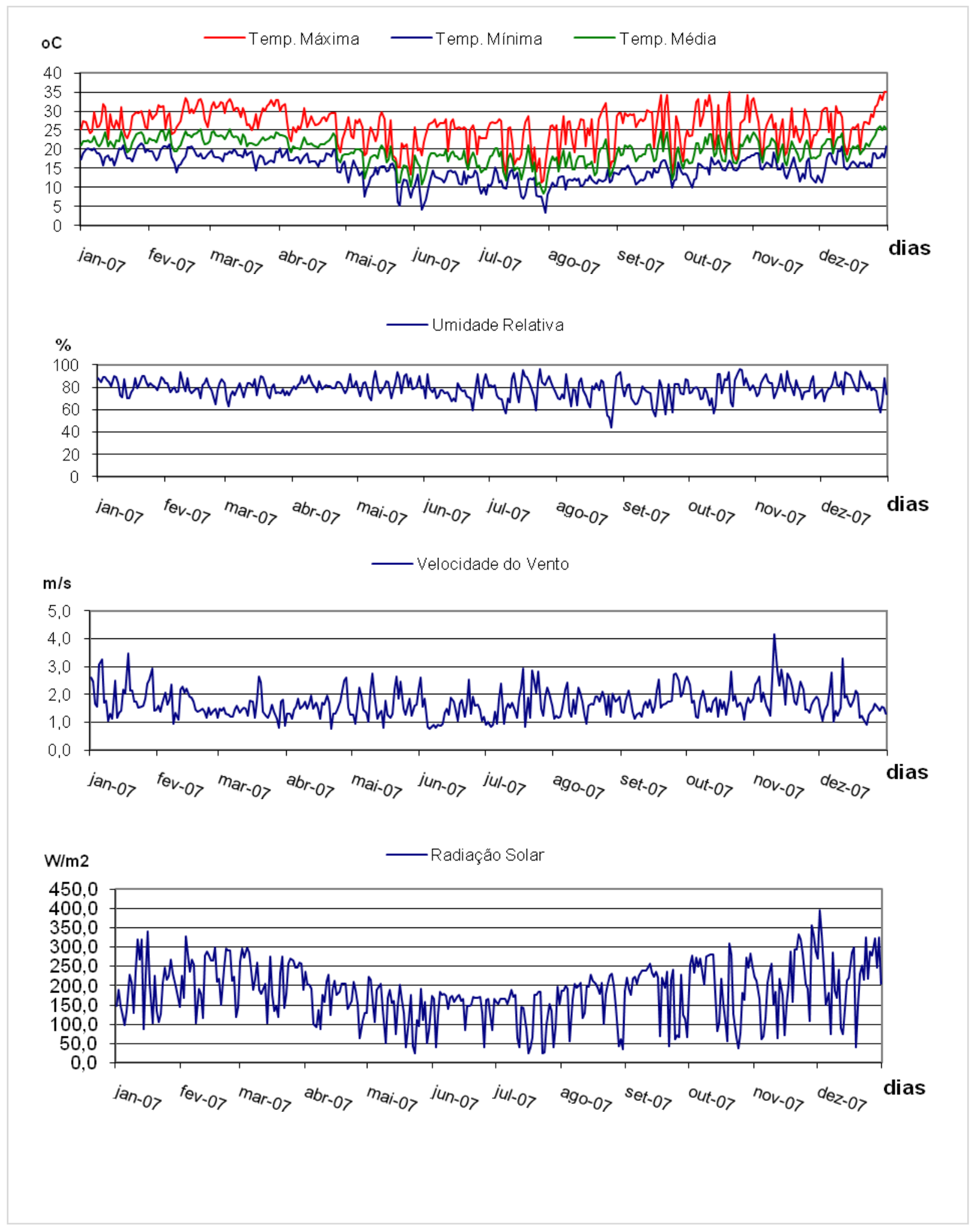

Fonte: EM-IAG/USP 
As Figuras 14 a 19 apresentam a representação gráfica das médias mensais das temperaturas do ar média, máxima e mínima medidas na EM-IAG/USP, no período de 2003 a 2007.

Os valores de temperatura média estiveram entre $14^{\circ} \mathrm{C}$ e $26^{\circ} \mathrm{C}$. Os valores das temperaturas médias foram mais elevados nos meses de janeiro, fevereiro e março e mais baixos nos meses de maio a setembro. Contudo, essa configuração não é homogênea. Nota-se que os meses de janeiro e fevereiro tiveram médias mais elevadas nos anos de 2003, sendo que, nesse ano, o mês de fevereiro foi mais quente que em todos os outros anos. No ano de 2005, os maiores valores médios de temperatura ocorreram no mês de janeiro e, nos anos de 2006 e 2007, essa ocorrência foi entre os meses de janeiro e março. A partir de abril, os valores começam a declinar e o período com os menores valores de temperatura média vão de maio a setembro. No ano de 2003, o período mais frio ocorreu em agosto; em 2004, em junho e julho; em 2005 e 2007, em julho. Os valores voltam a aumentar em setembro, contudo podendo ter um "atraso" conforme observado nos anos de 2003, 2005 e 2006 (Figura 14).

A distribuição mensal dos valores médios das temperaturas máximas está expressa na Figura 15. Esses valores situaram-se entre $20^{\circ} \mathrm{C}$ e $32^{\circ} \mathrm{C}$. Os meses de janeiro a março apresentam, em geral, os maiores valores de temperaturas máximas médias. Os meses de fevereiro de 2003 e março de 2007 apresentaram os maiores valores de temperatura máxima. Os menores valores ocorrem entre os meses de maio a agosto. Nos anos de 2006 e 2007 valores elevados estenderam-se até o mês de março. O ano de 2004 apresentou os menores valores de temperatura máxima nos meses de maio, junho e julho.

A Figura 16 mostra a distribuição mensal dos valores médios das temperaturas mínimas - entre $10^{\circ} \mathrm{C}$ e $20^{\circ} \mathrm{C}$. Os maiores valores ocorrem entre janeiro e março, exceto no ano de 2004, em que os valores foram mais baixos do que nos mesmos meses dos outros anos. Os valores começam a diminuir em maio e os menores valores ocorrem em julho e agosto. Contudo, no ano de 2006, os menores valores médios ocorreram de maio a agosto e, em 2007, de junho a agosto. 
Os valores de umidade relativa média mensal são, em geral, bastante elevados durante o ano - entre $65 \%$ e $90 \%$. Os maiores valores ocorreram entre setembro e abril e, os menores, nos meses de inverno. Em 2003 o menor valor ocorreu em julho; de 2004 a 2006, em agosto e; em 2007, em setembro (Figura 17).

A velocidade média diária do vento está representada na Figura 18 - entre 1,0 e 2,5m/s. Os ventos com maior velocidade ocorrem a partir de outubro, estendendo-se até dezembro. Em geral, os valores médios são bastante homogêneos, sendo que os meses de abril, maio, junho e julho apresentam valores médios baixos. Os anos de 2005 e 2006 caracterizaram-se por apresentar média de vento mensal baixo em maio, junho e julho. Em 2003, o mês de abril apresentou média baixa e, em 2007, no mês de março - entre 1,0 e 1,5 m/s.

Os valores médios da radiação solar global são apresentados na Figura 19. Os maiores valores correspondem aos meses de primavera-verão, sendo que, a partir do mês de março, começam a diminuir. O período com os menores valores médios são os meses de junho e julho. No ano de 2005 o mês de setembro apresentou valores médios baixos. 


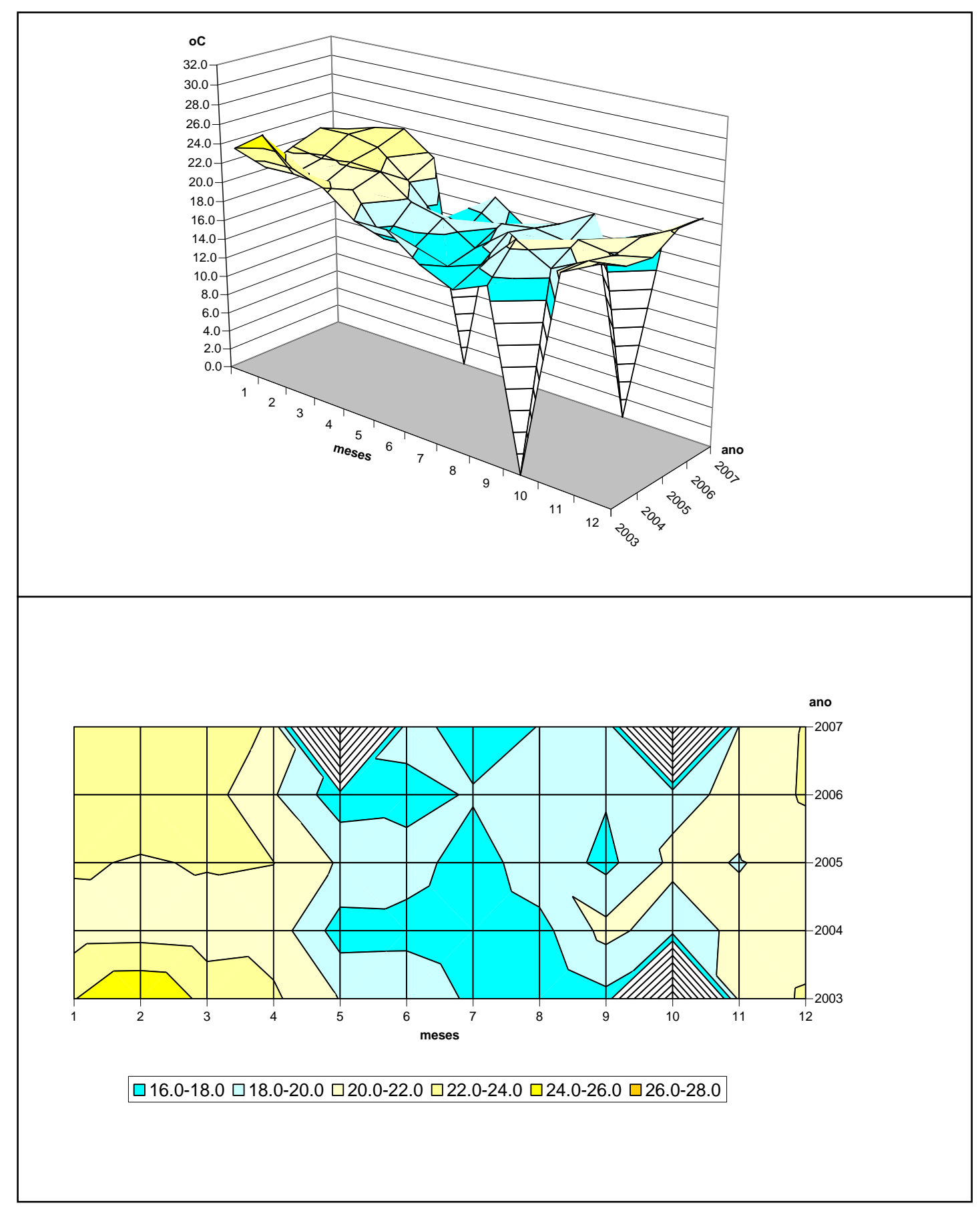

Figura 14 - Média mensal da temperatura do ar na EM-IAG/USP, no período de 2003 a 2007, São Paulo, SP.

Fonte: EM- IAG/USP 


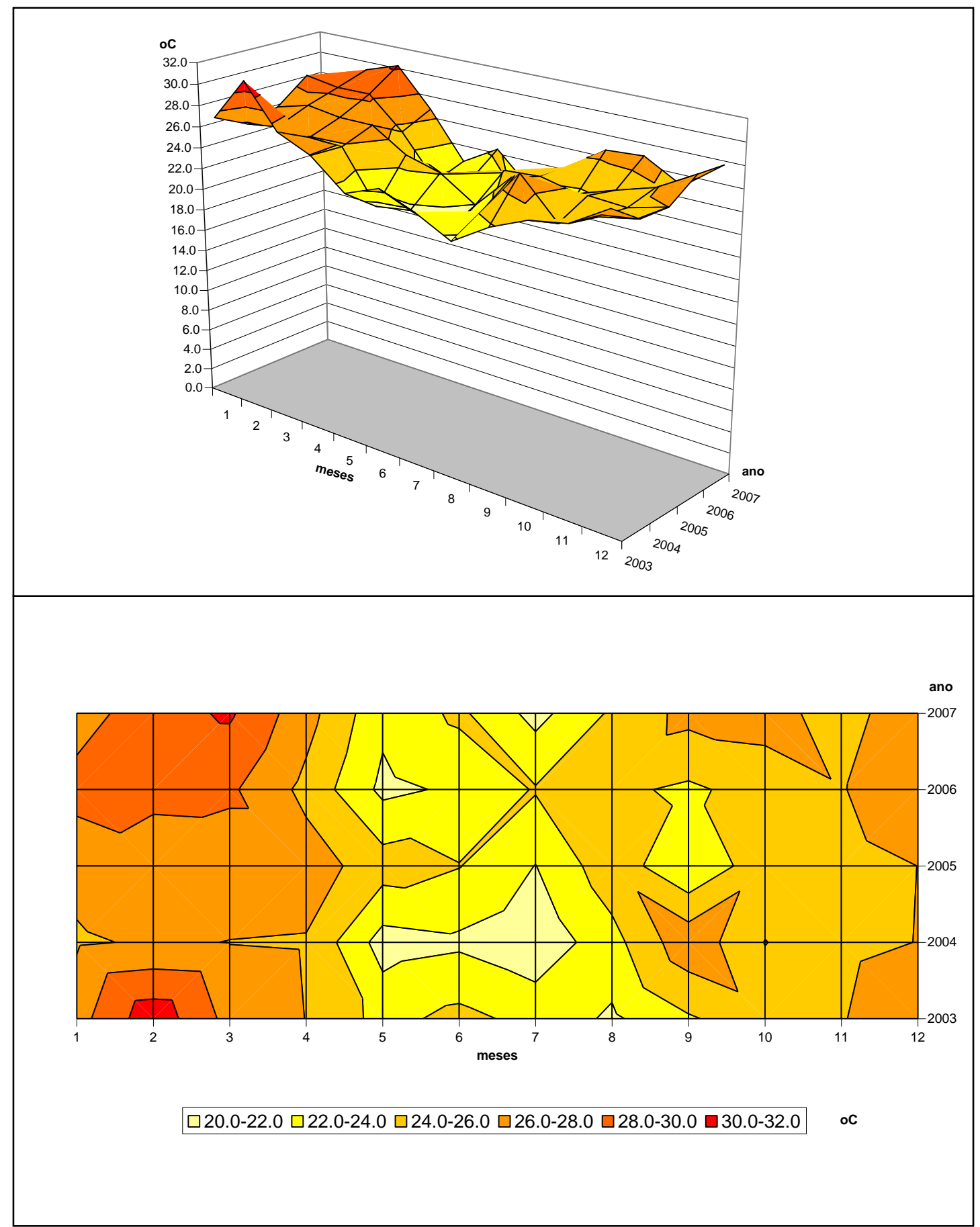

Figura 15 - Média mensal da temperatura máxima do ar na EM-IAG/USP, no período de 2003 a 2007, São Paulo, SP.

Fonte: EM-IAG/USP 


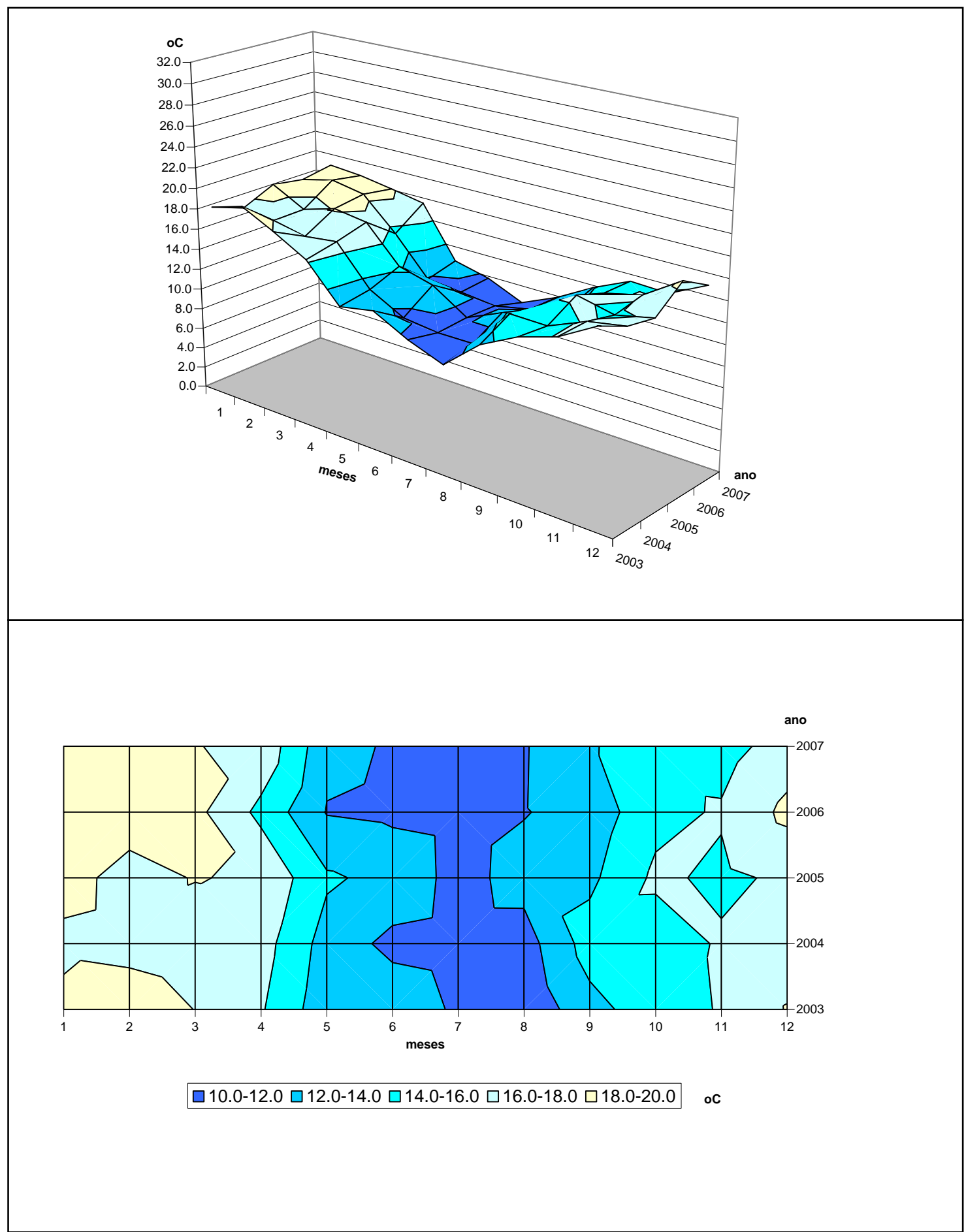

Figura 16 - Média mensal da temperatura do ar mínima na EM-IAG/USP, no período de 2003 a 2007, São Paulo, SP.

Fonte: EM-IAG/USP 


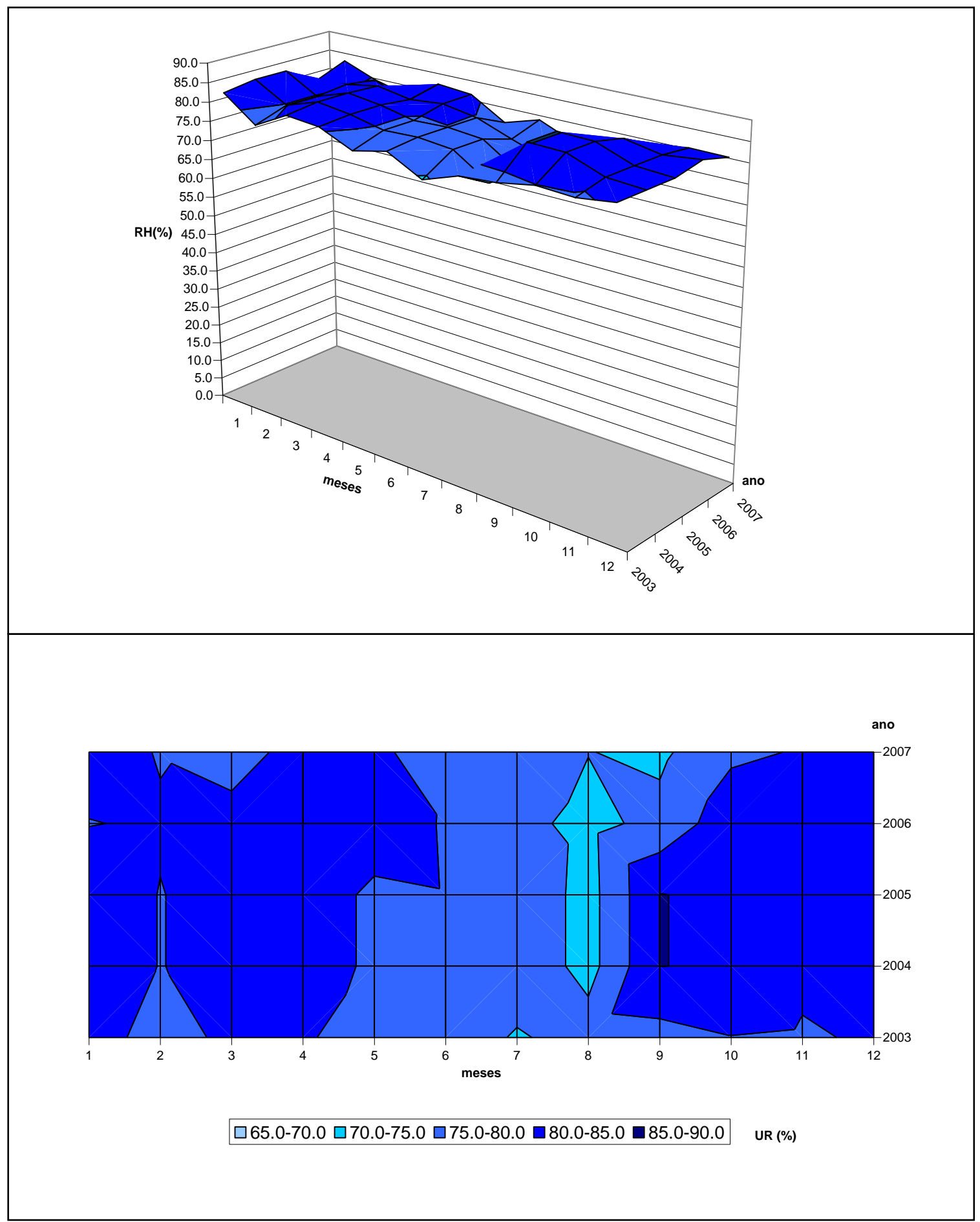

Figura 17 - Média mensal da umidade relativa do ar na EM-IAG/USP, no período de 2003 a 2007, São Paulo, SP.

Fonte: EM-IAG/USP 


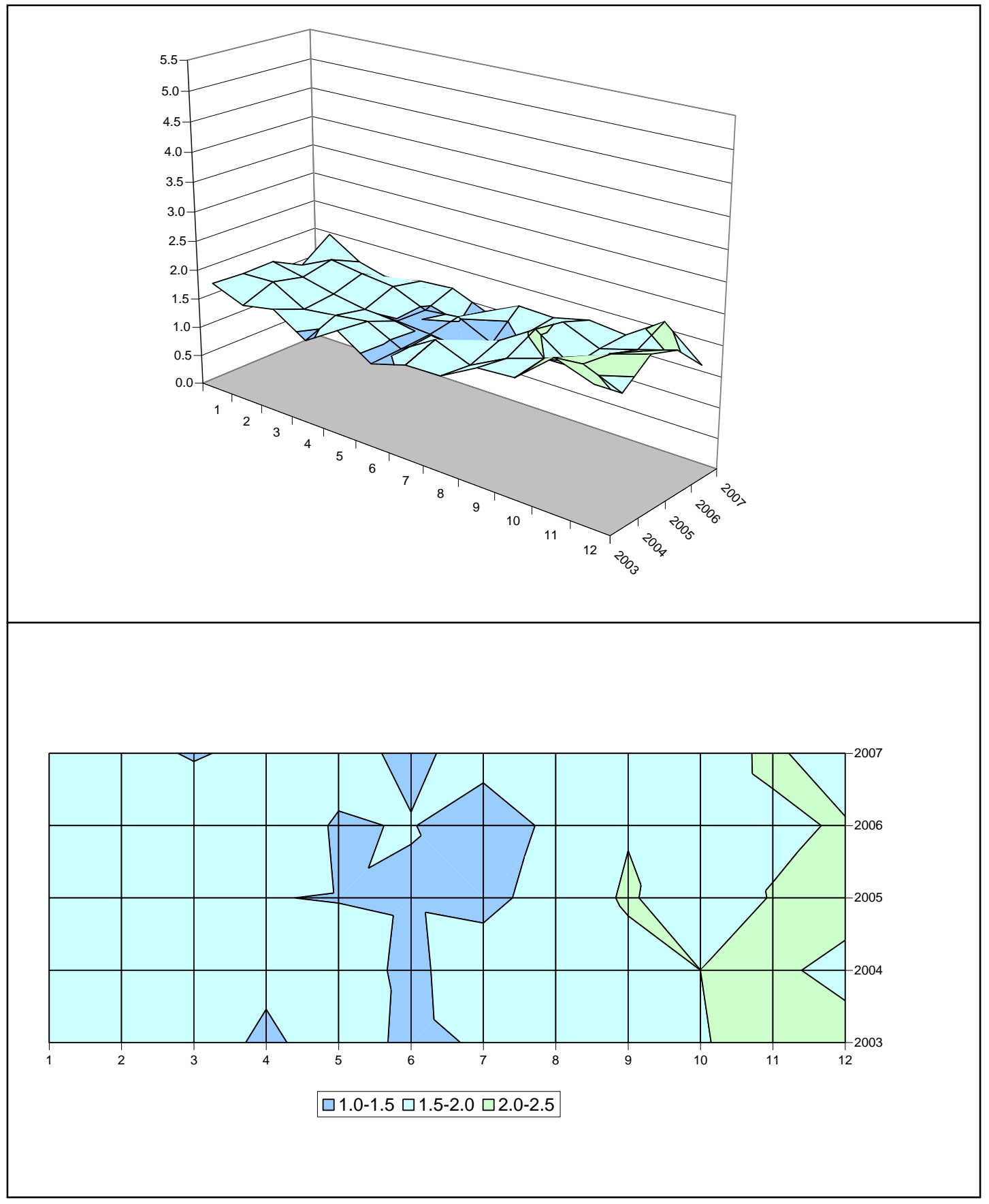

Figura 18 - Média mensal da velocidade do vento na EM-IAG/USP, no período de 2003 a 2007, São Paulo, SP.

Fonte: EM-IAG/USP 


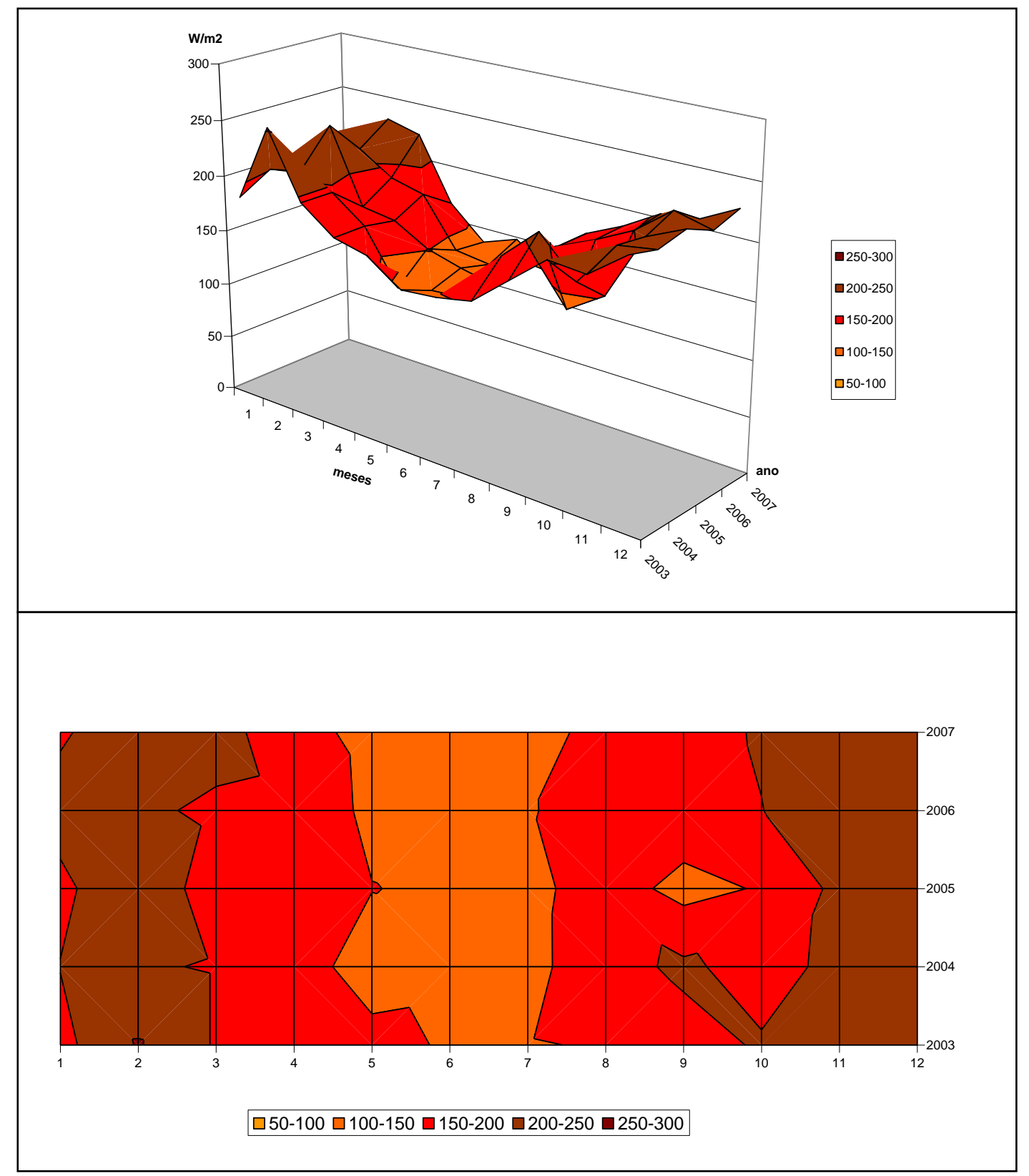

Figura 19 - Média mensal da radiação solar (W/m2) na EM-IAG/USP, no período de 2003 a 2007, São Paulo, SP.

Fonte: EM-IAG/USP 


\subsubsection{EM-CONGONHAS}

A Estação Meteorológica de Congonhas é uma estação automática. É comum, nessas estações, haver falha no registro dos dados. Dos 1826 dias observados, em 1722 dos dias $(94,3 \%)$ houve registro, ou seja, em 104 dias não houve medição. Houve falha na obtenção nos meses de outubro de 2003, maio de 2007 e outubro de 2007.

A Tabela 6 mostra a estatística descritiva dos cinco anos de observação na EM-CONGONHAS. O valor médio da temperatura média foi de $20,1^{\circ} \mathrm{C}$, o valor máximo de $28,6^{\circ} \mathrm{C}$ e o valor mínimo de $10,3^{\circ} \mathrm{C}$. A média das máximas foi de $24,6^{\circ} \mathrm{C}$ e o mínimo de $10,7^{\circ} \mathrm{C}$ e o valor máximo de $35,4^{\circ} \mathrm{C}$. O valor médio das temperaturas mínimas foi de $16,8^{\circ} \mathrm{C}$, sendo $10,0^{\circ} \mathrm{C}$ e $23,8^{\circ} \mathrm{C}$ os valores mínimo e máximo, respectivamente.

O valor médio da umidade relativa do ar foi de $75,5 \%$, sendo que o valor mínimo foi de $31 \%$ e valor máximo de $95 \%$.

A média da velocidade diária do vento foi de $2,9 \mathrm{~m} / \mathrm{s}$. O valor máximo foi de $7,1 \mathrm{~m} / \mathrm{s}$ e o valor mínimo de $0,1 \mathrm{~m} / \mathrm{s}$.

O índice de conforto PET calculado com os dados da EM-CONGONHAS teve valor médio de $18,5^{\circ} \mathrm{C}$, valor mínimo de $4,2^{\circ} \mathrm{C}$ e máximo de $34,2^{\circ} \mathrm{C}$.

Tabela 6 - Estatística descritiva dos dados meteorológicos da EM-CONGONHAS, no período de 1.01.2003 a 31.12.2007.

\begin{tabular}{|c|c|c|c|c|c|c|c|}
\hline \multicolumn{2}{|l|}{ 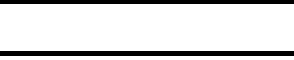 } & Ta $\left({ }^{\circ} \mathbf{C}\right)$ & $\operatorname{TaMax}\left({ }^{\circ} \mathrm{C}\right)$ & $\operatorname{TaMin}\left({ }^{\circ} \mathrm{C}\right)$ & RH (\%) & $\mathbf{V}(\mathbf{m} / \mathbf{s})$ & PET $\left({ }^{\circ} \mathrm{C}\right)$ \\
\hline \multicolumn{2}{|l|}{ Média } & 20,2 & 24,9 & 16,9 & 75,6 & 2,9 & 18,5 \\
\hline \multicolumn{2}{|l|}{ Mediana } & 20,5 & 25,3 & 17,1 & 77,0 & 2,8 & 18,5 \\
\hline \multicolumn{2}{|l|}{ Moda } & 22,1 & 24,6 & 17,4 & 81,0 & 3,0 & 18,1 \\
\hline \multicolumn{2}{|c|}{ Desvio Padrão } & 3,4 & 4,5 & 3,1 & 10,6 & 1,1 & 5,1 \\
\hline \multicolumn{2}{|c|}{ Mínimo } & 10,3 & 10,7 & 10,0 & 31,0 & 0,1 & 4,2 \\
\hline \multicolumn{2}{|l|}{ Máximo } & 28,6 & 35,4 & 23,8 & 95,0 & 7,1 & 34,2 \\
\hline \multirow[t]{3}{*}{ Percentil } & 25 & 17,9 & 22,0 & 14,6 & 70,0 & 2,2 & 15,4 \\
\hline & 50 & 20,5 & 25,3 & 17,1 & 77,0 & 2,8 & 18,5 \\
\hline & 75 & 22,7 & 28,1 & 19,3 & 83,0 & 3,7 & 22,0 \\
\hline
\end{tabular}

Fonte: Estação Meteorológica de Congonhas n=1722 
As pranchas 6 a 10 mostram o ritmo diário das variáveis meteorológicas de temperatura do ar, umidade relativa do ar e velocidade do vento, medidas na EMCONGONHAS e utilizadas neste estudo.

O ritmo diário das variáveis medidas na EM-CONGONHAS acompanham aqueles observados na EM-IAG/USP. A marcha das temperaturas caracterizam-se pela forte oscilação inter-diária, principalmente na primavera-verão, menores valores no outono-inverno e maiores na primavera-verão. Contudo, há algumas diferenças que serão ressaltadas.

As temperaturas mínimas apresentam valores mais elevados do que as temperaturas mínimas observadas na EM-IAG/USP. Os valores médios diários situam-se entorno dos $10^{\circ} \mathrm{C}$. As temperaturas máximas oscilaram entre $15^{\circ} \mathrm{C}$ e $35^{\circ} \mathrm{C}$, sendo que, no ano de 2003, houve maior número de dias com valores próximos a $35^{\circ} \mathrm{C}$.

A umidade relativa do ar é relativamente elevada durante o ano todo, sendo que valores baixos (menores de 60\%) ocorrem nos meses que vão de maio a outubro.

A velocidade do vento é mais elevada do que aquela medida no EMIAG/USP. No período estudado houve dias com velocidade acima de 5,0 m/s. Observa-se a tendência de aumento da velocidade do vento no final do ano.

As Figuras 20 a 24 mostram a representação gráfica das variáveis médias mensais medidas na EM-CONGONHAS, nos anos de 2003 a 2007.

Os gráficos da Figura 20 mostram os valores de temperaturas médias mensais. Os valores médios de temperatura situaram-se entre $16^{\circ} \mathrm{C}$ e $26^{\circ} \mathrm{C}$. Os maiores valores médios ocorrem nos meses de verão, ou seja, dezembro, janeiro e fevereiro. O mês de fevereiro de 2003 apresentou o maior valor de temperatura média. O ano de 2004 apresentou valores mais baixos do que os outros anos em quase todos os meses. Os menores valores ocorrem de maio a setembro. Chamam a atenção os meses de setembro nos anos de 2003 e 2005, em que ocorreu o menor valor médio para o período. 
Prancha 6 - Ritmo diário das temperaturas do ar, umidade relativa média do ar e velocidade do vento, na EM-CONGONHAS, de 1 de janeiro a 31 de dezembro de 2003.
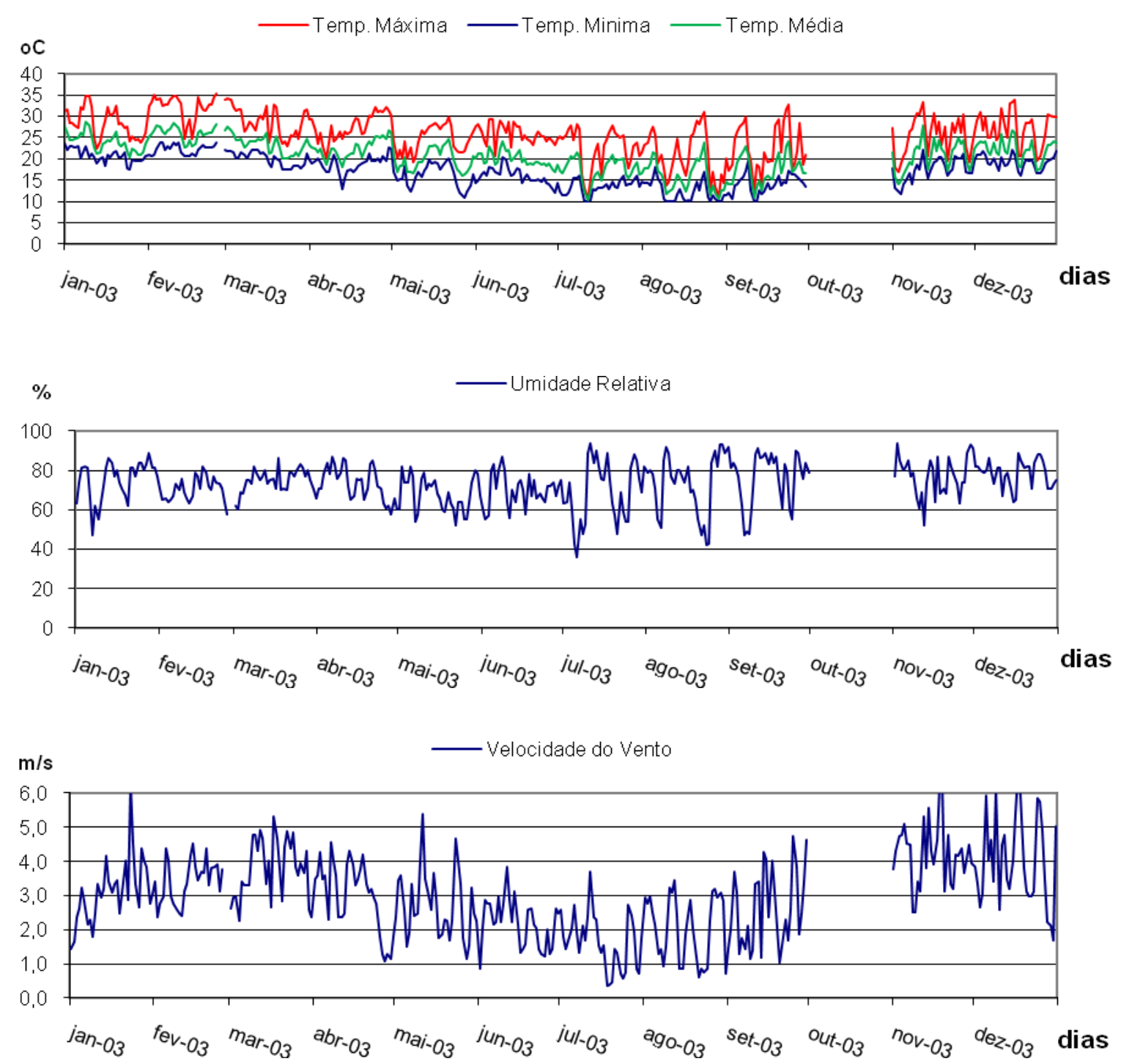

Fonte: EM-Congonhas 
Prancha 7 - Ritmo diário das temperaturas do ar, umidade relativa média do ar e velocidade do vento, na EM-CONGONHAS de 1 de janeiro a 31 de dezembro de 2004.

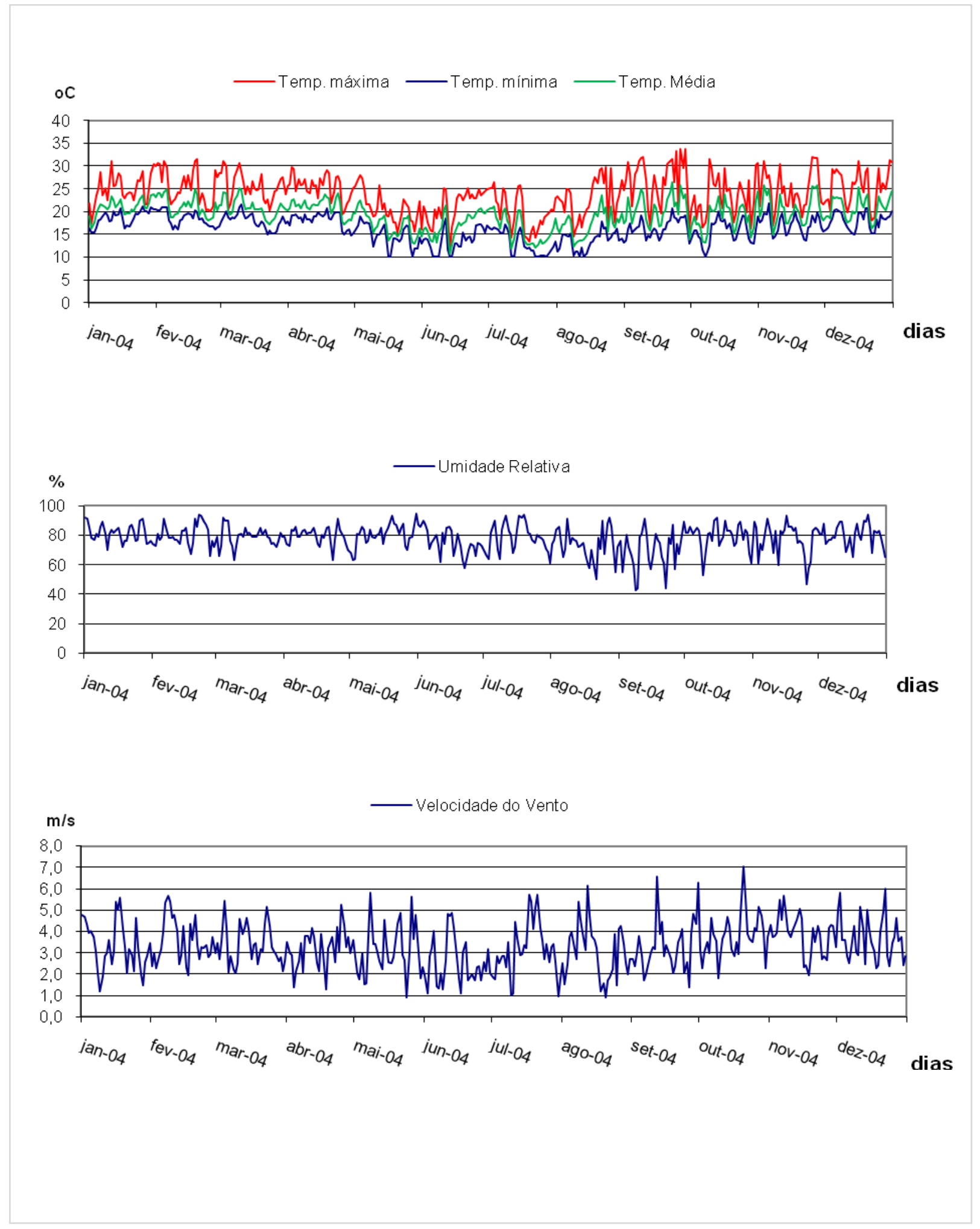

Fonte: EM-Congonhas 
Prancha 8 - Ritmo diário das temperaturas do ar, umidade relativa média do ar e velocidade do vento, na EM-CONGONHAS de 1 de janeiro a 31 de dezembro de 2005.
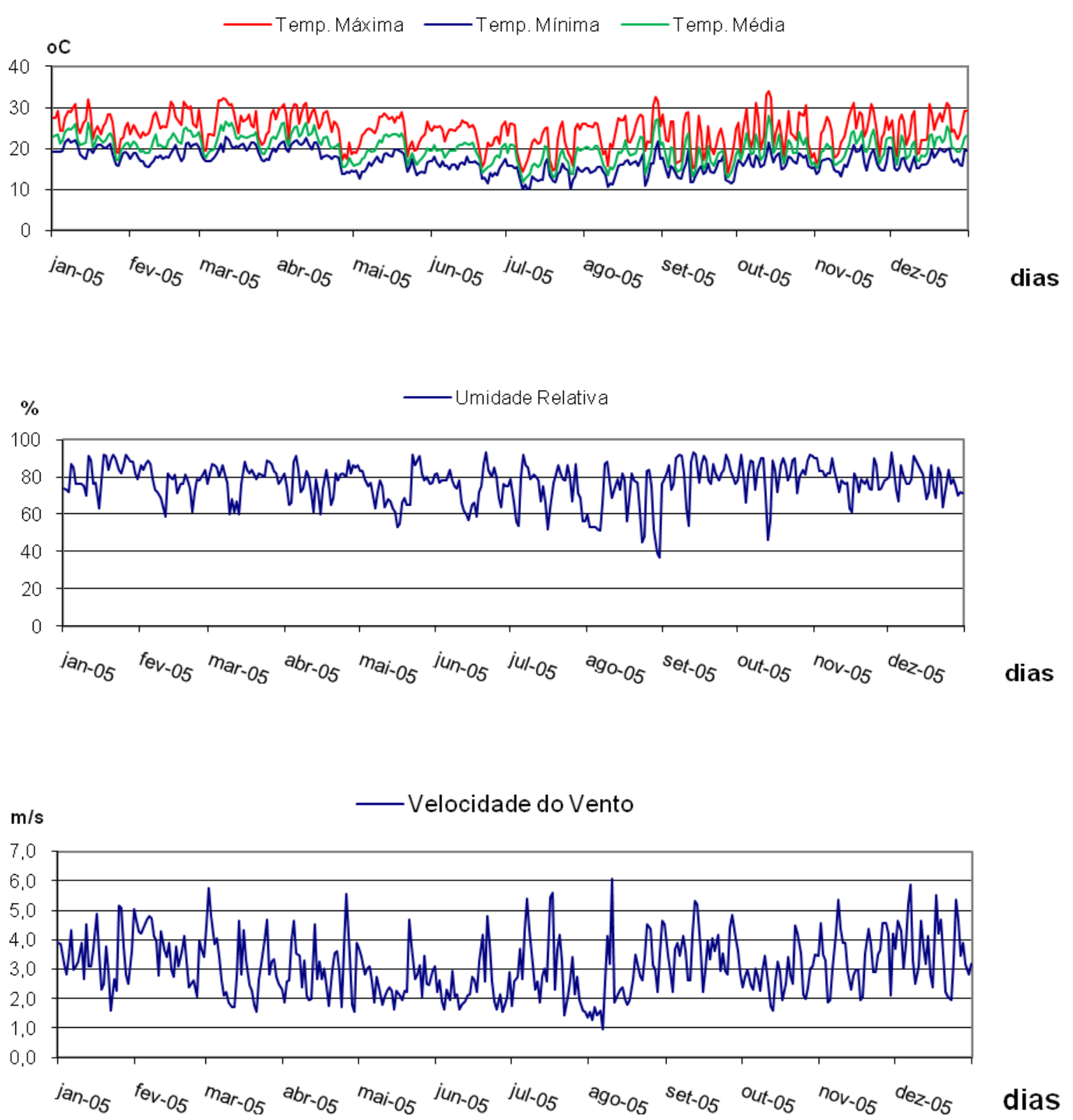
Prancha 9 - Ritmo diário das temperaturas do ar, umidade relativa média do ar e velocidade do vento, na EM-CONGONHAS, de 1 de janeiro a 31 de dezembro de 2006.

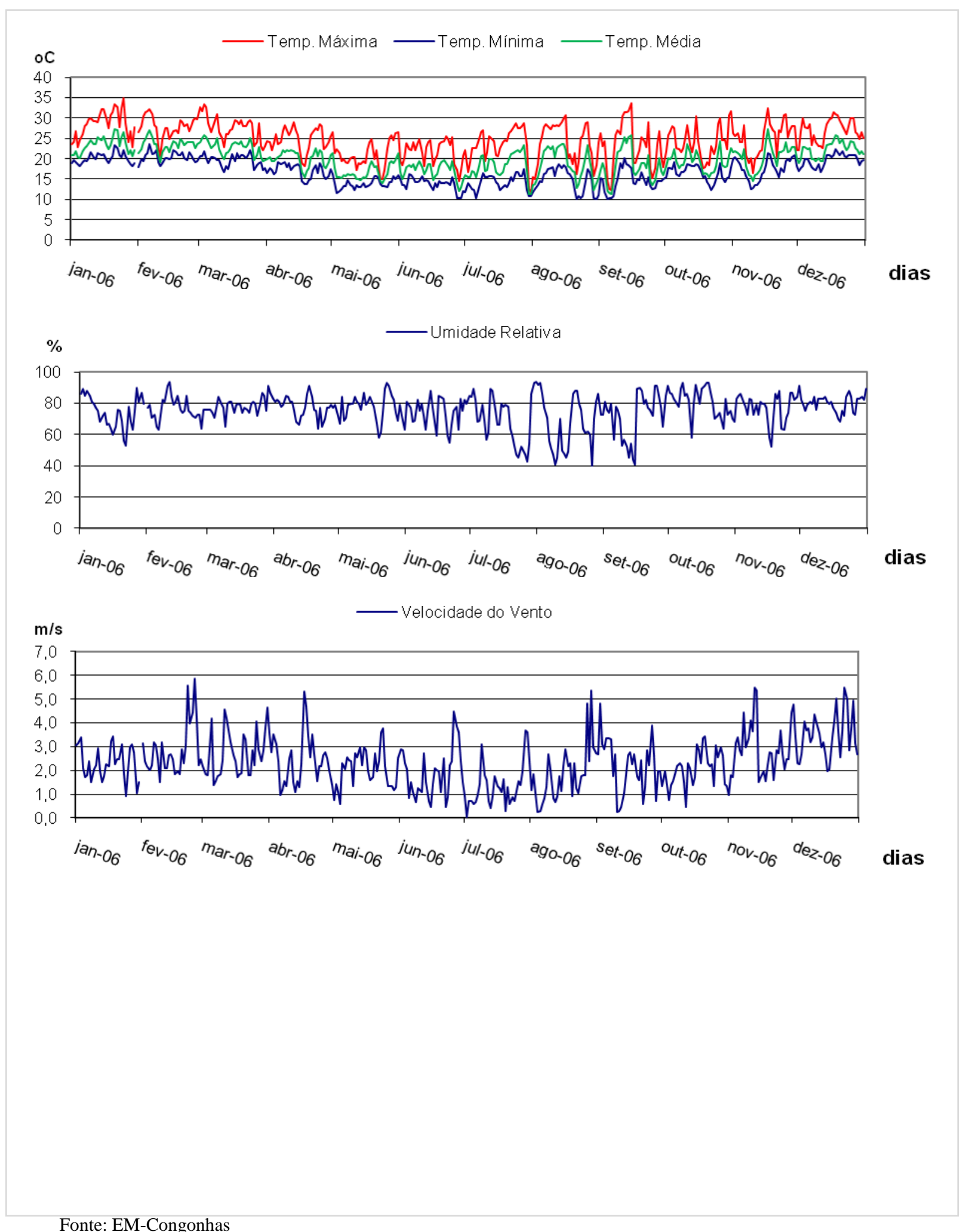

Fonte: EM-Congonhas 
Prancha 10 - Ritmo diário das temperaturas do ar, umidade relativa média do ar e velocidade do vento, na EM-CONGONHAS, de 1 de janeiro a 31 de dezembro de 2007.

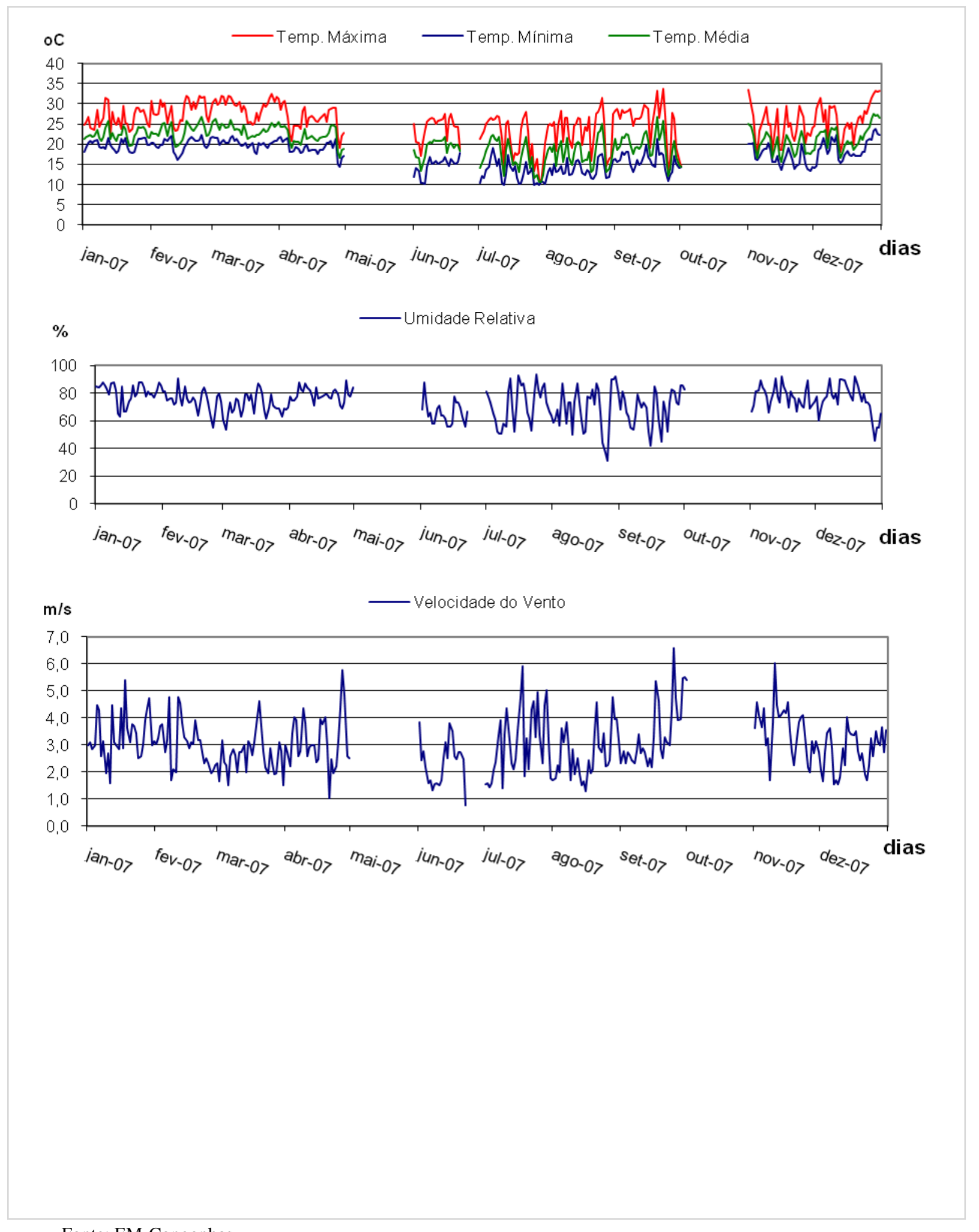

Fonte: EM-Congonhas 


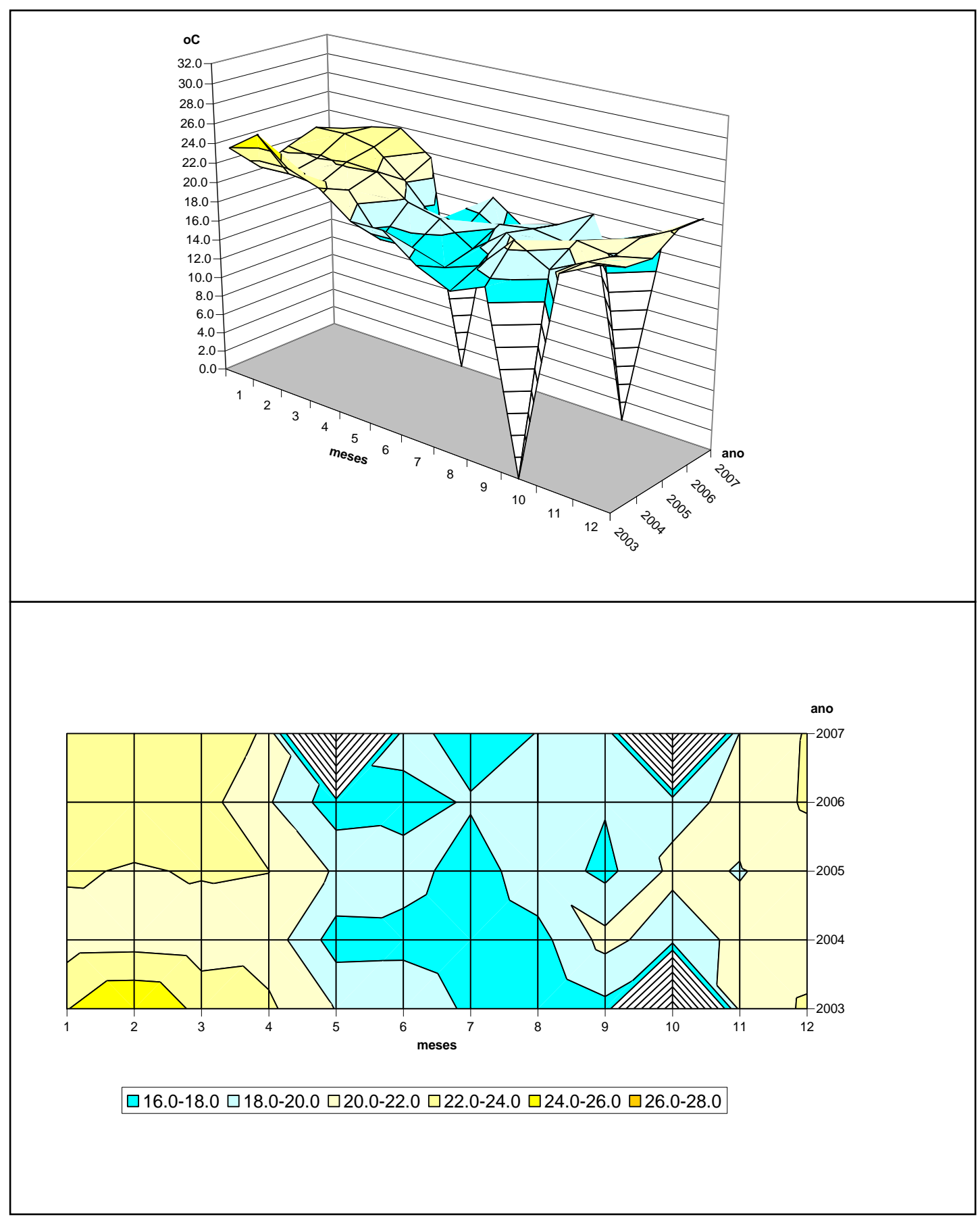

Figura 20 - Média mensal da temperatura média do ar na EM-CONGONHAS, no período de 2003 a 2007, São Paulo, SP.

Fonte: EM-CONGONHAS 
A Figura 21 mostra os valores médios das temperaturas máximas. Os valores situaram-se entre $20^{\circ} \mathrm{C}$ e acima de $32^{\circ} \mathrm{C}$. Os maiores valores ocorreram entre dezembro e abril e, os menores, entre maio e agosto.

O mês de fevereiro de 2003 apresentou a maior média máxima do período, $32,2^{\circ} \mathrm{C}$. O mês de setembro de 2004 apresentou valor médio mais elevado e, em 2005, mais baixo do que o mesmo mês nos outros anos.

Os valores médios mensais de temperatura mínima situaram-se entre $12^{\circ} \mathrm{C} \mathrm{e}$ $24^{\circ} \mathrm{C}$ e são apresentados na Figura 22. Os maiores valores ocorreram entre janeiro e março, especificamente nos anos de 2003, 2006 e 2007 (exceto janeiro). O mês de fevereiro teve o maior valor de mínima $\left(22,2^{\circ} \mathrm{C}\right)$ do período. Os menores valores (menor do que $16^{\circ} \mathrm{C}$ ) ocorreram entre maio e setembro, sendo que valores abaixo de $14^{\circ} \mathrm{C}$ ocorreram entre julho e agosto, exceto no ano de 2004 , em que esses valores ocorrem em maio, junho e julho.

Os valores médios mensais de umidade relativa do ar são apresentados na Figura 23. De modo geral, a umidade relativa média é elevada e os valores situaramse entre $65 \%$ e $85 \%$. Os valores mais baixos (abaixo de $70 \%$ ) ocorreram nos meses de maio e julho de 2003, agosto de 2005, julho e agosto de 2006, agosto e setembro de 2007.

A velocidade média mensal do vento na EM-CONGONHAS é de modo geral mais elevada do que na EM-IAG/USP situando-se entre $1,0 \mathrm{~m} / \mathrm{s}$ e 4,5 m/s, conforme se observa na Figura 24. Valores mais elevados concentram-se nos meses de primavera-verão (setembro a março) e os menores valores nos meses de inverno. 


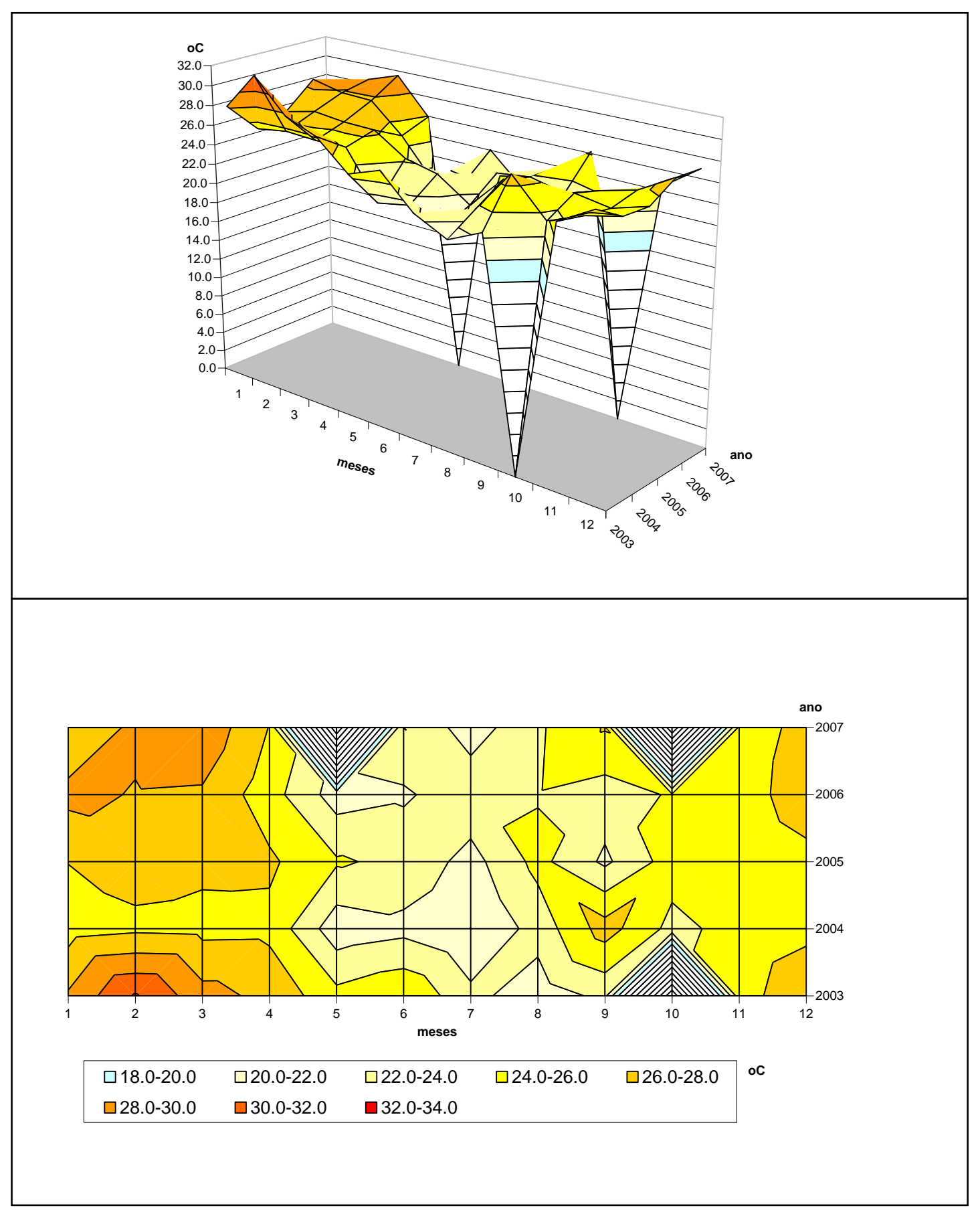

Figura 21 - Média mensal da temperatura máxima do ar na EM-CONGONHAS, no período de 2003 a 2007, São Paulo, SP.

Fonte: EM-CONGONHAS 


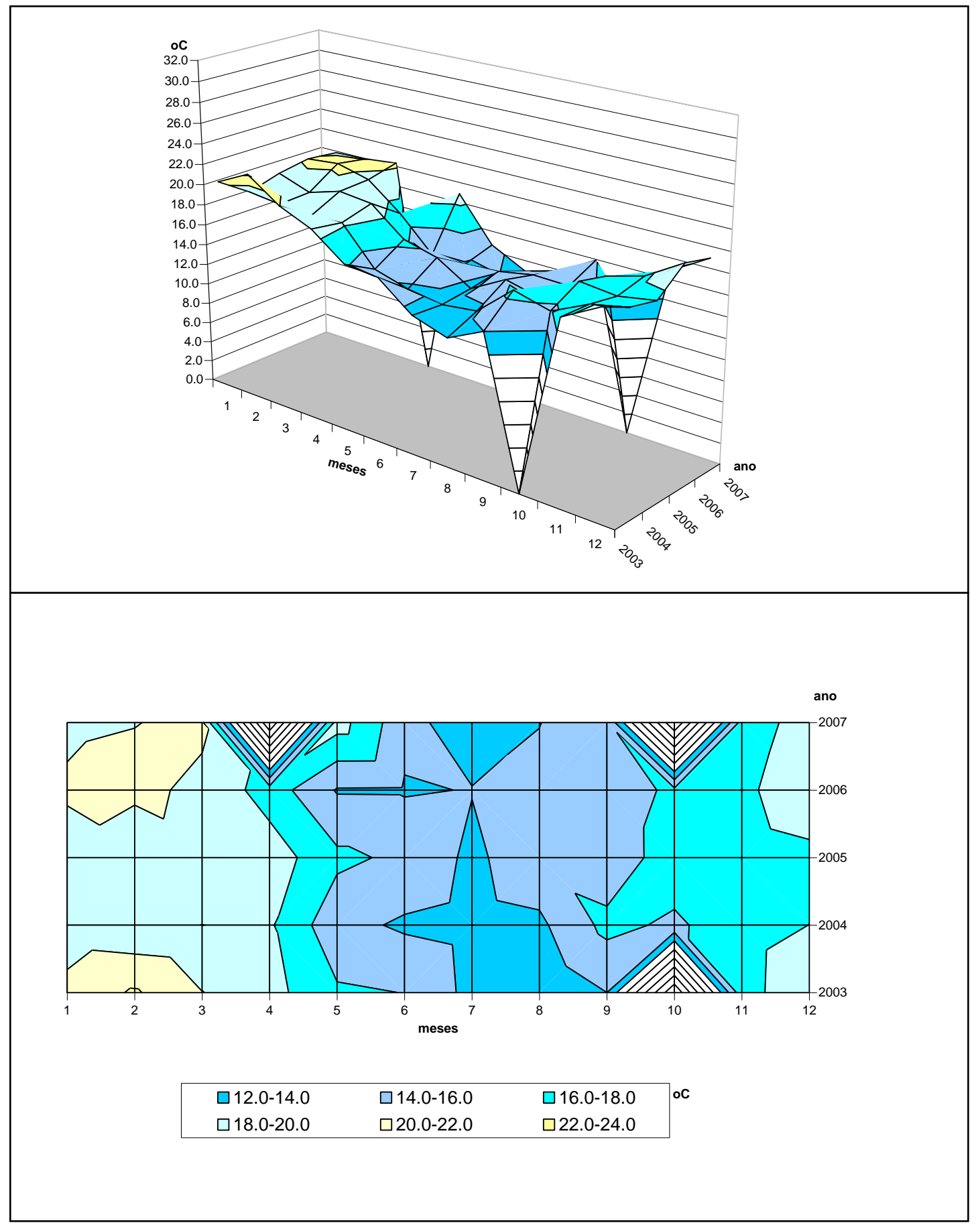

Figura 22 - Média mensal da temperatura mínima do ar na EM-CONGONHAS, no período de 2003 a 2007, São Paulo, SP.

Fonte: EM-CONGONHAS 


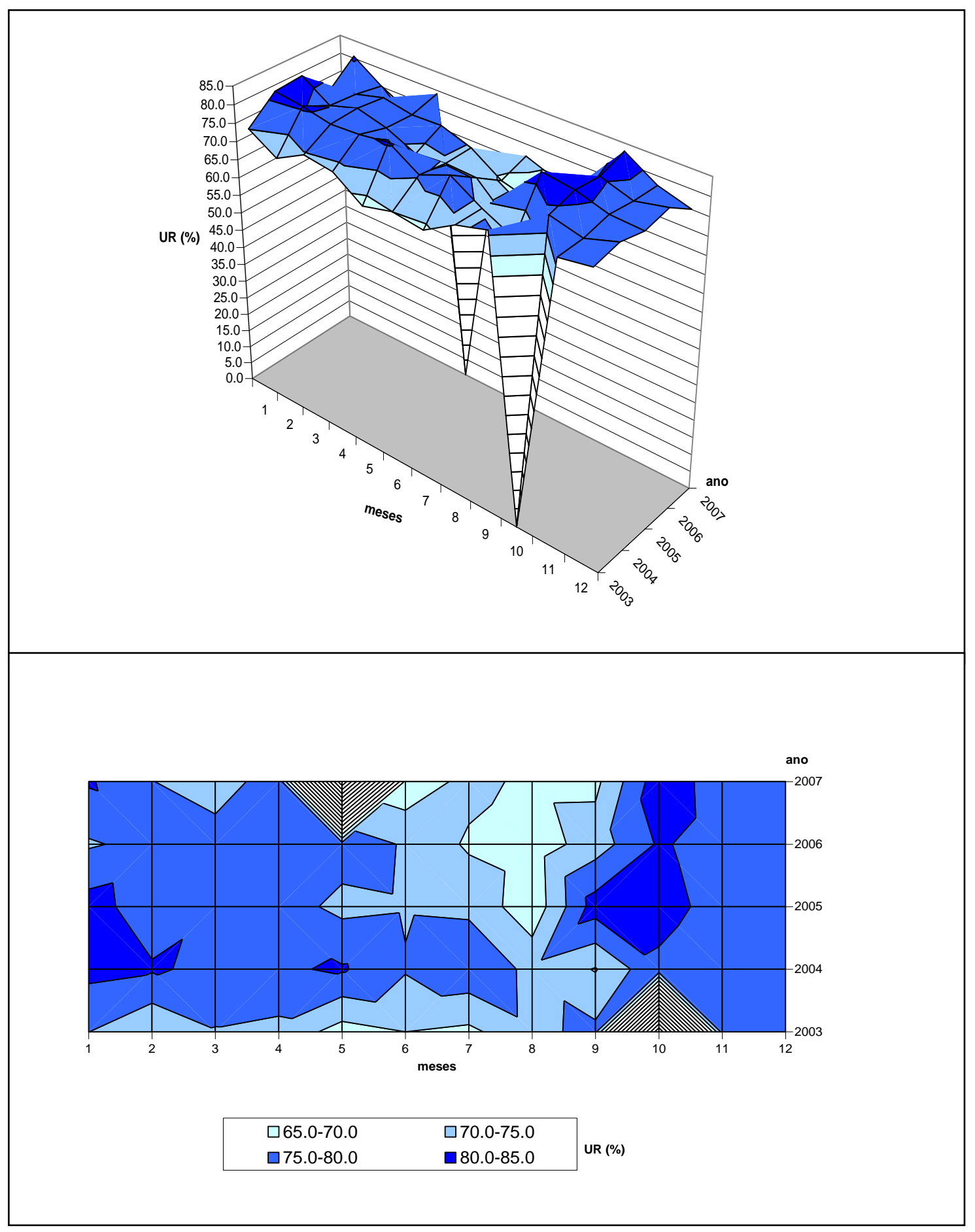

Figura 23 - Média mensal da umidade relativa do ar na EM-CONGONHAS, no período de 2003 a 2007, São Paulo, SP.

Fonte: EM-CONGONHAS 


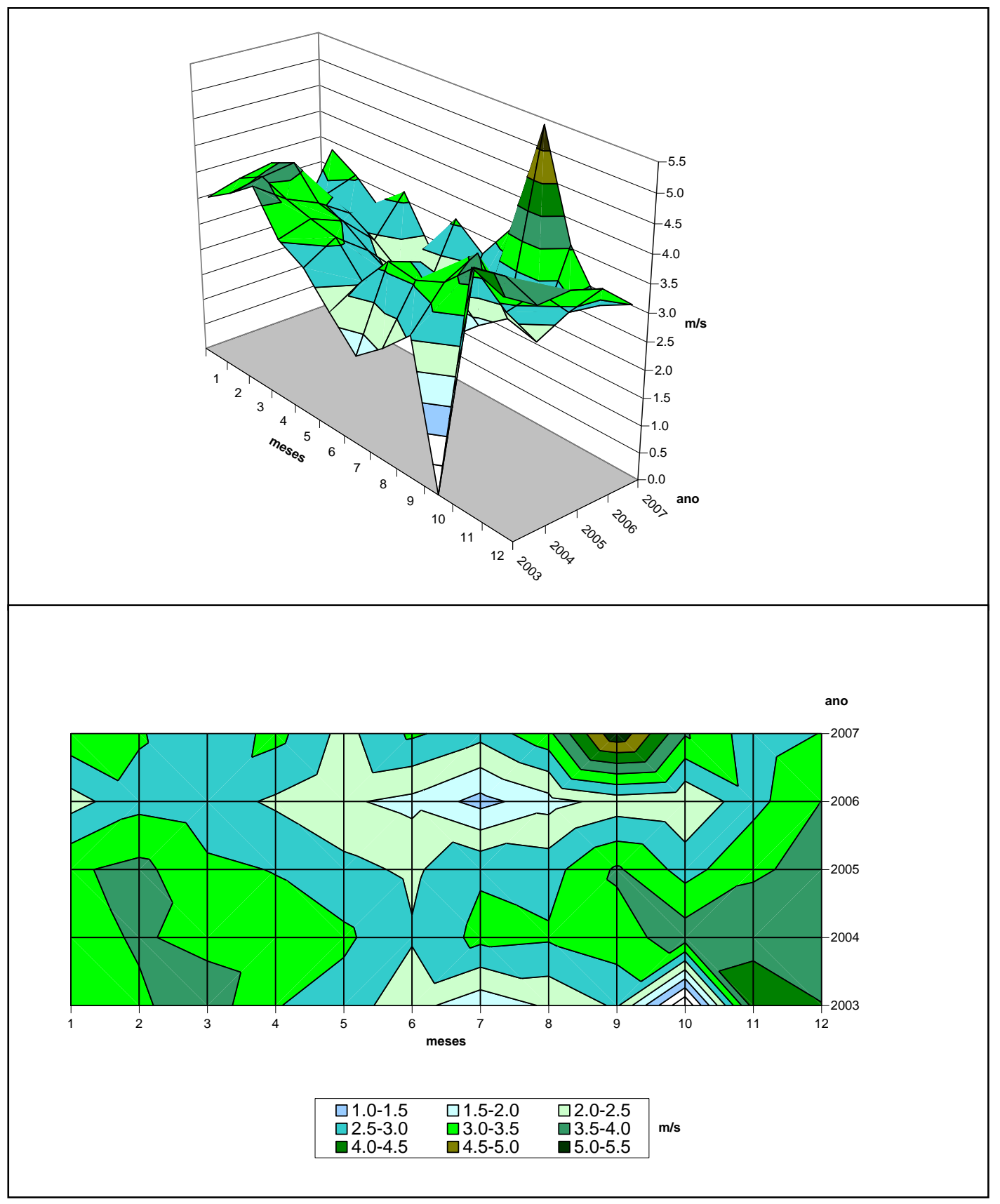

Figura 24 - Média mensal da velocidade do vento na EM-CONGONHAS, no período de 2003 a 2007, São Paulo, SP.

Fonte: EM-CONGONHAS 


\subsubsection{Séries Temporais do ambiente termal na EM-IAG/USP e EM- CONGONHAS}

As Figuras a seguir apresentam os gráficos de distribuição mensal das variáveis medidas nas estações meteorológicas EM-IAG/USP e EM-CONGONHAS, nos anos de 2003 a 2007.

Os gráficos de Boxplot apresentam a distribuição dos valores mensais, ou seja, eles mostram a variabilidade, a mediana, o valor máximo e mínino, os quartis 75 e 25 . Os pontos fora das caixas representam os outliers ${ }^{20}$

A Figura 25 e a Figura 26 mostram a distribuição mensal da temperatura média na EM-IAG/USP e na EM-CONGONHAS, respectivamente. O gráfico da temperatura média aponta tendência à sazonalidade; apresenta os maiores valores nos meses de primavera-verão (setembro a março) e declínio dos valores nos meses de outono-inverno (abril-agosto). Nota-se que, em geral, a maior variabilidade mensal das temperaturas ocorre nos meses de inverno-primavera (maio a outubro).

Não há um padrão para ocorrência de outliers, ou seja, valores que se distanciaram do centro da distribuição das temperaturas do mês, contudo há maior predominância de valores extremos baixos, exceto no mês de fevereiro de 2006, na EM-CONGONHAS.

\footnotetext{
${ }^{20}$ O box-plot (diagrama de caixa), é um gráfico que descreve simultaneamente várias características importantes de um conjunto de dados, tais como centro, dispersão, desvio e identificação das observações que estão longe do centro dos dados. Essas observações são chamadas de outliers ESTANISLAU e SEGRI (s/d).
} 


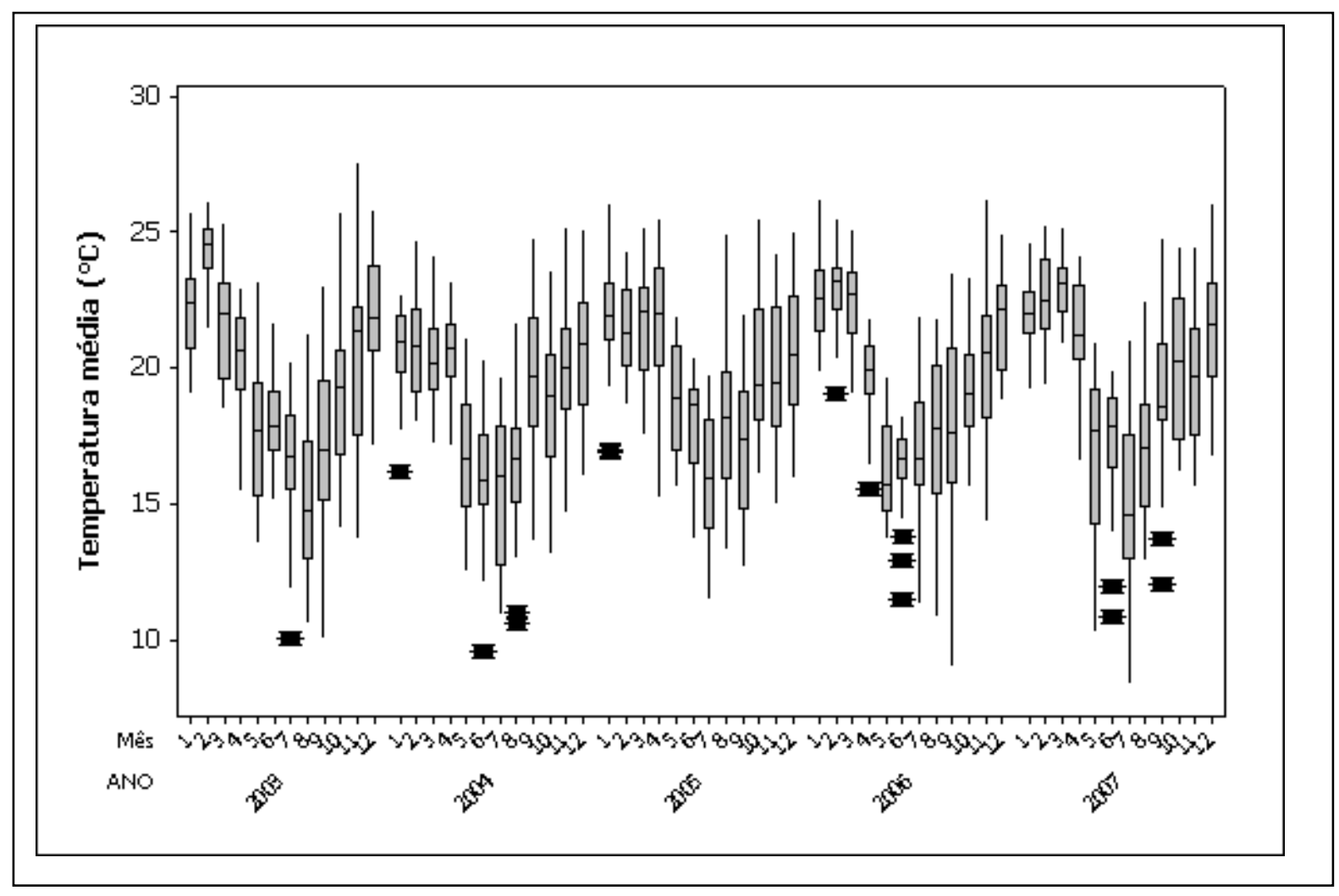

Figura 25 - Ritmo mensal da temperatura média na EM-IAG/USP, São Paulo, SP, 2003 a 2007.

Fonte: EM-IAG/USP

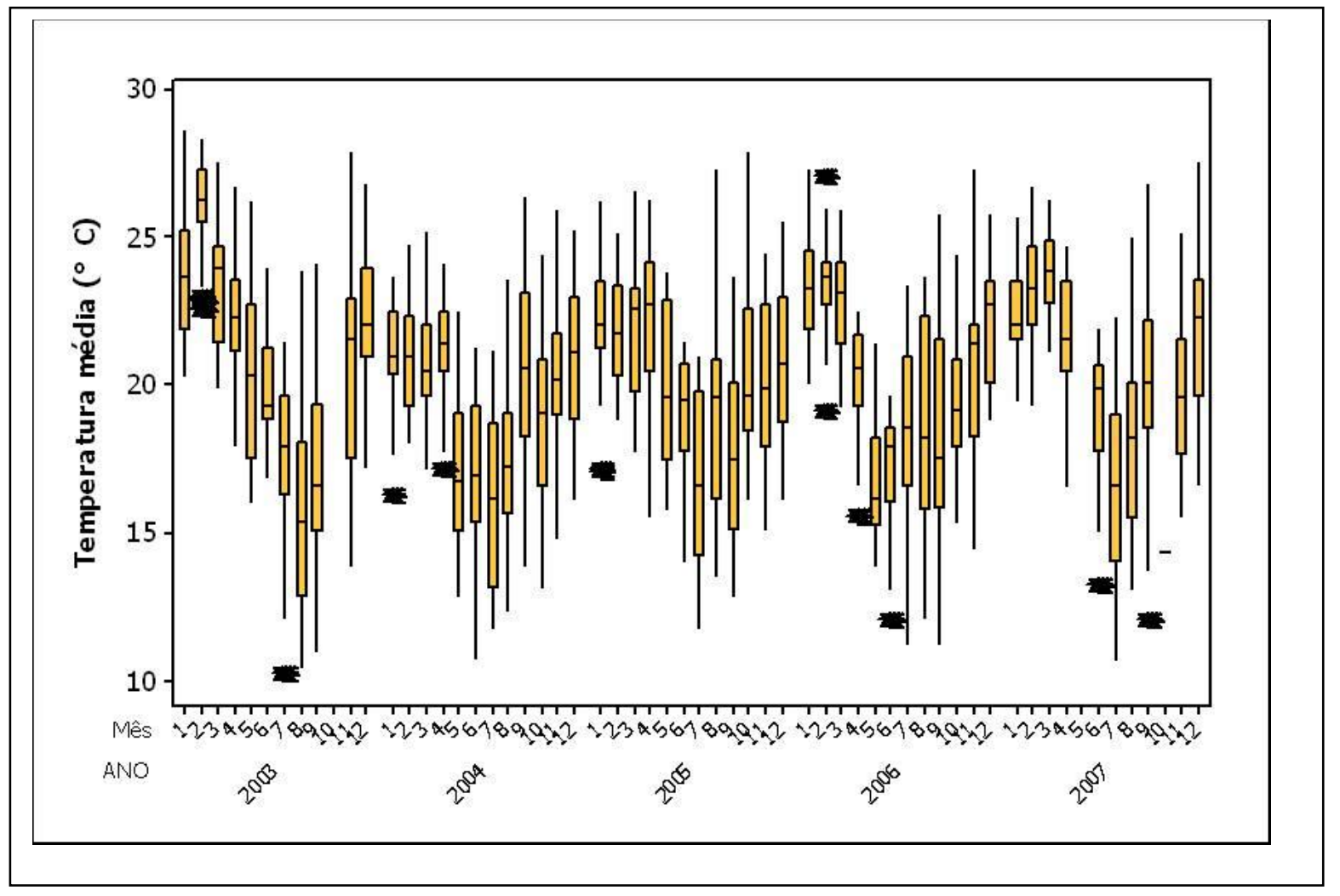

Figura 26 - Ritmo mensal da temperatura média na EM-CONGONHAS, São Paulo, SP, 2003 a 2007.

Fonte: EM-CONGONHAS 
A Figura 27 e a Figura 28 mostram os gráficos da distribuição mensal das temperaturas mínimas na EM-IAG/USP e EM-CONGONHAS. Nota-se também o padrão sazonal da distribuição das temperaturas mínimas, em que os maiores valores ocorrem nos meses de primavera-verão (setembro a março) e os menores valores no outono-inverno (abril a agosto). A maior variabilidade das temperaturas mínimas mensais ocorre nos meses de outono-inverno, contudo os dados da EMCONGONHAS apresentam maior variabilidade na distribuição das temperaturas mínimas do que os da EM-IAG/USP.

Neste caso, também não há padrão para ocorrência dos outliers, contudo há predominância de valores mais baixos do que mais altos com relação à distribuição mensal das temperaturas mínimas.

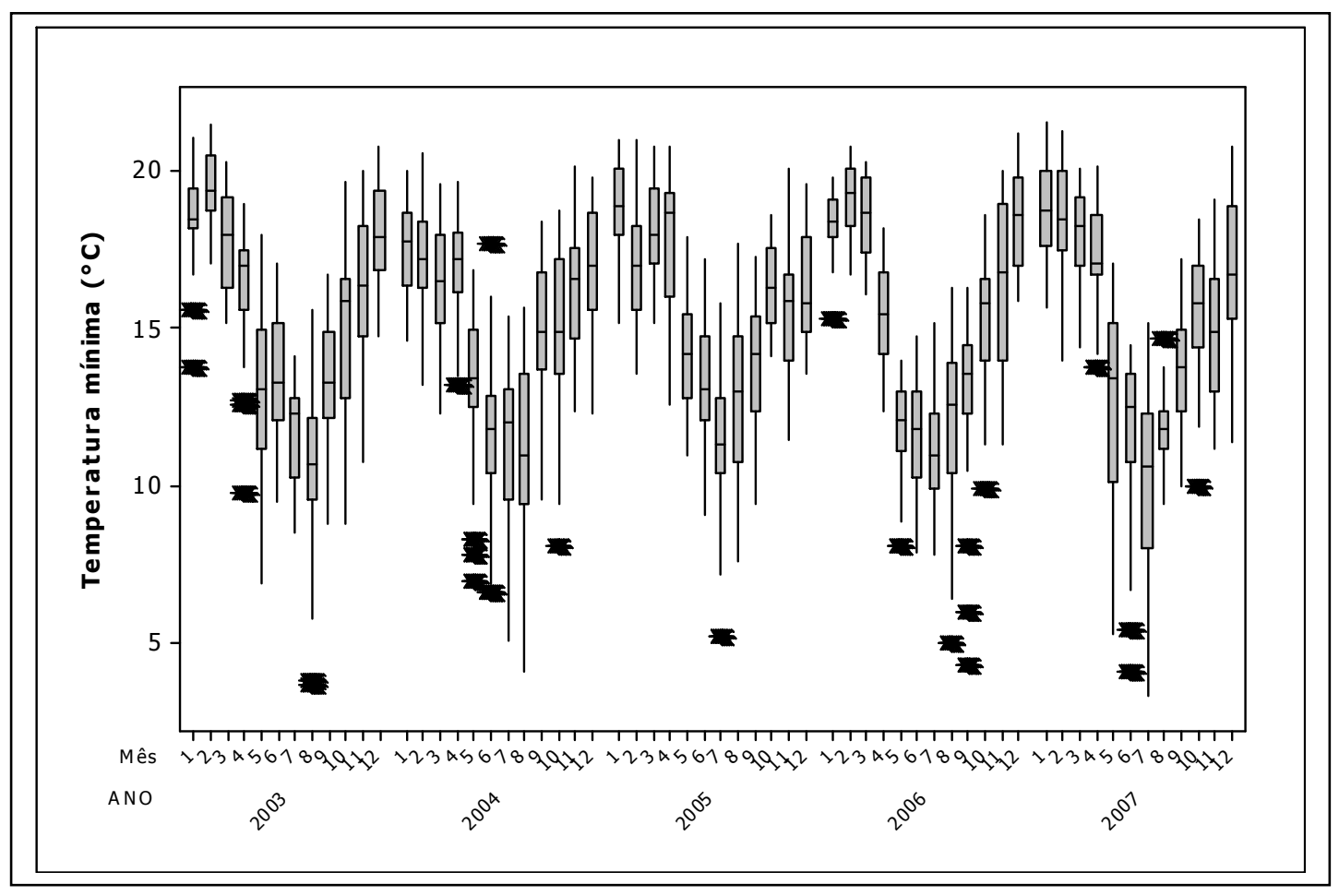

Figura 27 - Ritmo mensal da temperatura mínima na EM-IAG/USP, São Paulo, SP, 2003 a 2007.

Fonte: EM-IAG/USP 


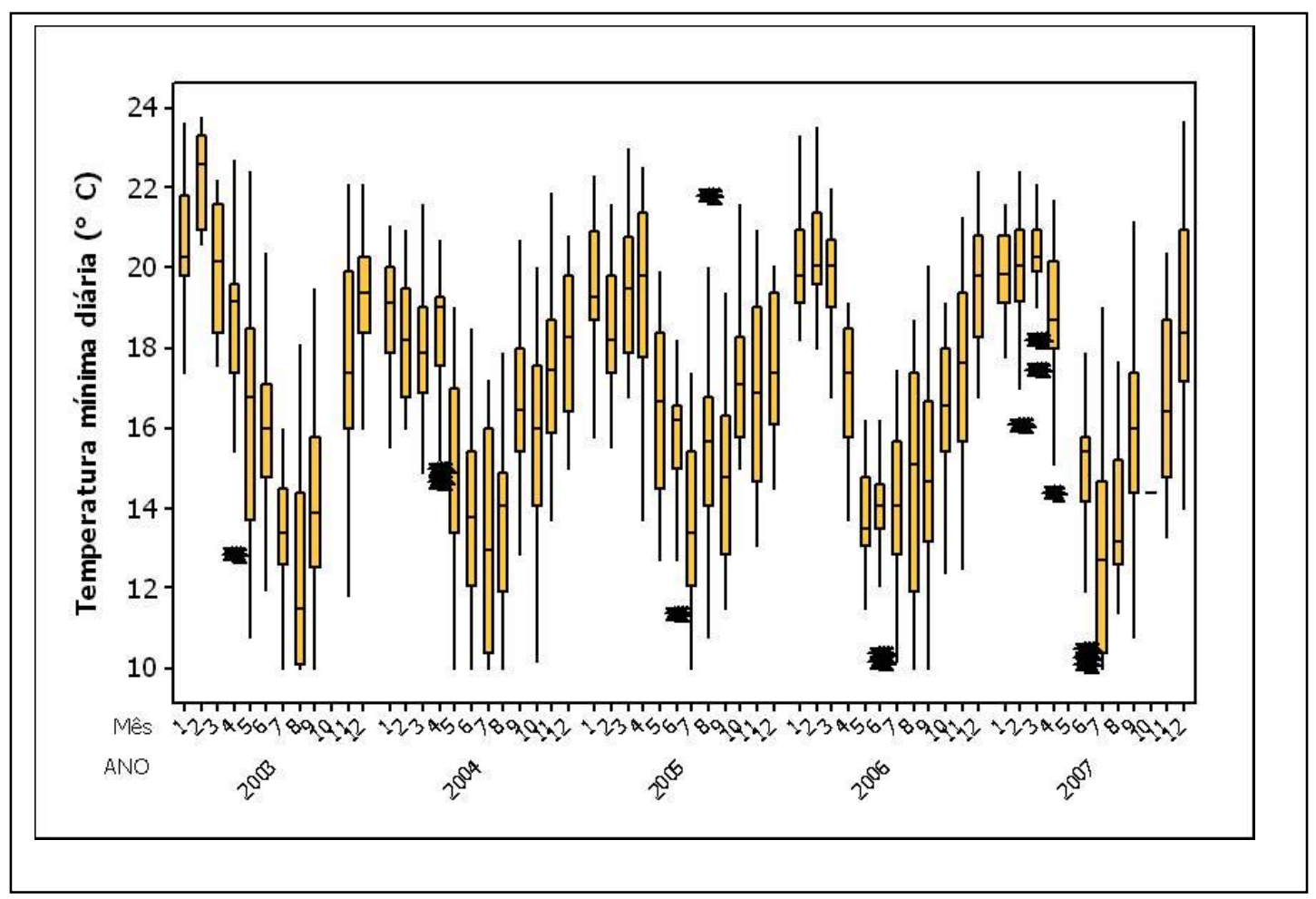

Figura 28 - Ritmo mensal da temperatura mínima na EM-CONGONHAS, São Paulo, SP, 2003 a 2007.

Fonte: EM-CONGONHAS

A Figura 29 e a Figura 30 mostram os gráficos da distribuição da amplitude térmica na EM-IAG/USP e na EM-CONGONHAS. Os valores oscilaram entre $5^{\circ} \mathrm{C}$ e $20^{\circ} \mathrm{C}$. Os dados medidos na EM-IAG/USP apresentam valores ligeiramente maiores de $20^{\circ} \mathrm{C}$ enquanto na EM-CONGONHAS os dados não ultrapassam os $20^{\circ} \mathrm{C}$.

Os maiores valores de amplitude térmica ocorrem nos meses de invernoprimavera (julho a outubro). Esses meses apresentam também a maior variabilidade mensal dos valores de amplitude térmica, ou seja, esses meses apresentam maior variação diária entre a temperatura máxima e mínima em grande parte do período (mês). Os meses de verão (dezembro a março) apresentam valores mais baixos e menor variabilidade mensal.

Os outliers mais altos e mais baixos ocorreram em toda série temporal, sem, contudo, haver um padrão definido. 


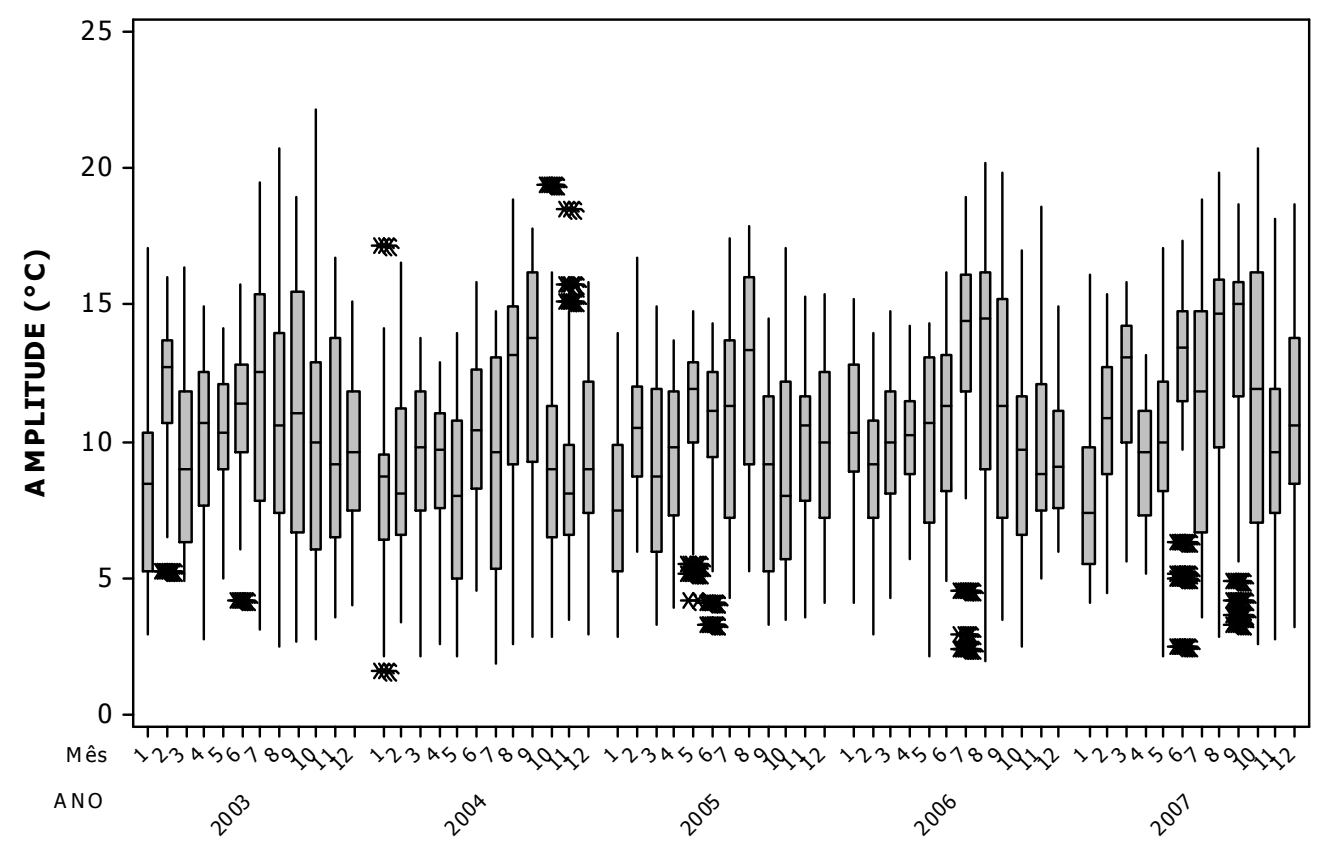

Figura 29 - Ritmo mensal da amplitude térmica na EM-IAG/USP, São Paulo, SP, 2003 a 2007.

Fonte: EM-IAG/USP

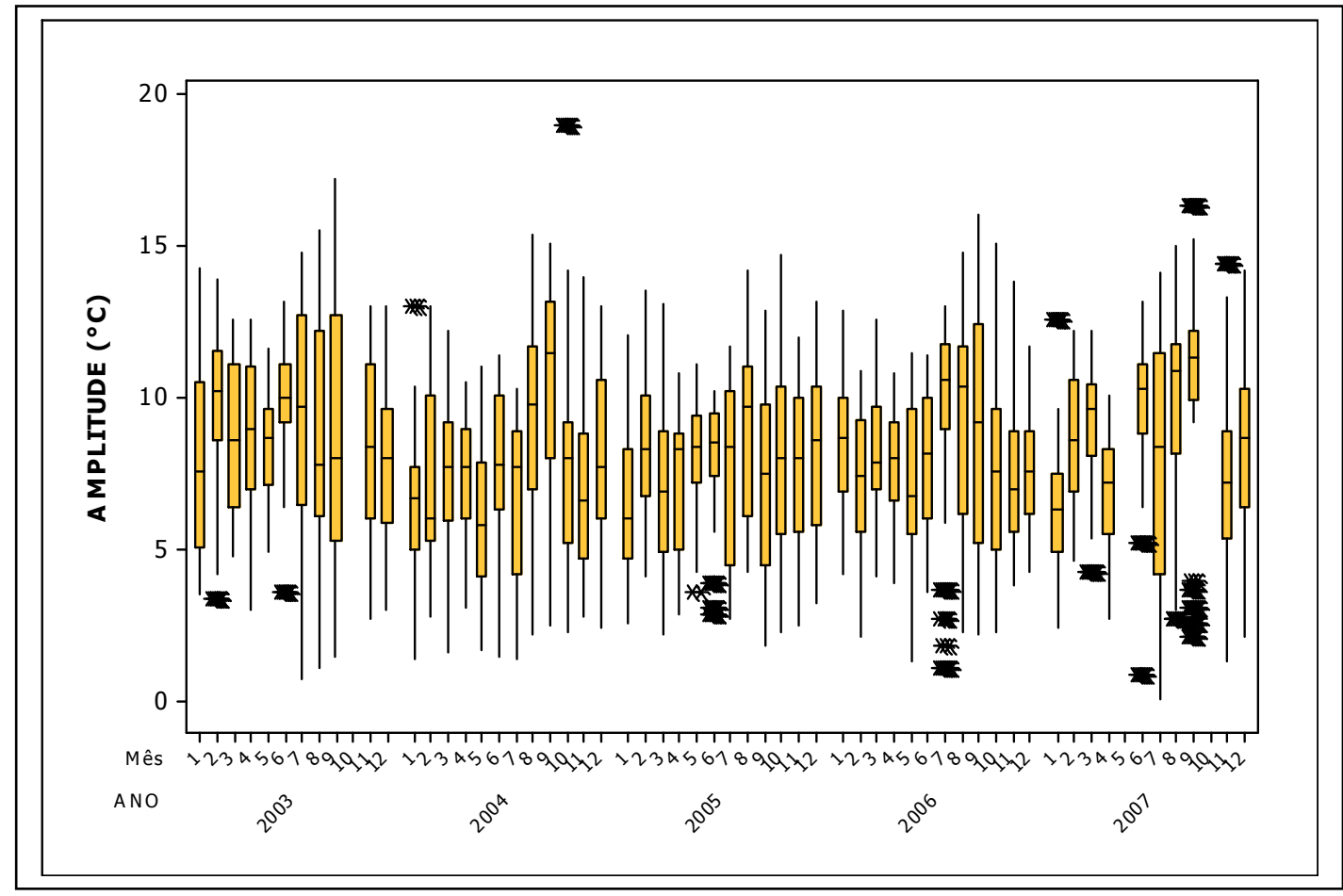

Figura 30 - Ritmo mensal da amplitude térmica na EM-CONGONHAS, São Paulo, SP, 2003 a 2007.

Fonte: EM-CONGONHAS 
A Figura 31 e a Figura 32 mostram os gráficos da distribuição dos valores do índice de conforto PET na EM-IAG/USP e na EM-CONGONHAS. Há um padrão sazonal e, em geral, os valores mais elevados ocorrem nos meses de setembro a abril e valores mais baixos nos meses de maio a agosto. Há uma forte variabilidade dos valores do PET, principalmente, nos meses de inverno e primavera (julho a outubro).

Valores de outliers ocorreram em todos os anos, porém sem um padrão definido, sendo que os valores baixos foram mais freqüentes do que os valores de altos.

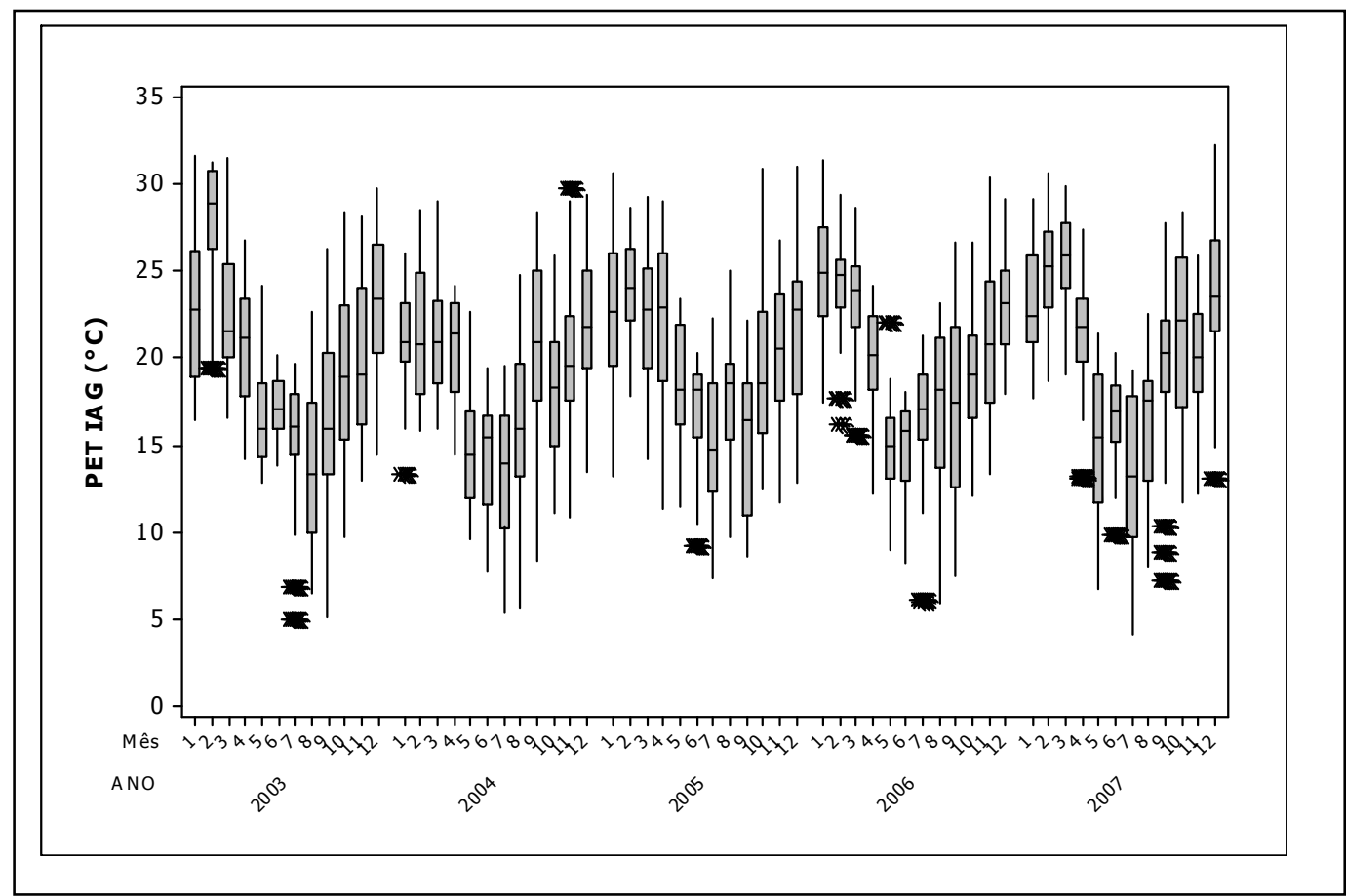

Figura 31 - Ritmo mensal do PET na EM-IAG, São Paulo, SP, 2003 a 2007.

Fonte: EM-IAG/USP 


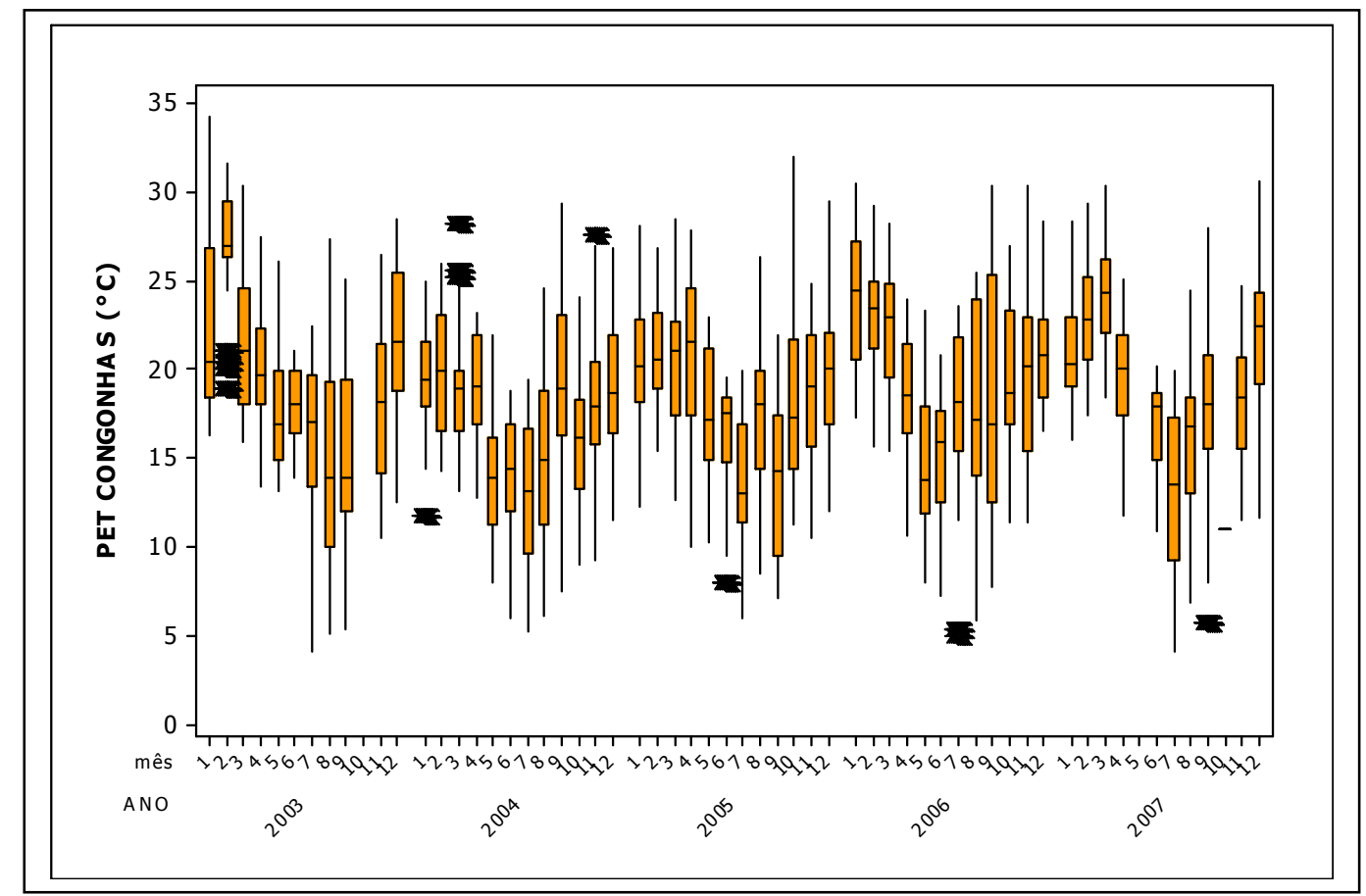

Figura 32 - Ritmo mensal do PET na EM-CONGONHAS São Paulo, SP, 2003 a 2007.

Fonte: EM-CONGONHAS

\subsection{EM-IAG/USP X EM-CONGONHAS}

As estações meteorológicas do IAG/USP e CONGONHAS estão separadas por menos de $10 \mathrm{~km}$ de distância. No entanto, a estação do IAG/USP situa-se numa área de entorno arborizado, enquanto a EM-CONGONHAS situa-se em uma área densamente urbanizada (Figura 3).

As análises mostram que há forte correlação linear positiva entre as variáveis medidas nas duas estações meteorológicas, como mostradas na Tabela 8 indicando que os valores medidos em uma estação são também medidos na outra estação meteorológica. As variáveis de temperatura apresentam correlação mais forte do que as variáveis: velocidade do vento e umidade relativa do ar.

A Tabela 7 mostra o teste de correlação e a Tabela 8 o teste de médias entre as variáveis medidas na EM-IAG e EM-CONGONHAS. Os resultados apontam que os valores não são exatamente iguais, principalmente, no que diz respeito às temperaturas do ar mínimas e velocidade do vento. O teste das médias mostra que a temperatura média do ar; temperatura mínima do ar e a velocidade do vento são 
maiores na EM-CONGONHAS; das temperaturas máximas do ar e das umidades relativas do ar são maiores na EM-IAG/USP.

Tabela 7 - Teste de correlação entre as variáveis medidas no EM-IAG/USP e EMCONGONHAS.

\begin{tabular}{l|r|r}
\hline & \multicolumn{1}{|c}{ Correlação } & \multicolumn{1}{c}{ Sig. } \\
\hline Ta IAG \& Ta CONG & 0,926 & 0,00 \\
TaMaxIAG \& TaMaxCONG & 0,930 & 0,00 \\
TaMinIAG \& TaMinCONG & 0,839 & 0,00 \\
RHIAG \& RHCONG & 0,632 & 0,00 \\
VIAG \& VCONG & 0,669 & 0,00 \\
& & \\
\hline N=133 & & \\
Fonte: EM-IAG/USP e EM-CONGONHAS.
\end{tabular}

Tabela 8 - Teste de médias pareadas para as variáveis medidas na EM-IAG/USP e EMCONGONHAS no período de 01 de janeiro de 2003 a 31 de dezembro de 2007

\begin{tabular}{l|rrrrrr}
\hline & Média & Desvio padrão & P valor & \multicolumn{3}{c}{$\begin{array}{c}\text { Intervalo } \\
\text { confiança (95\%) }\end{array}$} \\
& & & & & de \\
Ta IAG - Ta CONG & $-0,48$ & 0,68 & 0,00 & $-0,59$ & $-0,36$ \\
TaMaxIAG & 0,37 & 0,85 & 0,00 & 0,22 & 0,52 \\
TaMaxCONG & & & & & \\
TaMinIAG & & 1,57 & 0,00 & $-1,65$ & $-1,12$ \\
TaMinCONG & $-1,38$ & 6,01 & 0,05 & $-0,01$ & 2,05 \\
RHIAG - RHCONG & 1,02 & 1,02 & 0,00 & $-1,92$ & $-1,57$ \\
VIAG - VCONG & $-1,74$ & & &
\end{tabular}

Fonte: EM-IAG/USP e EM-CONGONHAS.

Foram calculadas as diferenças entre as variáveis: temperatura média do ar, temperatura máxima do ar, temperatura mínima do ar e umidade relativa média do ar na EM-IAG e EMCONGONHAS (varEM-IAG)-(varEM-CONGONHAS).

A Figura 33 mostra o histograma das diferenças entre as temperaturas máximas do ar nas estações meteorológicas. A distribuição mostra maior frequiência de diferenças positivas, ou seja, aponta maior frequiência de temperaturas máximas do ar mais elevadas na EM-IAG, com valores de até $2^{\circ} \mathrm{C}$. No entanto, há ocorrência de dias em que, embora com menor frequiência, as temperaturas máximas são mais elevadas na EM-CONGONHAS, podendo atingir valores acima de $2^{\circ} \mathrm{C}$ de diferença entre elas.

A Figura 34 mostra o histograma das diferenças entre as temperaturas mínimas do ar com maior frequiência negativa, isto é, evidenciando que os valores de 
temperatura mínima do ar medidas na EM-CONGONHAS são mais elevadas e com grande freqüência de diferença de até $2^{\circ} \mathrm{C}$, mas podendo atingir valores acima de $6^{\circ}$ C.

O histograma das diferenças entre as temperaturas médias do ar (Figura 35) mostram grande freqüência de dias com diferenças próximas de zero, ou seja, as temperaturas médias são iguais ou muito próximas. Contudo, a distribuição mostra que as temperaturas médias medidas na EM-CONGONHAS são freqüentemente maiores do que no EM-IAG/USP, com diferenças acima de $1^{\circ} \mathrm{C}$. A ocorrência de temperaturas médias mais elevadas na EM-IAG/USP é pequena e não ultrapassa a $1^{\circ}$ $\mathrm{C}$ de diferença.

O histograma das diferenças entre a umidade relativa do ar nas duas estações meteorológicas mostra maior freqüência de diferenças positivas, ou seja, com valores de umidade mais elevados na EM-IAG, em até 20\% (Figura 36)

A Figura 37 e a Figura 38 mostram os histogramas das frequiências dos valores de velocidade médio do vento medidos na EM-IAG/USP e EMCONGONHAS, respectivamente. Observa-se a ocorrência de maior freqüência de ventos mais intensos na EM-CONGONHAS, com velocidades mais freqüentes entre 2,0 e 4,0 m/s. Na EM-IAG/USP a maior freqüência situa-se entre 1,0 e 2,0 m/s.

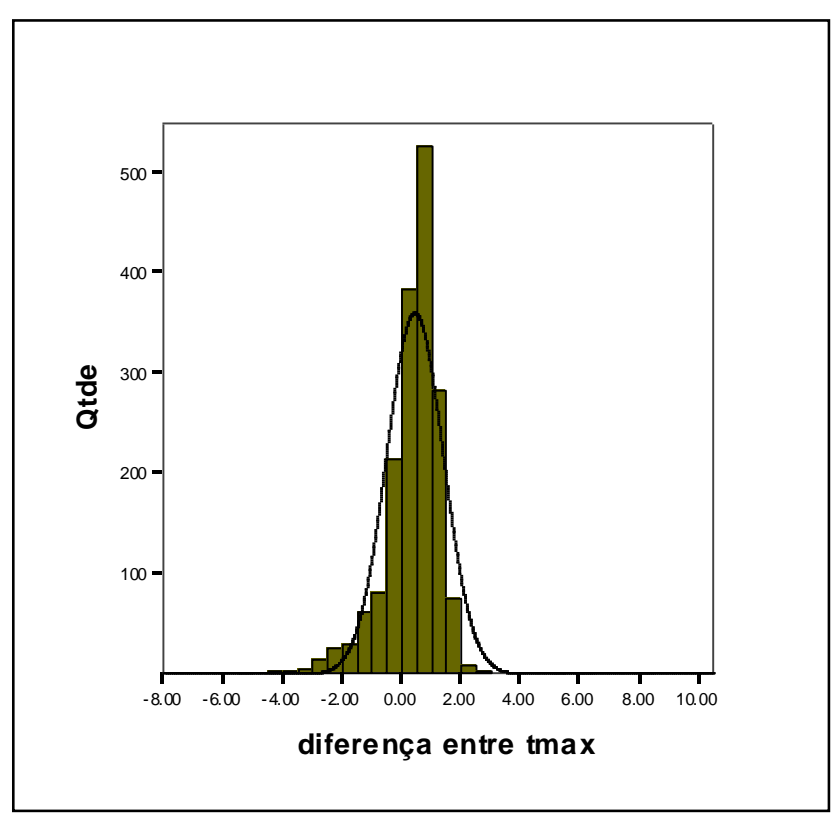

Figura 33 - Freqüência das diferenças entre as temperaturas máximas na EM-IAG/USP e EM-Congonhas.

Fonte: EM-IAG/USP e EM-CONGONHAS 


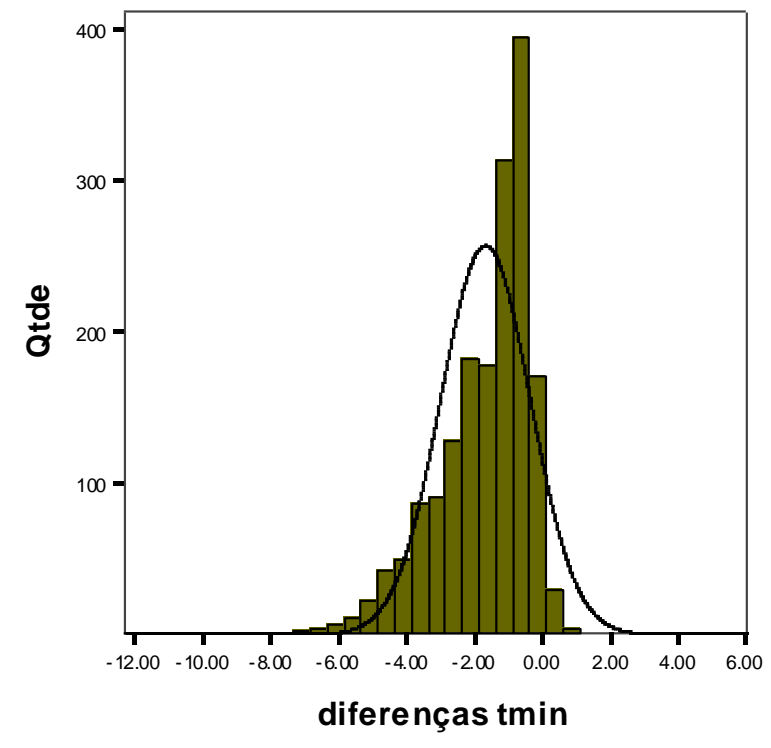

Figura 34 - Freqüência das diferenças entre as temperaturas mínimas nas EM-IAG/USP e EM-Congonhas.

Fonte: EM-IAG/USP e EM-CONGONHAS

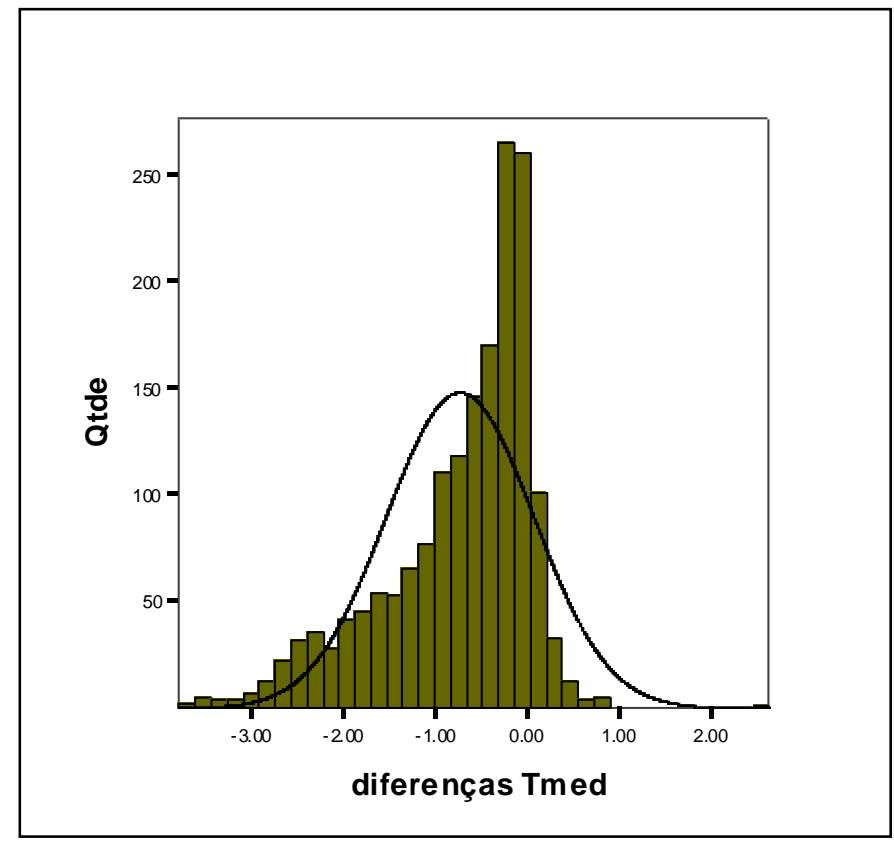

Figura 35 - Freqüência das diferenças entre as temperaturas médias nas EM-IAG/USP e EM-Congonhas.

Fonte: EM-IAG/USP e EM-CONGONHAS 


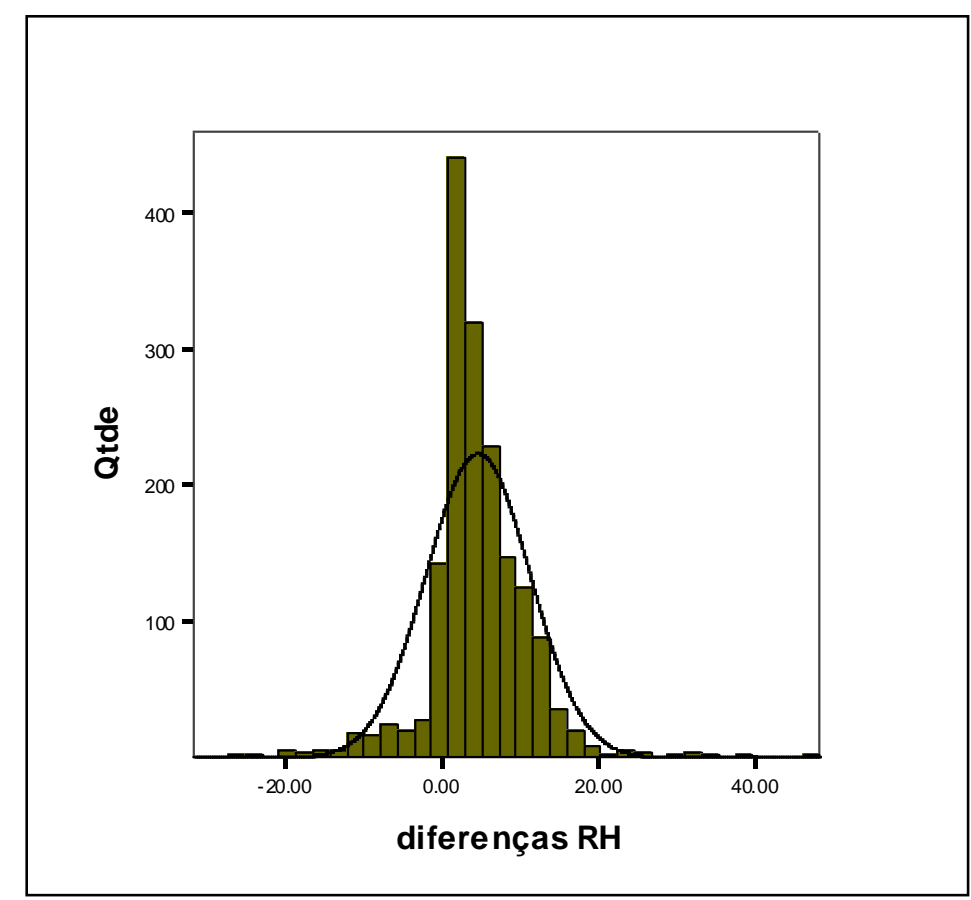

Figura 36 - Freqüência das diferenças entre Umidade Relativa do ar nas EM-IAG/USP e EM-Congonhas.

Fonte: EM-IAG/USP e EM-CONGONHAS

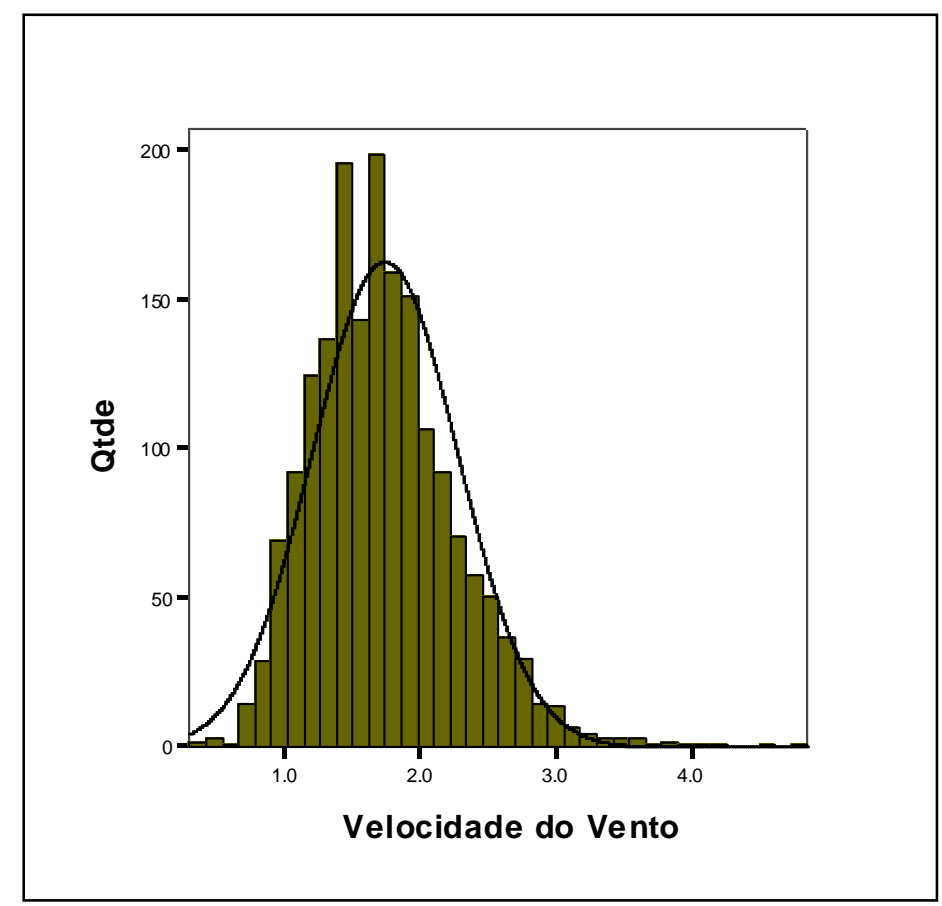

Figura 37 - Frequiência da velocidade media diária do vento medido na EM-IAG/USP. Fonte: EM-IAG/USP 


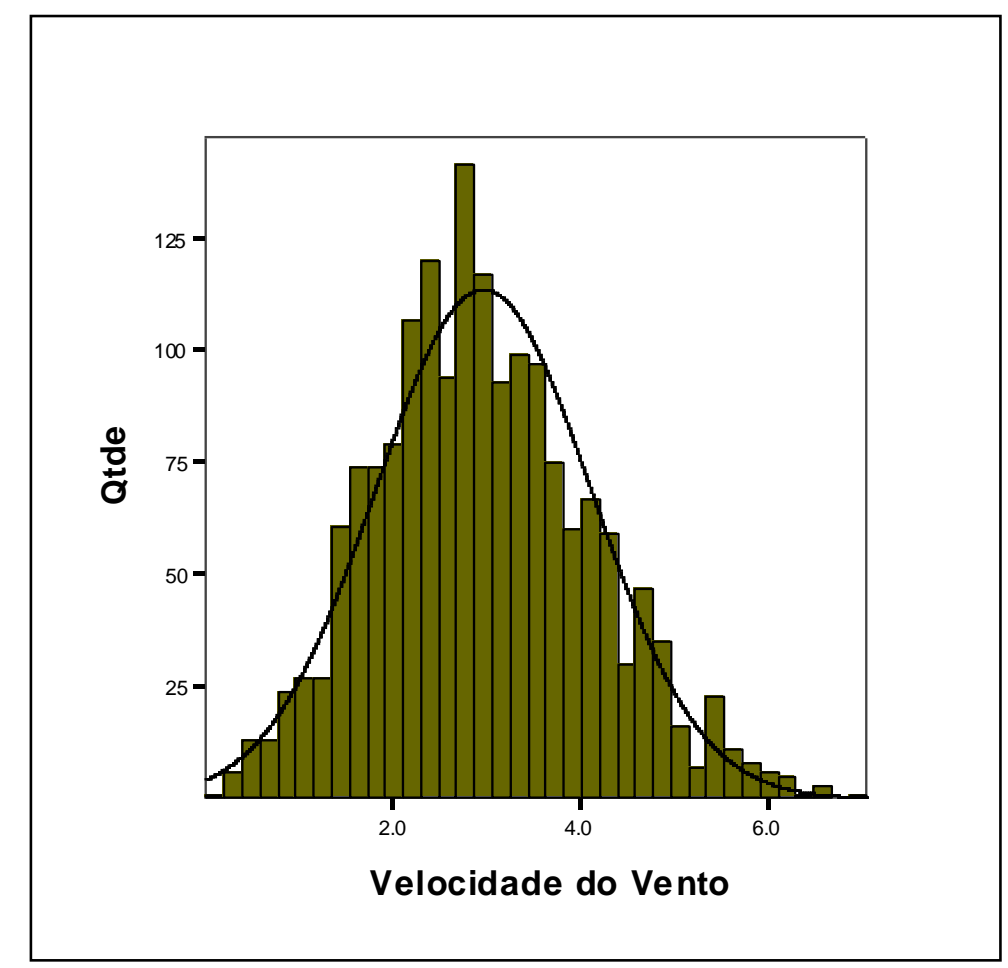

Figura 38 - Freqüência da velocidade media diária do vento medido na EM-CONGONHAS. Fonte: EM-CONGONHAS

\subsection{Características bioclimáticas do Setor Sul/Sudeste}

As Figuras 39 a 43 mostram o ritmo diário dos valores de conforto nas duas estações meteorológicas por ano. Deve-se ressaltar que, nenhum dia dos cinco anos estudados (2003-2007) apresentou valores de conforto de extremo estresse de calor $\left(>43^{\circ} \mathrm{C}\right)$ e de frio $\left(<4^{\circ} \mathrm{C}\right)$.

Nota-se a grande variabilidade inter-diária durante todo o ano, mas, principalmente nos meses de primavera e início do verão, ou seja, de setembro a dezembro.

O ano de 2003 apresentou, nos primeiros meses do ano (verão), valores acima do nível da faixa de conforto, ou seja, com estresse de calor. Os meses de julho a setembro apresentam dias de desconforto para o frio com valores menores de $12^{\circ} \mathrm{C} \mathrm{e}$ dias com valores próximos a $4^{\circ} \mathrm{C}$ (estresse de frio). Os meses de primavera apresentam forte oscilação entre pouco calor $\left(>26^{\circ} \mathrm{C}\right)$, confortável $\left(18^{\circ} \mathrm{C}-26^{\circ} \mathrm{C}\right)$, pouco frio $\left(<18^{\circ} \mathrm{C}\right)$ e frio $\left(<12^{\circ} \mathrm{C}\right)$ (Figura 39).

Em 2004, (Figura 40) os primeiros dias do ano apresentaram índices de desconforto para frio $\left(<18^{\circ} \mathrm{C}\right)$ e dias com valores próximos a $12^{\circ} \mathrm{C}$ (extremo frio), situação atípica para o período de verão. Nos meses de dezembro a março, a maior 
parte dos dias apresentou valores dentro da faixa de conforto $\left(18^{\circ}\right.$ e $\left.26^{\circ} \mathrm{C}\right)$, com poucos dias de pouco calor $\left(>26^{\circ} \mathrm{C}\right)$ e dias de pouco frio $\left(<18^{\circ} \mathrm{C}\right)$. Os meses de outono-inverno (abril a agosto) caracterizaram-se pelo predomínio de dias com desconforto para o frio, ou seja, pouco frio $\left(<18^{\circ} \mathrm{C}\right)$ e frio $\left(<12^{\circ} \mathrm{C}\right)$. A partir do final de agosto até dezembro os dias intercalam-se entre confortáveis $\left(18^{\circ}\right.$ e $\left.26^{\circ} \mathrm{C}\right)$, pouco frio e frio $\left(<18^{\circ} \mathrm{C} ;<12^{\circ} \mathrm{C}\right)$ e pouco calor $\left(>26^{\circ} \mathrm{C}\right)$.

No ano de 2005, os meses de verão caracterizaram-se por dias com pouco calor $\left(>26^{\circ} \mathrm{C}\right)$ e confortável $\left(18^{\circ} \mathrm{C}\right.$ e $\left.26^{\circ} \mathrm{C}\right)$ com poucos dias em que os valores situaram-se na faixa do pouco frio $\left(<18^{\circ} \mathrm{C}\right)$ e frio $\left(<12^{\circ} \mathrm{C}\right)$. Os meses de outono e inverno os dias oscilaram entre a faixa do confortável $\left(18^{\circ} \mathrm{C}\right.$ e $\left.26^{\circ} \mathrm{C}\right)$; pouco frio $\left(<18^{\circ} \mathrm{C}\right)$ e frio $\left(<12^{\circ} \mathrm{C}\right)$. No mês de outubro de 2005 , no dia 13/10/2005 o índice de conforto chegou a $32^{\circ} \mathrm{C}$ na EM-CONGONHAS e $30,8^{\circ} \mathrm{C}$ na EM-IAG/USP estresse de calor. No final do período - dezembro - há dois dias em que os valores ultrapassam a $30^{\circ} \mathrm{C}-21$ e 22 de dezembro de 2005 (Figura 41).

Em 2006, os primeiros dias do mês de janeiro apresentaram índices baixos, mas dentro da faixa de conforto - próximo a $18^{\circ} \mathrm{C}$. Nos meses de janeiro até abril predominaram dias confortáveis e de pouco calor. A partir do mês de abril intensificam dias com desconforto para o frio com valores abaixo de $12^{\circ} \mathrm{C}$ que vai até novembro. A partir de setembro intercalam-se dias de calor $\left(>31^{\circ} \mathrm{C}\right)$, pouco calor $\left(>26^{\circ} \mathrm{C}\right)$, confortável $\left(18^{\circ} \mathrm{C}\right.$ e $\left.26^{\circ} \mathrm{C}\right)$, pouco frio $\left(<18^{\circ} \mathrm{C}\right)$ e frio $\left(<12^{\circ} \mathrm{C}\right)$ (Figura 42).

Os primeiros meses do ano de 2007 apresentaram dias com pouco calor $\left(>26^{\circ}\right.$ C) e confortáveis $\left(18^{\circ} \mathrm{C}\right.$ a $\left.26^{\circ} \mathrm{C}\right)$. A partir de abril há predomínio de dias desconfortáveis para o frio - dias de pouco frio $\left(<18^{\circ} \mathrm{C}\right)$ e frio $\left(<12^{\circ} \mathrm{C}\right)$. A partir de agosto há predominância de dias confortáveis com a presença de dias de pouco calor (acima de $26^{\circ} \mathrm{C}$ ) e pouco frio (abaixo de $18^{\circ} \mathrm{C}$ ). Em setembro desse ano ocorrem alguns dias de frio $\left(<12^{\circ} \mathrm{C}\right)$. Nota-se que o final do mês de dezembro há um aumento dos valores do índice de conforto para o calor atingindo a $32^{\circ} \mathrm{C}$, nos últimos dias de dezembro (Figura 43). 


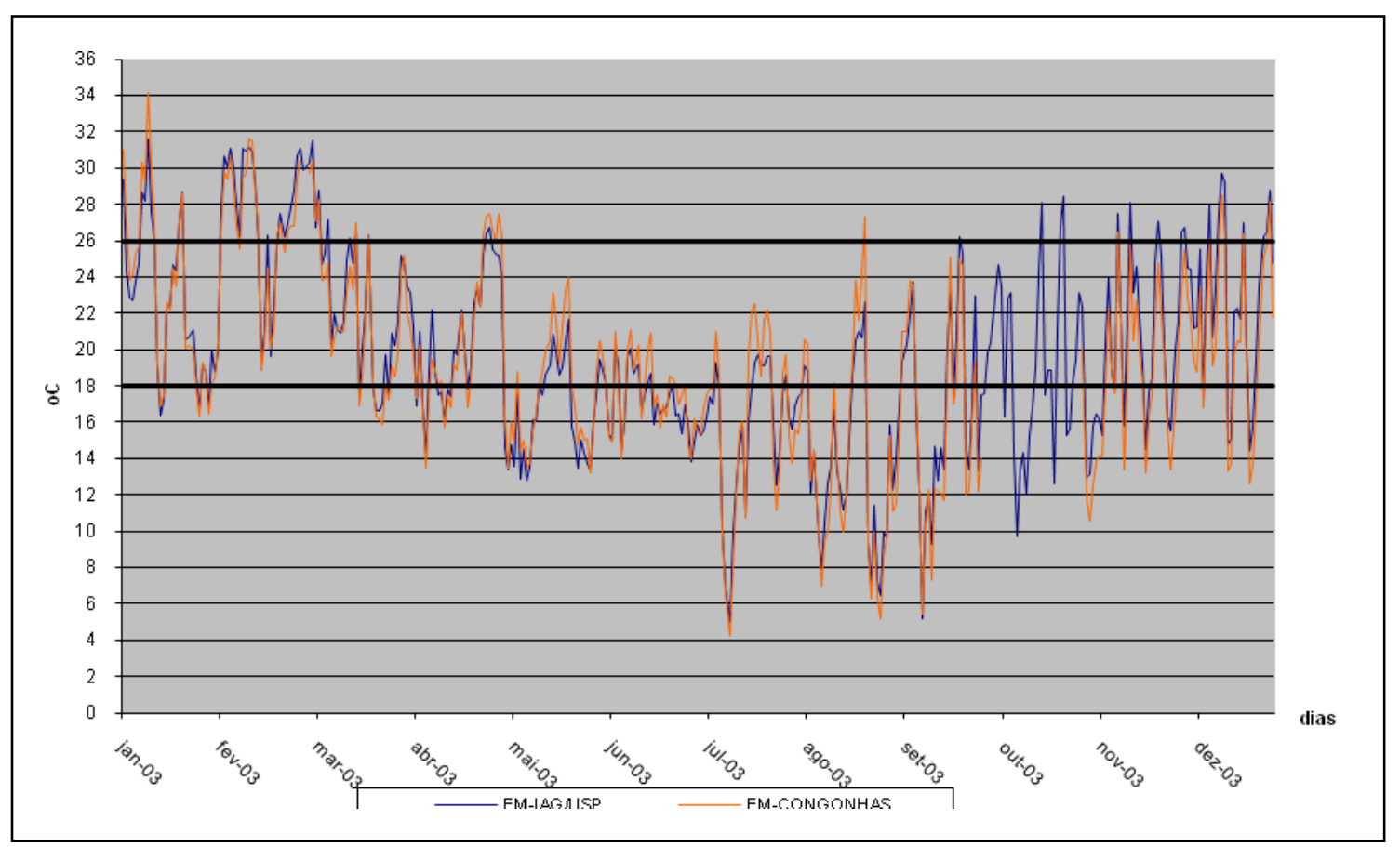

Figura 39 - Ritmo diário do conforto térmico (PET) na EM-IAG/USP e na EMCONGONHAS, no período de 01 de janeiro a 31 de dezembro 2003.

Fonte: EM-IAG/USP e EM- Congonhas.

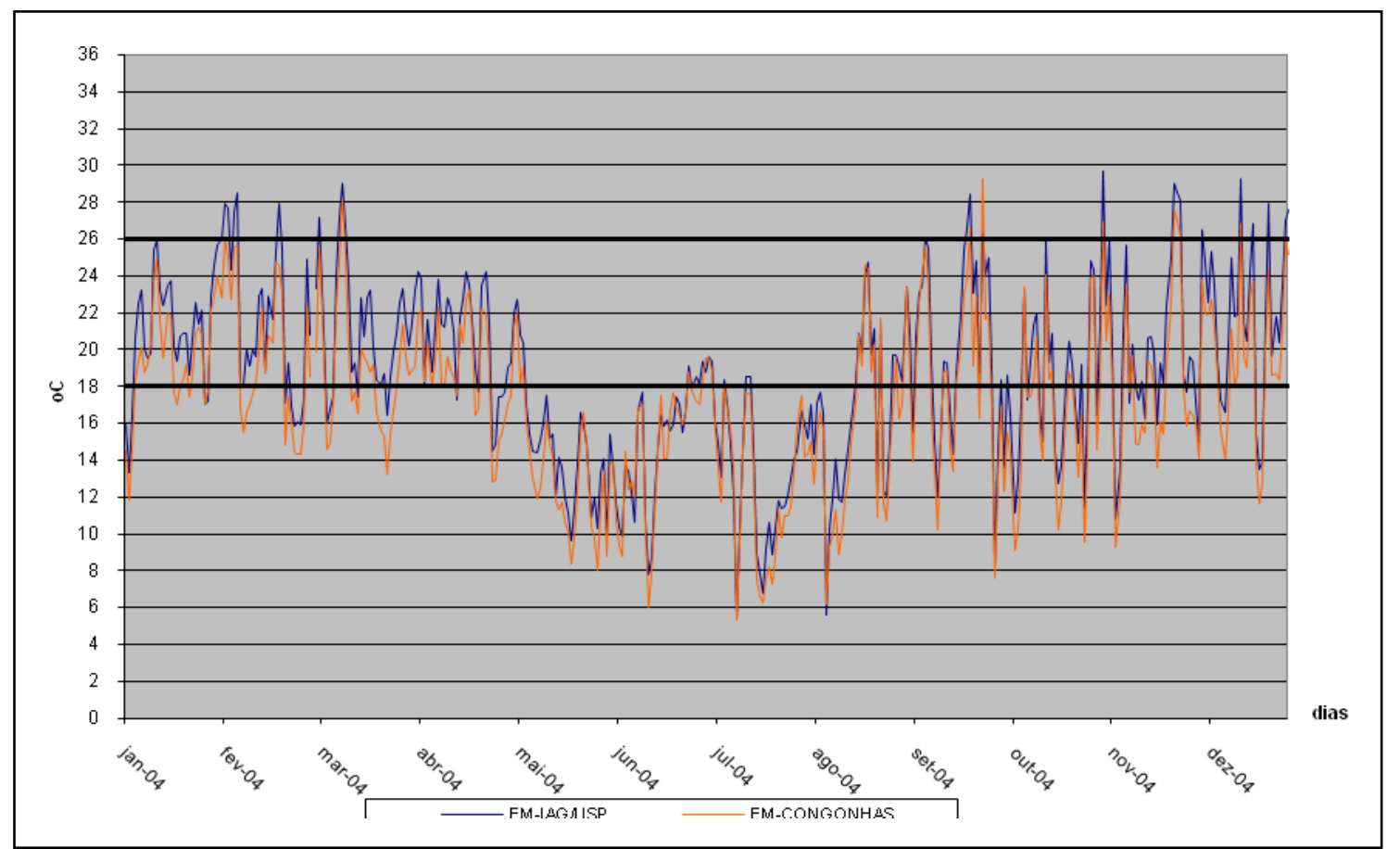

Figura 40 - Ritmo diário do conforto térmico (PET) na EM-IAG/USP e na EMCONGONHAS, no período de 01 de janeiro a 31 de dezembro 2004.

Fonte: EM-IAG/USP e EM- Congonhas. 


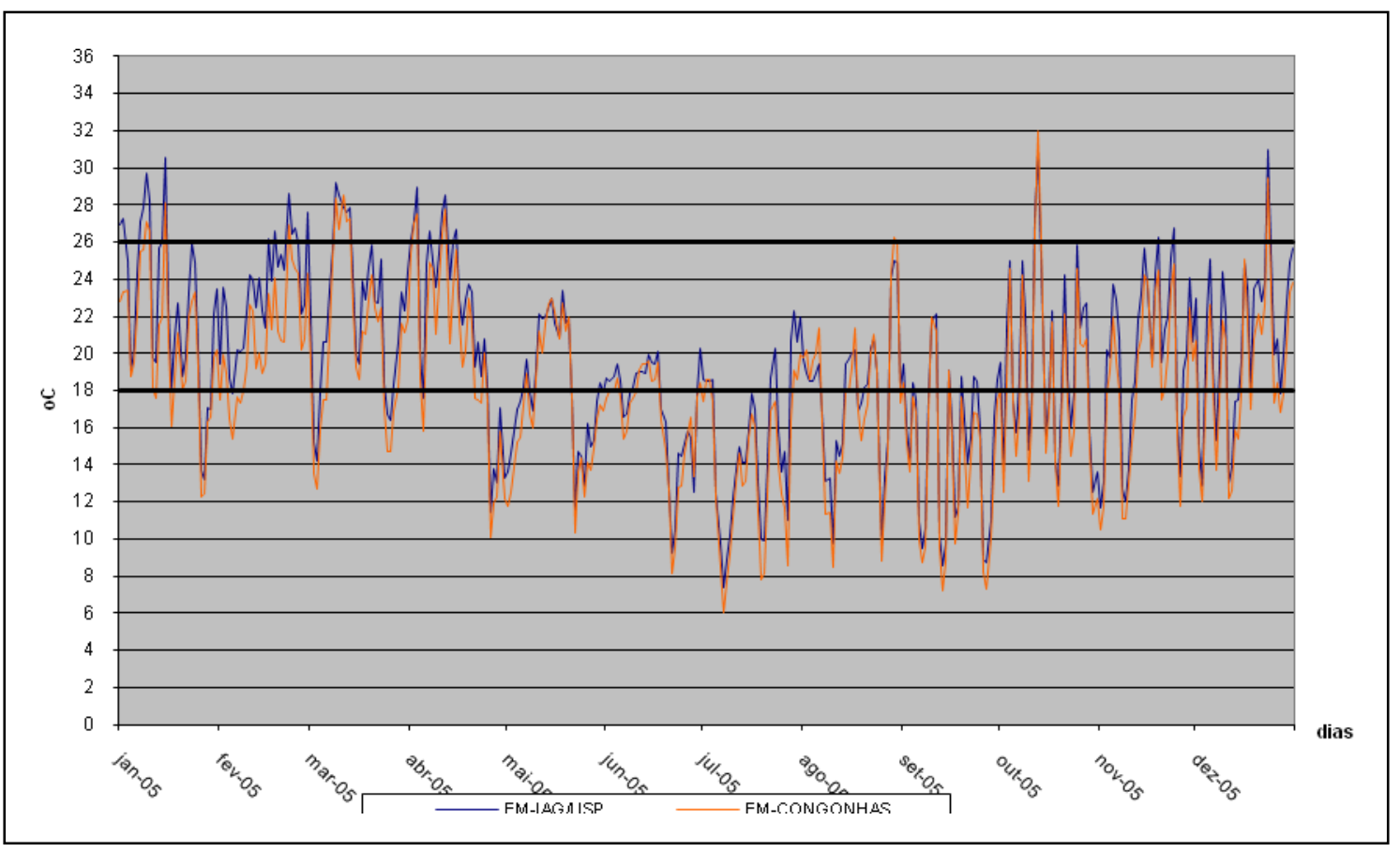

Figura 41 - Ritmo diário do conforto térmico (PET) na EM-IAG/USP e na EMCONGONHAS, no período de 01 de janeiro a 31 de dezembro 2005.

Fonte: EM-IAG/USP e EM- Congonhas.

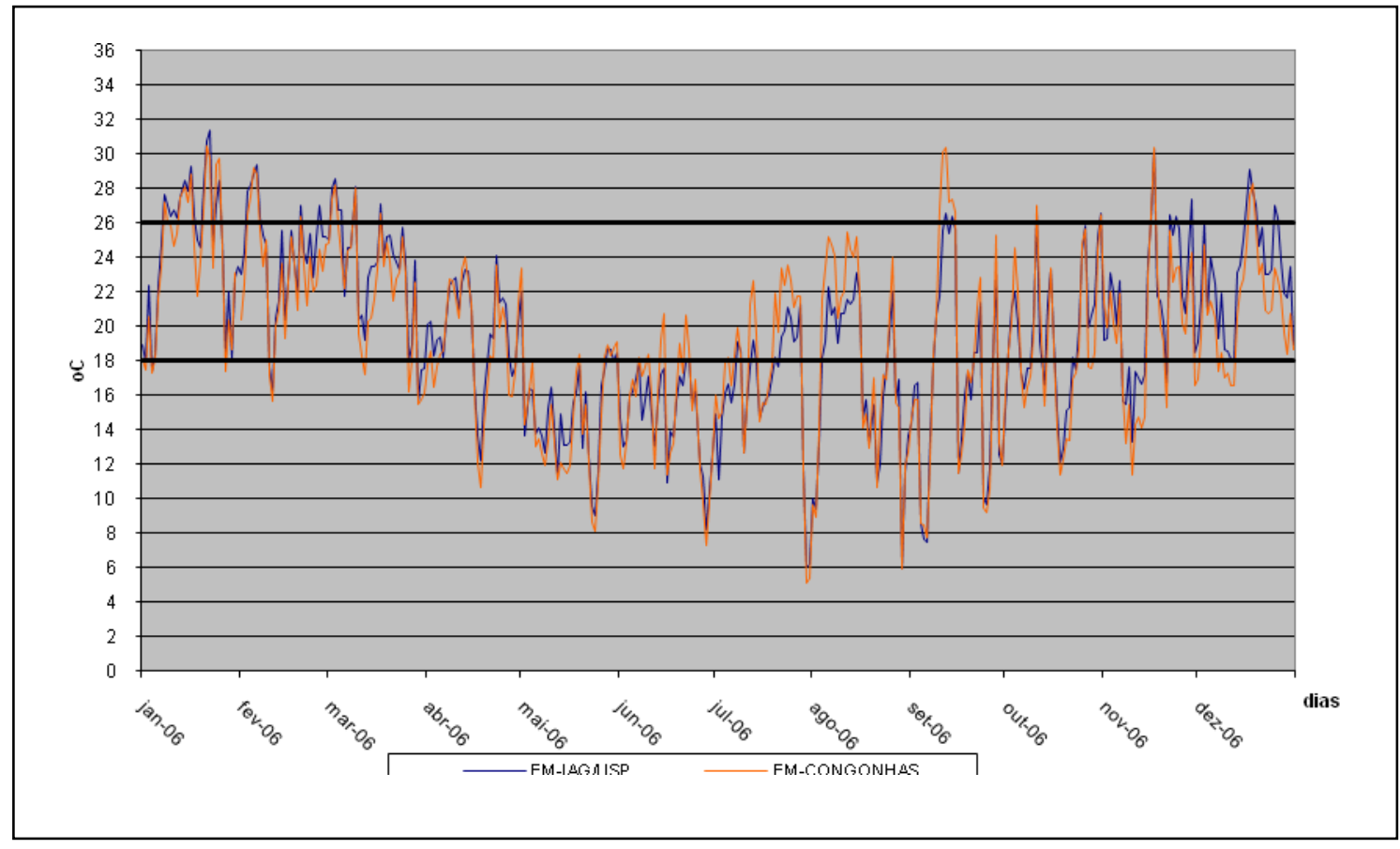

Figura 42 - Ritmo diário do conforto térmico (PET) na EM-IAG/USP e na EMCONGONHAS, no período de 01 de janeiro a 31 de dezembro 2006.

Fonte: EM-IAG/USP e EM- Congonhas 


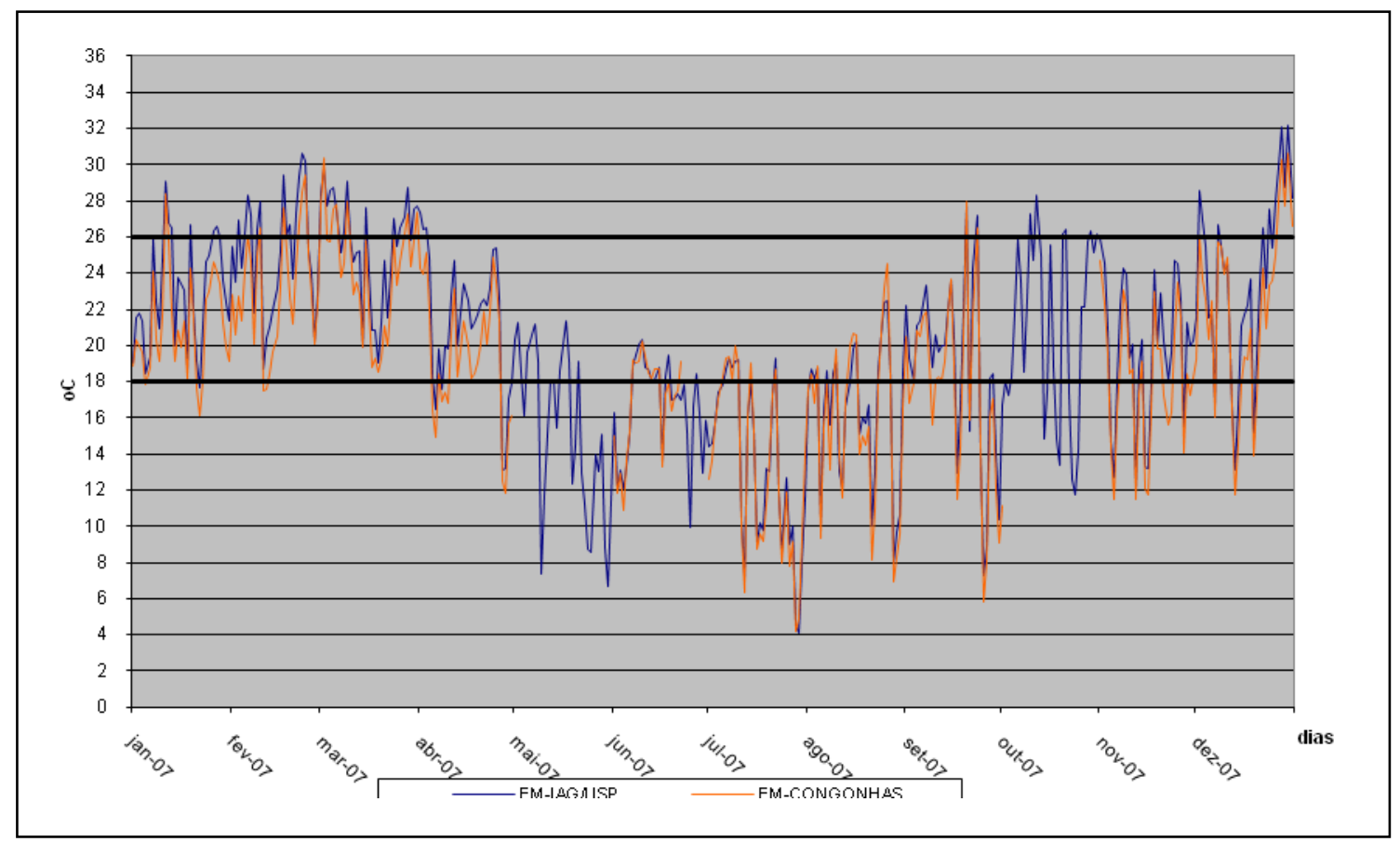

Figura 43 - Ritmo diário do conforto térmico (PET) na EM-IAG/USP e na EMCONGONHAS, no período de 01 de janeiro a 31 de dezembro 2007

Fonte: EM-IAG/USP e EM- Congonhas

A Prancha 11 mostra os gráficos de frequiência dos dias com diferentes faixas de conforto por mês e ano, na EM-IAG/USP. O ano de 2003 caracterizou-se pela maior freqüência (80\%) de dias de pouco calor e calor no mês de fevereiro. Os meses de janeiro e março apresentaram dias de calor e pouco calor em menor freqüência em torno de $20 \%$ dos dias. O mês de abril apresentou cerca de $5 \%$ dos dias de calor. Há ocorrência de dias confortáveis em todos os meses do ano, com menor frequiência nos meses de inverno - junho, julho, agosto, setembro. Dias de Frio $\left(<12^{\circ} \mathrm{C}\right)$ aparecem nos meses de julho, agosto, setembro, outubro com maior freqüência no mês de agosto $-40 \%$ dos dias. Dias de pouco frio $\left(<18^{\circ} \mathrm{C}\right)$ ocorreram em todos os meses do ano, com maior freqüência em maio e junho.

Em 2004 não houve dias de calor $\left(>31^{\circ} \mathrm{C}\right)$ e os dias de pouco calor $\left(>26^{\circ} \mathrm{C}\right)$ foram menos freqüente do que em 2003. Dias de frio $\left(<12^{\circ} \mathrm{C}\right)$ ocorreram nos meses de maio a novembro, com maior frequiência em maio, junho e julho. Os dias - pouco frio $\left(<18^{\circ} \mathrm{C}\right)$ - ocorreram em todos os meses do ano, com maior frequiência em maio, junho, julho e agosto. Os dias confortáveis ocorreram em todos os meses do ano com maior freqüência nos meses de primavera-verão. 
Em 2005 ocorreu menos de $1 \%$ dos dias de calor $\left(>31^{\circ} \mathrm{C}\right)$ em dezembro e os dias de pouco calor $\left(>26^{\circ} \mathrm{C}\right.$ ) ocorreram nos meses de janeiro a abril (mais freqüente com até $20 \%$ dos dias) e outubro a dezembro (menos freqüente menos de $5 \%$ dos dias). Nos meses de abril a setembro e o mês de novembro ocorreram dias de frio $\left(<12^{\circ} \mathrm{C}\right)$, sendo que nos meses de julho e setembro houve maior frequiência (cerca de $20 \%$ e $40 \%$ respectivamente). Os dias confortáveis ocorreram em todos os meses do ano sendo mais freqüente nos meses de janeiro a abril, agosto, novembro e dezembro.

No ano de 2006, o mês de janeiro apresentou poucos dias de calor $\left(>31^{\circ} \mathrm{C}\right) \mathrm{e}$ dias de pouco calor $\left(>26^{\circ} \mathrm{C}\right.$ ) ocorreram nos meses de janeiro a março (maior freqüência em janeiro $-40 \%)$ e de setembro a dezembro. Os dias de frio $\left(<12^{\circ} \mathrm{C}\right)$ ocorreram de maio a setembro - com maior freqüência em setembro - $20 \%$ dos dias. Os dias confortáveis $\left(18^{\circ} \mathrm{C}\right.$ e $\left.26^{\circ} \mathrm{C}\right)$ ocorreram em todos os meses do ano - com menor freqüência em maio e junho. Os dias pouco frio $\left(<18^{\circ} \mathrm{C}\right)$ ocorreram em todos os meses do ano com maior freqüência de maio a julho.

No ano de 2007 houve ocorrência de dias de calor $\left(>31^{\circ} \mathrm{C}\right)$ em dezembro e pouco calor $\left(>26^{\circ} \mathrm{C}\right.$ ) de janeiro a abril, setembro e outubro e dezembro. O mês de novembro caracterizou-se pela predominância de dias confortáveis $\left(18^{\circ} \mathrm{C}\right.$ e $\left.26^{\circ} \mathrm{C}\right)-$ cerca de $80 \%$ e o restante de dias pouco frio $\left(<18^{\circ} \mathrm{C}\right)$. Os dias de frio $\left(<12^{\circ} \mathrm{C}\right)$ ocorreram nos meses de maio a outubro com maior freqüência em maio (mais de $20 \%$ dos dias) e julho (mais de $40 \%$ dos dias). Os meses com dias - pouco frio $\left(<18^{\circ}\right.$ C) ocorreram de abril a dezembro com maior frequiência em junho, julho e agosto. Os dias confortáveis ocorreram em todos os meses do ano.

A Prancha 12 mostra a frequiência de dias com diferentes faixas de conforto na EM-CONGONHAS. Os dias de calor $\left(>31^{\circ} \mathrm{C}\right)$ foram pouco freqüentes em janeiro e fevereiro de 2003 - menos de $5 \%$. Os dias de pouco calor $\left(>26^{\circ} \mathrm{C}\right)$ ocorreram em quase todo o ano, exceto nos meses de junho, julho e setembro. Os dias de frio $\left(<12^{\circ}\right.$ C) ocorreram nos meses de julho, agosto, setembro e novembro, sendo que em agosto houve maior freqüência de dias frio (mais de 40\%). Os dias confortáveis ocorreram em todos os meses do ano, com menor freqüência em fevereiro, julho e agosto de 2003. Os dias pouco frio $\left(<18^{\circ} \mathrm{C}\right)$ ocorreram em todos os meses do ano, 
exceto em fevereiro, sendo que nos meses de maio, junho e julho com maior freqüência dos dias.

O ano de 2004 diferencia-se do ano de 2003, pois não houve dias de calor $\left(>31^{\circ} \mathrm{C}\right)$ e os dias de pouco calor $\left(>26^{\circ} \mathrm{C}\right)$ ocorreram com pouca freqüência - menos de $20 \%$ dos dias. Os meses em que ocorreram dias com pouco calor foram: março, setembro, novembro e dezembro. Os dias frios $\left(<12^{\circ} \mathrm{C}\right)$ ocorreram em quase todos os meses do ano, inclusive uma pequena proporção dos dias de janeiro, fato atípico para esse mês. De maio a agosto houve maior freqüência de dias frios $\left(<12^{\circ} \mathrm{C}\right)$. Os dias confortáveis ocorreram em todos os meses do ano, porém com menor freqüência de maio a agosto.

$\mathrm{O}$ ano de 2005 apresentou uma pequena proporção de dias de calor $\left(>31^{\circ} \mathrm{C}\right)$, no mês de outubro - menos de 5\%. Os meses de janeiro a abril apresentaram pequena proporção (menos de 20\%) e os meses de agosto, outubro e dezembro menos de $5 \%$ dos dias de calor $\left(>26^{\circ} \mathrm{C}\right)$. Os dias confortáveis ocorreram em todos os meses do ano, com maior freqüência entre janeiro e abril; novembro e dezembro. Os dias frios $\left(<12^{\circ} \mathrm{C}\right)$ começaram a ocorrer em abril com menor freqüência - menos de $5 \%$ e aumentaram a freqüência em julho, agosto e setembro - até $40 \%$ dos dias. Os dias pouco frio ocorreram em todos os meses do ano com maior freqüência em maio, junho e julho. 
Prancha 11 - Frequiência das faixas de conforto térmico (PET) na EM-IAG/USP, no período de 2003 a 2007.

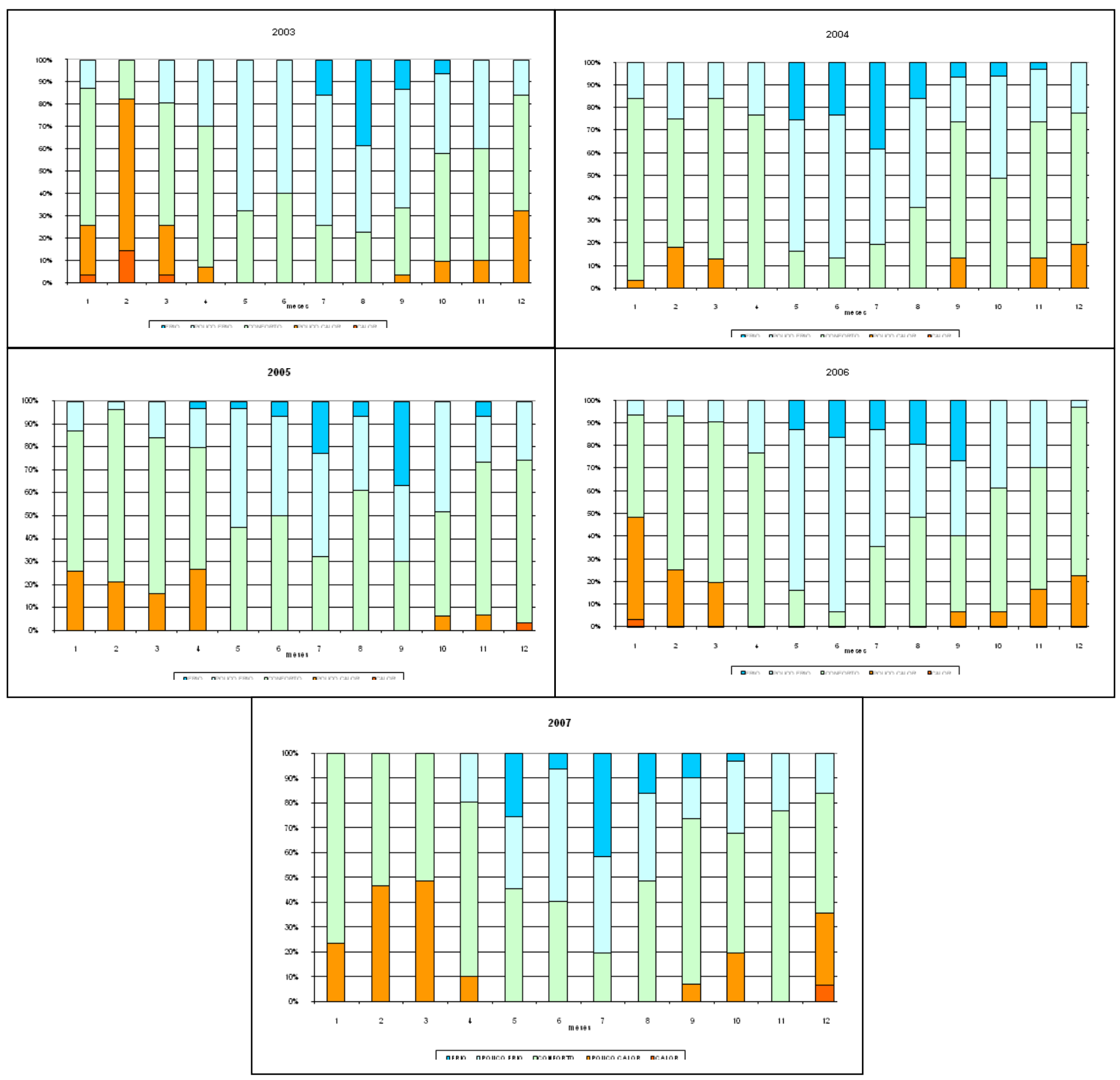


No ano de 2006 não houve a ocorrência de dias de calor $\left(>31^{\circ} \mathrm{C}\right)$. Os dias de pouco calor $\left(>26^{\circ} \mathrm{C}\right)$ ocorreram de janeiro a março e de setembro a dezembro, sendo que no mês de janeiro ocorreu maior freqüência de dias de pouco calor - mais de $20 \%$. Os dias de frio $\left(<12^{\circ} \mathrm{C}\right)$ começaram a ocorrer em abril - pouca freqüência e aumentaram de maio até setembro - cerca de $20 \%$ dos dias - e em outubro e novembro pouca freqüência - menos de $5 \%$. Os dias de pouco frio $\left(<18^{\circ} \mathrm{C}\right)$ ocorreram em todos os meses do ano com maior freqüência de maio a outubro. Os dias confortáveis ocorreram em todos os meses do ano com menor freqüência em maio e junho.

No ano de 2007 os dias de calor (>26 C) ocorreram nos meses de janeiro a março, setembro e dezembro. Observa-se que no mês de abril e novembro não ocorreu dias de calor e pouco calor. Os dias de frio $\left(<12^{\circ} \mathrm{C}\right)$ ocorreram em abril menos de $5 \%$ e, julho - mais de $40 \%$ - mês com maior proporção de dias com pouco frio e, agosto, setembro, novembro e dezembro - menos freqüente. Os dias confortáveis ocorreram em todos os meses, sendo menos freqüente em julho e agosto. Os dias de pouco frio $\left(<18^{\circ} \mathrm{C}\right)$ também ocorreram em todos os meses, exceto março, sendo que a maior freqüência ocorreu em abril, julho a novembro. 
Prancha 12 - Freqüência das faixas de conforto térmico (PET) na EM-CONGONHAS no período de 2003 a 2007.

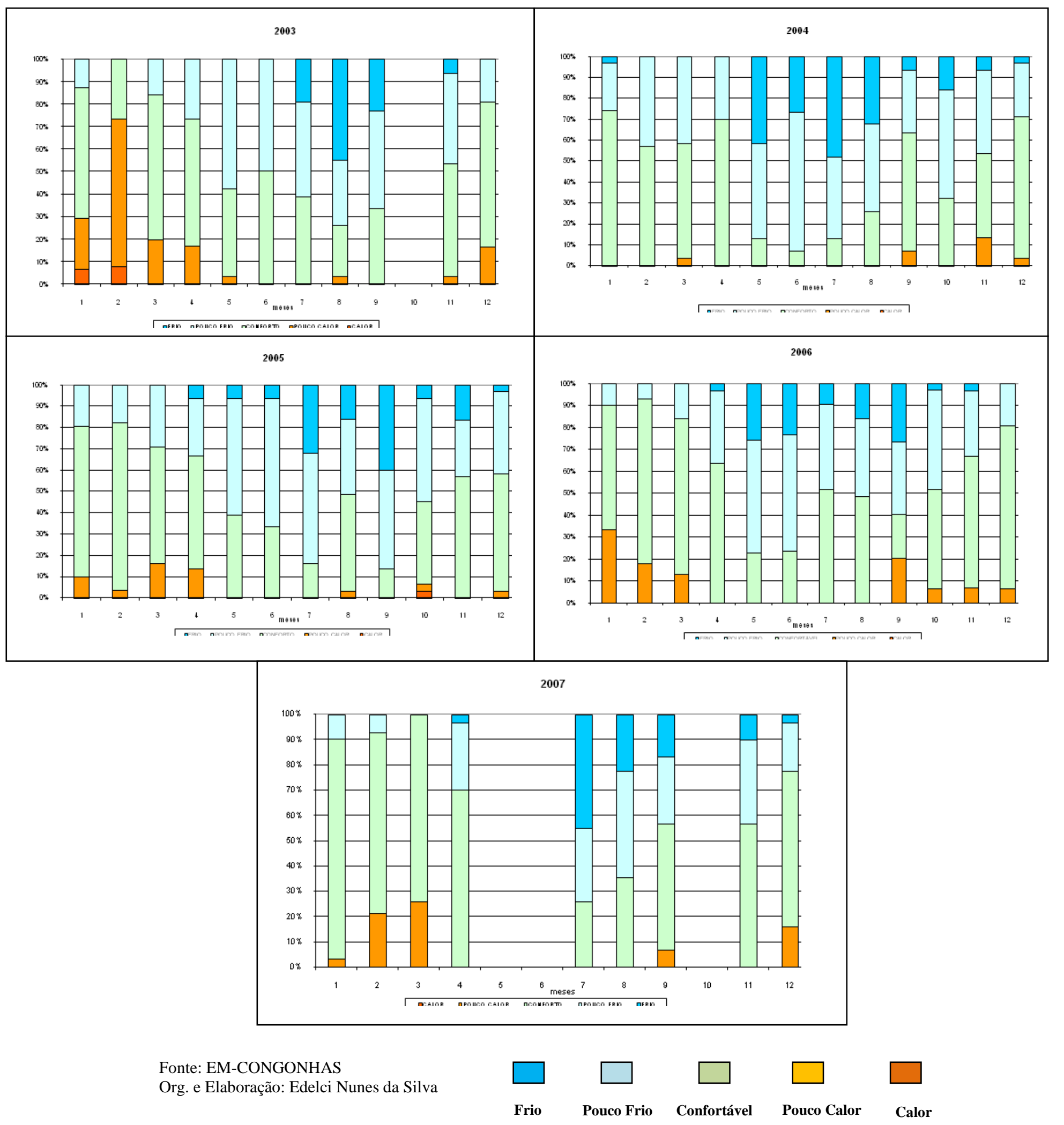


A Tabela 9 mostra a quantidade e a proporção de dias segundo a faixa de sensação térmica nas duas estações meteorológicas. De modo geral, a EM-IAG/USP apresentou proporção de dias mais quentes e a EM-CONGONHAS dias mais frios. A EM-CONGONHAS a proporção de dias Frio foi de 11,3\% e Pouco Frio 33,1\%, na EM-IAG/USP foram de 7,9\% e 30,7\%. Os dias confortáveis ocorreram em proporção ligeiramente maior na EM-IAG/USP - 49,9\%, enquanto que na EM-CONGONHAS foi 48,3\%; os dias de calor e pouco calor também ocorreram em maior proporção na EM-IAG/USP $(11,0 \%$ e $0,5 \%)$.

Tabela 9 - Quantidade e porcentagem de dias, segundo faixa de sensação térmica, na EMIAG/USP e na EM-CONGONHAS, no período de 2003 a 2007.

\begin{tabular}{lllll}
\hline Sensação Térmica & \multicolumn{2}{l}{$\begin{array}{l}\text { EM-IAG/USP } \\
\text { Qtde }\end{array}$} & $\mathbf{\%}$ & \multicolumn{2}{l}{ EM-CONGONHAS } \\
& 910 & 49,9 & 832 & \% \\
\hline Confortável & 145 & 7,9 & 195 & 48,3 \\
Frio & 560 & 30,7 & 570 & 11,3 \\
Pouco Frio & 200 & 11,0 & 120 & 33,1 \\
Pouco Calor & 10 & 0,5 & 05 & 7,0 \\
Calor & 1825 & 100 & 1722 & 0,3 \\
\hline Total & \multicolumn{5}{l}{100} \\
\hline Fonte: EM-IAG/USP e EM/CONGONHAS. Organização e Elaboração: Edelci Nunes
\end{tabular}

Foram calculadas as diferenças entre os valores do índice PET na EMIAG/USP e na EM-CONGONHAS. Os valores positivos indicam que a temperatura de conforto na EM-IAG/USP é maior do que na EM-CONGONHAS.

A Figura 44 mostra a distribuição dessas diferenças. É possível observar que os valores do índice PET na EM-IAG/USP são freqüentemente mais elevados do que na EM-CONGONHAS, em todas as faixas de conforto. As diferenças em até de $+2^{\circ}$ C são as mais freqüentes. As diferenças negativas, ou seja, quando os valores do índice PET são maiores na EM-CONGONHAS também ocorrem, embora com menos freqüência. Contudo, a distribuição das freqüências da diferença entre os valores calculados da EM-IAG/USP e da EM-CONGONHAS mostrou que, na EMIAG/USP, os valores apresentaram-se freqüentemente mais elevados em todas as faixas de conforto em pelo menos dois graus. Isso significa que, se a temperatura fisiológica observada na EM-CONGONHAS é de $18^{\circ} \mathrm{C}$ - limite inferior da faixa de conforto - na EM-IAG/USP é de $20^{\circ} \mathrm{C}$ - mais próxima do centro da zona de conforto; ou se a temperatura fisiológica na EM-CONGONHAS é de $26^{\circ} \mathrm{C}$ - limite 
superior da faixa de conforto - na EM-IAG/USP é de $28^{\circ} \mathrm{C}$ - ou seja, encontra-se na faixa de pouco calor $\left(>26^{\circ} \mathrm{C}\right)$.

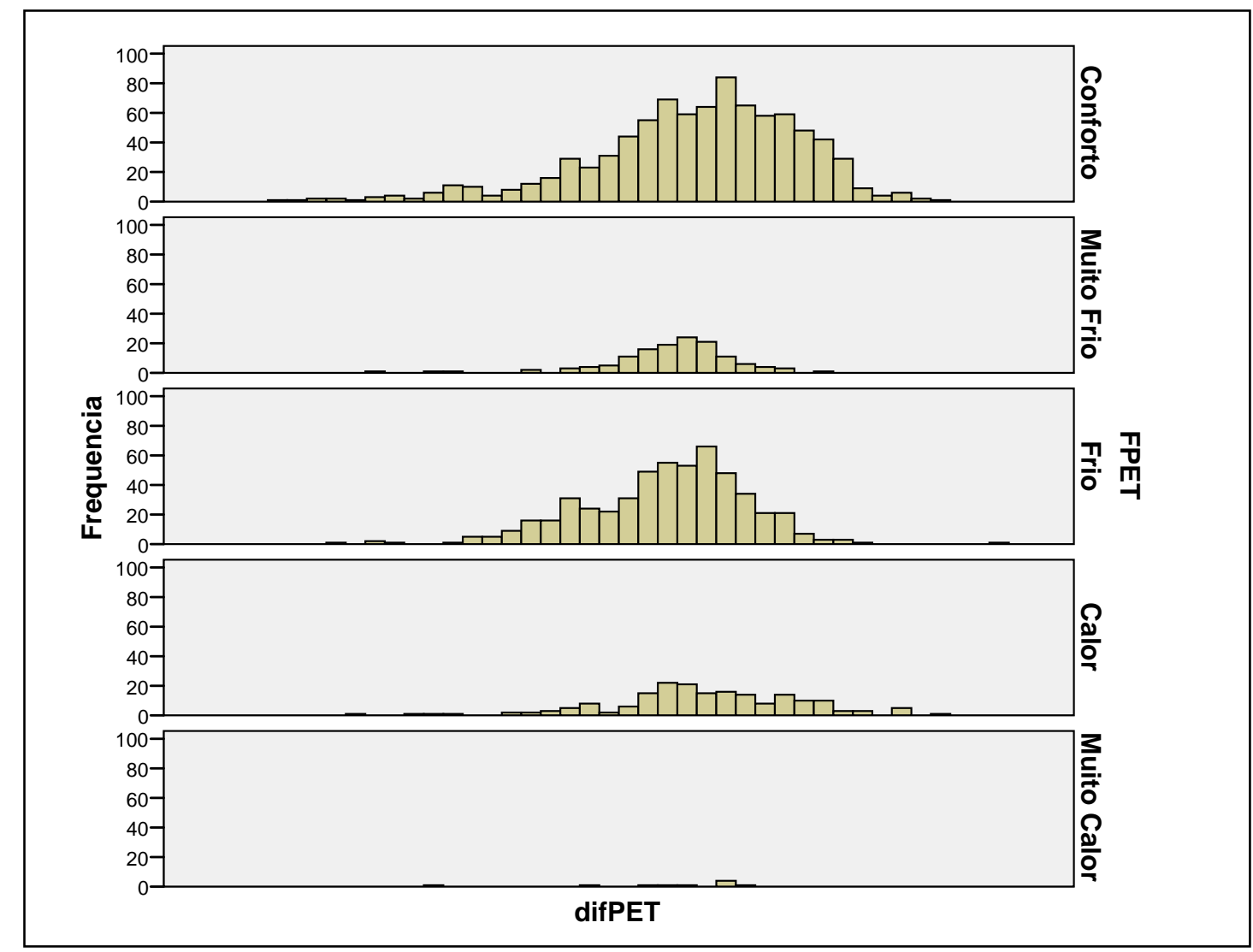

Figura 44 - Frequencia das diferenças entre os valores do índice PET da EM-IAG/USP e EM-CONGONHAS, no período de 2003 a 2007, São Paulo, SP

Fonte: EM-IAG/USP e EM-CONGONHAS.

\subsection{Qualidade do Ar no setor Sul/Sudeste}

A fim de avaliar as condições de poluição do ar no setor Sul/Sudeste foram coletados os índices de qualidade do ar medidos na estação de monitoramento da CETESB-Estação Congonhas.

Conforme se observa, na Figura 45, o $\mathrm{NO}_{2}$ prevaleceu como o pior poluente medido na estação, nos anos de 2003, 2004 e 2007 em mais de 80\% dos dias. Nos anos de 2005 e 2006 houve uma redução de dias em que o $\mathrm{NO}_{2}$ esteve entre os piores poluentes medidos e, observa-se um aumento significativo da proporção de dias em que o $\mathrm{CO}$ esteve como pior poluente. 
$\mathrm{O} \mathrm{MP}_{10}$ também é um poluente que aparece como o pior neste ponto, porém em menor proporção de dias. No ano de 2006 , mais de $20 \%$ dos dias o $\mathrm{MP}_{10}$ foi o pior poluente. $\mathrm{O} \mathrm{SO}_{2}$ aparece como pior poluente em proporção muito pequena em todo o período.

A Figura 46 mostra a proporção do índice de qualidade do ar. No ano de 2003 houve uma pequena proporção dos dias em que a qualidade do ar esteve BOA. Na maior parte do ano a qualidade do ar esteve regular. No ano de 2004 e 2007 a proporção de dias com BOA qualidade do ar foi de cerca de $20 \%$ e cerca de $80 \%$ dos dias estiveram com qualidade do ar regular. Nos anos de 2005 e 2006 houve certo "equilíbrio" na proporção de dias com qualidade do ar regular e boa. A proporção de dias com qualidade do ar inadequado foi muito pequena, sendo que no ano de 2003 apresentou $1,8 \%$ dos dias.

Durante este período houve dias sem observação, sendo que o ano de 2006 foi aquele em que houve mais dias com falhas na medição dos dados. 


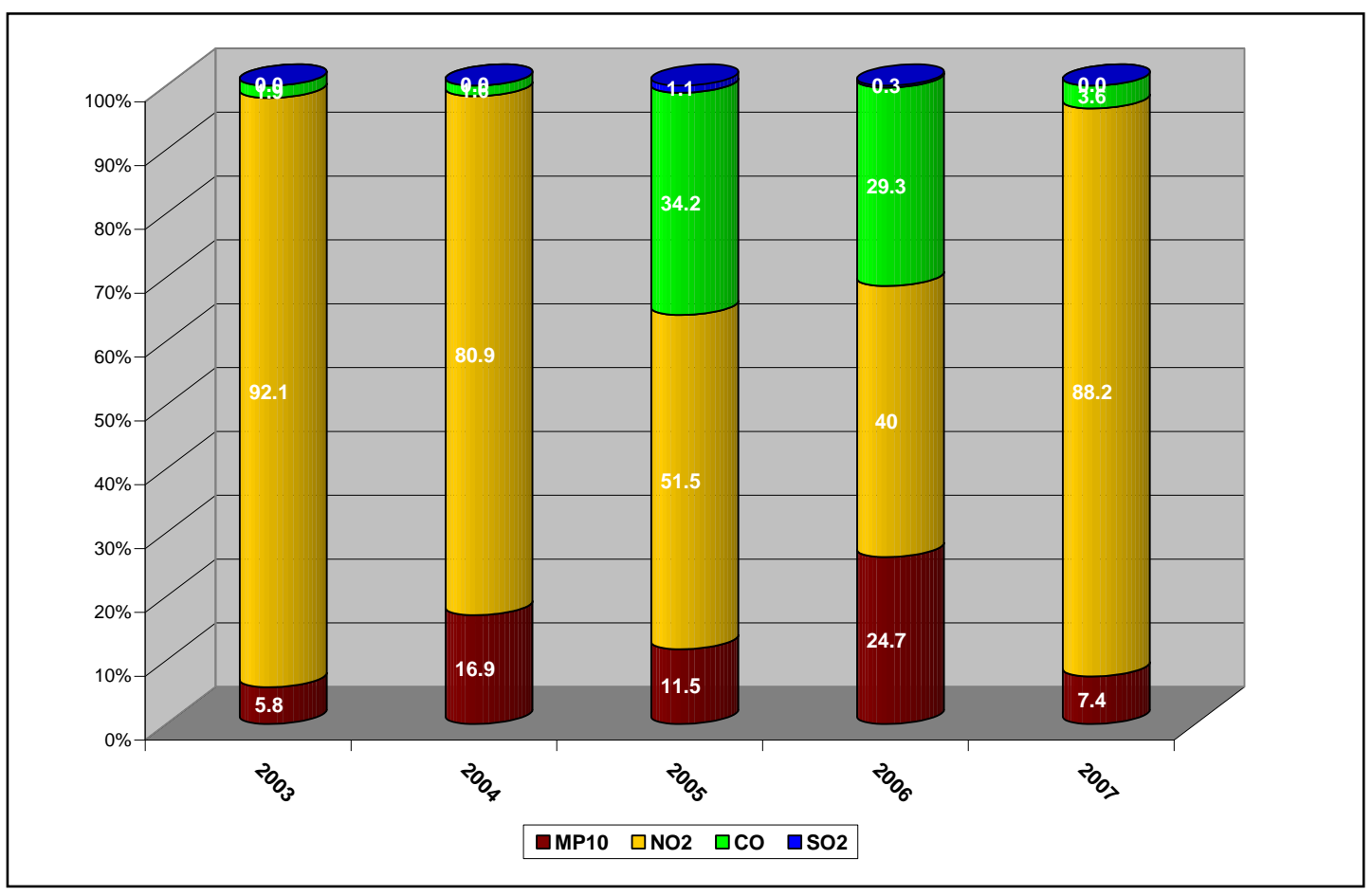

Figura 45 - Proporção (\%) dos poluentes relacionados a composição do índice de qualidade do ar, na Estação de Congonhas, São Paulo, SP. 2003 a 2007

Fonte: www.cetesb.sp.com.br Org. e Elaboração: Edelci Nunes da Silva

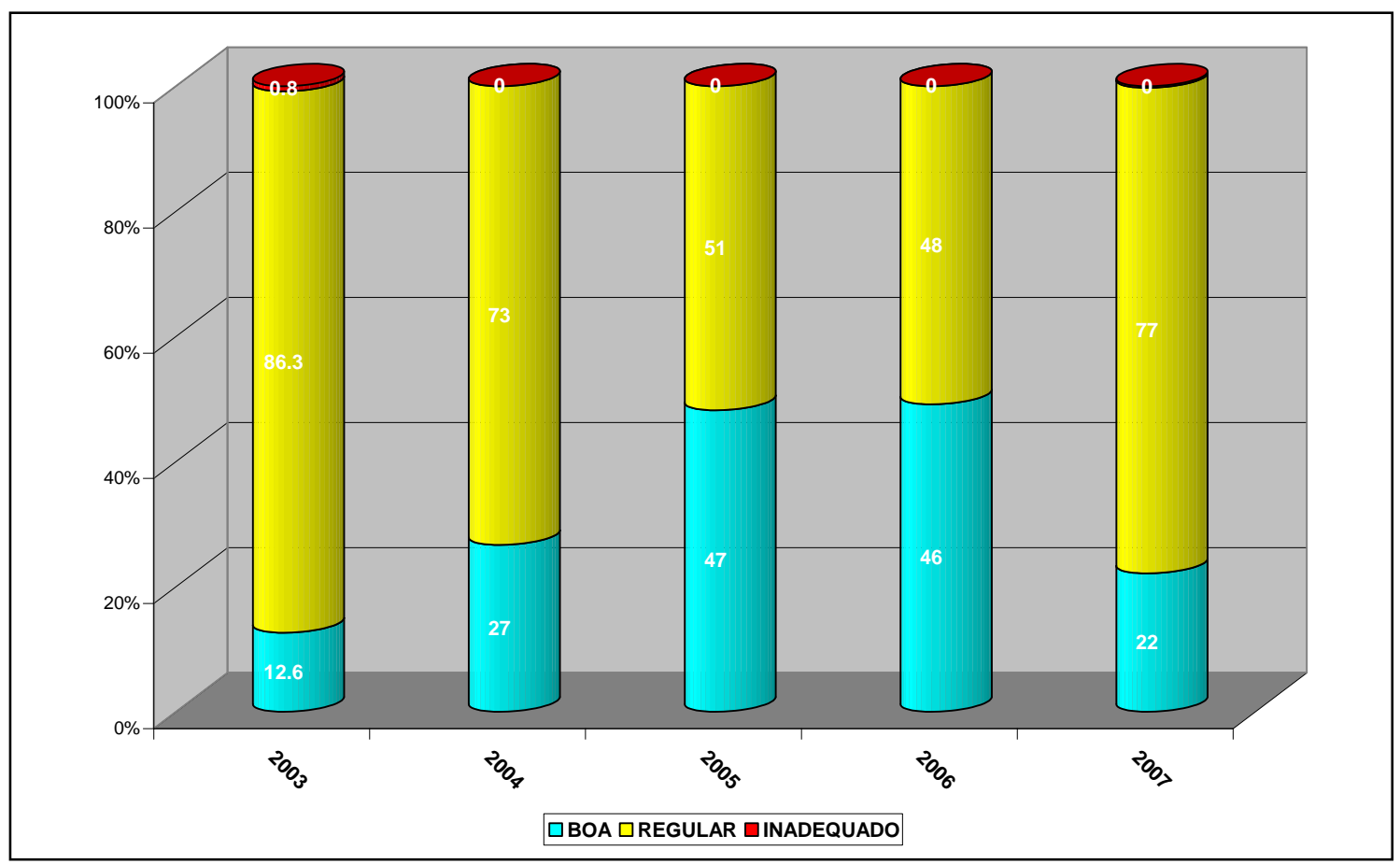

Figura 46 - Proporção (\%) do índice de qualidade do ar medido na Estação de Congonhas, São Paulo, SP, 2003 a 2007.

Fonte: www.cetesb.sp.com.br 


\subsection{As Internações hospitalares no setor Sul/Sudeste}

\subsubsection{Séries temporais das internações hospitalares no setor Sul/Sudeste.}

As Figuras 47 a 49 mostram a distribuição diária das internações hospitalares no setor $\mathrm{Sul} / \mathrm{Sudeste}$.

A Figura 47 mostra a distribuição das internações hospitalares por doenças circulatórias em pessoas de 60 anos e mais nos anos de 2003 a 2007. Os valores oscilaram entre 0 e mais de 30 internações/dia. Os dados diários apresentam grande variabilidade e, portanto, não é possível identificar um padrão claro de tendência ou sazonalidade. A média móvel de 30 dias, no entanto, indica uma tendência de aumento das internações a partir de 2004. Percebem-se alguns picos de internação durante o ano, contudo não é possível afirmar que há um padrão sazonal nas internações por doenças circulatórias.

A Figura 48 mostra a distribuição das internações por doenças respiratórias em pessoas com mais de 60 anos. Os valores oscilaram entre 0 e cerca de 15 internações/dia. Também nesse caso há grande variabilidade diária do número de internações, não sendo possível identificar tendência ou sazonalidade. A média móvel de 30 dias aponta uma leve tendência de aumento das internações a partir de 2004. Nota-se diminuição no número de internações nos meses relacionados ao verão (início e final do ano) e aumento a partir de março/abril. 


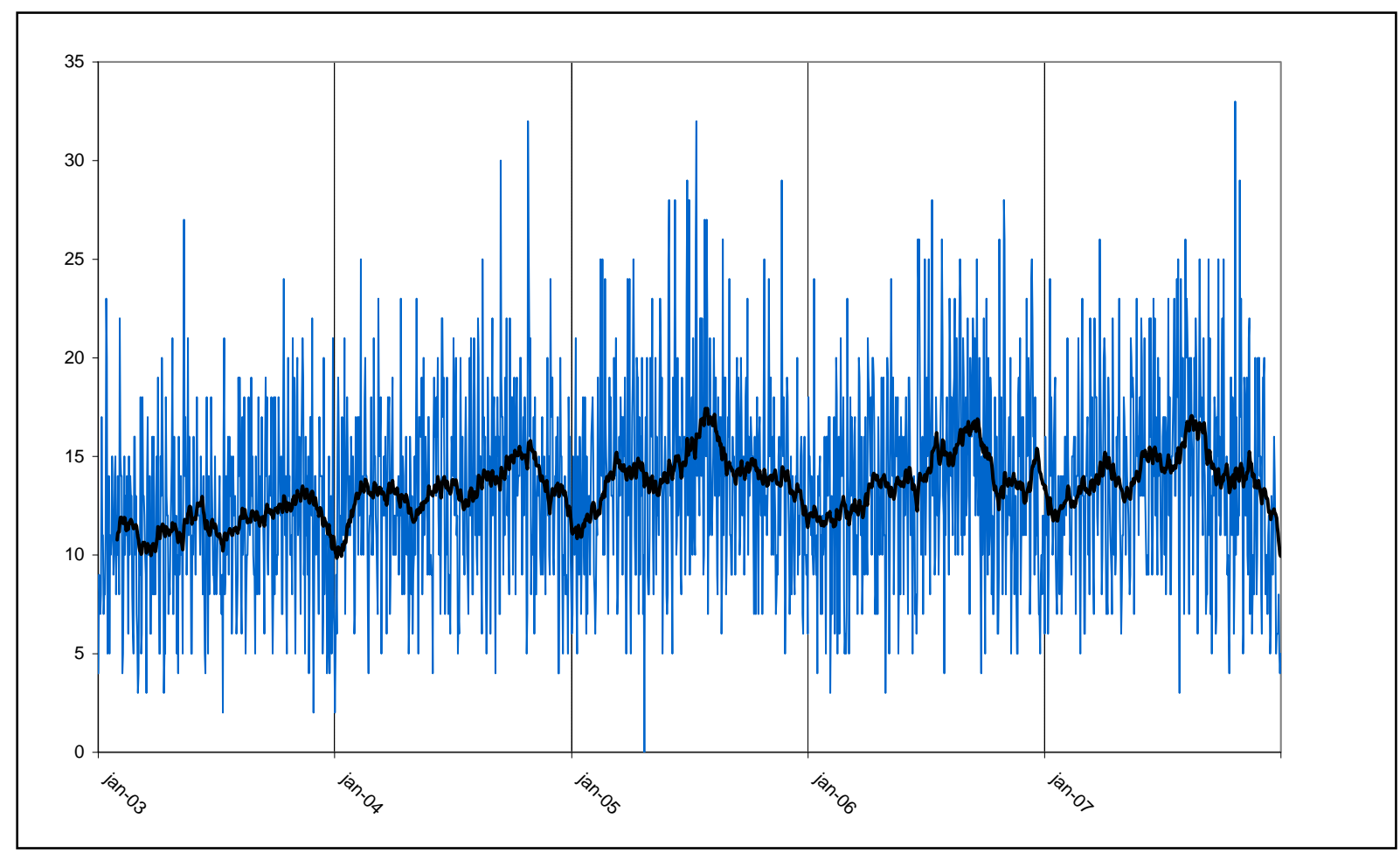

Figura 47 - Série temporal das internações hospitalares por doenças do aparelho circulatório em pessoas de sessenta e mais anos, no setor Sul/Sudeste, SP, 2003 a 2007.

Fonte: DATASUS 2009

A Figura 49 mostra a distribuição das internações diária por doenças respiratórias em crianças de menores de 5 anos. Os valores oscilaram entre 0 e mais de 25 internações/dia. Os dados diários apontam uma clara sazonalidade. A média móvel de 30 dias mostra que os picos de internação ocorrem no primeiro semestre do ano, aumentando consideravelmente nos meses de outono (a partir de março). Esses picos foram maiores entre 2003 e 2005, diminuindo em 2006-2007. Houve dois picos de internação nos anos de 2006 e 2007: no primeiro semestre e no segundo semestre. 


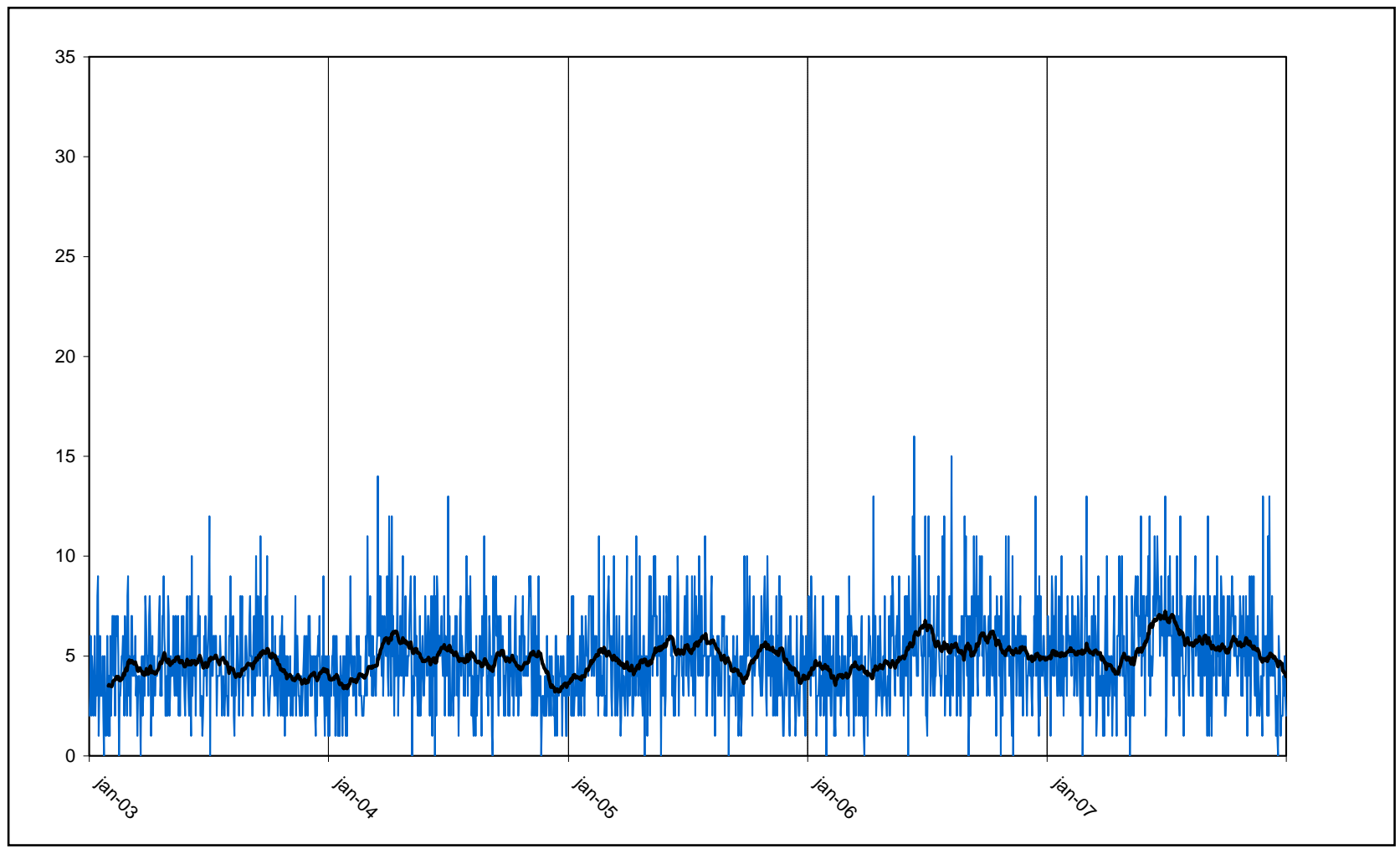

Figura 48 - Série temporal das internações hospitalares por doenças do aparelho respiratório em pessoas de sessenta e mais anos, no setor Sul/Sudeste, SP, 2003 a 2007.

Fonte: DATASUS 2009

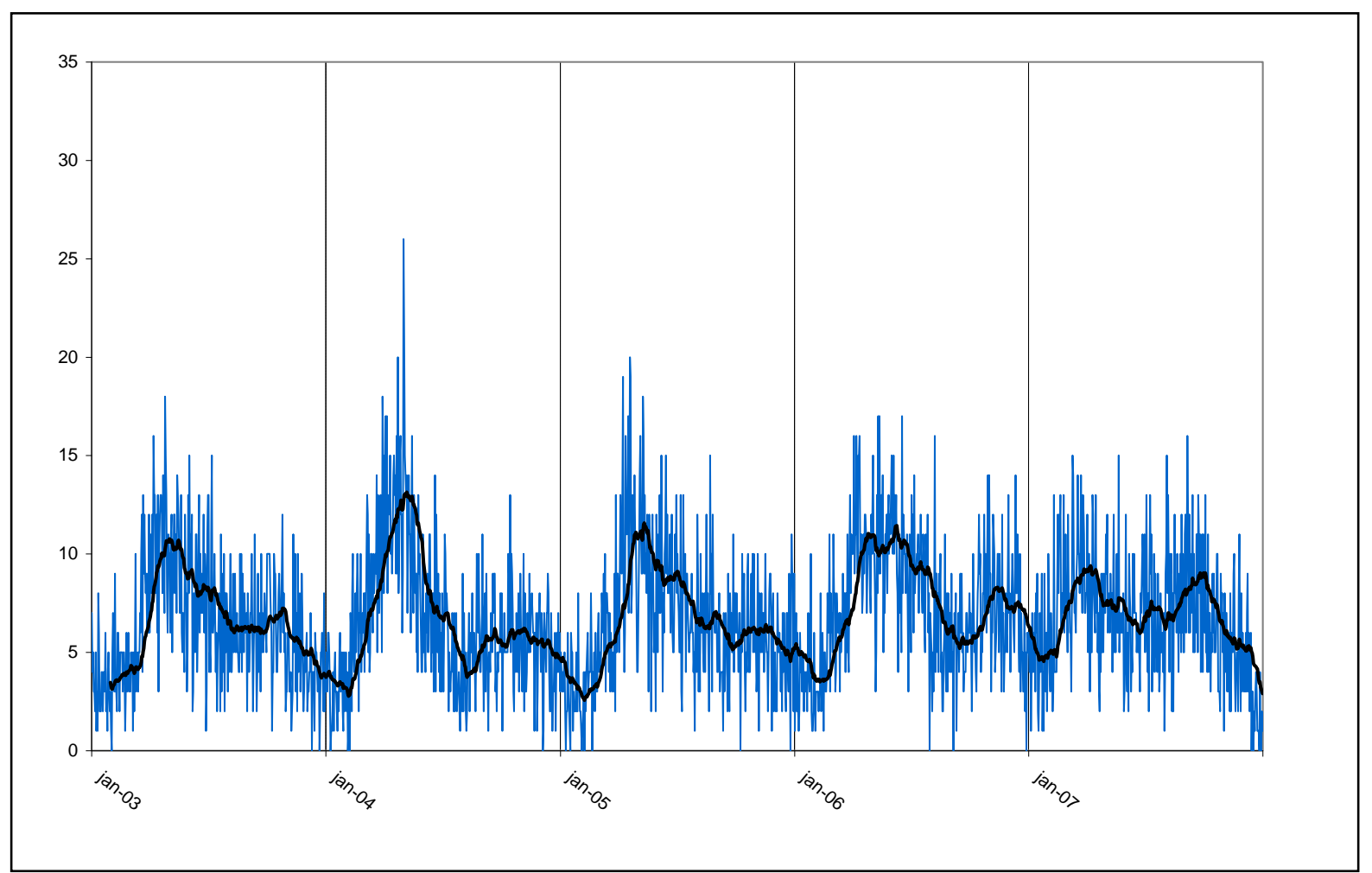

Figura 49 - Série temporal das internações hospitalares por doenças do aparelho respiratório em crianças de menores de cinco anos, no setor Sul/Sudeste, SP, 2003 a 2007.

Fonte: DATASUS 2009 
Os gráficos boxplot apresentados a seguir mostram a distribuição mensal das internações hospitalares no setor Sul/Sudeste no período de 2003 a 2007.

O gráfico boxplot apresentado, na Figura 50 mostra que há grande variabilidade mensal das internações por doenças circulatórias em pessoas de 60 e mais anos. Contudo, em alguns meses do ano, essa variabilidade é maior, como no mês de abril e novembro de 2003, maio a setembro de 2004, abril e julho de 2005 , fevereiro e agosto a outubro de 2006, julho, agosto e setembro a outubro de 2007, não apresentando um padrão claro. O gráfico de boxplot também indica uma tendência de aumento das internações a partir de 2004, mas não aponta uma sazonalidade clara. É possível identificar um leve aumento da mediana nos meses relacionados ao outono/inverno/primavera.

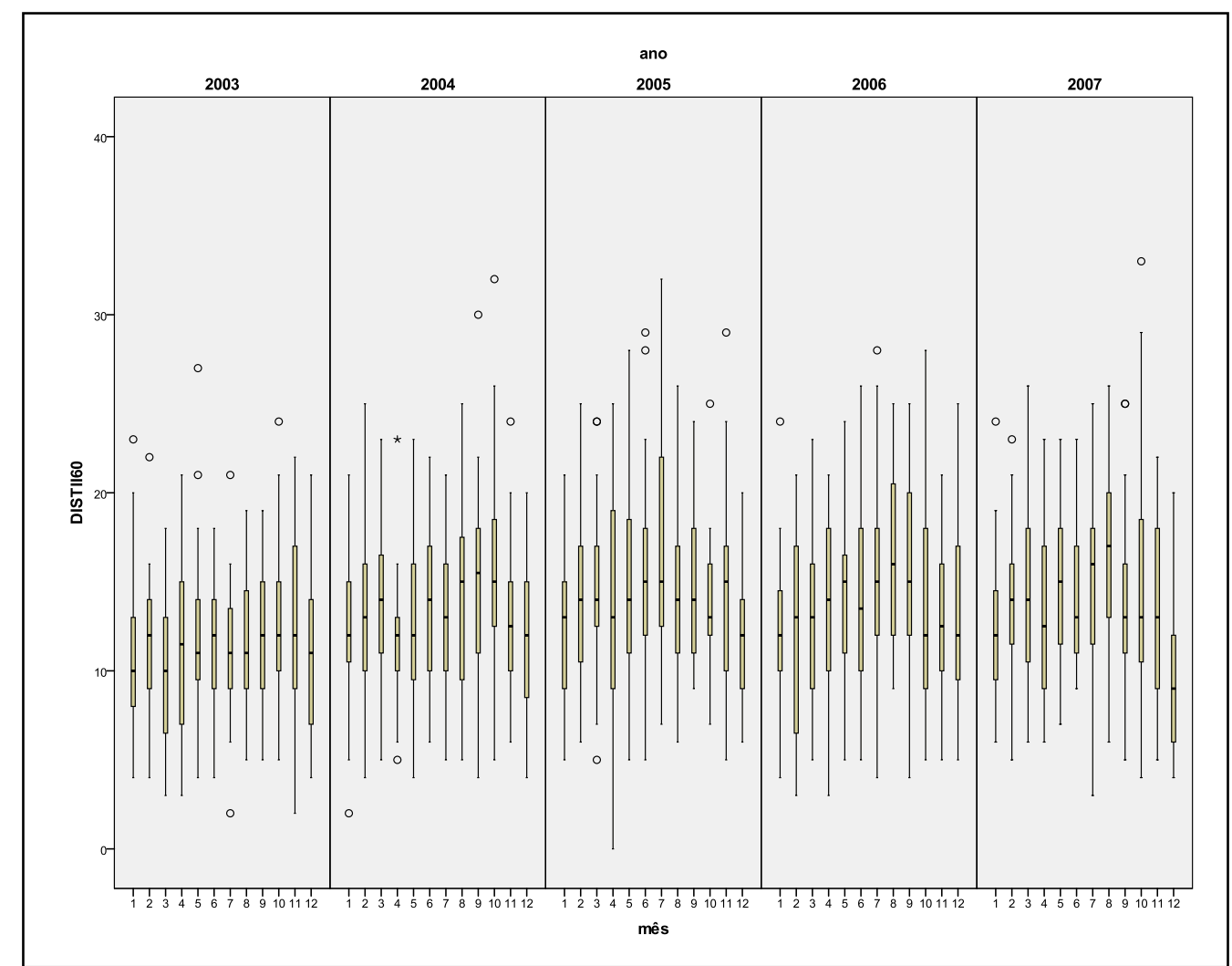

Figura 50 - Ritmo mensal das internações hospitalares por doenças do aparelho circulatório em pessoas de sessenta e mais anos, no setor Sul/Sudeste, SP, 2003 a 2007.

Fonte: DATASUS 2009. Org. e Elaboração: Edelci Nunes da Silva

A Figura 51 apresenta as internações por doenças respiratórias em pessoas de 60 e mais anos. O gráfico de boxplot também indica uma tendência de aumento das internações a partir de 2004. Não aponta uma sazonalidade clara, mas é possível 
identificar tendência de aumento da mediana nos meses relacionados ao outono/inverno/primavera, ou seja, de março a outubro e diminuição nos meses de verão - dezembro/janeiro. O ano de 2006 apresentou grande quantidade de outliers, ou seja, valores de internação que ficaram muito distantes da distribuição do respectivo mês.

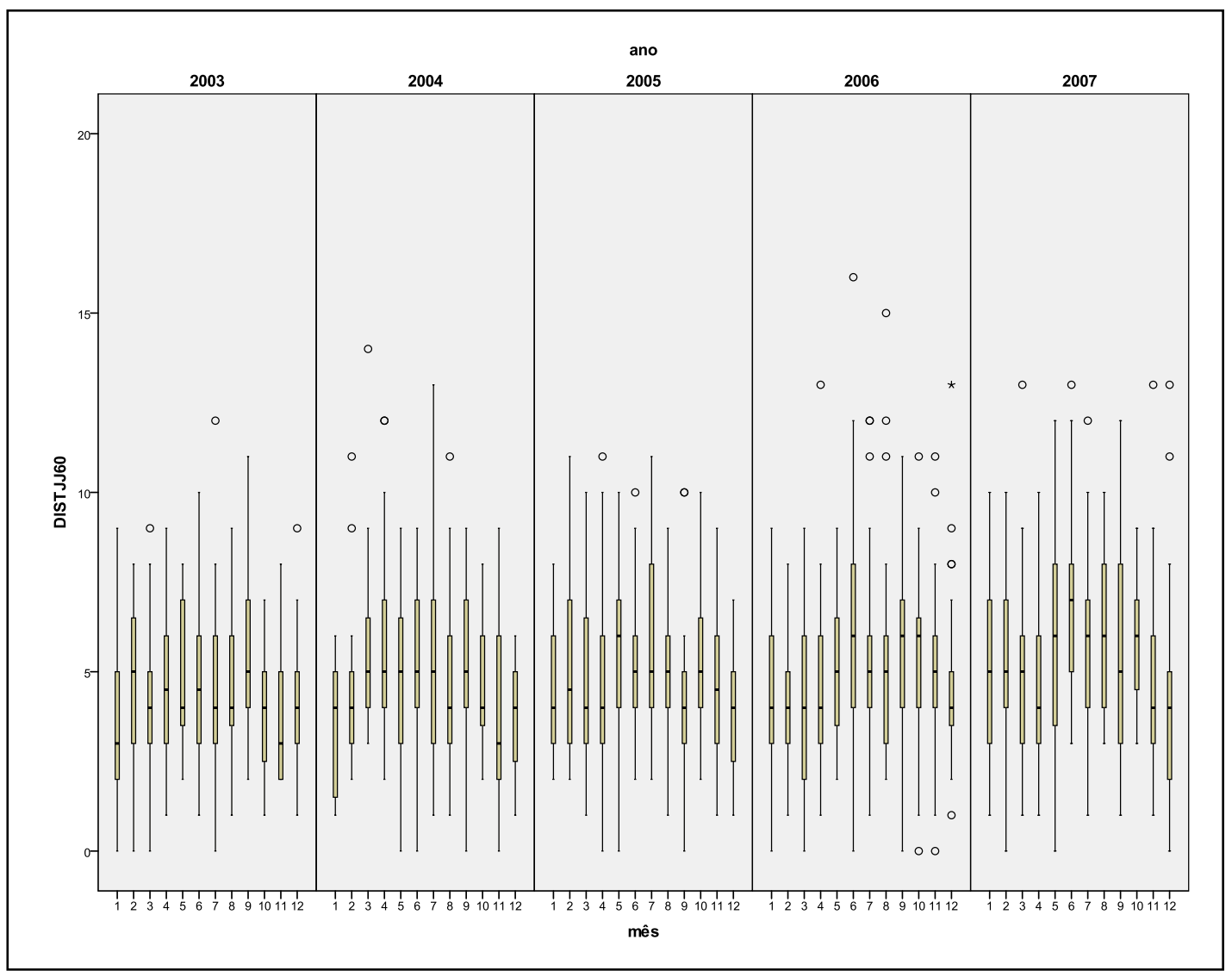

Figura 51 - Ritmo mensal das internações hospitalares por doenças do aparelho respiratório em pessoas de sessenta e mais anos, no setor Sul/Sudeste, SP, 2003 a 2007.

Fonte: DATASUS 2009.

O gráfico boxplot apresentado, na Figura 52, mostra clara sazonalidade na distribuição mensal das internações por doenças respiratórias em crianças de menores de 5 anos, exceto no ano de 2007 em que esse padrão não é claro. Há aumento na variabilidade e na quantidade de internações a partir do mês de março até o mês de junho, exceto em 2006, o mês de julho que também apresentou valores altos. Os meses de dezembro a fevereiro apresentam a menor variabilidade e quantidade nas internações hospitalares. 


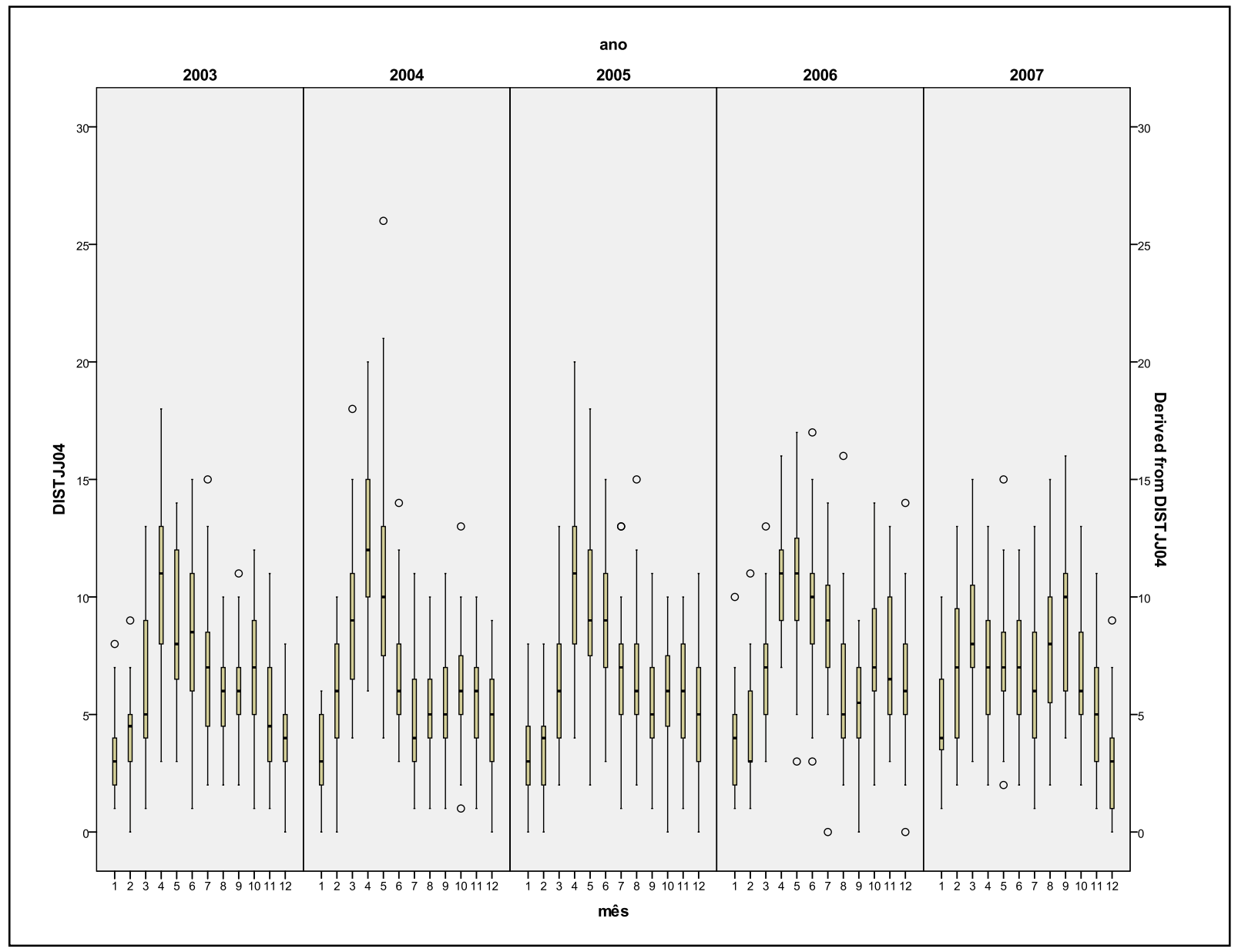

Figura 52 - Ritmo mensal das internações hospitalares por doenças do aparelho respiratório em crianças de menores de cinco anos, no setor Sul/Sudeste, SP, 2003 a 2007.

Fonte: DATASUS 2009.

\subsubsection{Análises espaciais das internações hospitalares no setor Sul/Sudeste}

A distribuição espacial das internações por doenças do aparelho circulatório no setor Sul-Sudeste é apresentada nos mapas da Prancha 13. A taxa de internação por 10.000 habitantes foi de 74,6 a mais baixa e 408,3 a mais alta taxa no setor estudado.

Os distritos Sacomã, Jabaquara, Cidade Ademar, Pedreira e Cidade Dutra foram aqueles que apresentaram as mais altas taxas de internação por doenças circulatórias no período de 2003 a 2006. Em 2007, as maiores taxas restringiram-se aos distritos do Jabaquara, Cidade Ademar e Pedreira. Os distritos com as menores taxas de internação - entre 74,6 a 150,0 internações por 10.000 habitantes. - foi Ibirapuera, Moema, Saúde, Campo Belo em todo período estudado. O distrito 
Cursino apresentou taxas baixas, no ano de 2003 e 2004 e, o distrito Socorro, no ano de 2003. Os distritos restantes apresentaram taxas intermediárias de internação em todo o período.

A distribuição das internações por doenças do aparelho respiratório em pessoas de 60 e mais anos é apresentada nos mapas da Prancha 14. Nota-se que as maiores taxas de internação não obedecem a um padrão homogêneo no período de 2003 a 2007. O distrito do Jabaquara apresentou as maiores taxas no período de 2004 a 2007; o distrito de Pedreira em 2003 e o distrito Cidade Ademar em 2004.

Os distritos do Ibirapuera, Moema, Campo Belo, Saúde e Cursino apresentaram as menores taxas de internação durante todo o período estudado.

A Prancha 15 apresenta os mapas de internação por doenças respiratórias em crianças menores de cinco anos. O distrito de Santo Amaro apresentou as maiores taxas de internação por todo o período estudado - entre 750,1 e 1500,0 internações por 10.000 habitantes, seguido do distrito do Jabaquara que apresentou taxas entre 500,1 e 750,0 internações por 10.000 habitantes.

Os distritos do Ibirapuera, Moema, Saúde, Campo Belo, Cursino, Campo Grande e Sacomã apresentaram taxas baixas por todo período estudado - 2003 a 2007 - entre 28,8 e 150,0 internações por 10.000 habitantes.

A distribuição das internações por doenças respiratórias em crianças menores de cinco anos, no setor Sul/Sudeste, não apresenta um padrão de distribuição muito claro. Embora, o distrito de Santo Amaro e Jabaquara apresente altas taxas em todo o período o restante dos distritos ora apresentam taxas mais altas, ora mais baixas como é o caso do distrito de Vila Mariana e Socorro, por exemplo. Os distritos do Ibirapuera, Moema, Campo Belo, Saúde, Socorro e Campo Grande apresentaram menores taxas de internação em todo o período. 
Prancha 13 - Mapas da incidência das internações por doenças do aparelho circulatório em adultos de sessenta e mais anos, no setor Sul/Sudeste, município de São Paulo, 2003 a 2007. 
Prancha 14 - Mapas da incidência das internações por doenças do aparelho respiratório em adultos de sessenta e mais anos, no setor Sul/Sudeste, município de São Paulo, 2003 a 2007. 
Prancha 15 - Mapas da incidência das internações por doenças do aparelho respiratório em crianças menores de cinco anos, no setor Sul/Sudeste, município de São Paulo, 2003 a 2007. 


\subsection{A relação clima e saúde no setor Sul/Sudeste}

\subsubsection{Doenças circulatórias em pessoas de sessenta e mais anos}

5.6.1.1 Incidência mensal e o ambiente térmico

A Figura 53 e a Figura 54 apresentam a taxa de incidência mensal (por 10.000 habitantes) das internações hospitalares no setor Sul/Sudeste e o ritmo das temperaturas médias, mínimas e máximas, no período de 2003 a 2007.

As taxas de internação por doenças do aparelho circulatório (Figura 58) não apresentam um padrão sazonal muito claro, mas é possível identificar alguns picos de ocorrência de taxas mais elevadas nos meses de outubro de 2003 e 2004, julho de 2005, agosto de 2006 e 2007, correspondendo aos meses de inverno e primavera. O gráfico mostra que os picos altos de internação hospitalar ocorrem em períodos de temperaturas mais baixas. O gráfico indica que os meses com temperaturas mínimas (absolutas) muito baixas apresentam maior incidência de internação, como no mês de maio de 2003, julho de 2005, agosto de 2006, por exemplo. De modo geral, os meses mais quentes, ou seja, aqueles com temperaturas máximas e mínimas absolutas e médias elevadas correspondem às menores taxas de internação por doenças do aparelho circulatório. 


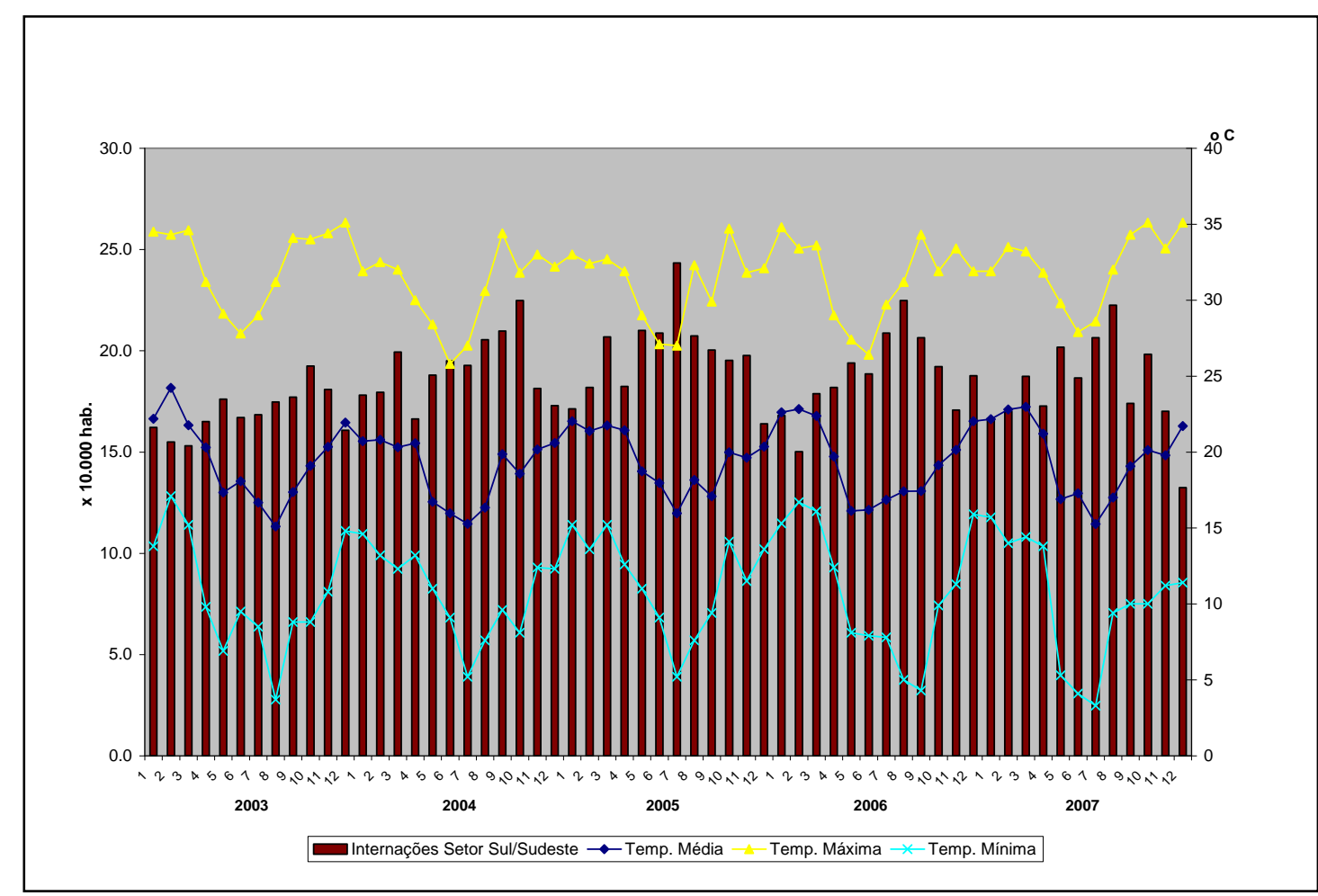

Figura 53 - Incidência de mensal de internação hospitalar por doenças do aparelho circulatório em pessoas com sessenta e mais anos, temperatura máxima e mínima absoluta e temperatura média mensal na EM-IAG/USP, no período de 2003 a 2007, Setor Sul/Sudeste, São Paulo, SP.

Fonte: DATASUS 2009, EM-IAG/USP

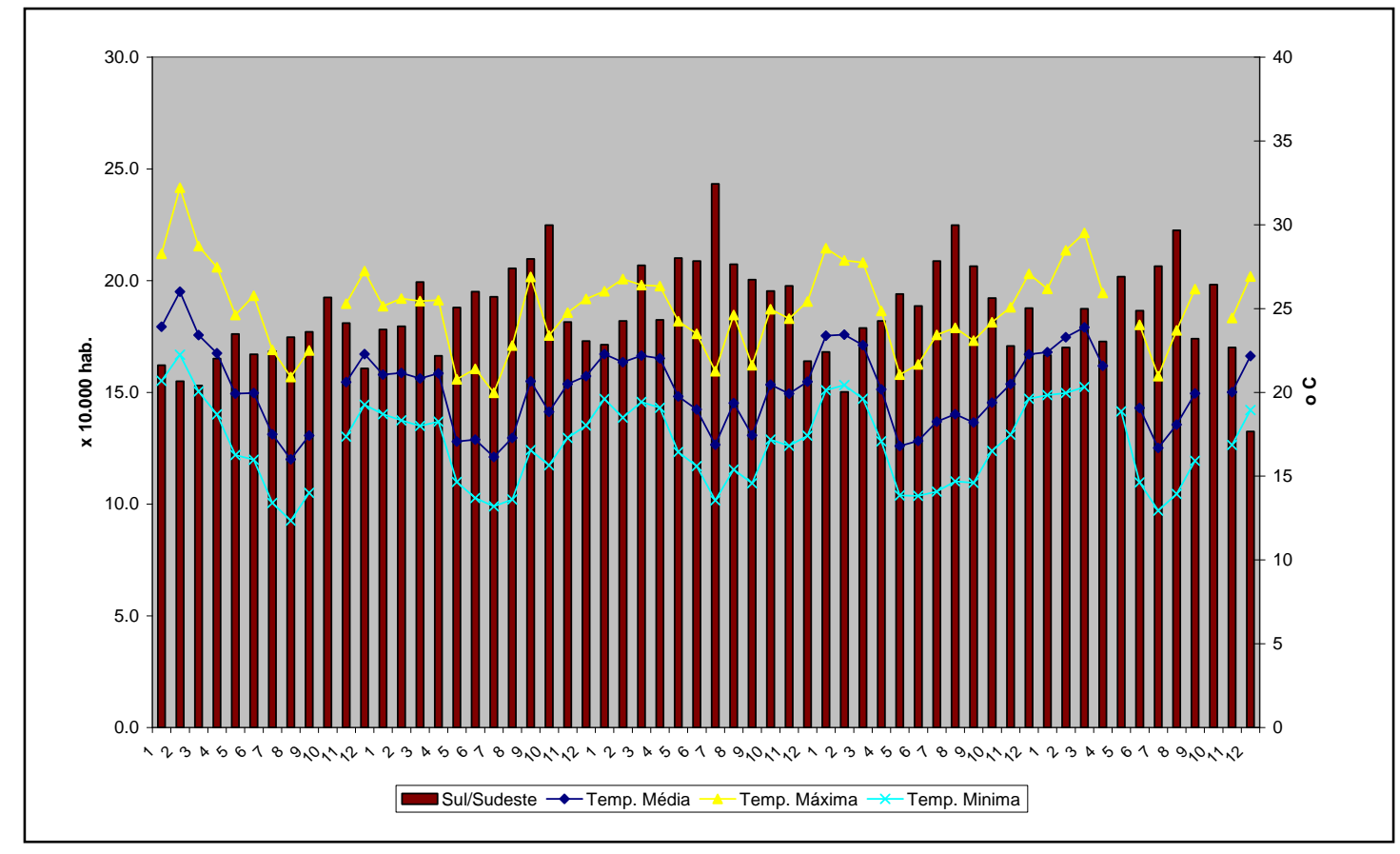

Figura 54 - Incidência de mensal de internação hospitalar por doenças do aparelho circulatório em pessoas com 60 e mais anos, temperaturas médias da máxima e mínima e temperatura média mensal na EM-CONGONHAS, no período de 2003 a 2007, Setor Sul/Sudeste, São Paulo, SP.

Fonte: DATASUS 2009, EM-CONGONHAS 
5.6.1.1 Modelo Linear Generalizado com distribuição binomial negativa (GLM)

Para o número de internações diárias por doenças circulatórias em pessoas de 60 e mais anos, o modelo ajustado final manteve como variáveis explicativas a temperatura média diária, amplitude da temperatura diária, índice de poluição diário, ano e dia da semana (Tabela 10).

Em relação às variáveis explicativas contínuas, as estimativas positivas dos coeficientes produzem risco relativo estimado maiores do que um. A relação com a amplitude térmica apontou um risco relativo de 1,006, ou seja, a cada aumento de $1{ }^{\circ} \mathrm{C}$ na amplitude da temperatura diária, o número de internações diárias por doenças circulatórias aumenta, em média, 0,6\%, mantidos constantes os valores das outras variáveis do modelo.

Com relação ao índice de poluição o risco relativo foi de 1,002 , ou seja, a cada aumento de uma unidade do índice de poluição diário, o número de internações diárias por doenças circulatórias aumenta, em média, $0,2 \%$, mantidos fixos os valores das demais variáveis do modelo.

Quando a estimativa do coeficiente é negativa, seu risco relativo estimado é menor do que um e, a interpretação é feita utilizando o inverso do risco relativo estimado. A temperatura média apontou um risco relativo de 0,991 ou 1/0,991=1,009, ou seja, a cada decréscimo de $1^{\circ} \mathrm{C}$ na temperatura média diária, o número de internações diárias por doenças circulatórias aumenta, em média, 0,9\%, mantidos constantes os valores das outras variáveis do modelo.

Em relação ao fator ano, os riscos relativos maiores do que 1 indicam porcentagens de aumento do número esperado de internações diárias por doenças circulatórias em idosos naquele ano, em relação a 2003, em 2004 o número esperado de internações diárias em 2004 é 12,4\% maior; em 2005 o número esperado de internações diárias em 2005 é 21\% maior; em 2006 o número esperado de internações diárias em 2006 é 18,8\% e, em 2007, o número esperado de internações diárias é 16,5\% maior do que o esperado em 2003.

Com relação ao dia da semana, foi considerado o domingo como dia de referência. Nas segundas-feiras o número esperado de internações diárias é 72,6\% maior; nas terças-feiras o número esperado de internações diárias é 56,8\% maior; nas quartas-feiras o número esperado de internações diárias é 35,8\% maior; nas quintas- 
feiras o número esperado de internações diárias é $42,8 \%$ maior; às sextas-feiras o número esperado de internações diárias às sextas-feiras é $28,3 \%$ maior aos sábados o número esperado de internações diárias é $1 / 0,888=1,126$ ou $12,6 \%$ menor do que o esperado aos domingos.

Deve-se ressaltar que essas interpretações valem quando são mantidos fixos os valores das demais variáveis do modelo.

Tabela 10 - Resultados do modelo final ajustado para o número de internações por doenças circulatórias em pessoas de sessenta e mais anos, no setor Sul/Sudeste, São Paulo, SP, no período de 2003 a 2007

\begin{tabular}{|c|c|c|c|c|c|c|}
\hline Efeitos & Estimativa & Erro Padrão & Valor - p & Risco Relativo & IC(95\%) INF & IC(95\%)SUP \\
\hline intercepto & 2,035 & 0,058 & $<<0,0001$ & . & . & ( . \\
\hline Temperatura Média $\left({ }^{\circ} \mathrm{C}\right)$ & $-0,009$ & 0,002 & $<0,0001$ & 0,991 & 0,987 & 0,995 \\
\hline Amplitude & 0,0058 & 0,0026 & 0,03 & 1,006 & 1,001 & 1,011 \\
\hline Índice de Poluição & 0,0019 & 0,0004 & 0,001 & 1,002 & 1,001 & 1,003 \\
\hline \multicolumn{7}{|l|}{ Ano } \\
\hline 2003 & . & . & . & . & . & . \\
\hline 2004 & 0,117 & 0,023 & $<0,0001$ & 1,124 & 1,075 & 1,176 \\
\hline 2005 & 0,191 & 0,024 & $<0,0001$ & 1,210 & 1,155 & 1,269 \\
\hline 2006 & 0,172 & 0,024 & $<0,0001$ & 1,188 & 1,133 & 1,245 \\
\hline 2007 & 0,153 & 0,023 & $<0,0001$ & 1,165 & 1,114 & 1,219 \\
\hline \multicolumn{7}{|l|}{ Dia da semana } \\
\hline domingo & . & . & . & . & . & . \\
\hline segunda-feira & 0,546 & 0,028 & $<0,0001$ & 1,726 & 1,634 & 1,824 \\
\hline terça-feira & 0,450 & 0,031 & $<0,0001$ & 1,568 & 1,476 & 1,667 \\
\hline quarta-feira & 0,306 & 0,031 & $<0,0001$ & 1,358 & 1,278 & 1,443 \\
\hline quinta-feira & 0,356 & 0,029 & $<0,0001$ & 1,428 & 1,349 & 1,511 \\
\hline sexta-feira & 0,249 & 0,030 & $<0,0001$ & 1,283 & 1,209 & 1,360 \\
\hline sábado & $-0,119$ & 0,031 & 0,0001 & 0,888 & 0,835 & 0,943 \\
\hline lag1 & 0,009 & 0,002 & $<0,0001$ & . & . & . \\
\hline lag2 & 0,005 & 0,002 & 0,01 & . & . & . \\
\hline
\end{tabular}

Fonte: DATASUS 2009 e EM-CONGONHAS.

\subsubsection{Análise de regressão logística}

As variáveis meteorológicas contínuas índice PET, temperaturas médias, máximas e mínimas apresentaram associação significativa $(\mathrm{p}<0,05)$ com taxa diária de internação de doenças circulatórias em pessoas de 60 e mais anos. As variáveis do campo térmico foram testadas separadamente a fim de avaliar aquelas que melhor explicam condições do excesso de internação, segundo a faixa de exposição.

A Tabela 11 apresenta os resultados da análise de regressão logística para as faixas de conforto PET controladas pela poluição do ar.

A faixa confortável $\left(18^{\circ} \mathrm{C}-26^{\circ} \mathrm{C}\right)$ foi considerada como referência, ou seja, infere-se que, para essa faixa, não há risco. Como pode ser observado na Tabela 12 
não há associação estatisticamente significante entre o índice PET e as internações por doenças circulatórias, exceto quando considerado a faixa de pouco calor $\left(26^{\circ} \mathrm{C}\right.$ a $31^{\circ} \mathrm{C}$ ). Neste intervalo o risco relativo é de 0,667 ou $1 / 0,667$ ou 1,499 , em outras palavras, significa que há $49 \%$ menos chance de haver dias com excesso de internações hospitalares por doenças circulatórias quando as condições atmosféricas são de pouco calor em relação à faixa de conforto e controladas pela poluição do ar.

Tabela 11 - Risco Relativo; Intervalo de Confiança; valor p para o índice de conforto térmico (PET) e internações por doenças circulatórias em pessoas de sessenta e mais anos no setor Sul/Sudeste, São Paulo, SP, por faixa de exposição, controladas pela poluição do ar, 2003 a 2007.

\begin{tabular}{|c|c|c|c|c|}
\hline \multirow[b]{2}{*}{ Variáveis } & \multicolumn{2}{|l|}{ EM-CONGONHAS* } & \multicolumn{2}{|l|}{ EM- IAG/USP** } \\
\hline & $\mathbf{R R}\left(\mathbf{I C}_{95 \%}\right)$ & $p$ & $\mathbf{R R}\left(\mathbf{I C}_{95 \%}\right)$ & $p$ \\
\hline \multicolumn{5}{|c|}{ Faixa de Sensação Térmica } \\
\hline Confortável (18 a $\left.26{ }^{\circ} \mathrm{C}\right)$ & \multicolumn{2}{|l|}{1} & \multicolumn{2}{|l|}{1} \\
\hline Frio $\left(<12{ }^{\circ} \mathrm{C}\right)$ & $1,280(0,93-1,76)$ & 0,13 & $1,245(0,87-1,78)$ & 0,23 \\
\hline Pouco Frio $\left(<18^{\circ} \mathrm{C}\right)$ & $1,004(0,80-1,25)$ & 0,97 & $0,966(0,78-1,19)$ & 0,75 \\
\hline Pouco Calor $\left(>26^{\circ} \mathrm{C}\right)$ & $0,667(0,45-0,99)$ & 0,05 & $0,667(0,48-0,91)$ & 0,01 \\
\hline Calor $\left(>31{ }^{\circ} \mathrm{C}\right)$ & $0,602(0,09-3,65)$ & 0,58 & $0,373(0,09-1,46)$ & 0,16 \\
\hline \multicolumn{5}{|l|}{ Poluição**** } \\
\hline Ruim & $1,53(1,2-1,9)$ & 0,00 & $1,50(1,2-1,8)$ & 0,00 \\
\hline
\end{tabular}

A Tabela 12 mostra a associação entre as internações hospitalares por doenças circulatórias e a faixa de exposição das temperaturas mínimas.

Nesse caso, a faixa de referência utilizada foi a das temperaturas mínimas mais elevadas, ou seja, considera-se que, para temperaturas mínimas altas, não há risco. Nota-se que o risco aumenta com a diminuição das temperaturas mínimas. Contudo, só há associação estatística significante $(\mathrm{p}<=0,05)$ quando as temperaturas mínimas são menores de $14,5^{\circ} \mathrm{C}$. Nesse caso, há 1,4 vezes mais chance de ocorrer dias com excesso de internação quando as temperaturas mínimas são menores de $14,5^{\circ} \mathrm{C}$ em relação à faixa de referência $\left(\operatorname{tmin}>19,3^{\circ} \mathrm{C}\right)$. 
Tabela 12 - Risco Relativo; Intervalo de Confiança; valor $p$ para a temperatura mínima e internações por doenças circulatórias em pessoas de sessenta e mais anos no setor Sul/Sudeste, São Paulo, SP, por faixa de exposição, controladas pela poluição do ar, 2003 a 2007.

\begin{tabular}{|c|c|c|c|c|}
\hline \multirow[b]{2}{*}{ Variáveis } & \multicolumn{2}{|c|}{ EM-CONGONHAS* } & \multicolumn{2}{|c|}{ EM-IAG/USP** } \\
\hline & $\mathbf{R R}\left(\mathbf{I C}_{95 \%}\right)$ & $p$ & $\mathbf{R R}\left(\mathrm{IC}_{95 \%}\right)$ & $p$ \\
\hline \multicolumn{5}{|c|}{ Temperatura Mínima ${ }^{\circ} \mathrm{C}$} \\
\hline$>19,3$ & \multicolumn{2}{|l|}{1} & \multicolumn{2}{|l|}{1} \\
\hline $17,1-19,2$ & $1.166(0,89-1,52)$ & 0.26 & $1.036(0.72-1.48)$ & 0.84 \\
\hline $14,6-17,0$ & $1.252(0,95-1,60)$ & 0.10 & $1.272(0.89-1.80)$ & 0.18 \\
\hline$<14,5$ & $1.448(1,09-1,90)$ & 0.01 & $1.431(1.02-2.00)$ & 0.04 \\
\hline \multicolumn{5}{|c|}{ Poluição**** } \\
\hline Ruim & $1.484(1,20-1,82)$ & 0.00 & $1.406(1.14-1.72)$ & 0.00 \\
\hline
\end{tabular}

A seguir, a Tabela 13 apresenta a associação entre as temperaturas máximas e internações por doenças circulatórias. Nesse caso, o objetivo foi avaliar o impacto das maiores temperaturas em relação ao excesso de internação (dias doentes), portanto a faixa de referência foi a de dias com temperaturas máximas menores de $22^{\circ} \mathrm{C}$, ou seja, o quartil inferior $(25 \%)$.

Quando avaliadas as faixas de temperatura em relação a esse quartil, a relação é de proteção, ou seja, o risco diminui com o aumento das temperaturas máximas. É estatisticamente significante nas faixas de 22,1 a $25,3^{\circ} \mathrm{C}-1 / 0,703-1,42$ ou $42 \%$ menos chance de ocorrer excesso de internação - e na faixa superior a $28,1^{\circ} \mathrm{C}$ 1/0,609 - 1,64 ou 64\% menos chance de ocorrer excesso de internação por doenças circulatórias, considerando os dados da EM-CONGONHAS.

Deve-se ressaltar que a análise com os dados da EM-IAG/USP não apresentaram significância estatística quando considerada a faixa de 22,1 a $25,3^{\circ} \mathrm{C}$ e o risco na faixa superior a $28,1^{\circ} \mathrm{C}$ foi de $1 / 0,657-1,52$ ou $52 \%$ menos chance de ocorrer excesso de internações por doenças circulatórias. 
Tabela 13 - Risco Relativo; Intervalo de Confiança; valor $p$ para a temperatura máxima e internações por doenças circulatórias em pessoas de sessenta e mais anos no setor Sul/Sudeste, São Paulo, SP, por faixa de exposição, controladas pela poluição do ar, 2003 a 2007.

\begin{tabular}{|c|c|c|c|c|}
\hline \multirow[b]{2}{*}{ Variáveis } & \multicolumn{2}{|c|}{ EM-CONGONHAS* } & \multicolumn{2}{|c|}{ EM-IAG/USP $* *$} \\
\hline & $\mathbf{R R}\left(\mathbf{I C}_{95 \%}\right)$ & $p$ & $\mathbf{R R}\left(\mathbf{I C}_{95 \%}\right)$ & $p$ \\
\hline \multicolumn{5}{|c|}{ Temperatura Máxima ${ }^{\circ} \mathrm{C}$} \\
\hline$<22,0$ & \multicolumn{2}{|c|}{1} & \multicolumn{2}{|l|}{1} \\
\hline $22.1-25.3$ & $0.703(0,53-0.92)$ & 0.01 & $0.839(0.64-1.10)$ & 0.21 \\
\hline $25.4-28.0$ & $0.968(0.73-1.28)$ & 0.82 & $0.897(0.68-1.17)$ & 0.43 \\
\hline$>28.1$ & $0.609(0.46-0.79)$ & 0.00 & $0.657(0.50-0.85)$ & 0.00 \\
\hline Poluição** & & & & \\
\hline Ruim & $1.516(1,23-1,86)$ & 0.00 & $1.501(1.23-1.84)$ & 0.00 \\
\hline
\end{tabular}

A análise feita com as temperaturas médias é apresentada na Tabela 14. Nesse caso, buscou-se avaliar o impacto das menores temperaturas médias na morbidade por doenças circulatórias. Dessa forma, a faixa de referencia são as temperaturas maiores de $22,7^{\circ} \mathrm{C}$, que equivale ao quartil superior (75\%) da distribuição das temperaturas médias da EM-CONGONHAS. Houve significância estatística quando considerados os dias com temperaturas médias menores de $17,8^{\circ} \mathrm{C}$, ou seja, há nessa faixa 1,6 vezes mais chance de haver dias com internações acima da mediana, ou seja, dias doentes em relação aos dias com temperaturas acima de $22,7^{\circ} \mathrm{C}$.

Os dados da EM-IAG/USP apontam aumento no risco quando diminuem as temperaturas médias, mas também só é significante na faixa inferior a $17,8^{\circ} \mathrm{C}$. 
Tabela 14 - Risco Relativo; Intervalo de Confiança; valor p para a temperatura média e internações por doenças circulatórias em pessoas de sessenta e mais anos no setor Sul/Sudeste, São Paulo, SP, por faixa de exposição, controladas pela poluição do ar, 2003 a 2007.

\begin{tabular}{|c|c|c|c|c|}
\hline \multirow[b]{2}{*}{ Variáveis } & \multicolumn{2}{|c|}{ EM-CONGONHAS* } & \multicolumn{2}{|c|}{ EM-IAG/USP** } \\
\hline & $\mathbf{R R}\left(\mathbf{I C}_{\mathbf{9 5} \%}\right)$ & $p$ & $\mathbf{R R}\left(\mathrm{IC}_{95 \%}\right)$ & $p$ \\
\hline \multicolumn{5}{|c|}{ Temperatura Média ${ }^{\circ} \mathrm{C}$} \\
\hline$>22,7$ & 1 & 0.01 & 1 & 0.01 \\
\hline $22,6-20.5$ & $1.234(0,94-1,61)$ & 0.13 & $1.131(0,84-1,52)$ & 0.42 \\
\hline $17.7-20.4$ & $1.062(0,81-1,39)$ & 0.66 & $1.231(0,93-1,63)$ & 0.15 \\
\hline$<17.8$ & $1.558(1,18-2,04)$ & 0.00 & $1.560(1,18-2,06)$ & 0.00 \\
\hline \multicolumn{5}{|c|}{ Poluiçãa**** } \\
\hline Ruim & $1.508(1,22-1,85)$ & 0.00 & $1.455(1,19-1,78)$ & 0.00 \\
\hline
\end{tabular}

Em todos os modelos o indicador de poluição foi inserido como controle. Observa-se que em todos os casos os dias com poluição ruim, ou seja, com qualidade do ar regular e inadequado apresentam aproximadamente 1,5 vezes mais risco de ocorrência de dias doentes. Quando considerado o cenário com as temperaturas mínimas e médias, as menores temperaturas e a poluição atmosférica apresentam riscos aproximados.

\subsubsection{Doenças respiratórias em adultos com mais de 60 anos}

5.6.2.1 Incidência mensal das internações e o ambiente térmico

A relação com as temperaturas mensais, ou seja, temperatura média mensal, temperaturas máximas e mínimas absolutas apontam que as maiores taxas de internação ocorrem em meses com valores mais baixos de temperatura máxima absoluta, contudo, não há um padrão claro para as temperaturas mínimas, podendo ocorrer maiores taxas em meses com temperatura mínima baixa ou em meses em que a temperatura mínima foi mais elevada. Os meses com temperaturas médias mais baixas apontam maior incidência de internação, a partir da observação do gráfico 
(Figura 55). A Figura 56 mostra o ritmo das taxas de internação mensal para as doenças do aparelho respiratório em pessoas de sessenta e mais anos. É possível observar um padrão sazonal com alguns picos de internação nos meses de maio a setembro de cada ano, exceto no ano de 2004 em que ocorreu um pico de internação no mês de março.

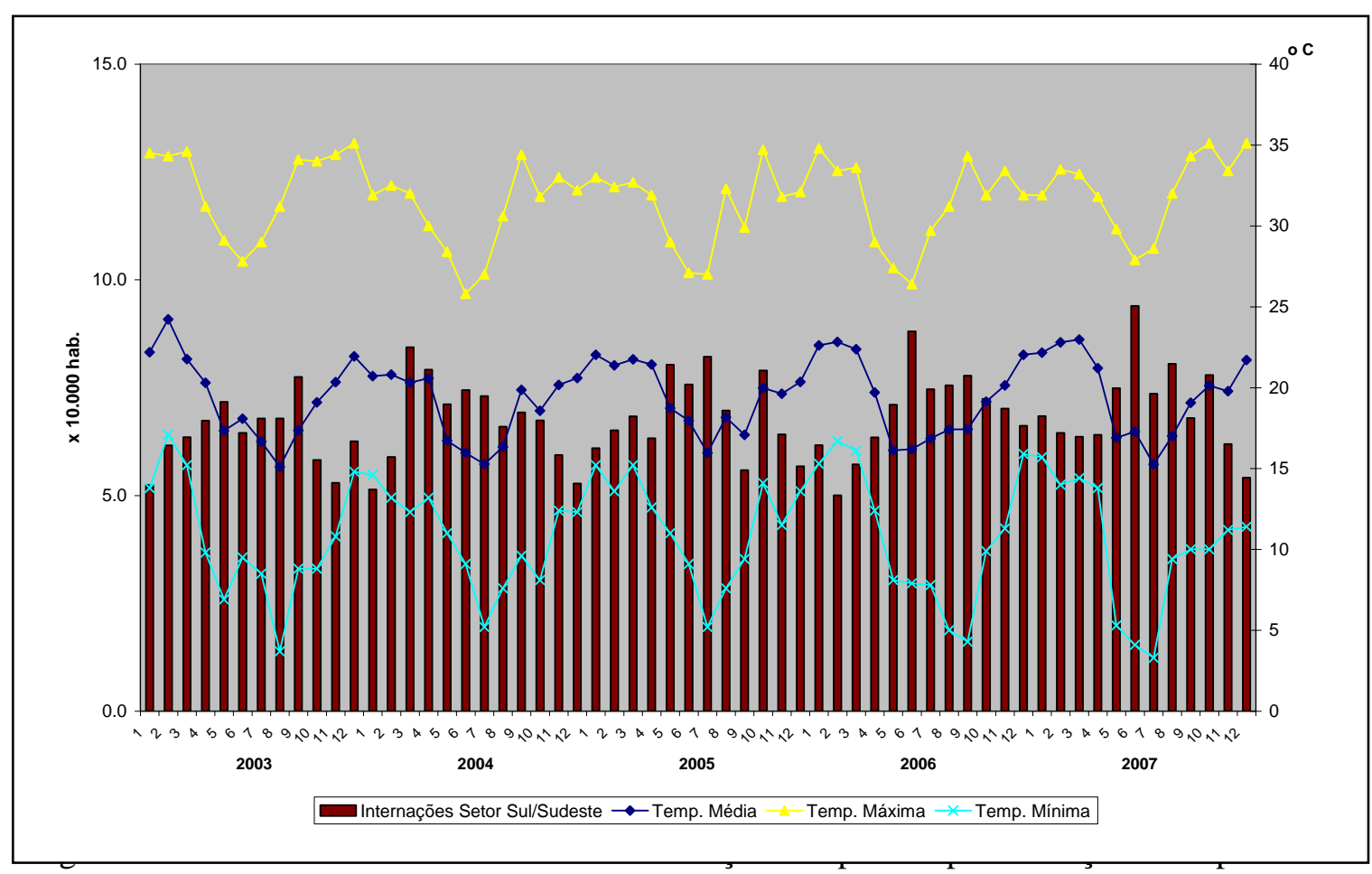

respiratório em pessoas com 60 e mais anos, temperatura máxima e mínima absoluta e temperatura média mensal na EM-IAG/USP, no período de 2003 a 2007, setor Sul/Sudeste, São Paulo, SP.

Fonte:DATASUS 2009, EM-IAG/USP 


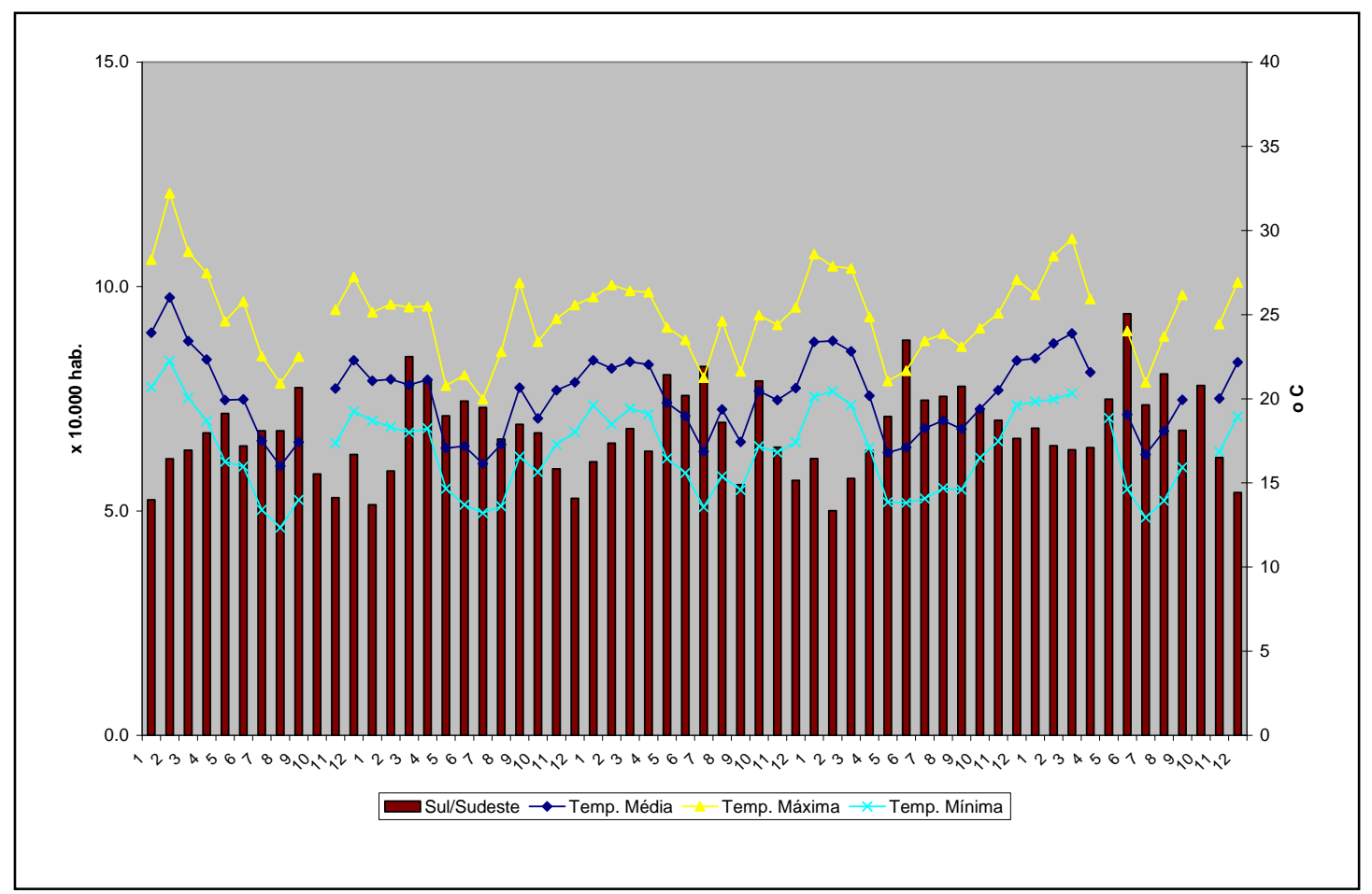

Figura 56 - Incidência de mensal de internação hospitalar por doenças do aparelho respiratório em pessoas com 60 e mais anos, temperaturas médias das máximas e das mínimas e temperatura média mensal na EM-IAG/USP, no período de 2003 a 2007, setor Sul/Sudeste, São Paulo, SP.

Fonte:DATASUS 2009, EM-CONGONHAS

5.6.2.2 Modelo Linear Generalizado com distribuição binomial negativa (GLM)

Para doenças respiratórias em pessoas de sessenta e mais anos, o modelo ajustado final considerou como variáveis explicativas do número de internações diárias, as variáveis amplitude da temperatura diária, índice PET diário, índice de poluição diário, ano e dia da semana. Na Tabela 15 estão apresentados os resultados do modelo final ajustado.

As variáveis: temperatura média e temperatura mínima não se mostraram significantes a $5 \%$ (valor- $\mathrm{p}=0,74$ e valor- $\mathrm{p}=0,25$, respectivamente).

Em relação às variáveis explicativas contínuas no modelo ajustado tem-se que para a amplitude térmica o risco relativo é de 1,021 ou a cada aumento de $1^{\circ} \mathrm{C}$ na amplitude da temperatura diária, o número esperado de internações diárias de idosos por doenças respiratórias aumenta 2,1\%; O índice PET apontou risco relativo de 0,990 ou a cada decréscimo de $1{ }^{\circ} \mathrm{C}$ no índice PET diário, o número esperado de internações diárias de idosos por doenças respiratórias aumenta 1\%; o risco relativo 
para o índice de poluição foi de 1,002, significa que a cada aumento de 1 unidade no índice de poluição diário, o número esperado de internações diárias de idosos por doenças respiratórias aumenta $0,2 \%$.

Observa-se que o ano de 2007 apresenta o maior percentual de aumento do número esperado de internações diárias $(21,3 \%)$ em relação a 2003 e o ano de 2004 apresenta o menor percentual de aumento $(7,4 \%)$ em relação a 2003.

Quanto ao dia da semana, sábado (10,2\%) e a quarta feira $(19,8 \%)$ apresentaram o menor percentual de aumento do número esperado de internações diárias em relação ao domingo. Os demais dias da semana, segunda-feira, terça-feira, quinta-feira e sexta-feira, apresentaram um percentual de aumento do número esperado de internações diárias em relação aos domingos, em torno de 33\%, mantidos fixos os valores das demais variáveis.

Tabela 15 - Resultados do modelo final ajustado para o número de internações por doenças respiratórias em pessoas de sessenta e mais anos, no setor Sul/Sudeste, São Paulo, SP, no período de 2003 a 2007.

\begin{tabular}{|c|c|c|c|c|c|c|}
\hline Efeitos & Estimativa & Erro Padrão & Valor - p & Risco Relativo & IC $(95 \%)$ INF & IC $(95 \%)$ SUP \\
\hline intercepto & 1,053 & 0,072 & $<<0,0001$ & . & - & . \\
\hline Amplitude $\left({ }^{\circ} \mathrm{C}\right)$ & 0,021 & 0,005 & $<0,0001$ & 1,021 & 1,011 & 1,031 \\
\hline PET $\left({ }^{\circ} \mathrm{C}\right)$ & $-0,01$ & 0,002 & 0,0002 & 0,990 & 0,986 & 0,994 \\
\hline Indice poluição & 0,002 & 0,001 & 0,0007 & 1,002 & 1,001 & 1,003 \\
\hline \multicolumn{7}{|l|}{ Ano } \\
\hline 2003 & & & & & & \\
\hline 2004 & 0,071 & 0,036 & 0,05 & 1,074 & 1,000 & 1,152 \\
\hline 2005 & 0,145 & 0,038 & 0,0001 & 1,156 & 1,073 & 1,245 \\
\hline 2006 & 0,18 & 0,038 & $<0,0001$ & 1,197 & 1,111 & 1,290 \\
\hline 2007 & 0,193 & 0,035 & $<0,0001$ & 1,213 & 1,132 & 1,299 \\
\hline \multicolumn{7}{|l|}{ Dia da semana } \\
\hline domingo & - & - & - & - & - & - \\
\hline segunda-feira & 0,287 & 0,043 & $<0,0001$ & 1,332 & 1,225 & 1,450 \\
\hline terça-feira & 0,298 & 0,044 & $<0,0001$ & 1,347 & 1,236 & 1,468 \\
\hline quarta-feira & 0,181 & 0,044 & $<0,0001$ & 1,198 & 1,099 & 1,306 \\
\hline quinta-feira & 0,290 & 0,043 & $<0,0001$ & 1,336 & 1,228 & 1,454 \\
\hline sexta-feira & 0,262 & 0,044 & $<0,0001$ & 1,300 & 1,192 & 1,417 \\
\hline sábado & 0,097 & 0,045 & 0,03 & 1,102 & 1,009 & 1,203 \\
\hline lag1 & 0,001 & 0,005 & 0,86 & . & . & . \\
\hline $\operatorname{lag} 2$ & 0,017 & 0,005 & 0,0005 & - & . & . \\
\hline
\end{tabular}

Fonte: DATASUS 2009 e EM-CONGONHAS.

\subsubsection{Análise de Regressão logística}

$\mathrm{Na}$ análise de regressão logística as variáveis contínuas: vento e amplitude térmica apresentaram significância estatística a um nível de 5\% em relação às internações hospitalares de doenças respiratórias em pessoas de 60 e mais anos. As demais variáveis: índice de conforto térmico (PET), temperaturas média, mínima e 
máxima não apresentaram associação estatística em relação aos dias com excesso de internação hospitalar - DIAS DOENTES (Apêndice D).

Dessa forma, a análise por faixa de exposição foi feita com o parâmetro amplitude térmica e os resultados são apresentados na Tabela 16.

Observa-se que os dados da EM-IAG/USP apresenta melhor associação estatística do que os dados da EM-CONGONHAS. Deve-se ressaltar que os dias de observação na EM-CONGONHAS (n=1722) e na EM-IAG/USP ( $\mathrm{n}=1825)$, portanto, nesta última o tamanho da amostragem é maior. Além disso, como vimos nos itens anteriores a estação meteorológica do IAG/USP apresenta temperaturas mínimas menores e máximas maiores, e, portanto, valores maiores de amplitude térmica.

A análise aponta que o risco aumenta com o aumento da faixa de amplitude térmica, ou seja, quanto maior a amplitude térmica, maior o risco de haver dias com excesso de internações hospitalares por doenças respiratórias em idosos.

Considerando os dados da EM-IAG/USP o risco é 1,3 vezes maior na faixa de 5,8 a $10,2^{\circ} \mathrm{C}$ e 1,6 vezes maior quando os valores de amplitude térmica ultrapassam os $10,2^{\circ} \mathrm{C}$.

$\mathrm{O}$ indicador de qualidade do ar também inserido nesse modelo aponta risco de 1,3 e 1,5 mais chance - CONGONHAS e IAG, respectivamente, de haver mais dias com excesso de internação hospitalar quando as condições da qualidade do ar são ruins.

Tabela 16 - Risco Relativo; Intervalo de Confiança; valor $p$ para a amplitude térmica e internações por doenças respiratórias em pessoas de sessenta e mais anos no setor Sul/Sudeste, São Paulo, SP, por faixa de exposição, controladas pela poluição do ar, 2003 a 2007.

\begin{tabular}{|c|c|c|c|c|}
\hline \multirow[b]{2}{*}{ Variáveis } & \multicolumn{2}{|c|}{ EM-CONGONHAS* } & \multicolumn{2}{|c|}{ EM-IAG/USP** } \\
\hline & $\mathbf{R R}\left(\mathbf{I C}_{95 \%}\right)$ & $p$ & $\mathbf{R R}\left(\mathbf{I C}_{95 \%}\right)$ & $p$ \\
\hline \multicolumn{5}{|c|}{ Amplitude Térmica $^{\circ} \mathrm{C}$} \\
\hline$<5.8$ & 1 & 0.15 & 1 & 0.01 \\
\hline $5.8-10.2$ & $1.110(0.88-1.40)$ & 0.38 & $1.337(1.00-1.78)$ & 0.05 \\
\hline$>10.2$ & $1.307(0.99-1.71)$ & 0.05 & $1.563(1.18-2.06)$ & 0.00 \\
\hline \multicolumn{5}{|c|}{ Poluiçãa**** } \\
\hline Ruim & $1.322(1.07-1.62)$ & 0.01 & $1.470(1.19-1.80)$ & 0.00 \\
\hline
\end{tabular}




\subsubsection{Doenças respiratórias crianças de menores de 5 anos}

5.6.3.1 Incidência mensal e o ambiente térmico

A Figura 57 e a Figura 58 mostram a incidência mensal das internações das doenças do aparelho respiratório em crianças de menores de 5 anos. O ritmo das taxas mensais mostra clara sazonalidade, com ocorrência de taxas mais elevadas de abril a julho, sendo que o mês de abril apresenta o pico mais alto de 2003 a 2006 e, em 2007, o pico mais alto ocorreu em março.

Observa-se também que os meses que correspondem à primavera setembro/outubro há ocorrência da elevação das taxas de incidência de internação muito embora mais baixas do que aquelas observadas nos meses de outono/inverno abril a julho.

A relação com as temperaturas mensais, máximas e mínimas absolutas e temperatura média mostram, de modo geral, que nos meses em que taxas de internação são mais elevadas coincidem com os meses de temperaturas máximas mais baixas, contudo esse padrão não é observado no ano de 2007.

Não é possível observar um padrão com relação às temperaturas mínimas, podendo ocorrer picos nos meses em que a temperatura mínima é muito baixa, como em maio de 2003 ou mais elevada como em maio de 2004.

Observa-se também meses com taxas de internação e temperaturas mínimas baixas. $\mathrm{O}$ aumento na incidência mensal das internações acompanha a diminuição das temperaturas médias mensais no final do verão, porém há diminuição das taxas não nos meses em que as temperaturas médias são as mais baixas, ou seja, no inverno. De qualquer forma, os meses com taxas mais baixas de internação correspondem aos meses em que as temperaturas médias, mínimas e máximas foram mais elevadas. 


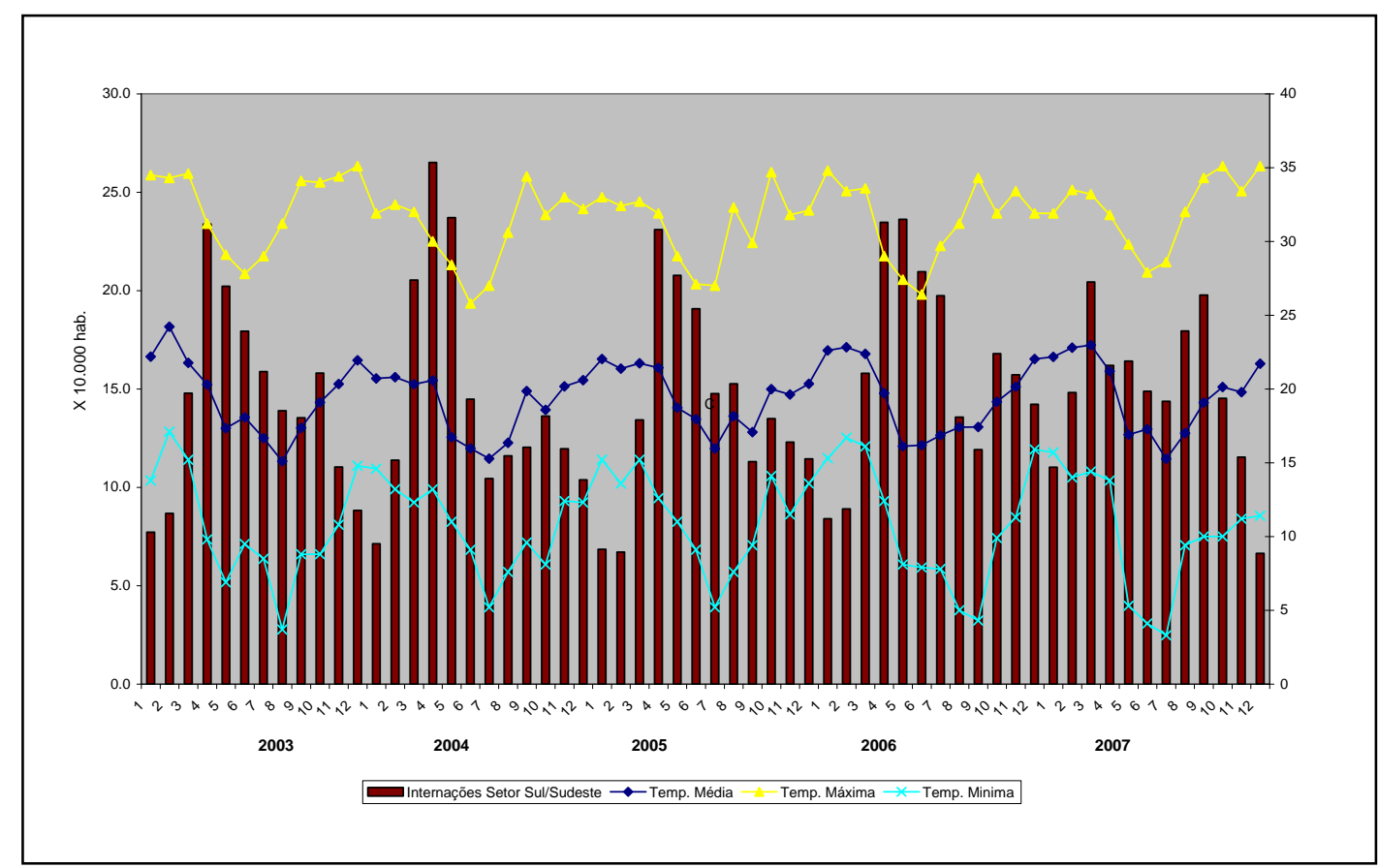

Figura 57 - Incidência de mensal de internação hospitalar por doenças do aparelho respiratório em crianças de menores de cinco anos, temperaturas médias das máximas e das mínimas e temperatura média mensal na EM-IAG/USP, no período de 2003 a 2007, setor Sul/Sudeste, São Paulo, SP.

Fonte:DATASUS 2009, EM-IAG/USP

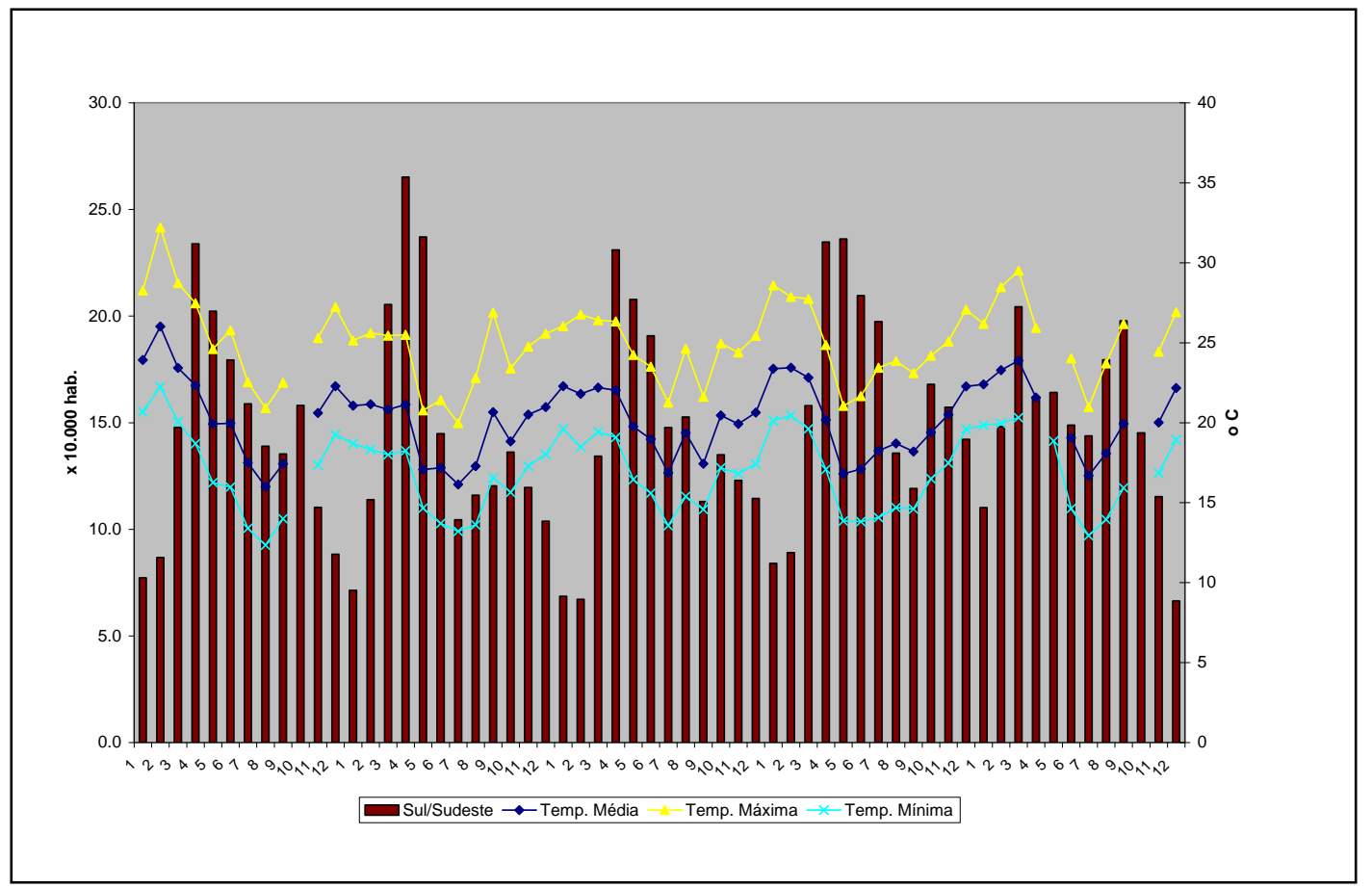

Figura 58 - Incidência de mensal de internação hospitalar por doenças do aparelho respiratório em crianças de menores de cinco anos, temperaturas médias das máximas e das mínimas e temperatura média mensal na EM-CONGONHAS, no período de 2003 a 2007, setor Sul/Sudeste, São Paulo, SP.

Fonte:DATASUS 2009 e EM-CONGONHAS 
5.6.3.2 Modelo Linear Generalizado com distribuição binomial negativa (GLM)

O modelo final ajustado para o número de internações diárias por doenças respiratórias em crianças considerou como variáveis explicativas a temperatura média diária, amplitude de temperatura diária, índice PET diário, índice de poluição diário, ano e dia semana. A variável temperatura mínima não se mostrou significante a $5 \%$ (valor-p $=0,71)$. Os resultados do modelo final estão apresentados na Tabela 17.

Com relação às variáveis explicativas contínuas que permaneceram no modelo ajustado, obteve- se para a temperatura média risco relativo de 1,037 ou a cada aumento de $1{ }^{\circ} \mathrm{C}$ na temperatura média diária, o número esperado de internações diárias por doenças respiratórias em crianças aumenta 3,7\%, para a amplitude o risco relativo foi de 1,027 , ou seja, a cada aumento de $1^{\circ} \mathrm{C}$ na amplitude da temperatura diária, o número esperado de internações diárias por doenças respiratórias em crianças aumenta 2,7\%, mantidos constantes os valores das demais variáveis do modelo; com relação ao índice PET o risco relativo foi de 0,966 , ou a cada decréscimo de $1^{\circ} \mathrm{C}$ no índice PET diário, o número esperado de internações diárias por doenças respiratórias em crianças aumenta 3,5\%, mantidos constantes os valores das demais variáveis do modelo; para o índice de poluição o risco relativo foi de 1,002, ou seja, a cada aumento de 1 unidade no índice de poluição diário, o número esperado de internações diárias por doenças respiratórias em crianças aumenta $0,2 \%$, mantidos constantes os valores das demais variáveis do modelo.

Destaca--se que, o ano de 2006 apresentou o maior percentual de aumento do número médio de internações diárias $(13,9 \%)$ em relação a 2003. Os demais anos 2004, 2005 e 2007 não apresentaram diferenças significantes no número médio de internações diárias quando comparados ao ano de 2003 (valor-p = 0,55, valor-p = 0,18, valor-p $=0,26$, respectivamente).

Para o dia da semana, as segundas-feiras apresentaram o maior percentual de aumento do número médio de internações diárias $(24,4 \%)$ em relação aos domingos. As quartas-feiras não apresentaram diferença significantes no número médio de internações diárias quando comparado ao domingo (valor-p = 0,89). O mesmo ocorre às sextas-feiras e aos sábados (valor-p $=0,62$, valor- $\mathrm{p}=0,27$, respectivamente) 
Tabela 17 - Resultados do modelo final ajustado para o número de internações por doenças respiratórias em crianças menores de cinco anos, no setor Sul/Sudeste, São Paulo, SP, no período de 2003 a 2007.

\begin{tabular}{|c|c|c|c|c|c|c|}
\hline Efeitos & Estimativa & Erro Padrão & Valor - $p$ & Risco Relativo & IC(95\%) INF & IC(95\%) SUP \\
\hline intercepto & 0,812 & 0,117 & $<0,0001$ & & & \\
\hline Temperatura Média $\left({ }^{\circ} \mathrm{C}\right)$ & 0,036 & 0,010 & 0,001 & 1,037 & 1,017 & 1,057 \\
\hline Amplitude $\left({ }^{\circ} \mathrm{C}\right)$ & 0,027 & 0,005 & $<0,0001$ & 1,027 & 1,017 & 1,037 \\
\hline $\operatorname{PET}\left({ }^{\circ} \mathrm{C}\right)$ & $-0,035$ & 0,008 & $<0,0001$ & 0,966 & 0,951 & 0,981 \\
\hline Indice poluição & 0,002 & 0,001 & 0,0007 & 1,002 & 1,001 & 1,003 \\
\hline \multicolumn{7}{|l|}{ Ano } \\
\hline 2003 & . & . & . & . & . & . \\
\hline 2004 & 0,021 & 0,034 & 0,55 & 1,021 & 0,955 & 1,092 \\
\hline 2005 & 0,048 & 0,036 & 0,18 & 1,049 & 0,978 & 1,126 \\
\hline 2006 & 0,13 & 0,037 & 0,0005 & 1,139 & 1,059 & 1,224 \\
\hline 2007 & 0,039 & 0,034 & 0,26 & 1,040 & 0,973 & 1,111 \\
\hline \multicolumn{7}{|l|}{ Dia da semana } \\
\hline domingo & . & . & - & . & . & . \\
\hline segunda-feira & 0,218 & 0,040 & $<0,0001$ & 1,244 & 1,150 & 1,345 \\
\hline terça-feira & 0,087 & 0,041 & 0,03 & 1,091 & 1,007 & 1,182 \\
\hline quarta-feira & 0,005 & 0,042 & 0,89 & 1,005 & 0,926 & 1,091 \\
\hline quinta-feira & 0,102 & 0,041 & 0,01 & 1,107 & 1,022 & 1,200 \\
\hline sexta-feira & 0,021 & 0,042 & 0,62 & 1,021 & 0,941 & 1,109 \\
\hline sábado & 0,045 & 0,042 & 0,27 & 1,046 & 0,963 & 1,136 \\
\hline $\operatorname{lag} 1$ & 0,040 & 0,003 & $<0,0001$ & & . & . \\
\hline $\operatorname{lag} 2$ & 0,038 & 0,003 & $<0,0001$ & & & \\
\hline
\end{tabular}

Fonte: DATASUS e EM-CONGONHAS.

\subsubsection{Análise de Regressão Logística}

As doenças respiratórias crianças de menores de cinco anos apresentaram associação estatisticamente significante com todas as variáveis, exceto com as temperaturas máximas. Então, foram feitas as análises considerando as faixas de exposição.

A Tabela 18 apresenta os resultados da associação entre as internações hospitalares e a faixa de sensação do índice PET.

Como na análise anterior, a faixa Confortável foi considerada como referencia, ou seja, sem risco. Os resultados mostram que a faixa de Frio $\left(<12^{\circ} \mathrm{C}\right)$ é protetora, ou seja, há menor risco de haver dias doentes ou com excesso de internações nessa faixa de conforto em relação aos dias confortáveis. Vale ressaltar que houve fraca significância com relação aos dados da EM-CONGONHAS para essa faixa, mas houve significância quando considerado os dados da EM-IAG/USP. 
Com relação à faixa de pouco frio $\left(18^{\circ} \mathrm{C}<12^{\circ} \mathrm{C}\right)$ houve 1,3 vezes mais chance de ocorrer dias doentes - com excesso de internações - em relação aos dias confortáveis, com significância estatística com relação aos dados da EMCONGONHAS e fraca significância na EM-IAG/USP.

A faixa de pouco calor $\left(26^{\circ} \mathrm{C}<31^{\circ} \mathrm{C}\right)$ foi protetora, ou seja, há cerca de $50 \%$ menos chance de haver dias doentes em relação à faixa confortável com significância estatística $\mathrm{p}<0,05$.

A faixa de calor $\left(>31^{\circ}\right.$ C) apresentou resultados contraditórios e estatisticamente não significantes. Deve-se ressaltar que a amostragem nessa faixa de exposição é muito pequena e correspondeu a somente cinco dias com os dados da EM-CONGONHAS e 10 dias com os dados da EM-IAG/USP.

Tabela 18 - Risco Relativo; Intervalo de Confiança; valor $p$ para o índice de conforto (PET) e internações por doenças respiratórias em crianças de menores de cinco anos e mais anos no setor Sul/Sudeste, São Paulo, SP, por faixa de exposição, controladas pela poluição do ar, 2003 a 2007.

\begin{tabular}{|c|c|c|c|c|}
\hline \multirow[b]{2}{*}{ Variáveis } & \multicolumn{2}{|c|}{ EM-CONGONHAS* } & \multicolumn{2}{|c|}{ EM- IAG/USP*** } \\
\hline & RR $\left(\right.$ IC $\left._{95 \%}\right)$ & $p$ & $\mathbf{R R}\left(\mathbf{I C}_{95 \%}\right)$ & $p$ \\
\hline \multicolumn{5}{|c|}{ Faixa de Sensação Térmica } \\
\hline Confortável $\left(18\right.$ a $\left.26^{\circ} \mathrm{C}\right)$ & 1 & 0.00 & 1 & 0.00 \\
\hline Frio $\left(<12{ }^{\circ} \mathrm{C}\right)$ & $0.751(0.54-1.03)$ & 0.08 & $0.665(0.46-0.96)$ & 0.03 \\
\hline Pouco Frio $\left(<18{ }^{\circ} \mathrm{C}\right)$ & $1.261(1.01-1.56)$ & 0.04 & $1.217(0.98-1.50)$ & 0.07 \\
\hline Pouco Calor $\left(>26^{\circ} \mathrm{C}\right)$ & $0.504(0.33-0.75)$ & 0.00 & $0.538(0.39-0.74)$ & 0.00 \\
\hline Calor $\left(>31{ }^{\circ} \mathrm{C}\right)$ & $3.993(0.44-36.10)$ & 0.22 & $0.396(0.10-1.55)$ & 0.18 \\
\hline \multicolumn{5}{|l|}{ Poluição *** } \\
\hline Ruim & $1.547(1.26-1.90)$ & 0.00 & $1.562(1.27-1.91)$ & 0.00 \\
\hline
\end{tabular}

A Tabela 19 apresenta os resultados da associação entre as internações hospitalares e as temperaturas mínimas, mostrando que houve associação estatisticamente significante $(\mathrm{p}<0,05)$ para todas as faixas de exposição. Nota-se que a exposição aumenta com a diminuição das temperaturas mínimas, em relação à faixa de referência de temperaturas maiores de $19,3^{\circ}$ C. Essa relação é mais evidente quando considerado as temperaturas da EM-IAG/USP. 
Considerando os dados da EM-CONGONHAS temos: 1,8 vezes mais chance de dias na faixa de $17,1^{\circ} \mathrm{C}-19,2^{\circ} \mathrm{C} ; 2,2$ vezes mais chance na faixa de $14,6^{\circ} \mathrm{C}$ $17,0^{\circ} \mathrm{C}$ e 1,6 vezes mais chance na faixa menor de $14,5^{\circ} \mathrm{C}$ de haver maior incidência de internações (acima da mediana) em relação à faixa de referência $\left(>19,3^{\circ} \mathrm{C}\right)$.

Com relação aos dados na EM-IAG/USP o risco é progressivamente maior em relação à diminuição das temperaturas mínimas: 1,5 vezes mais chance na faixa de $17,1^{\circ} \mathrm{C}-19,2^{\circ} \mathrm{C} ; 2,3$ vezes mais chance $14,6^{\circ} \mathrm{C}-17,0^{\circ} \mathrm{C}$ e 2,5 vezes mais chance menor de $14,5^{\circ} \mathrm{C}$ de ocorrência de maior incidência de internações em relação à faixa de referência.

Tabela 19 - Risco Relativo; Intervalo de Confiança; valor $p$ para a temperatura mínima e internações por doenças respiratórias em crianças de menores de cinco anos e mais anos no setor Sul/Sudeste, São Paulo, SP, por faixa de exposição, controladas pela poluição do ar, 2003 a 2007.

\begin{tabular}{|c|c|c|c|c|}
\hline \multirow[b]{2}{*}{ Variáveis } & \multicolumn{2}{|l|}{ EM-CONGONHAS } & \multicolumn{2}{|c|}{ EM-IAG/USP } \\
\hline & $\mathbf{R R}\left(\mathbf{I C}_{95 \%}\right)$ & $p$ & $\mathbf{R R}\left(\mathrm{IC}_{95 \%}\right)$ & $p$ \\
\hline \multicolumn{5}{|c|}{ Temperatura Mínima ${ }^{\circ} \mathrm{C}$} \\
\hline$>19,3$ & 1 & 0.00 & 1 & 0.00 \\
\hline $17,1-19,2$ & $1.779(1.35-2.33)$ & 0.00 & $1.516(1.04-2.20)$ & 0.03 \\
\hline $14,6-17,0$ & $2.167(1.65-2.84)$ & 0.00 & $2.277(1.57-3.28)$ & 0.00 \\
\hline$<14,5$ & $1.612(1.22-2.12)$ & 0.00 & $2.497(1.76-3.55)$ & 0.00 \\
\hline \multicolumn{5}{|c|}{ Poluição**** } \\
\hline Ruim & $1.479(1.20-1.82)$ & 0.00 & $1.399(1.13-1.72)$ & 0.00 \\
\hline
\end{tabular}

A Tabela 20 mostra os resultados da associação entre as internações hospitalares e as faixas de exposição para a temperatura média. Houve associação estatística significante com $\mathrm{p}<=0,05 \mathrm{em}$ todas as faixas e maior risco de haver dias doentes, ou seja, com maior incidência de internações.

Os resultados com os dados da EM-CONGONHAS foram diferentes daqueles da EM-IAG/USP. Considerando os dados da EM-CONGONHAS o risco é maior em 1,5 vezes na faixa de $22,6-20,5^{\circ} \mathrm{C} ; 1,8$ vezes na faixa de $17.7-20.4^{\circ} \mathrm{C}$ e 1,4 vezes na faixa de temperaturas médias menores de $17,8^{\circ} \mathrm{C}$ em relação à faixa de referencia $\left(>22,7^{\circ} \mathrm{C}\right)$. Em relação aos dados da EM-IAG/USP o risco foi de 1,4 vezes na faixa 
de $22,6-20,5^{\circ} \mathrm{C} ; 2,3$ vezes na faixa de $17,7-20,4^{\circ} \mathrm{C}$ e 1,6 vezes na faixa de temperaturas médias menores de $17.8^{\circ} \mathrm{C}$.

Vale observar que a segunda faixa de temperaturas médias $\left(17,7-20,4^{\circ} \mathrm{C}\right)$ apresenta maior risco de haver maior incidência de internações, nas duas estações meteorológica.

Tabela 20 - Risco Relativo; Intervalo de Confiança; valor $p$ para a temperatura média e internações por doenças respiratórias em crianças de menores de cinco anos e mais anos no setor Sul/Sudeste, São Paulo, SP, por faixa de exposição, controladas pela poluição do ar, 2003 a 2007.

\begin{tabular}{|c|c|c|c|c|}
\hline \multirow[b]{2}{*}{ Variáveis } & \multicolumn{2}{|c|}{ EM-CONGONHAS* } & \multicolumn{2}{|c|}{ EM-IAG/USP*** } \\
\hline & $\mathbf{R R}\left(\mathbf{I C}_{95 \%}\right)$ & $p$ & $\mathbf{R R}\left(\mathbf{I C}_{95 \%}\right)$ & $p$ \\
\hline \multicolumn{5}{|c|}{ Temperatura Média ${ }^{\circ} \mathrm{C}$} \\
\hline$>22,7$ & 1 & 0.00 & 1 & 0.00 \\
\hline $22,6-20.5$ & $1.490(1.13-1.95)$ & 0.01 & $1.353(1.00-1.83)$ & 0.05 \\
\hline $17.7-20.4$ & $1.831(1.39-2.40)$ & 0.00 & $2.248(1.69-3.00)$ & 0.00 \\
\hline$<17.8$ & $1.359(1.03-1.78)$ & 0.03 & $1.636(1.23-2.17)$ & 0.00 \\
\hline \multicolumn{5}{|c|}{ Poluição*** } \\
\hline Ruim & $1.529(1.24-1.88)$ & 0.00 & $1.506(1.23-1.85)$ & 0.00 \\
\hline
\end{tabular}

A Tabela 21 mostra os resultados da associação entre a amplitude térmica e as internações por doenças respiratórias em crianças de menores de 05 anos. A análise com os dados da EM-CONGONHAS não apresentaram associação estatística em nenhuma faixa de exposição.

Contudo, as análises com os dados da EM-IAG/USP apresentaram associação estatisticamente significante $\mathrm{p}<=0,05$. O risco aumenta com o aumento da amplitude térmica. A faixa de exposição de $5,8-10,2^{\circ} \mathrm{C}$ apresentou risco 1,3 vezes e, na faixa de amplitude acima de $10,2^{\circ} \mathrm{C}$ apresentou risco 1,6 vezes maior de ocorrência de dias com incidência de internações acima da mediana, ou seja, dias doentes.

Nesse caso também se ressalta que o tamanho da amostra da EM-IAG/USP é maior $\mathrm{n}=1822$ e, os valores das amplitudes térmicas também. 
Tabela 21 - Risco Relativo; Intervalo de Confiança; valor p para a amplitude térmica e internações por doenças respiratórias em crianças de menores de cinco anos e mais anos no setor Sul/Sudeste, São Paulo, SP, por faixa de exposição, controladas pela poluição do ar, 2003 a 2007.

\begin{tabular}{|c|c|c|c|c|}
\hline \multirow[b]{2}{*}{ Variáveis } & \multicolumn{2}{|c|}{ EM-CONGONHAS* } & \multicolumn{2}{|c|}{ EM-IAG/USP** } \\
\hline & $\mathbf{R R}\left(\mathbf{I C}_{95 \%}\right)$ & $p$ & $\mathbf{R R}\left(\mathbf{I C}_{95 \%}\right)$ & $p$ \\
\hline \multicolumn{5}{|c|}{ Amplitude Térmica $^{\circ} \mathrm{C}$} \\
\hline$<5.8$ & 1 & 0.19 & 1 & 0.01 \\
\hline $5.8-10.2$ & $1.190(0.94-1.50)$ & 0.15 & $1.337(1.00-1.78)$ & 0.05 \\
\hline$>10.2$ & $1.276(0.97-1.67)$ & 0.08 & $1.563(1.18-2.06)$ & 0.00 \\
\hline \multicolumn{5}{|c|}{ Poluição**** } \\
\hline Ruim & $1.473(1.19-1.81)$ & 0.00 & $1.470(1.19-1.80)$ & 0.00 \\
\hline
\end{tabular}

As internações hospitalares por doenças respiratórias em crianças apresentaram associação estatística significante com o índice de sensação térmica, temperatura mínima, temperatura máxima e amplitude térmica, por faixa de exposição indicando que o ambiente térmico é uma variante ambiental importante na ocorrência dessas internações no setor Sul/Sudeste, no período estudado.

Com relação à qualidade do ar, houve associação significante em todos os modelos apresentados com até 1,5 vezes mais chance de ocorrer internações quando a qualidade do ar é ruim (regular ou inadequado).

\subsection{A relação clima e saúde por perfil socioambiental no setor Sul/Sudeste}

Os resultados a seguir referem-se às análises do modelo de regressão para o grupo de distritos selecionados segundo o perfil socioambiental do setor Sul/Sudeste, conforme descrito no item 2.4. Os modelos ajustados foram construídos com as variáveis contínuas que, individualmente, tiveram associação estatisticamente significante $(\mathrm{p}<0,05)$ (Apêndice $\mathrm{D})$. 


\subsubsection{Doenças circulatórias em pessoas de sessenta e mais anos}

Os resultados mostram que a associação com as variáveis ambientais atmosféricas observadas na EM-CONGONHAS e EM-IAG/USP é diferenciado para os grupos de distritos e EMs (Tabela 22 e Tabela 23).

As análises entre as doenças circulatórias em pessoas de sessenta e mais anos e as variáveis meteorológicas e de poluição, no grupo de distritos com melhor perfil socioambiental não apresentou associação significante com nenhuma variável meteorológica. Houve associação significante $(\mathrm{p}<0,00)$ com o parâmetro poluente, ou seja, com risco relativo de 1,36 vezes maior de haver dias taxa de internação acima da mediana quando a qualidade do ar apresenta-se ruim em relação aos dias em que a qualidade do ar é boa.

Para o grupo de distritos com perfil socioambiental intermediário o modelo ajustado com os dados da EM-CONGONHAS mantém a significância estatística para o parâmetro umidade relativa do ar e poluente. O resultado indica que há 0,984 ou 1/0,984 ou 1,016 (1,6\%) mais chance de ocorrer dias doentes a cada 1 unidade de diminuição na umidade relativa do ar $(\mathrm{p}<0,05)$. Com relação ao parâmetro poluente o risco relativo é de 1,43 vezes maior de haver dias doentes quando o índice de qualidade do ar é ruim.

O grupo de distritos com pior perfil socioambiental apresentou associação estatística significante $(\mathrm{p}<0,05)$ com as variáveis: índice de conforto PET e temperatura máxima, no modelo ajustado, com os dados da EM-CONGONHAS. O índice de conforto PET apresentou risco relativo de 0,892 ou 1/0,892 ou 1,121 (12\%) mais chance de ocorrer dias doentes a cada $1^{\circ} \mathrm{C}$ de diminuição valor do índice de conforto e, cerca de $12 \%$ mais chance de ocorrer dias doentes a cada $1^{\circ} \mathrm{C}$ de aumento da temperatura máxima. 
Tabela 22 - Resultados do modelo ajustado para as variáveis atmosféricas da EMCONGONHAS e internações por doenças circulatórias em adultos maiores de sessenta anos, controladas pela poluição do ar, segundo o perfil socioambiental dos distritos, no setor Sul/Sudeste, São Paulo, SP, 2003 a 2007.

\begin{tabular}{|c|c|c|c|c|c|c|}
\hline & \multicolumn{6}{|c|}{ EM-CONGONHAS* } \\
\hline & \multicolumn{2}{|l|}{ MELHOR $* *$} & \multicolumn{2}{|c|}{ INTERMEDIÁRIO**** } & \multicolumn{2}{|l|}{ PIOR ***** } \\
\hline & RR (IC95\%) & $\mathbf{p}$ & RR (IC95\%) & $\mathbf{p}$ & RR (IC95\%) & $\mathbf{p}$ \\
\hline Índice PET & - & - & & - & $0.892(0,84-0,95)$ & 0.00 \\
\hline Temp. Max. & - & - & & - & $1.119(1,04-1,19)$ & 0.00 \\
\hline Temp. Min. & - & - & $1,061(0,95-1,19)$ & 0,31 & $0.967(0,92-1,01)$ & 0.19 \\
\hline Temp. Média & - & - & $0,907(0,81-1,02)$ & 0,10 & - & - \\
\hline U R do ar & - & - & $0,984(0,97-1,00)$ & 0,04 & - & - \\
\hline Vento & - & - & $0,940(0,86-1,03)$ & 0,17 & - & - \\
\hline $\begin{array}{l}\text { Poluição } \\
\text { (Ruim) }\end{array}$ & $1,366(1,12-1,66)$ & 0,00 & $1,434(1,16-1,77)$ & 0,01 & - & - \\
\hline
\end{tabular}

A Tabela 23 apresenta os resultados do modelo ajustado com os dados da EM-IAG/USP. No grupo de distritos com melhor perfil socioambiental as variáveis meteorológicas não foram associadas com as internações hospitalares por doenças circulatórias em idosos.

Para o grupo de distritos com perfil socioambiental intermediário o parâmetro índice de conforto PET e temperatura mínima apresentaram associação quando analisadas individualmente, porém, perdem a significância estatística no modelo ajustado. $\mathrm{O}$ parâmetro poluente mantém a significância e apresenta um risco de 1,4 vezes mais chance de ocorrer dias doentes quando o índice de qualidade do ar é ruim.

No grupo de distritos com pior perfil socioambiental o índice PET, temperatura máxima e temperatura mínima associaram-se individualmente, porém somente o índice PET mantém significância estatística, embora fraca $(\mathrm{p}=0,04)$. $\mathrm{O}$ risco relativo de haver dias doentes é de 0,939 ou $1 / 0,939$ ou $1,064(6 \%)$ a cada $1^{\circ} \mathrm{C}$ de diminuição nos valores do índice de conforto.

Ressalta-se que, o parâmetro poluente, não apresentou associação estatística significante para o grupo de distritos com pior perfil socioambiental. 
Tabela 23 - Resultados do modelo ajustado para as variáveis atmosféricas da EM-IAG/USP e internações por doenças circulatórias em adultos maiores de sessenta anos, controladas pela poluição do ar, segundo o perfil socioambiental dos distritos, no setor Sul/Sudeste, São Paulo, SP, 2003 a 2007.

\begin{tabular}{|c|c|c|c|c|c|c|}
\hline \multirow[b]{4}{*}{ Índice PET } & \multicolumn{6}{|c|}{ EM-IAG/USP* } \\
\hline & \multicolumn{2}{|l|}{ MELHOR** } & \multicolumn{2}{|c|}{ INTERMEDIÁRIO**** } & \multicolumn{2}{|l|}{ PIOR**** } \\
\hline & RR (IC95\%) & $\mathbf{p}$ & RR (IC95\%) & $\mathbf{p}$ & RR (IC95\%) & $\mathbf{p}$ \\
\hline & - & - & $0,992(0,97-1,02)$ & 0,55 & $0,939(0,88-1,00)$ & 0,04 \\
\hline Temp. Max. & - & - & - & - & $1,053(0,99-1,12)$ & 0,10 \\
\hline Temp. Min. & - & - & $0,970(0,93-1,01)$ & 0,12 & $0,976(0,94-1,01)$ & 0,24 \\
\hline Temp. Média & - & - & - & - & 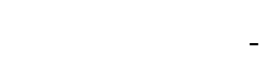 & - \\
\hline U R do ar & - & - & - & - & - & - \\
\hline Vento & - & - & - & - & - & - \\
\hline Poluição (Ruim) & $1,366(1,12-1,66)$ & 0,00 & $1,424(1,16-1,74)$ & 0,00 & - & - \\
\hline
\end{tabular}

\subsubsection{Doenças respiratórias em pessoas de sessenta e mais anos}

A Tabela 24 apresenta os resultados do modelo ajustado para as variáveis atmosféricas medidas na EM-CONGONHAS e as doenças respiratórias em pessoas com mais de sessenta anos, por grupo de distritos segundo perfil socioambiental.

No grupo de distritos com melhor perfil sócioambiental o modelo manteve como variável explicativa as temperaturas médias e máximas do ar e a umidade relativa do ar, contudo após o ajuste variável somente a umidade relativa do ar manteve significância estatística $(\mathrm{p}=0,05)$. O risco relativo é de 0,989 ou 1,011 (1\%) de haver dias doentes com a diminuição de 1 unidade da umidade relativa do ar.

Para grupo dos distritos com perfil socioambiental intermediário a temperatura mínima e o vento mantiveram significância estatística $(p<0,05)$, no modelo ajustado. O risco relativo é de 0,967 ou $1,034(3,4 \%)$ mais chance de haver dias doentes a cada diminuição em $1^{\circ} \mathrm{C}$ na temperatura mínima e 0,875 ou 1,142 (14\%) mais chance de haver dias doentes com a diminuição da velocidade do vento. A variável amplitude térmica e a variável poluente perderam a significância estatística no modelo ajustado.

O grupo dos distritos com pior perfil socioambiental não apresentou associação com as variáveis ambientais atmosféricas e com o parâmetro poluente. 
Tabela 24 - Resultados do modelo ajustado para as variáveis atmosféricas da EMCONGONHAS e internações por doenças respiratórias em adultos maiores de sessenta anos, controladas pela poluição do ar, segundo o perfil socioambiental dos distritos, no setor Sul/Sudeste, São Paulo, SP, 2003 a 2007.

\begin{tabular}{|c|c|c|c|c|c|c|c|}
\hline \multirow[b]{4}{*}{ Índice PET } & \multicolumn{7}{|c|}{ EM-CONGONHAS* } \\
\hline & \multicolumn{2}{|l|}{ MELHOR** } & \multicolumn{2}{|c|}{ INTERMEDIÁRIO**** } & \multicolumn{3}{|l|}{ PIOR***** } \\
\hline & RR (IC95\%) & $\mathbf{p}$ & RR (IC95\%) & $\mathbf{p}$ & RR (IC95\%) & & \\
\hline & - & & 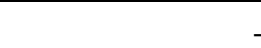 & - & & - & - \\
\hline Temp. Max. & $0,962(0,90-1,03)$ & 0,24 & - & - & & - & - \\
\hline Temp. Min. & - & - & $0,967(0,94-1,00)$ & 0,03 & & - & - \\
\hline Temp. Média & $1,063(0,98-1,15)$ & 0,12 & - & - & & - & - \\
\hline U R do ar & $0,989(0,98-1,00)$ & 0,05 & - & - & & - & - \\
\hline Vento & - & & $0,875(0,80-0,96)$ & 0,00 & & - & - \\
\hline Amp. Térmica & & & $1,014(0,98-1,05)$ & 0,42 & & - & - \\
\hline Poluição (ruim) & - & & $1,178(0,96-1,45)$ & 0,12 & & - & - \\
\hline
\end{tabular}

A Tabela 25 mostra os resultados da associação com as variáveis atmosféricas e as internações por doenças respiratórias em adultos maiores de sessenta anos com dos dados da EM-IAG/USP.

O grupo de distritos com melhor perfil socioambiental apresentou associação significativa, somente individualmente com a umidade relativa do ar. $\mathrm{O}$ grupo de distritos com pior perfil socioambiental não apresentou associação estatisticamente significante com nenhuma das variáveis atmosféricas (Apêndice D Tabela D3).

Para o grupo de distritos com perfil socioambiental intermediário as variáveis atmosféricas perdem significância estatística $(\mathrm{p}<0,05)$ no modelo ajustado. 
Tabela 25 - Resultados do modelo ajustado para as variáveis atmosféricas da EM-IAG/USP e internações por doenças respiratórias em adultos maiores de sessenta anos, controladas pela poluição do ar, segundo o perfil socioambiental dos distritos, no setor Sul/Sudeste, São Paulo, SP, 2003 a 2007.

\begin{tabular}{|c|c|c|c|c|c|c|c|}
\hline \multirow[b]{4}{*}{ Índice PET } & \multicolumn{7}{|c|}{ EM-IAG/USP* } \\
\hline & \multicolumn{2}{|l|}{ MELHOR $* *$} & \multicolumn{2}{|c|}{ INTERMEDIÁRIO**** } & \multicolumn{3}{|l|}{ PIOR ***** } \\
\hline & RR (IC95\%) & $\mathbf{p}$ & RR (IC95\%) & $\mathbf{p}$ & RR (IC95\%) & & \\
\hline & - & & - & - & & - & - \\
\hline Temp. Max. & - & & - & - & & - & - \\
\hline Temp. Min. & - & & $0,973(0,95-1,00)$ & 0,06 & & - & - \\
\hline Temp. Média & - & & - & - & & - & - \\
\hline U R do ar & - & & - & - & & - & - \\
\hline Vento & - & & $0,839(0,70-1,01)$ & 0,06 & & - & - \\
\hline Amp. Térmica & - & & $1,018(0,99-1,05)$ & 0,17 & & - & - \\
\hline Poluição (ruim) & - & & $1,175(0,96-1,44)$ & 0,13 & & - & - \\
\hline
\end{tabular}

\subsubsection{Doenças respiratórias em crianças menores de cinco anos}

A Tabelas 26 e a Tabela 27 apresentam os resultados da análise do modelo de regressão logística das variáveis atmosféricas e as doenças respiratórias em crianças menores de cinco anos nos diferentes os grupos de distritos e estações meteorológicas.

As variáveis que individualmente associaram-se com os dados das internações hospitalares, com significância estatística $(\mathrm{p}<0,05)$ e constituíram o modelo foram as mesmas para as duas estações meteorológicas e para os três grupos de distritos: índice de conforto PET, amplitude térmica e poluente.

Deve-se observar que, embora o parâmetro umidade relativa do ar também apresentou significância estatística quando analisada individualmente, não foi incluído no modelo, pois o índice de conforto contém o parâmetro umidade relativa do ar.

A Tabela 26 mostra os resultados do modelo ajustado com os dados da EMCONGONHAS. O modelo manteve a significância estatística para os três parâmetros analisados.

No grupo de distritos com melhor perfil socioambiental apresentaram forte associação estatística $(\mathrm{p}=0,00)$. $\mathrm{O}$ índice de conforto PET apresentou risco relativo de 
0,950 ou $1,052(5,2 \%)$ mais chance de ocorrer dias doentes com a diminuição em $1^{\circ}$ $\mathrm{C}$ na temperatura fisiológica. A amplitude térmica aponta um risco relativo de 1,078 $(7,8 \%)$ mais chance de ocorrer dias doentes a cada aumento em $1^{\circ} \mathrm{C}$ na amplitude térmica. O parâmetro poluente aponta risco de 1,994, ou quase duas vezes mais chance de ocorrer dias doentes quando a qualidade do ar é ruim.

O grupo de distritos com perfil socioambiental intermediário apresentou risco relativo de 0,974 ou $1,026(2,6 \%)$ mais chance de ocorrer dias doentes com a diminuição de $1^{\circ} \mathrm{C}$ no índice de conforto térmico, $1,071(7,1 \%)$ de chance de ocorrer dias doentes com o aumento em $1^{\circ} \mathrm{C}$ na amplitude térmica e 1,3 vezes mais chance de ocorrer dias doentes quando o índice de qualidade do ar é ruim.

O grupo de distritos com pior perfil socioambiental apresentou risco relativo de 0,969 ou $1,031(3,1 \%)$ mais chance de haver dias doentes com a diminuição em $1^{\circ}$ $\mathrm{C}$ na temperatura fisiológica, 1,055 (5,5\%) mais chance de haver dias doentes com o aumento em $1^{\circ} \mathrm{C}$ na amplitude térmica e 1,2 vezes mais chance de ocorrer dias doentes quando a qualidade do ar é ruim.

Tabela 26 - Resultados do modelo ajustado para as variáveis atmosféricas da EMCONGONHAS e internações por doenças respiratórias em crianças menores de cinco anos, controladas pela poluição do ar, segundo o perfil socioambiental dos distritos, no setor Sul/Sudeste, São Paulo, SP, 2003 a 2007.

\begin{tabular}{|c|c|c|c|c|c|c|}
\hline \multirow[b]{4}{*}{ Índice PET } & \multicolumn{6}{|c|}{ EM-CONGONHAS* } \\
\hline & \multicolumn{2}{|l|}{ MELHOR*** } & \multicolumn{2}{|c|}{ INTERMEDIÁRIO**** } & \multicolumn{2}{|l|}{ PIOR***** } \\
\hline & RR $($ IC95\%) & $\mathbf{p}$ & RR (IC95\%) & $\mathbf{p}$ & RR (IC95\%) & $\mathbf{p}$ \\
\hline & $0,950(0,93-0,97)$ & 0,00 & $0,974(0,95-0,99)$ & 0,03 & $0,969(0,95-0,99)$ & 0,01 \\
\hline Amplitude Térmica & $1,078(1,04-1,12)$ & 0,00 & $1,071(1,03-1,11)$ & 0,00 & $1,055(1,01-1,10)$ & 0,01 \\
\hline Poluição (Ruim) & $1,994(1,62-2,46)$ & 0,00 & $1,268(1,03-1,56)$ & 0,03 & $1,235(1,00-1,52)$ & 0,05 \\
\hline
\end{tabular}

A Tabela 27 mostra os resultados do modelo ajustado com os dados da EMIAG/USP.

O grupo dos distritos com melhor perfil socioambiental apresentou associação estatística significante $(\mathrm{p}<0,05)$ com as três variáveis incluídas no modelo: indice de conforto PET, amplitude térmica e índice de qualidade do ar. $\mathrm{O}$ índice de conforto PET apresentou risco relativo de 0,964 ou 1,037, ou seja, 3,7\% mais chance de ocorrer dias doentes com $1^{\circ} \mathrm{C}$ de decréscimo na temperatura fisiológica; 1,039 ou 
$3,9 \%$ mais chance de ocorrer dias doentes a cada $1^{\circ} \mathrm{C}$ de aumento na amplitude térmica e, 1,991 ou quase duas vezes mais chance de ocorrer dias doentes quando o índice de qualidade do ar é ruim.

O grupo de distritos com perfil socioambiental intermediário apresentou risco relativo de 0,964 ou 1,037, ou seja 3,7\% mais chance de ocorrer dias doentes quando a temperatura fisiológica diminui em $1^{\circ} \mathrm{C} ; 1,069$ ou $6,9 \%$ mais chance de ocorrer dias doentes quando a amplitude térmica aumenta em $1^{\circ} \mathrm{C}$ e 1,3 vezes mais chance de ocorrer dias doentes quando a qualidade do ar é ruim.

O grupo de distritos com pior perfil socioambiental apresentou risco relativo de 0,959 ou 1,042 ou seja, 4,2\% mais chance de ocorrer dias doentes com a diminuição em $1^{\circ} \mathrm{C}$ na temperatura fisiológica (PET), 1,051 ou 5,1\% mais chance de ocorrer dias doentes a cada aumento de $1^{\circ} \mathrm{C}$ na amplitude térmica e, 1,206 ou 1,2 vezes mais chance de ocorrer dias doentes quando o índice de qualidade do ar é ruim. Cabe ressaltar que a associação com o parâmetro poluente foi fraca, ou seja, $\mathrm{p}=0,07$, neste grupo de distritos.

Tabela 27 - Resultados do modelo ajustado para as variáveis atmosféricas da EM-IAG/USP e internações por doenças respiratórias em crianças menores de cinco anos, controladas pela poluição do ar, segundo o perfil socioambiental dos distritos, no setor Sul/Sudeste, São Paulo, SP, 2003 a 2007.

\begin{tabular}{|c|c|c|c|c|c|c|}
\hline \multirow[b]{4}{*}{ Índice PET } & \multicolumn{6}{|c|}{ EM-IAG/USP* } \\
\hline & \multicolumn{2}{|l|}{ MELHOR $* *$} & \multicolumn{2}{|c|}{ INTERMEDIÁRIO**** } & \multicolumn{2}{|l|}{ PIOR**** } \\
\hline & RR (IC95\%) & $\mathbf{p}$ & RR (IC95\%) & p & RR (IC95\%) & $\mathbf{p}$ \\
\hline & $0,964(0,94-0,98)$ & 0,00 & $0,964(0,94-0,98)$ & 0,01 & $0,959(0,94-0,98)$ & 0,01 \\
\hline Amplitude Térmica & $1,039(1,01-1,07)$ & 0,01 & $1,069(1,04-1,10)$ & 0,00 & $1,051(1,02-1,08)$ & 0,01 \\
\hline Poluição (Ruim) & $1,991(1,62-2,45)$ & 0,00 & $1,255(1,02-1,54)$ & 0,03 & $1,206(0,98-1,48)$ & 0,07 \\
\hline
\end{tabular}




\section{DISCUSSÃO DOS RESULTADOS}

Os aspectos do clima local, bem com das características do conforto térmico, no período de 2003 a 2007, foram avaliados considerando as diferenças entre os ambientes dos entornos da EM-IAG/USP e EM-CONGONHAS. As variáveis medidas nas duas estações meteorológicas são muito correlacionadas entre si, indicando que os valores medidos em uma são mensurados na outra e, portanto, considera-se que os dados são bastante confiáveis.

A caracterização das variáveis atmosféricas medidas no Aeroporto de Congonhas aponta a influência do entorno urbanizado, sobretudo, com relação às temperaturas mínimas que, de forma significativa, são mais elevadas do que aquelas medidas na EM-IAG/USP, com diferenças de até $6^{\circ} \mathrm{C}$; as temperaturas médias diárias também são ligeiramente mais elevadas; os valores de umidade relativa do ar são mais baixos, indicando um ambiente mais seco; os valores da velocidade do vento são mais elevados, provavelmente devido às características do entorno - mais aberto - e do fluxo de aviões; as temperaturas máximas são ligeiramente menores ou iguais e os valores de amplitude térmica mais baixos.

O comportamento do ritmo diário do índice PET e a frequência das faixas de conforto avaliada mostraram que este difere pouco nos dois ambientes estudados. As condições bioclimáticas, avaliadas a partir do índice de conforto PET caracterizaramse pela maior frequência de dias confortáveis, dias pouco frios e dias frios. Os dias de pouco calor e calor ocorreram em menor frequência durante todos os meses dos cinco anos estudados. As diferenças entre os valores do índice PET — da EMIAG/USP e EM-CONGONHAS - mostraram que as condições bioclimáticas na área mais urbanizada são ainda mais desconfortáveis para o frio do que aquelas encontradas na área menos urbanizada.

Esses resultados estão de acordo com aqueles encontrados por NEDEL (2008), que apontou maior frequência de períodos desconfortáveis por frio e mostrou que a população de São Paulo sofre mais com o frio do que com o calor.

A distribuição temporal das internações hospitalares por doenças do aparelho circulatório, a partir da média móvel de 30 dias, apontou tendência de aumento das internações a partir de 2004, com picos de internação a partir dos meses de março/abril e diminuição nos meses de novembro-fevereiro. Não foi possível, 
contudo, identificar sazonalidade clara para as internações. Essa tendência foi confirmada na análise com o modelo GLM, sendo que o ano de 2005 apresentou maior taxa de internação do período 2003-2007 (21\%).

A distribuição espacial das doenças circulatórias, no período estudado, aponta claro padrão socioespacial, ou seja, maiores taxas relacionadas aos distritos com pior perfil socioambiental e baixo IDH e taxas menores associadas aos distritos com melhor perfil socioambiental e alto IDH. Esse mesmo padrão foi observado por SILVA e RIBEIRO (2009) para os dados de mortalidade, no município de São Paulo, no mesmo período.

Essa distribuição pode estar relacionada ao viés da amostra, ou seja, os dados de internação aqui trabalhados referem-se às pessoas que procuraram o SUS; trata-se, portanto, da população com menor poder aquisitivo. Os dados sobre a população doente e residente nos distritos de melhor condição socioeconômica - que, eventualmente, pode ter sido internada na rede privada - não aparecem neste estudo.

De maneira geral, a descrição dos dados relativos às internações e às temperaturas mensais indicou que, para as doenças circulatórias em adultos com mais de sessenta anos, nos meses em que as temperaturas máximas, mínimas e médias são mais baixas ocorreram taxas mais elevadas de internação hospitalar. A análise estatística inferencial com o modelo GLM apontou maior risco de aumento nas internações hospitalares associadas tanto às altas amplitudes térmicas quanto à diminuição na temperatura média, no conjunto das internações do setor Sul/Sudeste.

A análise por faixa de exposição das temperaturas máximas e o índice de conforto PET indicou que o calor é protetor, isto é, ocorreram menos dias com excesso de internações em relação à faixa de conforto de referência. Com relação às temperaturas médias e mínimas, o conjunto das temperaturas mais baixas - quartil inferior a $25 \%$ - indicou risco de aumento do número de dias com excesso de internações.

As análises segundo os perfis socioambientais dos grupos de distritos, por doenças do aparelho circulatório em pessoas com mais de sessenta anos, apresentou, nos distritos com pior perfil socioambiental, forte associação estatística entre as taxas de internação diária e as variáveis atmosféricas temperatura máxima e índice PET, 
observadas na EM-CONGONHAS. Para esse grupo de distritos, os resultados apontaram risco aumentado de ocorrência de dias com excesso de internações (dias doentes) tanto em condições de desconforto para o frio, como nas situações com temperaturas máximas elevadas. Estes resultados apontam que, nas áreas com piores indicadores ambientais e sociais, há vulnerabilidade às condições do ambiente atmosférico nos dois extremos: de frio e de calor. O modelo ajustado apresentou risco de haver dias doentes para o grupo de distritos com perfil socioambiental intermediário, com a diminuição da umidade relativa do ar, porém com fraca associação estatística $(\mathrm{p}=0,04)$.

Não houve associação estatisticamente significante com as variáveis atmosféricas para as pessoas com mais de sessenta anos internadas por problemas circulatórios e residentes nos distritos com melhor perfil socioambiental, quando analisados os dados das duas estações meteorológicas. Quando observados os dados da EM-IAG/USP, o grupo de distritos com perfil intermediário não apresentou associação estatística significante $(\mathrm{p}<0,05)$. No grupo dos distritos com pior perfil, o índice de conforto PET manteve o risco em relação aos dias com maior taxa de internação (dias doentes), porém com fraca significância estatística $(\mathrm{p}=0,04)$.

Sabe-se que a etiologia das doenças do aparelho circulatório é múltipla e extremamente complexa. Alguns fatores de risco clássico são apontados, como a hipertensão, o hábito de fumar, a dislipidemia (alto teor de gordura no sangue), o diabetes e a obesidade. Além disso, estão ligadas ao modo de vida ocidental. Fatores psicossociais estressantes também têm sido associados como causas dessas doenças: estresse no trabalho, tristeza, depressão, tensão e ansiedade devido a fatores externos estão relacionadas ao maior risco de ocorrência do infarto do miocárdio (ROSENGREN et al. 2004).

Os resultados das análises do conjunto das internações no setor Sul/Sudeste, indicam que, para o grupo de adultos com mais de sessenta anos e com doenças do aparelho circulatório, os dias frios e de forte oscilação térmica estão mais associados ao agravamento das doenças. Para a cidade de São Paulo, estudos também relacionaram os dias mais frios com o aumento das doenças do aparelho circulatório, contribuindo para corroborar estas análises (GONÇALVES et al. 2007; SHAROVSKY et al. 2004). 
$\mathrm{O}$ agrupamento dos distritos por perfil socioambiental apontou que, nas áreas onde essa situação é pior, há forte associação entre as doenças do aparelho circulatório em pessoas com mais de sessenta anos e o ambiente atmosférico. Considerando que as áreas com perfil socioambiental pior apresentam, normalmente urbanização precária, estes resultados indicam que a precariedade do ambiente urbano e agrava os efeitos negativos da atmosfera sobre a saúde.

As doenças respiratórias foram analisadas considerando os grupos etários de crianças menores de cinco anos e de adultos acima de sessenta anos. Os perfis temporal e espacial das internações, em ambos os grupos, apresentam padrões diferenciados, assim como a associação das internações hospitalares com as variáveis meteorológicas e de poluição.

A distribuição da série temporal apontou tendência de aumento das internações a partir do ano de 2004, para as duas faixas etárias. Essa propensão foi parcialmente confirmada pela análise estatística GLM, que apresentou significância estatística para as doenças respiratórias em crianças somente para o ano de 2006.

As internações por doenças respiratórias apresentaram ciclo sazonal, com aumento das internações no período do outono-inverno, porém de forma mais pronunciada para as internações de crianças. BENICIO et al 2000 relatam o aumento da morbidade respiratória em crianças em todas as modalidades no período de outono-inverno, na cidade de São Paulo, o que pode apontar para influência do clima na ocorrência das doenças do aparelho respiratório.

As internações por doenças respiratórias na população de sessenta anos e mais apresentaram padrão socioespacial: verificou-se que as maiores taxas de internação ocorrem em distritos com o pior indicador socioambiental e de IDH. Esse padrão pode estar relacionado ao viés da amostra que, como mencionado anteriormente, refere-se à população de baixa renda.

Com relação às internações de crianças com menos de cinco anos não foi possível observar padrão socioespacial bem definido, no período de 2003 a 2007. As taxas mais baixas ocorrem em distritos de melhor IDH e perfil socioambiental, como Moema, Ibirapuera e Campo Belo, mas também aparecem taxas baixas em distritos de pior IDH e perfil socioambiental, como Pedreira e Campo Grande. Da mesma 
forma, taxas elevadas de internação podem ser observadas em distritos de melhor IDH e perfil socioambiental, como Santo Amaro.

A análise descritiva relacionando os dados de internação por doenças do aparelho respiratório em adultos com mais de sessenta anos e os valores de temperatura média, mínima e máxima mensal não apontou padrão claro de relação entre as maiores taxas de internação, os meses dessa ocorrência e as temperaturas. Contudo, nos meses de verão — os mais quentes — observou-se a ocorrência das menores taxas de incidência para esse grupo etário. Observação semelhante foi feita para a mortalidade por RIBEIRO SOBRAL (2005).

Os resultados das análises estatísticas para o conjunto dos dados de internação por doenças respiratórias em pessoas com sessenta e mais anos, no setor Sul/Sudeste, indicam que a oscilação diária de temperatura relaciona-se ao aumento das internações. O modelo GLM apontou também o índice PET como uma variável explicativa para o aumento das internações hospitalares, indicando as condições de desconforto para o frio como situações de maior vulnerabilidade.

As análises por grupos de distritos segundo perfil socioambiental apontaram melhor associação com as variáveis temperatura mínima e vento para o grupo de distritos com perfil socioambiental intermediário. Os distritos com melhor perfil socioambiental apresentaram fraca associação com a umidade relativa do ar e o grupo de distritos com pior perfil não apresentou associação estatisticamente significante com as variáveis atmosféricas.

A análise dos dados da EM-IAG/USP não apontou associação estatística significante $(\mathrm{p}<0,05)$ entre os dados de internação por doença respiratória em pessoas com mais de sessenta anos e o perfil socioambiental dos distritos.

Considera-se que os fatores de confusão que envolvem o grupo etário dos adultos acima de sessenta anos e com doenças do aparelho respiratório são muitos. Por exemplo, os fatores que desencadeiam problemas respiratórios em idosos podem ter origem ocupacional ou estarem relacionados ao hábito de fumar ou ao seu estado nutricional, entre outros. Dessa forma, para essa faixa etária e esse grupo de doenças a relação causal com os aspectos da atmosfera é mais complexa e menos evidente.

A análise descritiva dos dados das internações por doenças respiratórias em crianças menores de cinco anos mostrou clara sazonalidade, sendo que os meses de 
outono (março-maio) apresentaram as maiores taxas de internação. Cabe ressaltar que, embora os meses mais frios sejam relatados como aqueles de maior ocorrência de doenças respiratórias em crianças (PRIETSCH et al. 2003; BENICIO et al. 2000; TOYOSHIMA et al. 2005), no presente estudo, os meses de inverno (junho-julho) apresentaram taxas mais baixas do que os meses de outono (março-maio), apesar de serem mais elevadas do que nos meses de verão (novembro-dezembro).

O modelo GLM apontou crescimento do número esperado de internações hospitalares com os aumentos da temperatura média diária, da amplitude térmica e da poluição, bem como com a queda do índice PET.

Considera-se que os resultados apresentados pelo modelo GLM em relação às temperaturas médias devem ser interpretados com cautela, uma vez que, como observado na análise descritiva dos dados, nos meses de verão as temperaturas mais altas não correspondem ao aumento do número de internações. Certamente, as internações hospitalares não aumentam linearmente com a elevação das temperaturas médias.

Essa característica pode ser observada nas análises por faixa de exposição em que o maior risco de haver dias doentes foi na faixa das temperaturas médias intermediárias - entre $17,7^{\circ} \mathrm{C}$ e $20,4^{\circ} \mathrm{C}$ - em relação às temperaturas mais elevadas $\left(>22,7^{\circ} \mathrm{C}\right)$. Na faixa de pouco frio $\left(18^{\circ} \mathrm{C}>12^{\circ} \mathrm{C}\right)$ houve risco aumentado de haver dias doentes em relação à faixa confortável, indicando que os ambientes atmosféricos amenos são mais favoráveis ao desencadeamento de doenças respiratórias em crianças.

O aumento do risco relativo para as faixas de exposição de menor temperatura mínima ou da amplitude térmica indica maior vulnerabilidade em dias com forte oscilação térmica diária, principalmente quando os valores são muito pronunciados, conforme os resultados obtidos a partir dos dados da EM-IAG/USP permitem observar. Nas faixas de pouco calor $\left(26^{\circ} \mathrm{C}<31^{\circ} \mathrm{C}\right)$ e de frio $\left(<12^{\circ} \mathrm{C}\right)$ há proteção, indicando possível adaptação ao ambiente térmico durante o meio da estação, com diminuição das doenças respiratórias.

As análises para os três grupos de distritos mostraram padrão homogêneo de associação para os três perfis socioambientais, tanto em relação às variáveis quanto no que diz respeito às estações meteorológicas. Os resultados mostram que há 
associação de forma robusta entre as variáveis atmosféricas e as internações hospitalares por doenças respiratórias em crianças menores de cinco anos, uma vez que, após ajuste do modelo, as variáveis mantiveram-se significantes $(\mathrm{p}<0,05)$. As análises, no entanto, não apontaram diferença significativa entre as variáveis na comparação entre os três grupos de distritos

BENICIO et al. (2000) consideram que fatores como a poluição atmosférica, a presença de ácaros na moradia e a frequência a creches estão relacionados ao aumento das doenças respiratórias em crianças. Além desses fatores, estão relacionadas ao desencadeamento das doenças respiratórias em crianças, a circulação de vírus, a densidade nos domicílios, o estado nutricional e a convivência com fumantes, fatores esses que independem da das condições climáticas.

Três modelos estatísticos foram utilizados para avaliar as possíveis associações entre as variáveis ambientais atmosféricas e o aumento da morbidade por doenças respiratórias e circulatórias no setor Sul/Sudeste. As análises estatísticas elaboradas - modelo GLM, regressão por faixa de exposição e modelo de regressão agrupada por perfil dos distritos - mostram que as crianças são sensíveis às condições climáticas e respondem negativamente às condições de frio e de forte oscilação térmica.

O modelo GLM, com distribuição binomial negativa, foi apontado como mais adequado para modelar o conjunto de dados, mas não possibilitou a modelagem dos dados separados por grupos de distritos, devido ao grande número de zeros, ou seja, dias sem internação.

O uso da técnica com o modelo de regressão logística solucionou o problema da quantidade de zeros, pois a variável resposta - internações hospitalares — foi dicotomizada em dias doentes e dias não doentes. Dessa forma, essa técnica permitiu a análise entre as variáveis atmosféricas e as internações hospitalares, por grupo, de distritos, segundo perfil socioambiental e por faixa de exposição.

Os modelos, apesar dos métodos diferenciados, apresentaram coerência nos resultados. É importante observar que estes não são perfeitos; dessa forma, o uso diversificado de técnicas, incluindo mesmo aquelas consideradas menos sofisticadas — como os gráficos e as médias — podem fornecer informações não reveladas pela modelagem complexa. 
Uma estrutura de defasagem de um e dois dias foi utilizada indicando que a resposta às alterações da atmosfera pode ocorrer em um curtíssimo espaço de tempo. Esse tempo de resposta também é apontado em outros estudos realizados no Brasil em outros lugares do mundo, como apontado na revisão da literatura.

Outros estudos têm observado tanto a diminuição e/ou as oscilações da temperatura e da umidade, quanto o aumento da amplitude térmica como fatores agravantes das doenças respiratórias em crianças pequenas em áreas urbanas (CARDOSO 2007; NEDEL 2008; ALCOFORADO 1998; BOTELHO et al. 2003; PITTON e DOMINGOS 2004; BARROS 2006; SOUZA 2007).

McMICHAEL et al (2008) observam que, as cidades por eles estudadas entre as quais São Paulo se inclui —, com temperaturas mínimas baixas e elevada amplitude térmica, apresentaram larga flutuação sazonal na mortalidade, com as mais altas taxas de morte ocorrendo em períodos relativamente frios.

A pesquisa aqui empreendida apresentou associação estatística entre o aumento das internações por doenças circulatórias e respiratórias e as variáveis meteorológicas e o índice de conforto PET, no setor Sul/Sudeste do município de São Paulo, no período de 2003 a 2007. Estes resultados indicam que a população estudada é sensível aos impactos negativos do clima, porém de forma diferenciada entre os grupos etários, os grupos de doenças e os diferentes grupos de distritos, segundo perfil socioambiental.

O índice de conforto PET, usado como indicador complexo na caracterização bioclimática intraurbana, indicou que, no ambiente mais urbanizado, há maior aguçamento das condições de frio. As condições de desconforto para o frio apresentaram maior vulnerabilidade no desencadeamento das doenças respiratórias em crianças e circulatórias em pessoas acima de sessenta anos. Grande amplitude térmica também consistiu em um fator importante para a ocorrência da morbidade nos três grupos estudados.

As pesquisas que avaliam a relação entre clima e saúde, conduzidas em cidades de diferentes países do hemisfério norte, têm incluído, crescentemente, pelo menos um indicador de conforto térmico como parâmetro de exposição ao agravamento da saúde da população. Os autores apontam que as condições de estresse térmico de frio e calor são mais agravantes às condições de saúde do que as 
condições consideradas como confortáveis (RUDEL et al. 2007; NASTOS et al. 2006; SMOYER 2000; DONATO et al. 2008; MARQUES 2007; LASCHEWSKI e JENDRITZKY 2002).

O calor é um fator de grande preocupação entre os pesquisadores e os estudos indicam alto risco de morte entre as pessoas vulneráveis e com desordens de saúde em dias quentes, sobretudo aquelas com problemas cardiorrespiratórios (BASU e SAMET 2002).

Estudo de BELL et al. (2008) aponta preocupação em compreender os efeitos do calor na saúde dos residentes nas cidades de países pobres. Essa pesquisa avaliou o impacto do calor na mortalidade em São Paulo e apontou maior aumento no risco da mortalidade por unidade de aumento da temperatura para o grupo etário de maior de sessenta e cinco anos.

As características do clima de São Paulo são de forte flutuação nas temperaturas diárias e interdiárias, não sendo raros os episódios de passagem de um dia de muito calor para um dia de muito frio, como demonstrado pelos resultados da caracterização climática e bioclimática no período estudado. As amplitudes térmicas passam de $20^{\circ} \mathrm{C}$ e essa condição é mais frequente nos meses das estações de transição (outono e primavera).

No entanto, quando observados os dados por grupos de distritos, as características climáticas do ambiente mais urbanizado foram mais fortemente associadas com as internações hospitalares, indicando maior vulnerabilidade da população aos efeitos adversos do clima urbano.

Estudo realizado em microescala mostrou que, em favela, há o aguçamento de extremos de temperatura, e, nesses ambientes, as oscilações térmicas são mais pronunciadas do que em ambientes de melhor padrão urbano (SILVA e RIBEIRO 2006). Pesquisas realizadas em ambientes internos apontaram que, em áreas mais pobres da cidade de São Paulo, a precariedade das construções faz com que as moradias não protejam os moradores do clima externo, levando a um risco ampliado de adoecimento (NEDEL 2008 e CARDOSO 2007).

O parâmetro poluição foi avaliado como controle nas análises e também se configurou em um indicador importante como variável atmosférica no aumento da morbidade por doenças circulatórias e respiratórias, no conjunto da população do 
setor Sul/Sudeste. O parâmetro poluição, porém, não apresentou associação estatística significante com as internações por doenças do aparelho respiratórios em idosos, quando agrupados por perfil socioambiental.

Houve maior risco relativo de ocorrência de dias doentes quando a qualidade do ar é ruim relacionada ao grupo dos distritos com melhor perfil socioambiental.

Vale mencionar que o índice de qualidade do ar utilizado, nesta pesquisa, foi obtido na estação CETESB-Congonhas, localizada próxima aos distritos com melhor perfil socioambiental. Pode-se aventar a possibilidade de que esta pesquisa apontou a associação entre melhor perfil socioambiental e maior risco ao agravamento de doenças por poluentes atmosféricos porque o grupo de distritos com este perfil é justamente o que está exposto ao maior fluxo de tráfego, tanto terrestre quanto aéreo.

No que diz respeito ao perfil socioambiental, os resultados por grupos de distritos apontaram:

a) as características do ambiente atmosférico da área mais urbanizada (EMCONGONHAS) apresentam associação com as internações hospitalares e relacionam-se mais fortemente com o aumento da taxa de internação diária (dias doentes) por doenças circulatórias e respiratórias em idosos;

b) maior vulnerabilidade das pessoas com problemas no aparelho circulatório residentes nos distritos com pior perfil socioambiental;

c) não há diferenças importantes entre os grupos de distritos quando analisada a associação entre os fatores ambientais atmosféricos e as internações por doenças respiratórias de crianças menores de cinco anos;

d) maior vulnerabilidade para as pessoas com mais de sessenta anos com doenças no aparelho respiratório residentes nos distritos com perfil socioambiental intermediário, sem correlação com o índice de qualidade do ar.

Os resultados confirmam, em parte, a hipótese a partir da qual foi construída esta pesquisa, de que, sob a mesma condição atmosférica, o impacto negativo sobre a saúde é maior na população residente em áreas com piores condições socioambientais. Esta constatação aplica-se aos adultos com mais de sessenta anos com problemas do aparelho respiratório e circulatório, mas não é evidente em relação às crianças com menos de cinco anos. 


\section{CONCLUSÃO}

As alterações que as aglomerações urbanas provocam na atmosfera urbana são bem conhecidas, bem como os efeitos deletérios à saúde causados pela poluição atmosférica.

Essa pesquisa buscou relacionar as características do ambiente atmosférico na escala intraurbana sob o aspecto das trocas de calor e sua influência no desencadeamento das doenças dos aparelhos respiratório e circulatório. A fím de caracterizar o clima e as condições de conforto e desconforto térmico nesta escala foram utilizados um indicador de conforto térmico - o índice PET - e os atributos climáticos, mensurados em estações meteorológicas circundadas por diferentes situações de urbanização no que se refere ao uso do solo.

Trata-se de um estudo de bioclimatologia urbana, que relaciona os aspectos do clima urbano e a sua influência na saúde da população. A construção do conhecimento da influencia do clima sobre a saúde humana requer uma compreensão integradora de algumas áreas do conhecimento, tais como a geografia, epidemiologia, a medicina e a estatística, consistindo em uma área intrinsecamente interdisciplinar.

Os resultados mostraram associação entre a morbidade e as variáveis climáticas e o índice de conforto, no setor Sul/Sudeste, porém de forma diferenciada nos grupos etários e de doenças indicando que os efeitos do clima sobre a saúde são diversos e específicos. As condições de desconforto para frio e a alta amplitude térmica consistiram em fatores mais agravantes para o desencadeamento das doenças.

O grupo de distritos com pior perfil socioambiental apresentou maior vulnerabilidade aos efeitos negativos do ambiente atmosférico urbano para as pessoas com doenças do aparelho circulatório. Foi notada associação entre os fatores ambientais atmosféricos do ambiente mais urbanizado e ao agravamento de doenças entre adultos com mais de sessenta anos, com problemas respiratórios e residentes em distritos com perfil socioambiental intermediário. As crianças com doenças respiratórias apresentaram padrão homogêneo em relação aos diferentes grupos de distritos e às variáveis atmosféricas, ou seja, não houve diferenças significativas 
quando considerados os agrupamentos de distritos segundo perfil socioambiental e o impacto das variáveis atmosféricas.

Esses resultados confirmam parcialmente a hipótese, de que os distritos com pior condições socioambientais representam maior risco aos impactos negativos à saúde ao apresentarem os distritos com piores condições socioambientais associados ao maior risco aos impactos negativos à saúde para adultos com mais de sessenta anos, embora não tenham permitido observar diferenças significativas para o grupo de crianças com doenças respiratórias menores de cinco anos.

A construção da metodologia com uso da técnica de regressão e a dicotomização da variável resposta em dias doentes e não doentes permitiu avaliar as diferenças no padrão de ocupação do uso do solo e das faixas de exposição. Considera-se que, esse método foi satisfatório na avaliação da relação clima e morbidade, pois associações significativas foram observadas, as quais não foram evidenciadas a partir das análises descritivas, das representações gráficas e da construção do modelo linear generalizado.

O recorte espacial intraurbano permitiu comparar as características de um ambiente mais urbanizado e outro menos urbanizado, utilizando dados secundários climáticos e de internações hospitalares. - disponíveis e de fácil acesso. Muito embora as informações sobre as internações hospitalares disponibilizadas pelo SUS apresentem uma série de problemas como: falhas no diagnóstico e no endereçamento postal, entre outros, detectados no processamento das informações, desta pesquisa, essas informações estão disponíveis na rede mundial de computadores e são os dados atualmente disponíveis e podem ser acessados por meio da rede mundial de computadores.

Deve-se ressaltar que a limitação da amostra, ou seja, os dados das internações - relativos ao SUS - referem-se, de forma geral, à camada mais pobre da população. A ausência de informações sistematizadas e confiáveis relacionadas às internações na rede hospitalar privada não permitiu avaliar o universo mais amplo e as diferenças entre os grupos socioeconômicos.

Essa pesquisa avaliou as internações hospitalares que correspondem à ponta do iceberg, isto é, correspondem aos efeitos agudos da manifestação da enfermidade. No entanto, os efeitos do clima sobre a saúde podem variar desde um simples 
incômodo, para um enfraquecimento e alterações subclínicas e mesmo danos clínicos e aumento da mortalidade. A avaliação dos impactos negativos do clima urbano sobre a saúde da população requer uma base de informações de saúde que permita refinar os resultados obtidos nesta pesquisa. É necessário compreender as manifestações subclínicas, ou seja, aquelas manifestações que não necessariamente as levam à internação.

Considera-se, portanto, que informações mais abrangentes sobre doenças devem ser produzidas e sistematizadas a fim de ampliar o conhecimento dos efeitos atmosféricos sobre a saúde e propiciar a busca por soluções para a melhoria dos ambientes urbanos e, consequentemente, para a saúde da população.

É necessário refinar os modelos de análise das relações clima e saúde em áreas urbanas. Nas regiões metropolitanas, países tropicais, além das características climáticas peculiares e com grande diversidade socioespacial é necessário expandir as pesquisas a fim de compreender a relação entre desigualdades sociais e ambientais e o processo saúde-doença da população. 


\section{REFERÊNCIAS}

ALCOFORADO M J Influência do tempo no desencadeamento de crises de dispnéia em doentes respiratórios. Finisterra. Revista Portuguesa de Geografia, v. XXVI, n.51, p. 105-116, 1991.

ALMEIDA E. Refuncionalização da metrópole no período técnico-científicoinformacional e os novos serviços. In SANTOS M e SILVEIRA M L - O Brasil. Território e sociedade no início do século XXI. Rio de Janeiro/São Paulo: Ed. Record, 2001, p. 389-400.

ALVES FILHO AP e RIBEIRO H A percepção do caos urbano, as enchentes e as suas repercussões nas políticas públicas da região Metropolitana de São Paulo. Saúde e Sociedade. São Paulo, v. 15, n. 3, p. 145-161, set-dez 2006.

ALVES FILHO AP e RIBEIRO H Configuração Espacial de eventos de precipitação extrema na Região Metropolitana de São Paulo: Interações entre a ilha de calor e a penetração da brisa oceânica. InterFACEHS v. 02 P. 1-8, 2007.

ANDRADE $\mathrm{H} \quad \mathrm{O}$ desconforto térmico estival em Lisboa. Uma abordagem bioclimática. Finisterra Revista Portuguesa de Geografia, v. XXXIII, n. 66, p. 4148, 1998.

ANDRADE H O Clima Urbano - Natureza, Escalas de Análise e Aplicabilidade. Finisterra Revista Portuguesa de Geografia, v. XL, n. 80, p. 67-91, 2005

ANDRADE H e ALCOFORADO M J Microclimatic variation of thermal comfort in a district of Lisbon (Telheiras) at night. Theor. Appl. Climatol,. v. 92, p. 225-237, 2008

ANDRADE H e OLIVEIRA S Na initial assessment of the bioclimatic comfort in an outdoor public space in Lisbon. International Journal of Biometeorology, v. 52, p. 69-84, 2007.

AULICIEMS A. Comfort, Clothing and Health in Applied Climatology. Principles and Practice. - Thompson Russel D. and Perry Allen (eds) Routledge: London, 1997.

AULICIEMS A. Human Bioclimatology: An Introduction in Advances in Bioclimatology 5. Berlin Springer, 1998 p.1-6.

AZEVEDO TR Distribuição Espacial da ocorrência dos maiores totais diários de precipitação na RMSP e arredores em função da intensidade relativa da atividade urbana. GEOUSP - Espaço e Tempo. São Paulo, 12, 2002, p. 54-68. 
BARATA RCB et al. - Gastroenterites e infecções respiratórias agudas em crianças menores de 5 anos em área da região Sudeste do Brasil, 1986-1987. I- Infecções respiratórias agudas. Revista de Saúde Pública, v. 30, n. 6, p. 553-63, 1996.

BARROS JR Tipos de Tempo e Incidência de Doenças Respiratórias: Um Estudo Geográfico Aplicado ao Distrito Federal. UNESP/IGCE/Rio Claro. Rio Claro, SP, 2006 (tese de doutoramento).

BASU R and SAMET J M. Relation between Elevated Ambient Temperature and Mortality: A Review of the Epidemiologic Evidence Epidemiology Reviews v. 24, n. 2, p.190-202, 2002.

BELL M L et al. Vulnerability to heat-related mortality in Latin América: a casecrossover study in São Paulo, Brazil, Santiago, Chile and Mexico City, Mexico. International Journal of Epidemiolgy v. 37, n. 4, p.796-804, may 2008.

BENICIO M H D’A et al. - Tendência secular da doença respiratória na infância na cidade de São Paulo (1984-1996). Revista de Saúde Pública. São Paulo, v. 34; n. 6, p. 91-101, dezembro 2000. Suplemento.

BITTENCOURT AS et al. - O Sistema de Informação Hospitalar e sua aplicação na saúde coletiva. Cadernos de Saúde Pública, Rio de Janeiro, v. 22, n. 1, p. 19-30, jan 2006.

BOTELHO C et al. Fatores ambientais e hospitalizações em crianças menores de cinco anos com infecção respiratória aguda Cadernos de Saúde Pública Rio de Janeiro, v. 19, n. 6, p.1771-1780, nov-dez, 2003.

CABRAL E Tendências térmicas urbanas no município de São Paulo (1887-1995).in X Congresso Brasileiro de Meteorologia e III Simpósio Brasileiro de Climatologia Geográfica, Brasília - DF e Salvador BA. Anais em CD ROM 1998.

CARDOSO MRA - Micro Clima dos domicílios e doenças sibilantes em crianças da Cidade de São Paulo. Faculdade de Saúde Pública da Universidade de São Paulo (Tese de livre docência). São Paulo, 2007.

CASTRO, A. Clima urbano e saúde: as patologias do aparelho respiratório associadas aos tipos de tempo de inverno de Rio Claro/SP. Tese de Doutoramento, IGCE/UNESP, Rio Claro, 2000, 202p.

CETESB Companhia Ambiental de São Paulo Caracterização das Estações da Rede Automática de Monitoramento da Qualidade do Ar na RMSP Estação Congonhas São Paulo: CETESB 2004. Disponível em http://www.cetesb.sp.gov.br/Ar/publicacoes.asp último acesso em 17/04/2010. 
CETESB Companhia Ambiental de São Paulo Relatório de qualidade do ar no estado de São Paulo 2008. São Paulo: CETESB 2009. Disponível em http://www.cetesb.sp.gov.br/Ar/publicacoes.asp último acesso em 17/04/2010.

CEM - CENTRO DE ESTUDOS DA METROPOLE http://www.centrodametropole.org.br/.

CHIAVERINI R. - Tipos Etiológicos de Cardiopatia em um núcleo ferroviário de São Paulo. Arq. Bras. De Cardiologia 4, p. 403-412, 1951.

Climate Index UTCI for Outdoor Applications. Disponível em http://www.utci.org/isb/documents/windsor_vers04.pdf. acesso em 05/03/2009.

CURIONI C. et al. - The decline in mortality from circulatory diseases in Brazil. Rev. Panam Salud Publica v. 25, n. 1, 2009.

DATASUS - $\underline{\text { http://www2.datasus.gov.br/DATASUS }}$

DIAZ J et al. Mortality impact of extreme winter temperatures. Int J. Biometeorol v. 49, p. 179-183, 2005.

DIAZ J et al. The impact of the summer 2003 heat wave in Iberia: how should we measure it? Int J Biometeorol v. 50, p.159-166, 2006.

DONATO E.K. et al. Airport and city-centre temperatures in the evaluation of the association between heat and mortality. Int J Biometeorol v. 52 p.301-310, 2008.

ESTANISLAU MV e SEGRI NJ Curso Introdutório de Estatística e suas aplicações na pesquisa clínica - [Apostila de curso] Sem data.

EUROWINTER GROUP THE Group Cold exposure and winter mortality from ischaemic heart disease, cerebrovascular disease, respiratory disease, and all causes in warm and cold regons of Europe. The Lancet v. 349, may 101997.

FRANÇA A. Estudo sobre o Clima da Bacia de São Paulo. FFCL/USP. 1946. [tese de doutoramento].

FROTA AF, SCHIFFER S R. Manual de Conforto Térmico. $5^{\circ}$. ed. São Paulo: Studio Nobel, 2001.

FUNARI FL O índice de Sensação Térmica Humana em função dos tipos de tempo na Região Metropolitana de São Paulo. USP/FFLCH/DG São Paulo, 2006 (tese de doutoramento). 
FUNDAÇÃO SEADE Perfil do Paulistano em 2007. 2007. Disponível em http://www.seade.gov.br/produtos/pdf/paulistano_2007.pdf.último acesso em $\underline{11 / 01 / 2010 .}$.

FUNDAÇÃO SEADE Sistema Seade de Projeções de População. Disponível em http://www.seade.gov.br/produtos/projpop/index.php último acesso em 20/11/2009.

GONÇALVES F L.T. et al. The effects of air pollution and meteorological parameters on respiratory morbidity during the summer in São Paulo city. Environment International, v. 31, p. 343-349, 2005.

GONÇALVES F L.T. et al. - Influences of the weather and air pollutants on cardiovascular disease in the metropolitan area of São Paulo. Environmental Research v. 104, p. 275-281, 2007.

GONZÁLES et al. Efeitos das condições climáticas no trimestre de nascimento sobre asma e pneumonia na infância e na vida adulta em uma coorte no Sul do Brasil. Cadernos de Saúde Pública. Rio de Janeiro, v. 24, n. 5, p. 1089-1102, maio 2008.

GOUVEIA N. et al. Socioeconomic differentials in the temperature-mortality relationship in São Paulo, Brazil. in International Journal of Epidemiology, no. 32, 2003, p. 390-397.

HÖPPE P Heat balance modeling Experientia. v. 49, p. 741-746, 1993.

HÖPPE P Aspects of human biometeorology in past, present and future. International Journal of Biometeorology v. 40, p. 19-23, 1997.

HÖPPE P A Universal Index for the Assessment of the Thermal Environment - The physiological Equivalent Temperature PET In DEAR RJ de, KALMA JD, OKE TR Biometeorology and Urban Climatology at the Turn of the Millennium. WCASP 50. WMO/TD n.1026. p.261-265, 1999.

HÖPPE P Different aspects of assessing indoor and outdoor thermal comfort. Energy and Buildings, v. 34, p. 661-665, 2002.

IBGE INSTITUTO BRASILEIRO DE GEOGRAFIA E ESTATÍSTICA. Censo Demográfico 2000. http://www.ibge.gov.br último acesso em 28/10/2009.

INFOPÉDIA [Em linha]. Porto: Porto Editora, 2003-2010. Disponível na www: <URL: http://www.infopedia.pt/\$homeotermico último acesso em 19/01/2010.

JAUREGUI E Urban bioclimatology in developing countries. Experientia v.49, p. 964-968, 1993. 
JENDRITZKY G e HAVENITH G The Thermal Environment of the Human Being - A subjective retrospection on methodologies. http://www.utci.org/cost/publications/ICB05\%20The\%20Thermal\%20Environment. doc. Acesso em janeiro 2009

JENDRITZKY G et al. Looking for a Universal Thermal Windsor-Conference on Thermal Standards, April 2001, Windsor, UK. http://www.utci.org/isb/documents/windsor_vers04.pdf Acesso em fevereiro 2009

JENDRITZKY G. Human biometeorology, Part I The atmospheric environment - an introduction. Experientia. v. 49, p. 733-740, 1993.

JENDRITZKY G. Human Health and Atmospheric Environment. WCASP-33 WMO/TD no. 682. May 1995. Appendix F.

LACAZ CS. Meteorologia Médica in LACAZ, CS et al. Introdução à geografia médica do Brasil. São Paulo:Edgard Blücher/Editora da Universidade de São Paulo, 1972, p. 39-84.

LANDSBERG HE The Climate of Towns in Thomas Jr WL (ed.). Man's role in Changing the face of the Earth. Chicago, University of Chicago Press Ltd.,Vol 2., p. 584-606. 1956

LASCHEWSKI $G$ and JENDRITZKY G Effects of the thermal environment on human health: an investigation of 30 years of daily mortality data from SW Germany. Climate Research, v. 21, p. 91-103, may 2002.

LECHA L B E. Biometeorological classification of daily weather types for the humid tropics. International Journal of Biometeorology, v. 42, p. 77-83, 1998:

LECHA L B. E Situações sinópticas e seu impacto sobre a saúde humana. [texto não publicado] 2009.

LOMBARDO MA. Ilha de Calor nas Metrópoles: O Exemplo de São Paulo. São Paulo: Hucitec; 1985.

LOTUFO P A Por que não vivemos uma epidemia de doenças crônicas: o exemplo das doenças cardiovasculares? Ciência \& Saúde Coletiva, v. 9, n. 4, p. 841-850, 2004.

LOTUFO PA e LOLIO CA de Tendências de Evolução da mortalidade por doenças cardiovasculares: O caso do Estado de São Paulo. In MONTEIRO CA (org.) Velhos e Novos Males da Saúde no Brasil. A Evolução do país e de suas doenças. Editora Hucitec/NUPENS/USP: São Paulo, 2000. p.279-288. 
MARQUES JMA Condições climáticas de inverno e a mortalidade diária no distrito de Lisboa. Universidade de Lisboa. Faculdade de Letras. Departamento de Geografia. (dissertação de mestrado) 2007.

MATZARAKIS A, AMELUNG B Physiological Equivalent Temperature as Indicator for Impacts of Climate Change on Thermal Comfort of Humans. In M.C. Thomson et al. (eds.) Seasonal Forecasts, Climatic Change and Human Health. 2008. Chapter 9. p.161-172.

MATZARAKIS A et al. Applications of a universal thermal index: physiological equivalent temperature. International Biometeorlogy, v. 43, p. 76-84, 1999.

MATZARAKIS A. and MAYER H. Atmospheric conditions and human thermal comfort in urban areas. In 11th Seminar on Environmental Protection "Environmental and Health" 20-23. November 2000. Thessaloniki, Greece, 155-166.

MAYER H Urban bioclimatology. Experientia v. 49 p. 957-963, 1993.

MCMICHAEL A et al. International study of temperature, heat and urban mortality: the 'ISOTHURM' PROJECT International Journal of Epidemiology v. 37, p. 1121-1131, 2008.

MENEZES CC et al. Relatório de Análise Estatística sobre o Projeto: "Ambientes atmosféricos e possíveis correlações com doenças do aparelho respiratório e circulatório em espaços intra-urbanos na cidade de São Paulo. Centro de Estatística Aplicada IME/USP, Código 09P18, São Paulo, 2009.

MONTEIRO CA e BENICIO MHA Estudo das condições de saúde das crianças no município de São Paulo, SP (Brasil) 1984/1985. VI. Doença Respiratória. Revista Saúde Pública, São Paulo, v. 21, n. 5, p. 380-86, 1987.

MONTEIRO CAF Análise Rítmica em Climatologia. Climatologia. IG/USP. São Paulo, p. 01-20, 1971.

MONTEIRO CAF. Teoria e Clima Urbano. São Paulo: IGEOG/USP; 1976. Série Teses e Monografias no. 25 (tese de livre-docência).

MONTEIRO CAF. A cidade como processo derivador ambiental e a geração de um Clima Urbano - Estratégias na Abordagem Geográfica Revista Geosul. Florianópolis-SC. v. 5, n. 9, p.80-114, 1990.

MONTEIRO CAF Clima e Excepcionalismo. Conjecturas sobre o desempenho da atmosfera como fenômeno geográfico. Editora da UFSC, Florianópolis:1991. 
MONTEIRO CAF De Tempos e Ritmos: Entre o Cronológico e o Meteorológico para a compreensão Geográfica dos Climas. Geografia, Rio Claro, v. 26, n.3, p.131154, dez. 2001.

MONTEIRO LM e ALUCCI MP Questões teóricas de conforto térmico em espaços abertos: consideração histórica, discussão do estado da arte e proposição de classificação de modelos. Ambiente Construído, Porto Alegre, v. 7, n. 3 p.43-58, jul/set. 2007.

MONTEIRO L M Modelos Preditivos de Conforto Térmico: Quantificação de relação entre variáveis microclimáticas e de sensação térmica para avaliação e projeto de espaços abertos. Faculdade de Arquitetura e Urbanismo da Universidade de São Paulo. (Tese de doutoramento). 2008.

MORAN EF Adaptabilidade Humana. São Paulo: Edusp, 1994

NASTOS PT e MATZARAKIS A. Weather impacts on respiratory infections in Athens, Greece International Journal of Biometeorology, v. 50, p. 358-369, 2006.

NEDEL AS Condições Meteorológicas favoráveis à ocorrência de doenças respiratórias em crianças da cidade de São Paulo. USP/IAG/DCA. São Paulo 2008. (Tese de doutoramento).

O'NEIL MS et al. Impact of control for air pollution and respiratory epidemics on the estimated associations of temperature and daily mortality International Journal of Biometeorology, v. 50, p. 121-129, 2005.

OKE TR. Inadvertent climate modification in Boundary Layer Climates. London Methuen \&Co. Ltd. 1978 reprinted 1981 Cap. 08 p. 229-331.

OKE TR. Urban Climates and Global Environmental Change. in Applied Climatology. Principles and Practice. - Thompson Russel D. and Perry Allen (eds) Routledge: New York, 1997, p. 273-287.

OKE TR Observing Urban Weather and Climate Using "Standard" Stations. In DEAR RJ de, KALMA JD, OKE TR Biometeorology and Urban Climatology at the Turn of the Millennium. WCASP 50. WMO/TD No. 1026. p. 443-448, 1999.

PEREIRA FILHO AJ et al. Caracterização do Clima e sua Evolução na Região Metropolitana de São Paulo. In PEREIRA FILHO AJ et al. (orgs.) Evolução do Tempo e do Clima na Região Metropolitana de São Paulo. São Paulo: Linear B/IAG/USP 2007, p. 99-122. 
PITTON S E C. e DOMINGOS A E Tempo e Doenças: efeitos dos parâmetros climáticos nas crises hipertensivas nos moradores de Santa Gertrudes-SP. Estudos Geográficos, Rio Claro, v. 2, n. 1, p. 75-56, junho 2004.

PMSP/CEM PREFEITURA MUNICIPAL DE SÃO PAULO e CENTRO DE ESTUDOS DA METRÓPOLE - Base Cartográfica Digital das favelas do Município de São Paulo - HABITASAMPA. 2003. [CDROM]

PMSP/SMS/CEInfo PREFEITURA MUNICIPAL DE SÃO PAULO/SECRETARIA MUNICIPAL DE SAÚDE/COORDENAÇÃO DE EPIDEMIOLOGIA E INFORMAÇÃO Diagnóstico Mínimo por Coordenadoria Regional de Saúde 2005 disponível em http://www.prefeitura.sp.gov.br/cidade/secretarias/upload/saude/arquivos/infsaude/D iagnostico_minino_regional_2005.pdf último acesso em 06/01/2010.

PORTELA M C et al.1. Algoritmo para a composição de dados por internação a partir do sistema de informações hospitalares do sistema único de saúde (SIH/SUS) Composição de dados por internação a partir do SIH/SUS. Cadernos de Saúde Pública, Rio de Janeiro, v. 13, n. 4, p. 771-774, out-dez, 1997.

PREFEITURA DO MUNICÍPIO DE SÃO PAULO http://www.prefeitura.sp.gov.br/cidade/secretarias/saude/

PRIETSCH SO. et al. Doença respiratória em menores de 5 anos no sul do Brasil: influência do ambiente doméstico. Revista Panam. Salud Publica/Pan Am Public Health v. 13, n. 5, p. 303-310, 2003.

RIBEIRO M.C.S.A et al. Perfil sociodemográfico e padrão de utilização de serviços de saúde para usuários e não-usuários do SUS-PNAD 2003. Ciência \& Saúde Coletiva v. 11 n.4, p. 1011-1022, 2006

RIBEIRO H Patologias do ambiente urbano: Desafios para a Geografia da Saúde. in SILVEIRA ML et al. (org.) Questões territoriais na América Latina. CLACSO Livros/Depto. De Geografia da Universidade de São Paulo 2006 P. 277-293.

RIBEIRO H. e AZEVEDO TR. O patrimônio em áreas verdes da USP e a atmosfera urbana. In Meio Ambiente: Patrimônio Cultural da USP. São Paulo:Edusp. 2003. p. $18-40$.

RIBEIRO H; CARDOSO MRA Air pollution and children's health in São Paulo (1986-1998) Social Science \& Medicine v. 57, p. 2013-2022, 2003.

RIBEIRO SOBRAL H Heat island in São Paulo, Brazil: Effects on health. Critical Public Health, v. 15, n. 2, p. 147-156, june 2005. 
RIPSA REDE INTERAGENCIAL DE INFORMAÇÃO PARA SAÚDE Indicadores Básicos para a Saúde no Brasil: Conceitos e Aplicações. $2^{\circ}$ edição 2008 disponível $\mathrm{em} \mathrm{http://www.ripsa.org.br/php/level.php?lang=pt \& component=68 \& \text {item } = 2 0}$ último acesso em 06/01/2010.

ROSENGREN A. et al. Association of psychosocial risk factors with risk of acute myocardial infarction in 11.119 cases and 13.548 controls from 52 countries (the INTERHEART study) case-control study. The Lancet, v. 364, p. 953-962, September 112004.

RUDEL E et al. Bioclimate and Mortality in Viena. Ber. Meteor. Inst. Univ. Freiburg n. 16, p. 25-30, 2007.

SANTOS M A Urbanização Brasileira. São Paulo: Editora Hucitec, 1996. $3^{\circ}$. edição.

SANTOS M Saúde e ambiente no processo de desenvolvimento. Ciência \& Saúde Coletiva, v. 8, n. 1, p. 309-314, 2003.

SANTOS M e SILVEIRA M L O Brasil. Território e sociedade no início do século XXI. Rio de Janeiro/São Paulo: Ed. Record, 2001.

SHAROVSKY R et al. Temperature, air pollution, and mortality from myocardial infarction in São Paulo, Brazil. Brazilian Journal of Medical and Biological Research n.37, p.1651-1657, 2004.

SIGAUD JFX Do clima e das doenças do Brasil ou Estatística Médica deste Império. Col. História \& Saúde. Editora Fiocruz, 2009.

SILVA E.N e RIBEIRO H Alterações de temperatura em ambientes externos de favela e o desconforto térmico. Revista de Saúde Pública v. 40, nº.4, p. 663-670, 2006.

SILVA E.N. e RIBEIRO H Perfil Intraurbano da Morbi-mortalidade por Doenças Cardiovasculares no Grupo Etário Acima de 60 Anos no Município de São Paulo. Saúde e Sociedade. Vol. 18. Suplemento 03. p. 378-379, 2009.[CDROM]

SILVA E. N. Aspectos do Microclima em ambientes externos de favela, visando subsidiar avaliação dos efeitos na saúde dos moradores: o caso de Paraisópolis, São Paulo, Brasil.. Faculdade de Saúde Pública, Universidade de São Paulo. (dissertação de mestrado) 2004.

SMOYER KE et al. Heat stress related mortality in five cities in Southern Ontário: 1980-1996. International Journal of Biometeorology, v. 44, p. 190-197, 2000. 
SORRE M. A adaptação ao meio climático e biossocial Geografia psicológica. In MEGALE, Januário F. (org.) Max. Sorre Geografia. São Paulo: Editora Ática. 1984, pág.29-86.

SOUZA C G A Influência do ritmo climático na morbidade respiratória em ambientes urbanos. UNESP/FCT/Presidente Prudente. Presidente Prudente, SP 2007 (dissertação de mestrado).

SVMA SECRETARIA MUNICIPAL DO VERDE E MEIO AMBIENTE Atlas Ambiental do Município de São Paulo - O Verde, o Território, o Ser Humano: Diagnóstico e Bases para a Definição de políticas Públicas para as Áreas Verdes no Município de São Paulo. SEPE, PM. e TOKIYA H (coord.). São Paulo: SVMA, 2004.

TASCHNER SP e BOGUS LMM São Paulo: o caleidoscópio urbano. São Paulo em Perspectiva, v.15, n. 1, p.31-44, 2001.

TARIFA JR e ARMANI G. Os climas "naturais" in TARIFA, J e AZEVEDO, T R (org.) Os climas na cidade de São Paulo. São Paulo. GEOUSP n. 4, p. 34-46, 2001 a.

TARIFA JR e ARMANI G. Os climas urbanos GEOUSP n. 4, p. 47-70, 2001 b.

TOMÁS DD Comportamento da Umidade Relativa do Ar em Centros Urbanos: O Exemplo da Metrópole de São Paulo. in Anais IV Simpósio Brasileiro de Climatologia Geográfica, 2000, Rio de Janeiro, RJ.

TOYOSHIMA M T. K et al. Morbidade por doenças respiratórias em pacientes hospitalizados em São Paulo/SP. Revista Assoc. Méd. Brasileira v. 51, n. 4, p. 209$13,2005$.

TROMP SW Human Biometeorology. International Journal of Biometeorology, v.7, n. 2, p. 145-158, 1963.

VANECKOWA et al. Effect of temperature on mortality during the six warmer months in Sydney, Australia, between 1993 and 2004. Environmental Research v. 108, p.361-369, 2008.

VASCONCELOS J e VIEIRA R Conforto Bioclimático da Amadora. Contributo para o Planeamento Saudável. In SANTANA P. (coord.) A Cidade e a Saúde. Ed. Almedina, Lisboa, 2007 p. 197-217.

VERAS CMT. e MARTINS MS A Confiabilidade dos Dados nos Formulários de Autorização de Internação Hospitalar (AIH), Rio de Janeiro, Brasil. Cadernos de Saúde Pública, Rio de Janeiro, v. 10, n. 3, p. 339-355, jul/set, 1994. 
WEIHE W. H La esperanza de vida en los climas tropicales en funcion de la urbanizacion. Conferencia Tecnica sobre Climatologia Urbana Y sus Aplicaciones con Especial Referencia a Las Zonas Tropicales. Mexico 20-30 de noviembre de 1984. OMM.

WHO WORLD HEALTH ORGANIZATION Urban Bioclimatology in Health and Global Environmental Change. Series no. 2 Heat waves Risks and Responses. Capitulo 5 P. 65-112 2004 Disponível em http://www.euro.who.int/globalchange acesso em 30/11/2009.

WMO WORLD METEOROLOGICAL ORGANIZATION Guide to Meteorological Instruments and Methods of Observation. WMO no. $087^{\circ}$ edição 06 august 2008 http://www.wmo.int/pages/prog/www/IMOP/publications/CIMO-

Guide/CIMO_Guide-7th_Edition-2008.html

XAVIER TMBS e PEREIRA FILHO AJ Análise das Medições e Observações Meteorológico-Climáticas de Superfície. In PEREIRA FILHO AJ e col (orgs.) evolução do Tempo e do Clima na Região Metropolitana de São Paulo. São Paulo: Linear B/IAG/USP 2007, p. 123-231. 
Apêndice A

Dados de População 
Tabela A.01 - Projeção da população de crianças menores de cinco anos nos distritos do setor Sul/Sudeste, município de São Paulo, no período de 2003 a 2007.

\begin{tabular}{|l|r|r|r|r|r|}
\hline DISTRITOS & $\mathbf{2 0 0 3}$ & $\mathbf{2 0 0 4}$ & $\mathbf{2 0 0 5}$ & $\mathbf{2 0 0 6}$ & $\mathbf{2 0 0 7}$ \\
\hline Campo Belo & 3796 & 3861 & 3922 & 3857 & 3794 \\
\hline Campo Grande & 6680 & 6875 & 7065 & 6900 & 6732 \\
\hline Cidade Ademar & 24516 & 25128 & 25743 & 25371 & 24983 \\
\hline Cidade Dutra & 18116 & 18322 & 18519 & 18131 & 17749 \\
\hline Cursino & 6838 & 6956 & 7070 & 6942 & 6811 \\
\hline Itaim Bibi & 3987 & 4138 & 4290 & 4236 & 4180 \\
\hline Jabaquara & 17819 & 18181 & 18541 & 18345 & 18150 \\
\hline Moema & 3607 & 3743 & 3878 & 3820 & 3762 \\
\hline Pedreira & 12911 & 12686 & 12454 & 12373 & 12283 \\
\hline Sacomã & 19516 & 19766 & 20008 & 19687 & 19362 \\
\hline Santo Amaro & 3294 & 3573 & 3870 & 3817 & 3763 \\
\hline Saúde & 6613 & 6945 & 7283 & 7084 & 6881 \\
\hline Socorro & 2415 & 2512 & 2610 & 2571 & 2532 \\
\hline Vila Mariana & 5911 & 6105 & 6295 & 6185 & 6065 \\
\hline
\end{tabular}

Fonte: Fundação SEADE 2009

Tabela A.02 - Projeção da população de crianças menores de cinco anos nos distritos do setor Sul/Sudeste, município de São Paulo, no período de 2003 a 2007.

\begin{tabular}{|l|r|r|r|r|r|}
\hline DISTRITOS & $\mathbf{2 0 0 3}$ & $\mathbf{2 0 0 4}$ & $\mathbf{2 0 0 5}$ & $\mathbf{2 0 0 6}$ & $\mathbf{2 0 0 7}$ \\
\hline Campo Belo & 11396 & 11642 & 11881 & 12199 & 12517 \\
\hline Campo Grande & 10398 & 10796 & 11203 & 11736 & 12282 \\
\hline Cidade Ademar & 17621 & 18077 & 18531 & 19243 & 19966 \\
\hline Cidade Dutra & 13576 & 14150 & 14732 & 15569 & 16446 \\
\hline Cursino & 14498 & 14556 & 14599 & 14822 & 15044 \\
\hline Itaim Bibi & 15529 & 15809 & 16072 & 16525 & 16981 \\
\hline Jabaquara & 22676 & 22953 & 23226 & 23838 & 24439 \\
\hline Moema & 12315 & 12612 & 12898 & 13412 & 13934 \\
\hline Pedreira & 7070 & 7553 & 8068 & 8707 & 9390 \\
\hline Sacomã & 22422 & 22957 & 23489 & 24321 & 25162 \\
\hline Santo Amaro & 11834 & 12096 & 12347 & 12701 & 13048 \\
\hline Saúde & 11834 & 12096 & 12347 & 12701 & 13048 \\
\hline Socorro & 5721 & 5844 & 5972 & 6134 & 6298 \\
\hline Vila Mariana & 22016 & 22202 & 22371 & 22900 & 23411 \\
\hline
\end{tabular}


Apêndice B

Gráficos de ajuste do Modelo Linear Generalizado com distribuição Binomial Negativa 


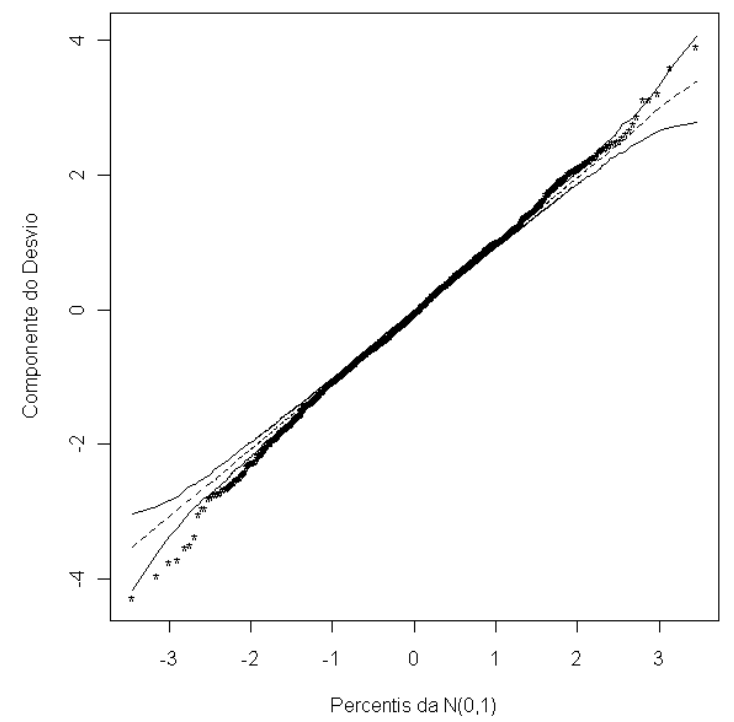

Figura B.01 - Gráfico de envelopes do número de internações por doenças circulatórias em idosos - GLM - Poisson

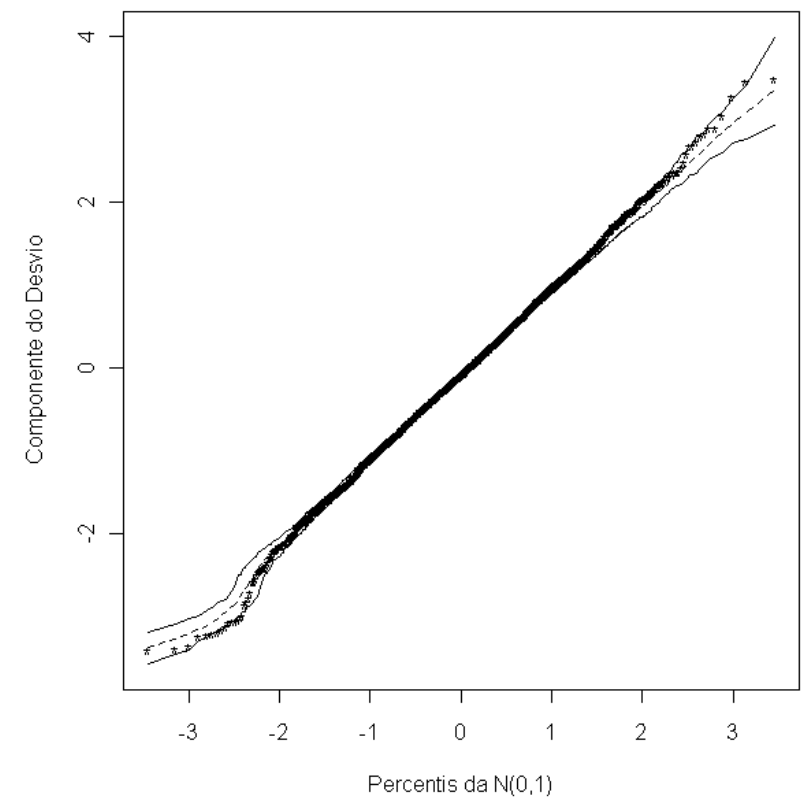

Figura B.02 - Gráfico de envelopes do número de internações por doenças respiratórias em idosos - GLM - Poisson 


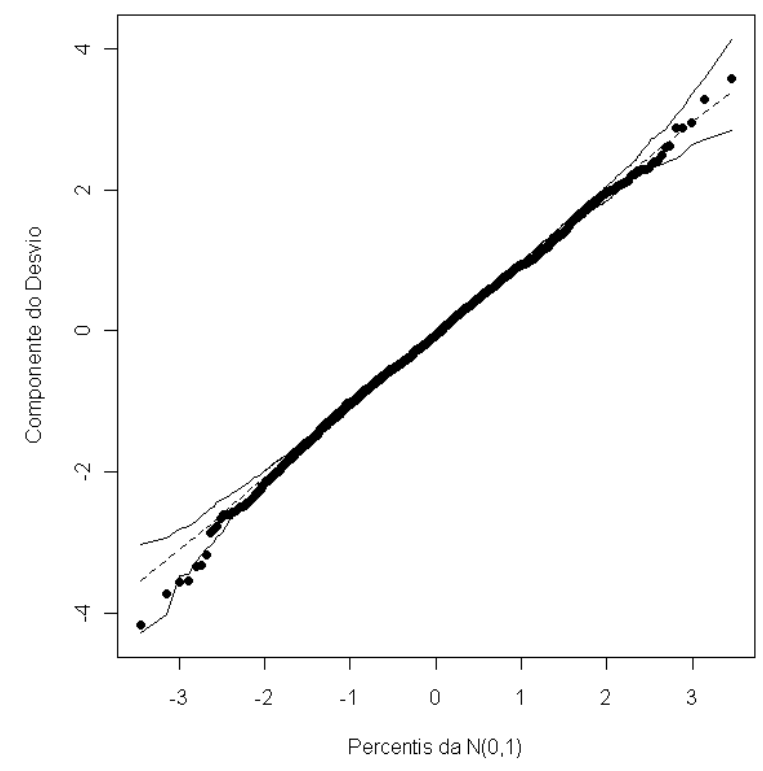

Figura B.03 - Gráfico de envelopes do número de internações por doenças respiratórias em crianças - GLM - Poisson
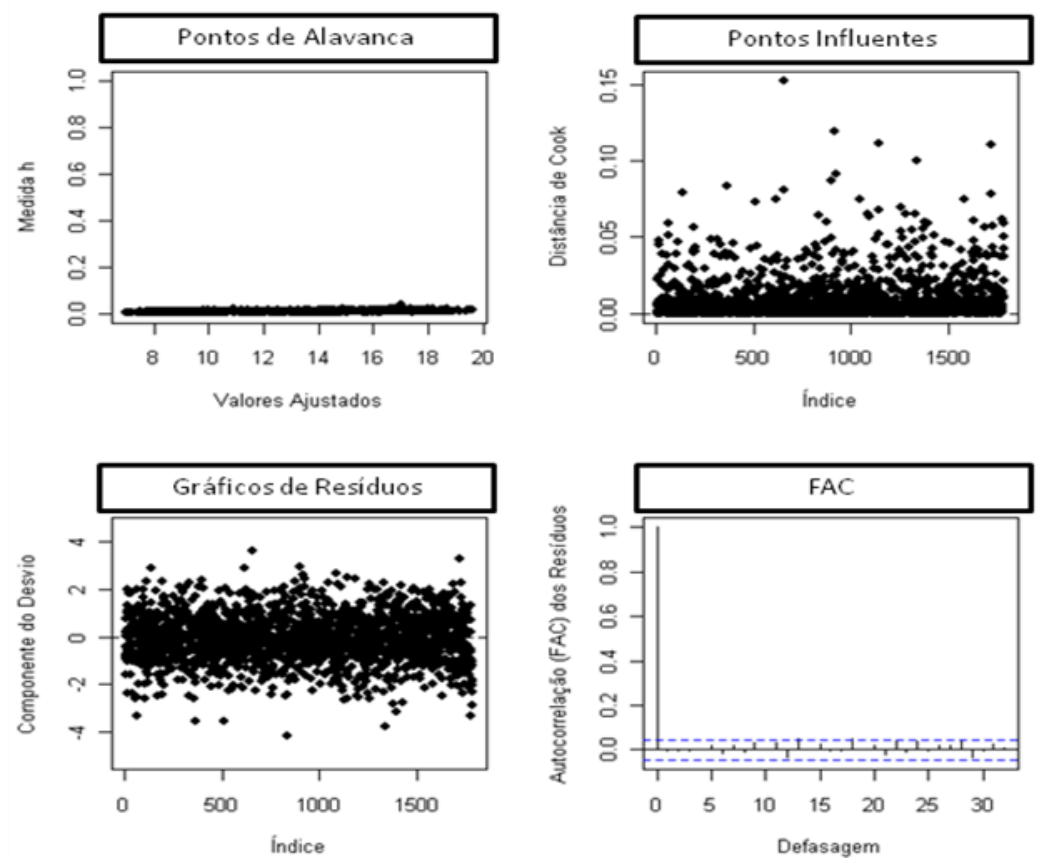

Figura B.05 - Gráficos de diagnóstico do número de internações por doenças circulatórias em idosos - GLM - binomial negativa 


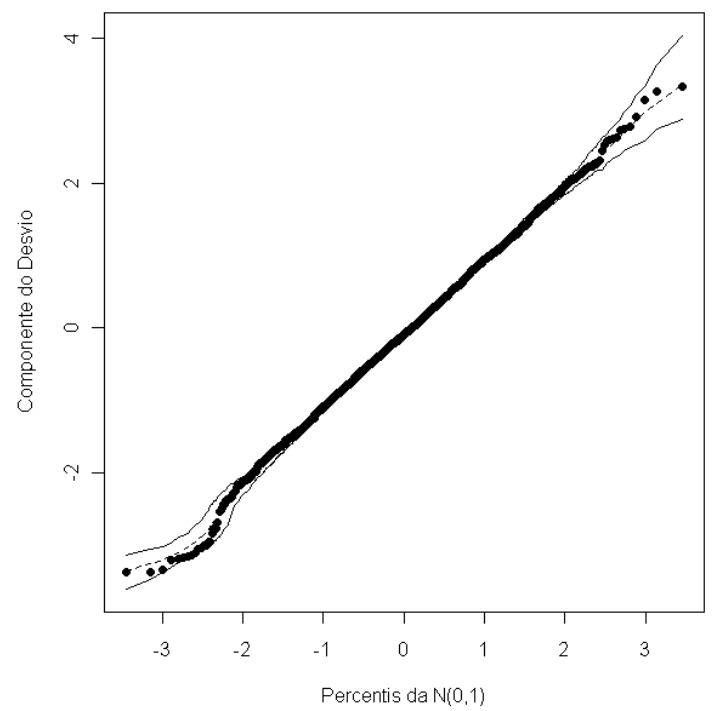

Figura B.06 - Gráfico de envelopes do número de internações por doenças respiratórias em idosos - GLM - binomial negativa
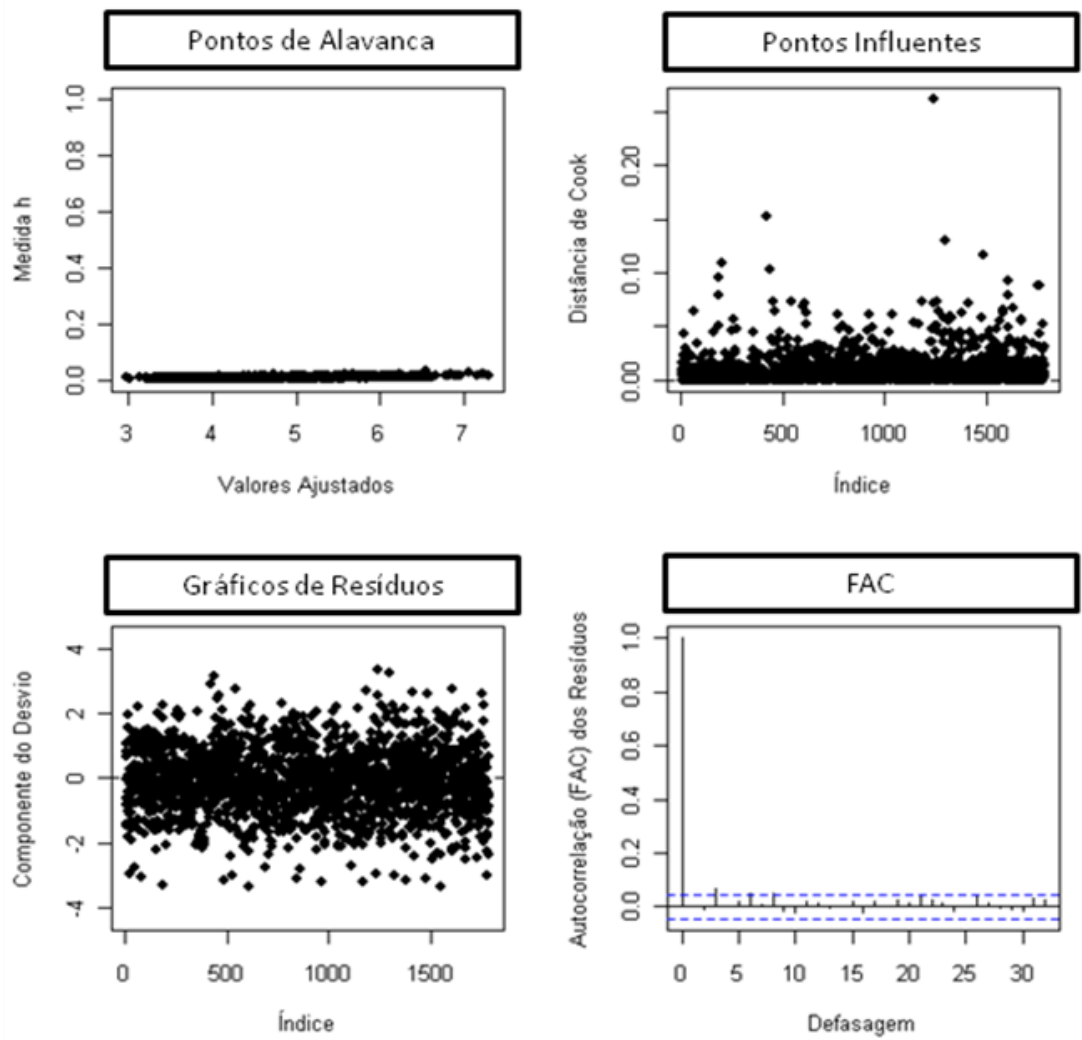

Figura B.07 - Gráficos de diagnóstico do número de internações por doenças respiratórias em idosos - GLM - binomial negativa 


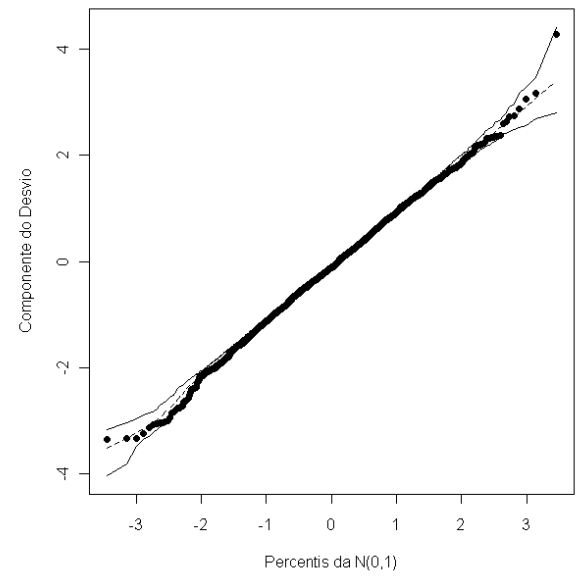

Figura B.08 - Gráfico de envelopes do número de internações por doenças respiratórias em crianças - GLM - binomial negativa
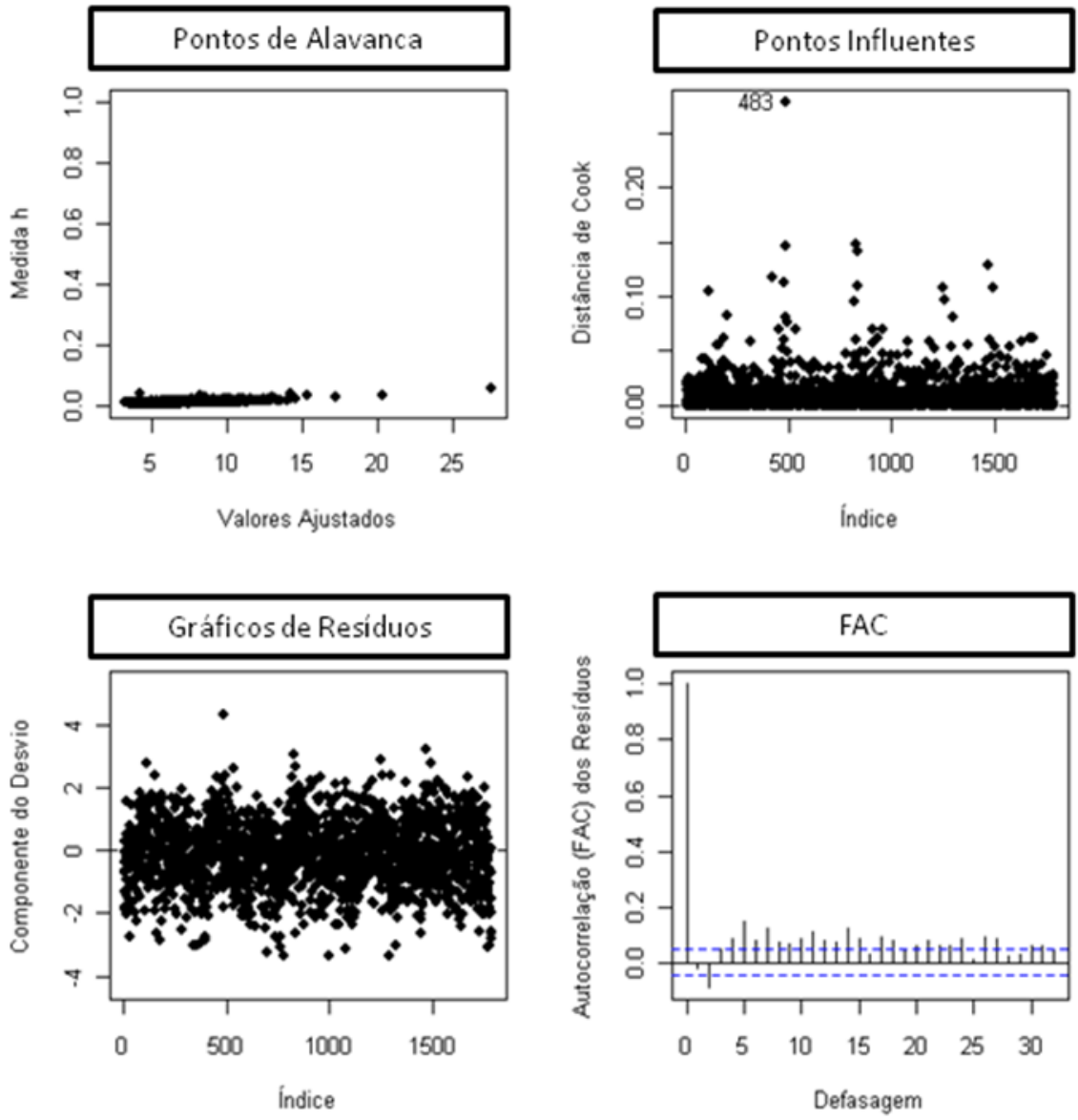

Figura B.09 - Gráficos de diagnóstico do número de internações por doenças respiratórias em crianças - GLM - binomial negativa 
Apêndice C

Resultados da Análise de Regressão Simples 
Tabela C.1 - Resultado da análise de regressão linear da temperatura média diária Congonhas em função da temperatura média diária IAG

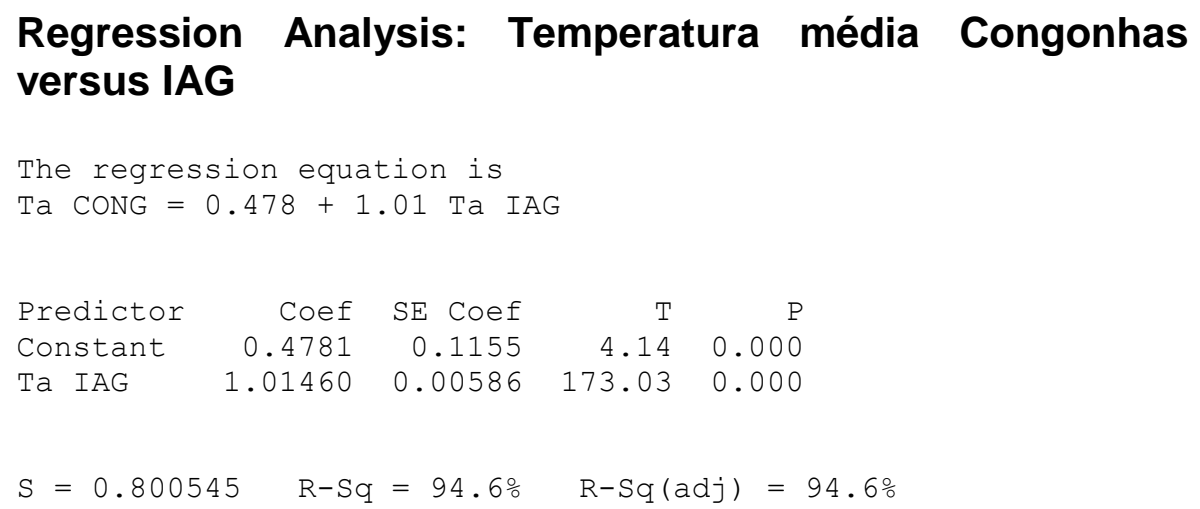

Tabela C.2 - Resultado da análise de regressão linear da temperatura mínima diária Congonhas em função da temperatura mínima diária IAG

Regression Analysis: Temperatura mínima Congonhas versus IAG

The regression equation is

TaMinCONG $=4.02+0.849 \mathrm{TaMinIAG}$

$\begin{array}{lrrrr}\text { Predictor } & \text { Coef } & \text { SE Coef } & T & P\end{array}$

$\begin{array}{lrrrr}\text { Constant } & 4.0250 & 0.1333 & 30.19 & 0.000 \\ \text { TaMinIAG } & 0.848656 & 0.008584 & 98.86 & 0.000\end{array}$

$\mathrm{S}=1.21220 \mathrm{R}-\mathrm{Sq}=85.0 \% \mathrm{R}-\mathrm{Sq}(\operatorname{adj})=85.0 \%$ 
Tabela C.3 - Resultado da análise de regressão linear da amplitude da temperatura diária Congonhas em função da amplitude da temperatura diária IAG

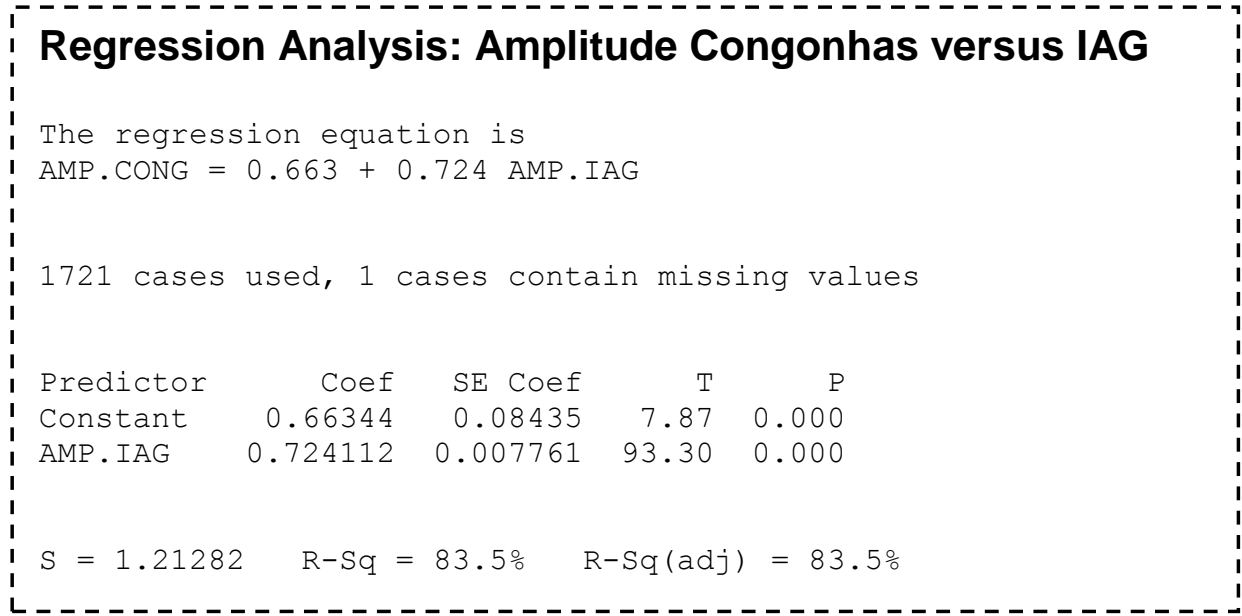

Tabela C.4 - Resultado da análise de regressão linear do PET diário Congonhas em função do PET diário IAG

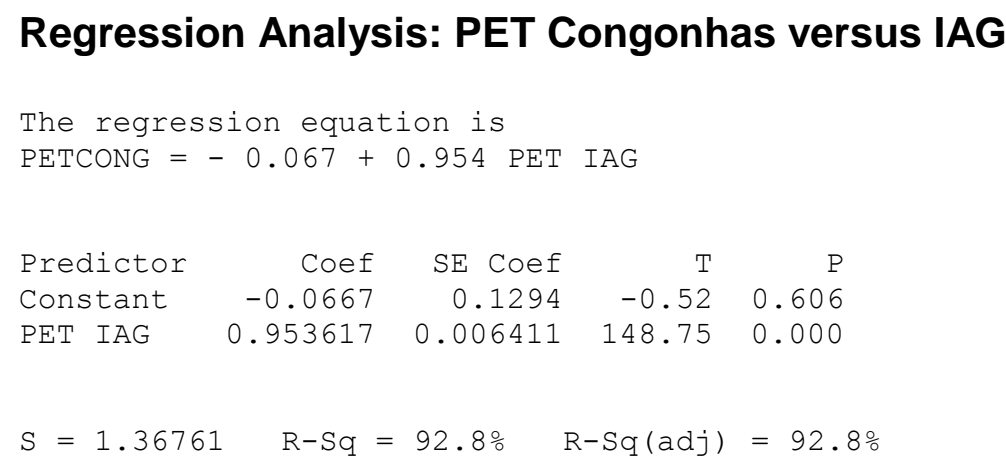


Apêndice D

Resultados da Análise de Regressão Logistica 
Tabela D2- Risco Relativo, p valor entre as variáveis meteorológicas, o índice PET e o índice de qualidade do ar e as doenças circulatórias em adultos com mais de sessenta anos, por perfil socioambiental dos distritos no Setor Sul/Sudeste, município de São Paulo, SP, no período de 2003 a 2007.

\begin{tabular}{|c|c|c|c|c|c|c|c|c|c|c|c|c|}
\hline \multirow{3}{*}{ Variáveis } & \multicolumn{4}{|c|}{ MELHOR } & \multicolumn{4}{|c|}{ INTERMEDIÁRIO } & \multicolumn{4}{|c|}{$\begin{array}{r}\text { PIOR } \\
\end{array}$} \\
\hline & \multicolumn{2}{|c|}{$\begin{array}{l}\text { EM- } \\
\text { CONGONHAS }\end{array}$} & \multicolumn{2}{|c|}{\begin{tabular}{|l|} 
EM- \\
IAG/USP \\
\end{tabular}} & \multicolumn{2}{|c|}{$\begin{array}{l}\text { EM- } \\
\text { CONGONHAS }\end{array}$} & \multicolumn{2}{|c|}{$\begin{array}{l}\text { EM- } \\
\text { IAG/USP }\end{array}$} & \multicolumn{2}{|c|}{$\begin{array}{l}\text { EM- } \\
\text { CONGONHAS }\end{array}$} & \multicolumn{2}{|c|}{$\begin{array}{l}\text { EM- } \\
\text { IAG/USP }\end{array}$} \\
\hline & $R R$ & $\mathbf{p}$ & RR & $\mathbf{p}$ & RR & $\mathbf{p}$ & RR & $\mathbf{p}$ & RR & $\mathbf{p}$ & RR & $\mathbf{p}$ \\
\hline Índice PET & 0.997 & 0.77 & 0.992 & 0.36 & 0.987 & 0.16 & 0.980 & 0.02 & 0.963 & 0.00 & 0.969 & 0.00 \\
\hline Temp. Média & 0.994 & 0.65 & 0.983 & 0.24 & 0.977 & 0.09 & 0.963 & 0.01 & 0.948 & 0.00 & 0.949 & 0.00 \\
\hline Temp. Máxima & 0.999 & 0.91 & 0,990 & 0,33 & 0.987 & 0.21 & 0,983 & 0,10 & 0.972 & 0.01 & 0,975 & 0,01 \\
\hline Temp. Mínima & 0.985 & 0.32 & 0.979 & 0.13 & 0.966 & 0.02 & 0.957 & 0.00 & 0.940 & 0.00 & 0.950 & 0.00 \\
\hline $\begin{array}{l}\text { Amplitude } \\
\text { Térmica }\end{array}$ & 1.015 & 0.35 & 1.002 & 0.86 & 1.009 & 0.60 & 1.011 & 0.39 & 1.006 & 0.72 & 1.004 & 0.76 \\
\hline Umidade Relativa & 0.996 & 0.39 & 1.005 & 0.42 & 0.991 & 0.05 & 0.998 & 0.71 & 1.005 & 0.26 & 1.002 & 0.67 \\
\hline Vento & 0.996 & 0.92 & 1.047 & 0.60 & 0.912 & 0.03 & 0.794 & 0.01 & 1.098 & 0.03 & 1.041 & 0.64 \\
\hline Poluente & 1.366 & 0.00 & & & 1.468 & 0.00 & & & 0.898 & 0.29 & & \\
\hline
\end{tabular}

Tabela D3- Risco Relativo, $\mathrm{p}$ valor entre as variáveis meteorológicas, o índice PET e o índice de qualidade do ar e as doenças respiratórias em adultos com mais de sessenta anos, por perfil socioambiental dos distritos no Setor Sul/Sudeste, município de São Paulo, SP, no período de 2003 a 2007.

\begin{tabular}{|c|c|c|c|c|c|c|c|c|c|c|c|c|}
\hline \multirow[t]{3}{*}{ Variáveis } & \multicolumn{4}{|c|}{ MELHOR } & \multicolumn{4}{|c|}{ MEDIO } & \multicolumn{4}{|c|}{ PIOR } \\
\hline & \multicolumn{2}{|c|}{$\begin{array}{l}\text { EM- } \\
\text { CONGONHAS }\end{array}$} & \multicolumn{2}{|c|}{ EM-IAG/USP } & \multicolumn{2}{|c|}{$\begin{array}{l}\text { EM- } \\
\text { CONGONHAS }\end{array}$} & \multicolumn{2}{|c|}{ EM-IAG/USP } & \multicolumn{2}{|c|}{$\begin{array}{l}\text { EM- } \\
\text { CONGONHAS }\end{array}$} & \multicolumn{2}{|c|}{ EM-IAG/USP } \\
\hline & $R R$ & $\mathbf{p}$ & $\mathbf{R R}$ & $\mathbf{p}$ & RR & p & $\mathbf{R R}$ & $\mathbf{p}$ & $\mathbf{R R}$ & $\mathbf{p}$ & RR & $\mathbf{p}$ \\
\hline Índice PET & 1.018 & 0.07 & 1.010 & 0.26 & 0.992 & 0.40 & 0.987 & 0.14 & 0.990 & 0.29 & 0.987 & 0.16 \\
\hline Temp. Média & 1.030 & 0.04 & 1.019 & 0.19 & 0.977 & 0.11 & 0.977 & 0.11 & 0.986 & 0.30 & 0.980 & 0.15 \\
\hline Temp. Máxima & 1.020 & 0.01 & 1.017 & 0.12 & 0.999 & 0.91 & 1.002 & 0.81 & 0.994 & 0.59 & 0.993 & 0.49 \\
\hline Temp. Mínima & 1.022 & 0.17 & 1.003 & 0.83 & 0.965 & 0.02 & 0.963 & 0.01 & 0.980 & 0.18 & 0.979 & 0.13 \\
\hline $\begin{array}{l}\text { Amplitude } \\
\text { Térmica }\end{array}$ & 1.022 & 0.19 & 1.021 & 0.10 & 1.036 & 0.03 & 1.034 & 0.01 & 1.008 & 0.61 & 1.007 & 0.60 \\
\hline Umidade Relativa & 0.989 & 0.02 & 0.986 & 0.01 & 0.995 & 0.29 & 0.993 & 0.21 & 1.000 & 0.98 & 1.000 & 0.93 \\
\hline Vento & 0.926 & 0.08 & & & 0.848 & 0.00 & 0.767 & 0.00 & 0.978 & 0.60 & 0.932 & 0.42 \\
\hline Poluente & 0.981 & 0.85 & & & 1.289 & 0.01 & & & 1.172 & 0.12 & & \\
\hline
\end{tabular}


Tabela D4- Risco Relativo, $\mathrm{p}$ valor entre as variáveis meteorológicas, o índice PET e o índice de qualidade do ar e as doenças respiratórias em crianças menores de cinco anos, por perfil socioambiental dos distritos no Setor Sul/Sudeste, município de São Paulo, SP, no período de 2003 a 2007.

\begin{tabular}{|c|c|c|c|c|c|c|c|c|c|c|c|c|}
\hline \multirow[t]{3}{*}{ Variáveis } & \multicolumn{4}{|c|}{ MELHOR } & \multicolumn{4}{|c|}{ MEDIO } & \multicolumn{4}{|c|}{ PIOR } \\
\hline & \multicolumn{2}{|c|}{$\begin{array}{l}\text { EM- } \\
\text { CONGONHAS }\end{array}$} & \multicolumn{2}{|c|}{ EM-IAG/USP } & \multicolumn{2}{|c|}{$\begin{array}{l}\text { EM- } \\
\text { CONGONHAS }\end{array}$} & \multicolumn{2}{|c|}{ EM-IAG/USP } & \multicolumn{2}{|c|}{$\begin{array}{l}\text { EM- } \\
\text { CONGONHAS }\end{array}$} & \multicolumn{2}{|c|}{ EM-IAG/USP } \\
\hline & $R R$ & $p$ & $\mathbf{R R}$ & $\mathbf{p}$ & $\mathbf{R R}$ & $\mathbf{p}$ & $\mathbf{R R}$ & $\mathbf{p}$ & RR & $\mathbf{p}$ & $\mathbf{R R}$ & $\mathbf{p}$ \\
\hline Índice PET & 0,976 & 0,01 & 0,977 & 0,01 & 0,999 & 0,91 & 0,988 & 0,21 & 0,988 & 0,19 & 0,977 & 0,01 \\
\hline Temp. Média & 0,985 & 0,27 & 0,972 & 0,05 & 0,993 & 0,62 & 0,980 & 0,16 & 0,983 & 0,22 & 0,967 & 0,02 \\
\hline Temp. Máxima & 1,000 & 0,98 & 0,997 & 0,74 & 1,008 & 0,49 & 1,008 & 0,47 & 0,995 & 0,66 & 0,992 & 0,47 \\
\hline Temp. Mínima & 0,966 & 0,03 & 0,960 & 0,00 & 0,970 & 0,06 & 0,955 & 0,00 & 0,966 & 0,03 & 0,955 & 0,00 \\
\hline $\begin{array}{l}\text { Amplitude } \\
\text { Térmica }\end{array}$ & 1,040 & 0,02 & 1,028 & 0,03 & 1,050 & 0,00 & 1,048 & 0,00 & 1,029 & 0,08 & 1,026 & 0,04 \\
\hline $\begin{array}{l}\text { Umidade } \\
\text { Relativa do ar }\end{array}$ & 0,988 & 0,01 & 0,989 & 0,04 & 0,981 & 0,00 & 0,982 & 0,00 & 0,988 & 0,01 & 0,980 & 0,00 \\
\hline Vento & 1,051 & 0,24 & 0,946 & 0,52 & 0,824 & 0,00 & 0,781 & 0,01 & 0,856 & 0,00 & 0,763 & 0,00 \\
\hline Poluente & 2,084 & 0,00 & & & 1,386 & 0,00 & & & 1,288 & 0,01 & & \\
\hline
\end{tabular}

